\title{
ANÁLISE DE PONTES DE MADEIRA PROTENDIDAS TRANSVERSALMENTE FORMADAS POR VIGAS-T
}

\author{
NÍVEA MARA PEREIRA ALVES
}

Dissertação apresentada à Escola de

Engenharia de São Carlos da Universidade de São Paulo, como parte dos requisitos para obtenção do título de Mestre em Engenharia de Estruturas

ORIENTADOR : Prof. Dr. Antonio Alves Dias 
À minha família, em especial à tia Nilda e Nilza, pelo apoio, incentivo e confiança. 


\section{AGRADECIMENTOS}

Ao professor Antonio Alves Dias, que sempre se mostrou um orientador amigo, compreensivo e dedicado.

À Coordenação de Aperfeiçoamento de Pessoal de Nível Superior (Capes), pela bolsa de estudo concedida.

Ao meu esposo e amigo Luciano Jorge (Jorginho), que sempre me incentivou a crescer profissionalmente e esteve comigo nos momentos difíceis.

Ao professor Rocco, pelas palavras amigas nos momentos de incertezas e esclarecimentos técnicos que me auxiliaram na elaboração deste trabalho.

Ao professor Calil, que se mostrou atencioso às minhas dúvidas e na obtenção de material bibliográfico.

Aos colegas, professores e funcionários do Laboratório de Madeiras e Estruturas de Madeira (LaMEM), pela colaboração em minhas atividades de mestrado. 
SUMÁRIO

LISTA DE FIGURAS

LISTA DE TABELAS _ iv

LISTA DE SIGLAS E ABREVIATURAS__ vi

LISTA DE SÍMBOLOS_ _ _ _ii

RESUMO

ABSTRACT —xii

1- INTRODUÇÃO _ 1

1.1- Objetivos__ 2

1.2- Justificativa

2- REVISÃO BIBLIOGRÁFICA

2.1- Introdução _ 4

2.2- Tabuleiros com seção transversal de altura constante

2.2.1- Sistema de protensão

2.2.2- Tensões de protensão __ 7

2.2.3- Parâmetros elásticos _ 10

2.2.4- Perda de protensão __ 11

2.2.5- Juntas de topo _ 13

2.2.6- Modelos de cálculo __ 14

2.2.7- Derivações do sistema _ 16

2.3- Tabuleiros formados por vigas de seção transversal $T$ _ 19

2.3.1- Construção pioneira _ـ 19

2.3.2- Variações construtivas do sistema $\mathrm{T}$

2.3.3- Ensaios de outros protótipos___ 28

2.3.4- Método WVU__ 31

2.4- Conclusões a respeito da revisão bibliográfica __ 33

3- ANÁLISE NUMÉRICA DO SISTEMA T_ 35 
3.1- Condições da análise numérica

3.1.1- Madeira utilizada 35

3.1.2- Características das pontes 37

3.2- Procedimento de cálculo 38

3.2.1- Dados de entrada 41

3.2.2- Cálculo do módulo de elasticidade na direção transversal das lâminas do tabuleiro $\mathrm{E}_{\mathrm{T}}$ 41

3.2.3- Cálculo do número mínimo de nervuras $\left(\mathrm{n}_{\text {mín }}\right)$ 42

3.2.4- Cálculo da largura efetiva da mesa de uma viga-T interna $\left(b_{\mathrm{e}}\right)$ 43

3.2.5- Cálculo do fator de distribuição da carga $\left(\mathrm{W}_{\mathrm{f}}\right)$ 46

3.2.6- Determinação do valor de cálculo do momento fletor total $\left(\mathrm{Md}_{\mathrm{T}}\right)$ 47

3.2.7- Determinação do valor de cálculo do esforço cortante total $\left(\mathrm{Vd}_{\mathrm{T}}\right)$ 49

3.2.8- Verificações 50

3.2.9- Cálculo do volume de madeira 53

3.3-Descrição e resultados da análise numérica 54

3.3.1- Dimensionamento das pontes formadas por vigas-T 54

3.3.2- Influência da altura do tabuleiro e da largura das nervuras na altura D_63

3.3.3- Influência da espécie de madeira do tabuleiro na altura $\mathrm{D}$ 66

3.3.4- Influência da espécie de madeira das nervuras na altura D 73

3.4-Discussões sobre a análise numérica 80

3.5- Exemplo do método de cálculo 82

4- EXPERIMENTAÇÃO DO MODELO REDUZIDO 83

4.1- Características do modelo reduzido 83

4.1.1- Caracterização das nervuras 84

4.1.2- Caracterização das lâminas do tabuleiro 86

4.1.3- Classificação das nervuras e das lâminas do tabuleiro 88

4.2- Montagem do modelo 88

4.2.1- Distribuição das nervuras e das lâminas do tabuleiro 88

4.2.2- Apoios do modelo 91

4.2.3- Sistema de protensão 92 
4.2.4- Dispositivos utilizados na experimentação 92

4.2.4.1- Dispositivos para aplicação das forças 92

4.2.4.2- Equipamentos utilizados para medir deslocamentos 93

4.2.5- Formas de aplicação das forças 93

4.3- Resultados obtidos e análises 95

4.3.1- Resultados 96

4.3.2- Análise da rigidez à flexão longitudinal do modelo 101

4.3.3- Análise do fator de distribuição da carga $\left(\mathrm{W}_{\mathrm{f}}\right)$ 104

4- CONCLUSÕES 107

6- REFER ÊNCIAS BIBLIOGRÁFICAS 109 APÊNDICE 1 - Programa para o cálculo e o dimensionamento de pontes de madeira protendidas transversalmente formadas por vigas- $\mathrm{T}$ 


\section{LISTA DE FIGURAS}

FIGURA 1 - Ponte de madeira com vigas-T (OKIMOTO, 1997) 1

FIGURA 2- Planta e seção transversal de tabuleiro laminado protendido 6

FIGURA 3-Elevação de tabuleiro laminado protendido 6

FIGURA 4 - Sistema de Ancoragem

FIGURA 5 - Curvas Finais das Relações Elásticas para as madeira Pinus Elliottii e

Eucalipto Citriodora (OKIMOTO, 1997) 8

FIGURA 6 - Transferência das cargas de roda 9

FIGURA 7 - Perda de Protensão e Sistemas de Retensão 13

FIGURA 8 - Tabuleiro com seção transversal de altura constante 16

FIGURA 9 - Tabuleiro de altura constante com peças em MLC 16

FIGURA 10 - Sistema sanduíche 17

FIGURA 11 - Tabuleiro formado por vigas-T 17

FIGURA 12 - Treliças longitudinais protendidas transversalmente. 18

FIGURA 13 - Tabuleiro com seção caixão 18

FIGURA 14 - Tabuleiro transversal com protensão longitudinal 19

FIGURA 15 - Dimensões da Ponte "Barlow Drive” 20

FIGURA 16 - Modelo ensaiado por DICKSON \& GANGARAO (1990) 20

FIGURA 17 - Localização da linha neutra da viga-T central do modelo 21

FIGURA 18 - Ponte "Barlow Drive" 22

FIGURA 19 - Dimensões da Ponte "Camp Arrowhead" 24

FIGURA 20 - Ponte "Camp Arrowhead" 25

FIGURA 21 - Pontes com Vigas-T de LVL 27

FIGURA 22 - Condição de carregamento A 28

FIGURA 23 - Condição de carregamento $B$ 29

FIGURA 24 - Modelo com três nervuras sob força estática na nervura interna e externa 30

FIGURA 25 - Modelo com quatro nervuras sob força estática na nervura interna e externa 30

FIGURA 26 - Distribuição de tensão não-linear de uma viga-T isolada_ 32

FIGURA 27 - Ponte com uma faixa de tráfego 38 
FIGURA 28 - Ponte com duas faixas de tráfego 38

FIGURA 29 - Número mínimo de nervuras 39

FIGURA 30 - Número máximo de nervuras 39

FIGURA 31 - Fluxograma do método de cálculo 40

FIGURA 32 - Desenho esquemático de uma ponte formada por vigas-T 41

FIGURA 33 - Viga-T interna efetiva 44

FIGURA 34 - Viga-T interna transformada 45

FIGURA 35 - Viga-T externa efetiva 45

FIGURA 36 - Viga-T externa transformada 46

FIGURA 37 - Viga-T interna solicitada pela carga móvel 48

FIGURA 38 - Viga-T interna solicitada pela carga permanente 49

FIGURA 39 - Viga-T interna solicitada pela carga móvel 50

FIGURA 40 - Viga-T interna solicitada pela carga móvel 52

FIGURA 41 - Gráficos D x L para pontes com 1 faixa de tráfego 57

FIGURA 42 - Gráficos V x L para pontes com 1 faixa de tráfego 58

FIGURA 43 - Gráficos D x L para pontes com 2 faixas de tráfego 61

FIGURA 44 - Gráficos Vx L para pontes com 2 faixas de tráfego 62

FIGURA 45 - Gráficos D x $B_{w}$ e D x t para pontes com 1 e 2 faixas de tráfego 65

FIGURA 46 - Gráficos D x n para pontes com 1 e 2 faixas de tráfego 71

FIGURA 47 - Gráficos Vx n para pontes com 1 e 2 faixas de tráfego 72

FIGURA 48 - Gráficos D x n para pontes com 1 e 2 faixas de tráfego 78

FIGURA 49 - Gráficos Vx n para pontes com 1 e 2 faixas de tráfego 79

FIGURA 50 - Dimensões das nervuras para pontes com 1 e 2 faixas de tráfego _ 81

FIGURA 51 - Altura do tabuleiro em função do espaçamento entre nervuras 82

FIGURA 52 - Dimensões do modelo reduzido 84

FIGURA 53 - Ensaio de caracterização das nervuras 84

FIGURA 54 - Ensaio de caracterização das lâminas do tabuleiro 86

FIGURA 55 - Distribuição das nervuras no modelo reduzido. 89

FIGURA 56 - Conjunto de lâminas formado por quatro peças 89

FIGURA 57 - Distribuição dos conjuntos de lâminas no modelo reduzido 91

FIGURA 58 - Detalhe do apoio do modelo 91

FIGURA 59 - Disposição das células de carga 92 
FIGURA 60 - Medida dos deslocamentos verticais no meio do vão das nervuras__93 FIGURA 61 - Força uniformemente distribuída____ 94 FIGURA 62 - Simulação de um eixo centrado ___ 94

FIGURA 63 - Simulação de um eixo não centrado ___ 95

FIGURA 64 - Gráficos $\delta$ X P para os carregamentos correspondentes___ 100 FIGURA 65 - Linhas elásticas transversais para os carregamentos correspondentes 101 103 


\section{LISTA DE TABELAS}

TABELA 1 - Valores de projeto para o fator de redução da rigidez longitudinal (OKIMOTO, 1997)

TABELA 2 - Tensões e deslocamentos máximos da porção do tabuleiro entre as nervuras 3 e 4 26

TABELA 3 - Tensões e deslocamentos máximos das nervuras 3 e 4 26

TABELA 4 - Dimensões e detalhes da pontes (RITTER et al, 1996) 28

TABELA 5 - Classes de resistência para coníferas (NBR 7190/97) 37

TABELA 6 - Classes de resistência para dicotiledôneas (NBR 7190/97) 37

TABELA 7 - Alturas das nervuras D para pontes com 1 faixa de tráfego 55

TABELA 8 - Volumes de madeiras V para pontes com 1 faixa de tráfego 56

TABELA 9 - Alturas das nervuras D para pontes com 2 faixas de tráfego 59

TABELA 10 - Volumes de madeiras V para pontes com 2 faixas de tráfego 60

TABELA 11 - Alturas D para pontes com 1 faixa de tráfego $\left(B_{w}, t, D \mathrm{em} \mathrm{cm}\right)$ 63

TABELA 12 - Alturas $D$ para pontes com 2 faixas de tráfego $\left(B_{w}, t, D\right.$ em $\left.\mathrm{cm}\right)$ 64

TABELA 13 - Alturas das nervuras D para pontes com 1 faixa de tráfego 67

TABELA 14 - Volumes de madeiras V para pontes com 1 faixa de tráfego 68

TABELA 15 - Alturas das nervuras D para pontes com 2 faixas de tráfego 69

TABELA 16 - Volumes de madeiras V para pontes com 2 faixas de tráfego 70

TABELA 17 - Alturas das nervuras D para pontes com 1 faixa de tráfego 74

TABELA 18 - Volumes de madeiras V para pontes com 1 faixa de tráfego 75

TABELA 19 - Alturas das nervuras D para pontes com 2 faixas de tráfego 76

TABELA 20 - Volume de madeira V para pontes com 2 faixas de tráfego 77

TABELA 21 - Módulos de elasticidade na direção longitudinal $E_{L, n}$ das nervuras _ 85

TABELA 22 - Módulos de elasticidade na direção longitudinal das lâminas do tabuleiro $E_{L, t}$ 87

TABELA 23 - Distribuição final das nervuras 88

TABELA 24 - Distribuição final das lâminas do tabuleiro 90

TABELA 25 - Força uniformemente distribuída - (I) 96

TABELA 26 - Carregamento de um eixo com a roda externa na nervura 1 - (II) _ 97

TABELA 27 - Carregamento de um eixo com a roda externa na nervura 2 - (III) _ 97 
TABELA 28 - Carregamento de um eixo com a roda externa na nervura 5 - (IV) _ 98

TABELA 29 - Carregamento de um eixo com a roda externa na nervura $6-(V) \ldots 98$

TABELA 30 - Carregamento centrado de um eixo - (VI)___ 99

TABELA 31 - Valores geométricos, efetivos e transformados das nervuras e abas 103 


\section{LISTA DE SIGLAS E ABREVIATURAS}

$\begin{array}{ll}\text { AASHTO } & \text { American Association of State Highway and Transportation Officials } \\ \text { LVL } & \text { Lâminas de pequena espessura coladas com as fibras orientadas na } \\ & \text { mesma direção (Laminated Veneer Lumber) } \\ \text { MLC } & \text { Madeira laminada colada } \\ \text { NBR } & \text { Norma Brasileira Registrada } \\ \text { OHBDC } & \text { Ontario Highway Bridge Design Code } \\ \text { USDA } & \text { United States Department of Agriculture } \\ \text { WVU } & \text { West Virginia University }\end{array}$




\section{LISTA DE SÍMBOLOS}

a

$\mathrm{A}_{\mathrm{gr}}$

$\mathrm{A}_{\mathrm{n}}$

$\mathrm{A}_{\mathrm{t}}$

$\mathrm{A}_{\text {asf }}$

$A_{\text {bal }}$

$\mathrm{A}_{\text {balx }}$

b

$\mathrm{b}_{\mathrm{e}}$

$b_{\text {eti }}$

$\mathrm{b}_{1}$

$\mathrm{b}_{\mathrm{t}}$

$\mathrm{b}_{\text {tex }}$

B

$\mathrm{B}_{\mathrm{e}}$

$\mathrm{B}_{\mathrm{E}}$

$\mathrm{B}_{\mathrm{w}}$

c

$\mathrm{c}_{\mathrm{asf}}$

$\mathrm{C}_{\text {bj }}$

$\mathrm{C}_{0}$

D

$\mathrm{D}_{\mathrm{T}}$

$\mathrm{E}_{\mathrm{c} 0 \text {,ef }}$

$\mathrm{E}_{\mathrm{c} 0, \mathrm{~m}}$

$\mathrm{E}_{\text {L.n }}$

$\mathrm{E}_{\mathrm{L.t}}$

$\mathrm{E}_{\mathrm{T}}$
Largura de contato do pneu

Área do guarda-rodas

Área da nervura

Área do tabuleiro entre duas nervuras

Área do revestimento asfáltico sobre uma seção do tabuleiro

Área da aba de uma viga-T interna

Área da aba de uma viga-T externa

Largura da ponte

Largura efetiva da mesa de uma viga-T interna

Largura efetiva transformada da mesa de uma viga-T interna

Comprimento efetivo do pneu

Largura efetiva transformada da aba de uma viga-T interna

Largura efetiva transformada da aba de uma viga-T externa

Largura da aba de uma viga-T

Rigidez à flexão longitudinal de uma viga-T externa

Largura efetiva da aba de uma viga-T

Largura da nervura

Distância da linha neutra até a parte tracionada ou comprimida da viga-T

Espessura da capa asfáltica

Fator de redução da rigidez longitudinal

Coeficiente de deslocamento de uma viga-T externa

Altura da nervura

Rigidez à flexão transversal do tabuleiro

Módulo de elasticidade longitudinal efetivo na compressão paralela às fibras

Módulo de elasticidade longitudinal médio na compressão paralela às fibras

Módulo de elasticidade na direção longitudinal da nervura

Módulo de elasticidade na direção longitudinal das lâminas do tabuleiro

Módulo de elasticidade na direção transversal do tabuleiro 
$\mathrm{f}_{\mathrm{c} 0, \mathrm{k}} \quad$ Resistência característica da madeira à compressão paralela às fibras

$\mathrm{f}_{\mathrm{c} 0, \mathrm{~d}} \quad$ Resistência de cálculo da madeira à compressão paralela às fibras

$\mathrm{f}_{\mathrm{c} 90, \mathrm{k}} \quad$ Resistência característica da madeira à compressão perpendicular às fibras

$\mathrm{f}_{\mathrm{c} 90, \mathrm{~d}} \quad$ Resistência de cálculo da madeira à compressão perpendicular às fibras

$\mathrm{f}_{\mathrm{t} 0, \mathrm{k}} \quad$ Resistência característica da madeira à tração paralela às fibras

$\mathrm{f}_{\mathrm{t} 0, \mathrm{~d}} \quad$ Resistência de cálculo da madeira à tração paralela às fibras

$\mathrm{f}_{\mathrm{v} 0, \mathrm{k}} \quad$ Resistência característica ao cisalhamento paralelo às fibras

$\mathrm{f}_{\mathrm{v} 0, \mathrm{~d}} \quad$ Resistência de cálculo ao cisalhamento paralelo às fibras

$\mathrm{f}_{\mathrm{y}} \quad$ Tensão de escoamento do aço

$\mathrm{G}_{\mathrm{LT}} \quad$ Módulo de elasticidade transversal do tabuleiro

$\mathrm{I}_{\mathrm{i}}, \mathrm{I}_{\mathrm{ex}} \quad$ Momento de inércia da viga-T interna e externa, respectivamente

Itransformada Momento de inércia da viga-T transformada

$\mathrm{K}_{\text {mod }} \quad$ Coeficiente de modificação considerando influências não cobertas por $\gamma_{\mathrm{w}}$

$\mathrm{K}_{\delta}, \mathrm{K}_{\sigma} \quad$ Coeficiente de regressão do deslocamento e da tensão, respectivamente

$l_{\mathrm{b}} \quad$ Comprimento da barra de protensão

L Vão da ponte

$\mathrm{M}_{\text {máx.cm }} \quad$ Momento fletor máximo devido à carga móvel em função da força concentrada de projeto $\mathrm{P}_{\mathrm{d}}$

$\mathrm{M}_{\text {máx.cp }} \quad$ Momento fletor máximo devido à carga permanente total

$\mathrm{M}_{\text {máx.m }} \quad$ Momento fletor máximo devido à carga móvel

$\mathrm{Md}_{\mathrm{T}} \quad$ Valor de cálculo do momento fletor total

$\mathrm{M}_{\mathrm{R}} \quad$ Razão Modular

$\mathrm{M}_{\mathrm{S}} \quad$ Momento estático

n Número de nervuras

$\mathrm{N}_{\mathrm{L}} \quad$ Número de faixas de tráfego

p Força uniformemente distribuída na faixa ocupada pelo veículo-tipo

P Carga do eixo traseiro do veículo-tipo

$\mathrm{P}_{\mathrm{cN}} \quad$ Força concentrada aplicada no ensaio de caracterização das nervuras

$\mathrm{P}_{\mathrm{cT}} \quad$ Força concentrada aplicada no ensaio de caracterização das lâminas do tabuleiro

$\mathrm{P}_{\mathrm{d}} \quad$ Força concentrada de projeto 
$\mathrm{P}_{\mathrm{e}} \quad$ Força concentrada que produz um momento equivalente ao momento máximo devido à carga móvel

$\mathrm{P}_{\mathrm{nt}} \quad$ Carga permanente total suportada por uma nervura interna

$\mathrm{P}_{\text {asf }} \quad$ Peso-próprio do revestimento asfáltico sobre uma seção do tabuleiro, linearmente distribuído ao longo do vão

$\mathrm{P}_{\mathrm{b}} \quad$ Peso-próprio de uma barra de protensão

$\mathrm{P}_{\mathrm{bp}} \quad$ Peso-próprio das barras de protensão, linearmente distribuído ao longo do vão

$\mathrm{P}_{\mathrm{i}} \quad$ Parcela de carga absorvida por cada nervura do modelo

$\mathrm{P}_{\mathrm{i}, \text { máx }} \quad$ Parcela de carga máxima absorvida por cada nervura do modelo

$\mathrm{P}_{\mathrm{n}} \quad$ Peso-próprio da nervura, linearmente distribuído ao longo do vão

$\mathrm{P}_{\mathrm{t}} \quad$ Peso-próprio do tabuleiro entre duas nervuras, linearmente distribuído ao longo do vão

S Espaçamento entre as barras de protensão

S Espaçamento entre nervuras

t Altura do tabuleiro

V Esforço cortante devido ao puncionamento

$\mathrm{V}_{\mathrm{cp}} \quad$ Esforço cortante devido à carga permanente

$\mathrm{V}_{\text {crc }} \quad$ Esforço cortante devido às cargas de rodas concentradas, sem distribuição de carga

$\mathrm{V}_{\text {crd }} \quad$ Esforço cortante devido às cargas de rodas distribuídas

$\mathrm{V}_{\mathrm{cm}} \quad$ Esforço cortante devido à carga móvel

$\mathrm{V}_{\text {res }} \quad$ Esforço cortante resistente

$\mathrm{Vd}_{\mathrm{T}} \quad$ Valor de cálculo do esforço cortante total

$\mathrm{W}_{\mathrm{f}} \quad$ Fator de distribuição da carga

x Distância entre o apoio e a primeira carga de eixo P

x’ Duas vezes a altura da nervura

y bal Localização da linha neutra da aba

$\mathrm{y}_{\mathrm{n}} \quad$ Localização da linha neutra da nervura

$y_{i}, y_{e x} \quad$ Localização da linha neutra da viga-T interna e externa, respectivamente

$\alpha \quad$ Coeficiente para pontes rodoviárias com revestimento de concreto asfáltico 
$\delta_{\mathrm{cm}} \quad$ Deslocamento devido à carga móvel

$\delta_{\mathrm{cp}} \quad$ Deslocamento devido à carga permanente

$\delta_{\mathrm{T}} \quad$ Deslocamento total devido à carga permanente e à carga móvel

$\delta_{\mathrm{cN}} \quad$ Deslocamento da nervura medido no ensaio de caracterização

$\delta_{\mathrm{cT}}$ Deslocamento da lâmina do tabuleiro medido no ensaio de caracterização

$\phi \quad$ Impacto vertical

$\phi_{\mathrm{b}} \quad$ Diâmetro da barra de protensão

$\gamma_{\text {asf }} \quad$ Peso específico do asfalto

$\gamma_{\mathrm{Gi}} \quad$ Coeficiente de ponderação das ações permanentes

$\gamma_{\mathrm{Qi}} \quad$ Coeficiente de ponderação das ações variáveis

$\gamma_{\mathrm{w}} \quad$ Coeficiente de minoração das propriedades da madeira

$\lambda \quad$ Relação entre a largura e o vão da ponte

$\mu_{\mathrm{S}} \quad$ Coeficiente de atrito estático

$\rho \quad$ Densidade aparente

$\sigma_{t}, \sigma_{c} \quad$ Tensão de tração e compressão paralela às fibras, respectivamente

$\sigma_{\mathrm{N}} \quad$ Tensão de protensão no tabuleiro

$\tau \quad$ Tensão de cisalhamento

$\psi \quad$ Fator de combinação e de utilização para cargas móveis em pontes rodoviárias 


\section{RESUMO}

ALVES, N. M. P. (2002). Análise de pontes de madeira protendidas transversalmente formadas por vigas-T. São Carlos, 2002. 110p. Dissertação (Mestrado) - Escola de Engenharia de São Carlos, Universidade de São Paulo.

Neste trabalho é estudada uma variação do sistema estrutural de ponte de madeira com tabuleiro laminado protendido, em que a seção transversal é formada por vigas-T. As nervuras destas vigas são de madeira laminada colada e o tabuleiro de madeira serrada. São analisadas pontes da classe 30, com uma ou duas faixas de tráfego, dimensionando-se os elementos estruturais para diversas situações de projeto, e avaliando-se as influências das espécies e classes de resistência das madeiras e dos fatores geométricos (largura da nervura, altura do tabuleiro e espaçamento entre nervuras) na altura das nervuras. O procedimento de cálculo utilizado no dimensionamento das pontes de madeira formadas por vigas-T baseia-se no método WVU. Para o desenvolvimento deste trabalho, o método foi adaptado aos critérios da Associação Brasileira de Normas Técnicas, "NBR 7188/84 - Cargas Móveis em Pontes Rodoviárias e Passarelas de Pedestres" e "NBR 7190/97 - Projeto de Estruturas de Madeira”, e programado em software MATHCAD@. Os resultados obtidos indicam que não existe influência significativa na altura da nervura, ao se utilizar madeira da classe C 30 ou C 40 no tabuleiro, ou ao se variar a altura do tabuleiro de 15 até $25 \mathrm{~cm}$. O modelo teórico é avaliado experimentalmente, por meio de modelo reduzido na escala geométrica de 1:5, obtendo-se boa concordância entre os valores experimentais e os teóricos.

PALAVRAS-CHAVE: pontes de madeira, protensão transversal, vigas-T. 


\section{ABSTRACT}

ALVES, N. M. P. (2002). Analysis of Transversely Stressed Timber Bridges composed of T-Beams. São Carlos, 2002. 110p. Dissertação (Mestrado) - Escola de Engenharia de São Carlos, Universidade de São Paulo.

In this work it is studied a variation of the structural system of timber bridge with transversely laminated deck, in which the transversal section is composed of Tbeams. The stringers of those beams are made of glued laminated timber and the deck of sawed timber. Bridges of class 30 are analyzed, with one or two traffic lanes, where the structural elements are designed for different project situations, and evaluated the influences of specimens and wood classes and geometric factors (width of stringer, depth of deck and spacing of stringers) in the depth of stringers. The calculus procedure used in the design of the timber bridges composed of T-beams is based on the WVU Method. To the development of this work, the method was adapted to the criteria of the Brazilian standards "NBR 7188/84 - Live Loads in Highway Bridges and Pedestrian Bridges" and "NBR 7190/97 - Project of Timber Structures" and programmed in MATHCAD(C software. The results obtained show that there is no significant influence in the depth of stringer, either by using wood class C 30 or C 40 , or by varying the height of the deck from 15 to $25 \mathrm{~cm}$. The theoretical model is evaluated experimentally, by means of a reduced model at 1:5 geometric scale, being obtained well agreement between experimental and theoretical values.

KEYWORDS: timber bridges, transversal stress, T-beams. 


\section{1- INTRODUÇÃO}

O sistema estrutural de pontes de madeira com tabuleiro protendido se originou no Canadá, em 1976, como uma forma de recuperar tabuleiros pregados, que apresentavam problemas de delaminação. O bom desempenho estrutural dos tabuleiros recuperados com esta técnica incentivou a sua aplicação na construção de novas pontes.

O sistema laminado protendido consiste em peças de madeira posicionadas ao longo do vão, umas adjacentes às outras, e protendidas transversalmente por barras ou cabos de aço de alta resistência. Esta protensão transversal permite que o esforço cortante vertical seja transmitido lateralmente entre as lâminas, por meio do atrito. Com isto, o sistema comporta-se como uma placa ortotrópica capaz de distribuir lateralmente as cargas dos veículos e de resistir à flexão transversal.

Os tabuleiros protendidos com seção transversal constituído por peças de mesma altura são os mais utilizados para vãos menores que $10 \mathrm{~m}$. Devido à necessidade de se construir pontes para vencer vãos maiores, foram estudadas derivações deste sistema, utilizando formas estruturais mais eficientes para a seção transversal (sistema $T$, sistema sanduíche, seção caixão e outras). $O$ sistema $T$, mostrado na figura 1, consiste na introdução de vigas intermediárias com maiores dimensões no tabuleiro.

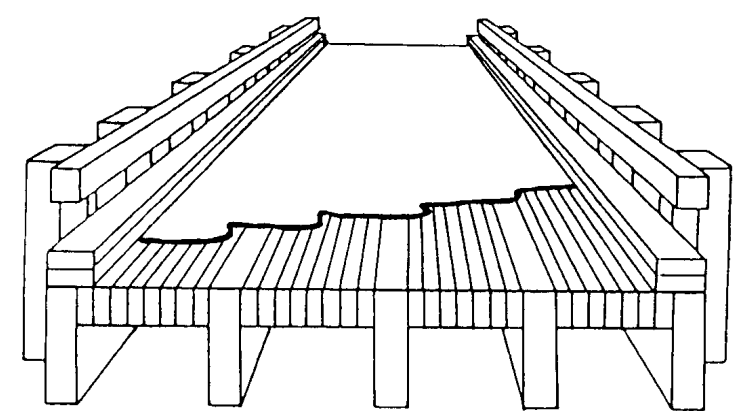

FIGURA 1 - Ponte de madeira com vigas-T (OKIMOTO, 1997) 
Neste trabalho são avaliadas as pontes formadas por vigas-T, utilizando nervuras de madeira laminada colada (MLC) e tabuleiro de madeira serrada. Inicialmente, é apresentada uma revisão bibliográfica a respeito das pontes de madeira protendidas, incluindo a variação que utiliza vigas- $\mathrm{T}$, contendo os aspectos mais importantes relacionados a este sistema estrutural. Posteriormente, são efetuados os dimensionamentos destas pontes, para diversas situações de projeto, seguindo o procedimento de cálculo baseado no método WVU (Método desenvolvido pelo Departamento de Engenharia Civil da West Virginia University e apresentado por DAVALOS \& SALIM (1992)) para o sistema T das pontes de madeira protendidas transversalmente, e um estudo para verificar a influência das espécies e classes de resistência das madeiras e das variações dos fatores geométricos na altura das nervuras. Por último, é realizado o ensaio de um modelo reduzido de ponte formada por vigas-T, para se avaliar o modelo teórico utilizado no dimensionamento destas pontes.

Para o desenvolvimento deste trabalho, o método WVU foi adaptado aos critérios da Associação Brasileira de Normas Técnicas, "NBR 7188/84 - Cargas Móveis em Pontes Rodoviárias e Passarelas de Pedestres" e "NBR 7190/97 - Projeto de Estruturas de Madeira", e programado em software MATHCAD@.

\section{1- Objetivos}

O objetivo deste trabalho é:

- determinar as dimensões efetivas das pontes de madeira protendidas transversalmente formadas por vigas- $\mathrm{T}$ (altura do tabuleiro, altura e largura da nervura, espaçamento entre nervuras), conhecendo-se o vão, a largura e a classe da ponte, as espécies e as classes de resistência das madeiras;

- verificar como a altura da nervura é influenciada pelas espécies e classes de resistência das madeiras, e pela altura do tabuleiro e largura da nervura;

- e avaliar o modelo teórico utilizado no dimensionamento destas pontes, por meio do ensaio de um modelo reduzido de ponte formada por vigas-T. 


\section{2- Justificativa}

Como o Brasil possui grandes áreas com potencialidade para o reflorestamento, uma solução possível para interligar bairros e regiões carentes de pontes em estradas vicinais é a construção de pontes de madeira de pequenos vãos para as vias secundárias ou rurais, utilizando espécies de reflorestamento.

Alguns estudos já foram desenvolvidos no Brasil para as pontes protendidas de madeira com tabuleiros de altura constante, notadamente os trabalhos de PRATA (1994) e OKIMOTO (1997). No entanto, devido à necessidade de superar a limitação apresentada pelos vãos destas pontes, da ordem de $10 \mathrm{~m}$, propõe-se a análise teórica e experimental das pontes protendidas de madeira formadas por vigas-T. 


\section{2- REVISÃO BIBLIOGRÁFICA}

\section{1- Introdução}

“A evolução da utilização do concreto armado e do aço na construção das pontes tem acompanhado a história do homem na idade moderna. A tecnologia da madeira também tem alcançado alto nível, mas sua utilização é muito menos freqüente" (HELLMEISTER, 1978). No entanto, a madeira é renovável, tem grande potencial de resistência e durabilidade, tornando-a um bom material para a construção de pontes em estradas vicinais. Sendo o Brasil um país de grandes reservas florestais e de grande potencialidade para o reflorestamento, a construção de pontes de madeira é economicamente viável.

As pontes em estrutura de madeira para pequenos e médios vãos são amplamente utilizadas em estradas vicinais nos E.U.A. e Canadá, principalmente com a utilização de MLC. Um dos sistemas estruturais interessantes recentemente desenvolvidos, foi o sistema estrutural de pontes de tabuleiro laminado protendido, que se originou no Canadá, na região de Ontário, em 1976, como um método de recuperar tabuleiros laminados pregados, que se encontravam deteriorados por falha na laminação. O sistema laminado pregado consiste em vigas de madeira serrada posicionadas ao longo do vão, umas adjacentes às outras, e conectadas por pregos. Devido à solicitação dinâmica da ponte e às condições químicas (o sal utilizado para descongelar a superfície de tráfego das pontes atacava os elementos de aço das conexões) impostas ao sistema, surgiram diversos problemas que comprometiam o desempenho e a função para os quais foram projetados. Um dos problemas encontrados foi a delaminação dos tabuleiros pregados que corresponde à perda da continuidade transversal do tabuleiro por separação das peças e, como a funcionalidade estrutural deste sistema depende da capacidade de distribuição das 
ações da roda entre as lâminas adjacentes, apenas as vigas imediatamente abaixo das rodas eram solicitadas. Apesar desta deficiência estrutural, a madeira estava em perfeitas condições e, deste modo, a solução aplicada foi a implementação de um novo sistema de transferência das ações pela utilização de barras posicionadas transversalmente ao tabuleiro. Estas barras são submetidas a um tensionamento que comprime as vigas de madeira fazendo com que surjam propriedades de resistência e elasticidade na direção transversal. Com força de protensão adequada, previne-se que as laminas se separem nas faces de contato na parte inferior das fibras quando as forças são aplicadas perpendicularmente ao plano do tabuleiro. Como resultado, a ponte voltou a operar com a capacidade de tráfego prevista em projeto, demonstrando a grande eficácia estrutural deste novo sistema. Este fato gerou estudos para aplicação do sistema protendido em projetos de novas construções (OKIMOTO, 1997).

\section{2- Tabuleiros com seção transversal de altura constante}

A seguir são apresentadas as informações relacionadas ao sistema estrutural de pontes com tabuleiro de altura constante e que são utilizadas para o sistema $\mathrm{T}$ das pontes de madeira protendidas transversalmente. Estas informações referem-se ao sistema de protensão, à tensão de protensão, aos parâmetros elásticos, à perda de protensão e às juntas de topo. Além disto, são mostrados os modelos de cálculo e as derivações do sistema protendido transversalmente.

As figuras 2 e 3 apresentam um desenho esquemático das pontes protendidas com seção transversal de altura constante. 


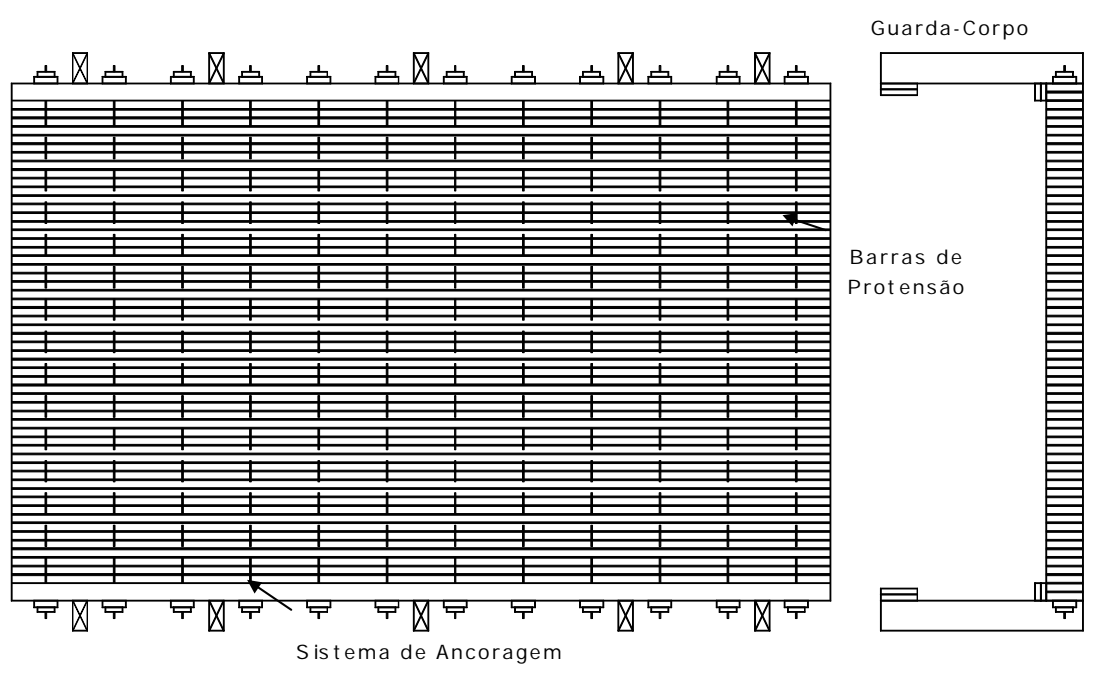

FIGURA 2- Planta e seção transversal de tabuleiro laminado protendido

(OKIMOTO, 1997)

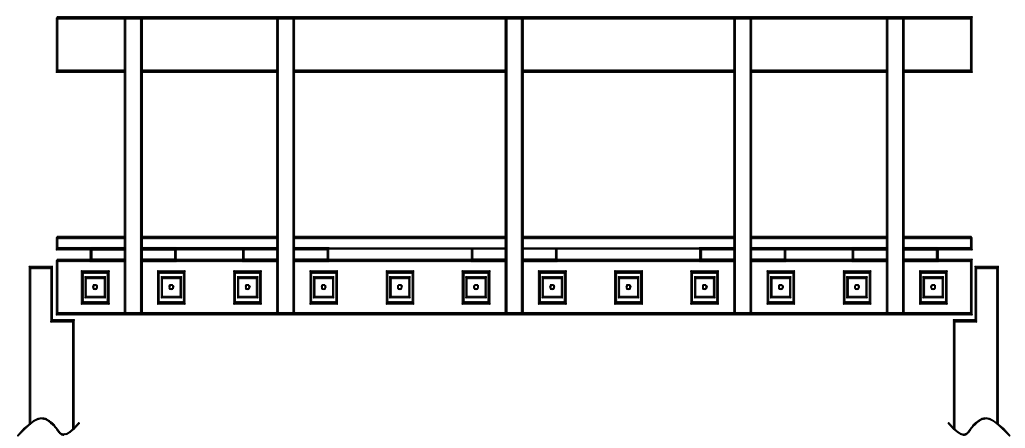

FIGURA 3- Elevação de tabuleiro laminado protendido

(OKIMOTO, 1997)

\subsection{1- Sistema de protensão}

Segundo OKIMOTO (1997), o sistema de protensão dos tabuleiros de altura constante pode ser constituído por cabos ou barras de aço de aço de alta resistência, com diâmetros nominais entre $15 \mathrm{~mm}$ e $32 \mathrm{~mm}$. Estas barras são tensionadas usando cilindros hidráulicos e ancoradas por um conjunto de porca sextavada, placa de ancoragem e placa de distribuição de aço comum que estão nas vigas de madeira externas, conforme mostrado na figura 4. 
Placa de distribuição

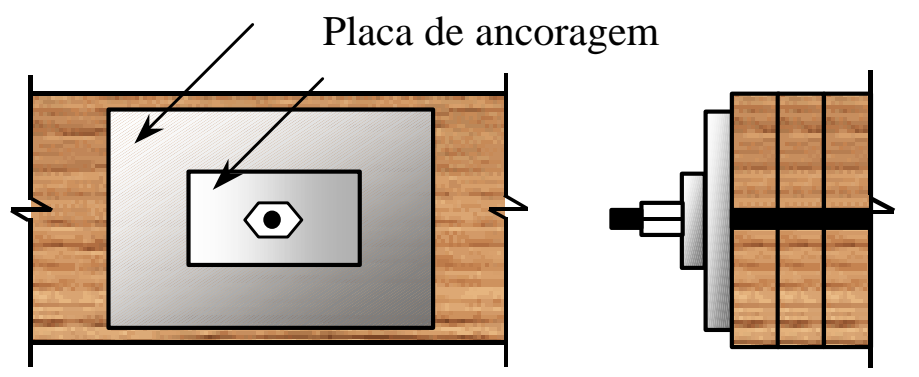

FIGURA 4 - Sistema de Ancoragem

\subsection{2- Tensões de protensão}

Para estabelecer a tensão de protensão adequada para as espécies de madeira nacionais, OKIMOTO (1997) ensaiou à flexão e à torção, placas de Pinus Elliottii (Pinus elliottii var. elliottii) e Eucalipto Citriodora (Eucalyptus citriodora) sob as tensões 0,$3 ; 0,5 ; 0,7 ; 0,8$ e 0,9 MPa. Deste modo, os parâmetros elásticos destes tabuleiros [módulo de elasticidade na direção transversal $\left(\mathrm{E}_{\mathrm{T}}\right)$ e módulo de elasticidade transversal $\left(\mathrm{G}_{\mathrm{LT}}\right)$ ] foram obtidos em função do módulo de elasticidade na direção longitudinal $\left(\mathrm{E}_{\mathrm{L}}\right)$. A aplicação da protensão igual a $0,3 \mathrm{MPa}$ não apresentou resultados satisfatórios para as placas de Eucalipto Citriodora, pois não desenvolveu atrito suficiente e ocorreram deslizamentos entre as lâminas. A aplicação dos demais valores está representada na figura 5. 


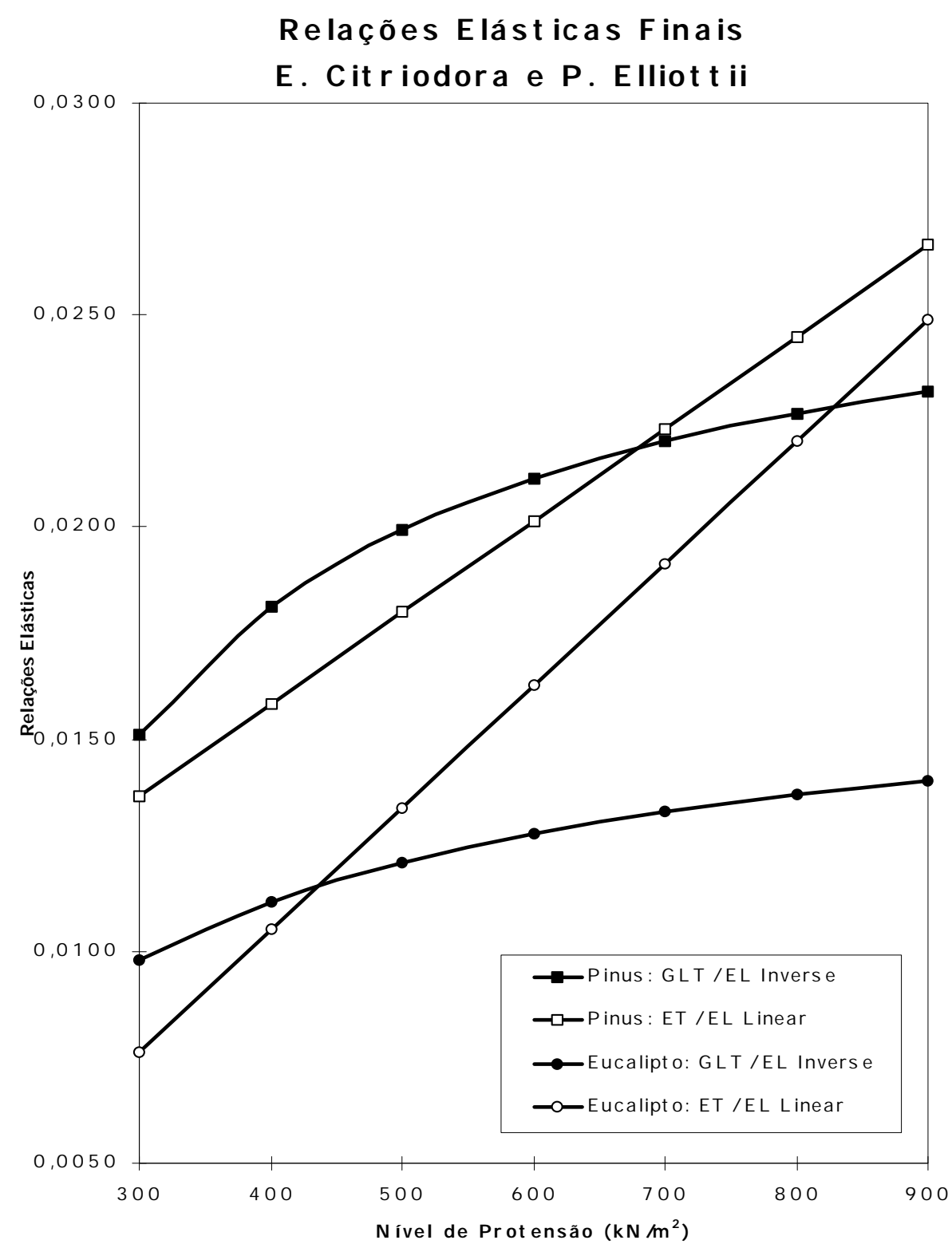

FIGURA 5 - Curvas Finais das Relações Elásticas para as madeira Pinus Elliottii e Eucalipto Citriodora (OKIMOTO, 1997)

A análise da figura 5 permite verificar:

- que tensões maiores que 0,7 MPa não ocasionam aumentos significativos nos valores de $\mathrm{G}_{\mathrm{LT}}$;

- a tendência de estabilização dos valores de $G_{\text {LT }}$ para as tensões maiores que 0,9 MPa. 
Sabendo assim, que a protensão deve ser maior que $0,3 \mathrm{MPa}$ e pode ser menor ou igual a $0,9 \mathrm{MPa}$, o autor recomenda $0,7 \mathrm{MPa}$ para qualquer classe de resistência da madeira definida de acordo com a NBR 7190/97.

No entanto, há autores que sugerem tensões de protensão menores. De acordo com GANGARAO \& LATHEEF (1991), a pesquisa realizada na University of Wisconsin e na West Virginia University indica que a tensão de protensão adequada para prevenir deslizamento vertical e separação das laminações dos tabuleiros protendidos é igual a $0,34 \mathrm{MPa}$.

Segundo CREWS (1998), o fator mais crítico para o projeto e a manutenção dos sistemas protendidos transversalmente é alcançar e manter a força de protensão adequada entre as lâminas, de tal modo que a atuação como placa ortotrópica seja mantida e o tabuleiro resista efetivamente às cargas aplicadas. Estas cargas são distribuídas lateralmente sobre uma largura de distribuição $\left(D_{w}\right)$ do tabuleiro (Figura 6) e transmitidas aos apoios. Os ensaios e monitoramento de campo na Austrália e nos E.U.A. demonstraram que os tabuleiros protendidos de seção constante comportam-se de modo elástico-linear quando a protensão mínima no tabuleiro é mantida (aproximadamente 0,5 MPa para "softwoods" ou madeiras moles e 0,7 MPa para "hardwoods" ou madeiras duras).

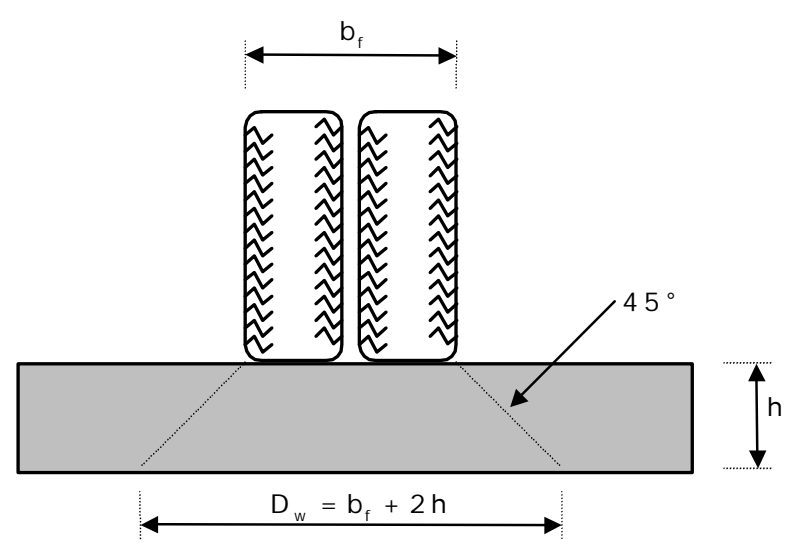

FIGURA 6 - Transferência das cargas de roda (OKIMOTO, 1997) 


\subsection{3- Parâmetros elásticos}

PRATA (1994) ensaiou duas placas de Eucalipto Citriodora sob tensão de protensão igual a 1,4 MPa com o objetivo de determinar os parâmetros elásticos das placas, visando a utilização desta madeira nas pontes protendidas. Estes ensaios permitiram determinar que os parâmetros elásticos destas foram: $\mathrm{E}_{\mathrm{T}}=3,6 \% \cdot \mathrm{E}_{\mathrm{L}}$ e $\mathrm{G}_{\mathrm{LT}}=4,9 \% \cdot \mathrm{E}_{\mathrm{L}}$.

Com o objetivo de estudar o comportamento estrutural das pontes protendidas de madeira com seção transversal de altura constante e pequenos vãos, OKIMOTO (1997) ensaiou em laboratório placas de Pinus Elliottii (Classe C 25 - Conífera) e Eucalipto Citriodora (Classe C 40 - Dicotiledônea) submetidas à flexão longitudinal para a determinação do $\mathrm{E}_{\mathrm{L}}$, à torção a $0^{\circ}$ para a determinação do $\mathrm{G}_{\mathrm{LT}} \mathrm{e}$ à torção $\mathrm{a}$ $\pm 45^{\circ}$ para a determinação do $E_{\mathrm{T}}$. $\mathrm{O}$ ângulo especificado é entre os eixos principais geométricos e os eixos de ortotropia elástica. As relações elásticas obtidas em função da tensão de protensão $\sigma_{\mathrm{N}}$ foram:

Para a madeira classe C 25:

$$
\begin{aligned}
& \frac{E_{T}}{E_{L}}=0,0000216 \cdot \sigma_{N}+0,00715 \\
& \frac{G_{L T}}{E_{L}}=0,02731989-3,75205953 \cdot\left(\sigma_{N}\right)^{-1}+26,60058663 \cdot\left(\sigma_{N}\right)^{-2}
\end{aligned}
$$

Para a madeira classe $\mathrm{C} 40$ :

$$
\begin{aligned}
& \frac{E_{T}}{E_{L}}=0,00002878 \cdot \sigma_{N}-0,001008 \\
& \frac{G_{L T}}{E_{L}}=0,01683333-2,74 \cdot\left(\sigma_{N}\right)^{-1}+186,66666667 \cdot\left(\sigma_{N}\right)^{-2}
\end{aligned}
$$

Substituindo-se a protensão $\sigma_{\mathrm{N}}=700 \mathrm{kN} / \mathrm{m}^{2}$ estabelecida por OKIMOTO (1997) nas equações 1 a 4, obtêm-se as relações elásticas dadas nas equações 5 a 8: 
Para a madeira classe C 25:

$$
\begin{aligned}
& \frac{E_{T}}{E_{L}}=0,0223 \\
& \frac{G_{L T}}{E_{L}}=0,0220
\end{aligned}
$$

Para a madeira classe $\mathrm{C} 40$ :

$$
\begin{aligned}
& \frac{E_{T}}{E_{L}}=0,0191 \\
& \frac{G_{L T}}{E_{L}}=0,0133
\end{aligned}
$$

Além das equações (1), (2), (3) e (4), OKIMOTO (2000) ${ }^{1}$ desenvolveu equações genéricas para os parâmetros elásticos:

$$
\begin{aligned}
\frac{\mathrm{E}_{\mathrm{T}}}{\mathrm{E}_{\mathrm{L}}} & =0,0183673-\left[2,0395 \cdot 10^{-5} \cdot \rho\right]+\sigma_{\mathrm{N}} \cdot\left(1,17275 \cdot 10^{-5}+1,795 \cdot 10^{-8} \cdot \rho\right) \\
\frac{\mathrm{G}_{\mathrm{LT}}}{\mathrm{E}_{\mathrm{L}}} & =0,042401-\left[2,758850 \cdot 10^{-5} \cdot \rho\right]-\frac{\left(5,891866-4,078686 \cdot 10^{-3} \cdot \rho\right)}{\sigma_{\mathrm{N}}}
\end{aligned}
$$

onde:

$\rho=$ densidade aparente $\mathrm{em} \mathrm{kg} / \mathrm{m}^{3}$

\subsection{4- Perda de protensão}

Os principais fatores que influem na perda de protensão são a perda de umidade, a fluência (deformação ao longo do tempo sob tensão constante) e a relaxação da madeira (diminuição da tensão ao longo do tempo sob deformação constante). É recomendado, portanto, que a tensão de protensão aplicada seja

${ }^{1}$ OKIMOTO, F. S. (2000). (USP. Escola de Engenharia de São Carlos. LaMEM). Comunicação pessoal. 
superior à tensão de projeto, que é a tensão mínima necessária para garantir o bom funcionamento do sistema.

Segundo GANGARAO \& LATHEEF (1991), os tabuleiros de madeira devem ser protendidos três vezes para estabilizar as forças de protensão na madeira e conseqüentemente minimizar a perda destas forças ao longo do tempo. Se o tabuleiro for protendido somente uma vez, ocorrerá uma perda de protensão de $80 \%$ ou mais, em um curto intervalo de tempo.

Uma ponte protendida com tabuleiro de madeira laminada funciona de acordo com as condições previstas em projeto, desde que seja mantida uma tensão de protensão suficiente entre as lâminas de madeira. Como a tensão de protensão diminui ao longo do tempo devido às características naturais da madeira (perda de umidade, fluência e relaxamento), aumenta-se a tensão aplicada no momento da montagem para compensar esta perda. Nestas condições, RITTER (1992) sugere que a protensão inicial seja 2,5 vezes o valor de projeto e que haja no mínimo 2 retensões com o mesmo valor da protensão inicial. O comportamento da ponte submetida à protensão e à retensão (Figura 7) mostra que se o tabuleiro for protendido apenas uma vez durante a construção, a perda final será maior que $80 \%$ e a protensão atuante estará em torno de $20 \%$ da inicial, que é inferior à tensão mínima exigida. No caso de haver duas retensões (uma após 3 dias, e a outra após 8 semanas), a perda final será pouco maior que $20 \%$ e a tensão final superior à tensão mínima exigida. E, quando houver três retensões, (uma após 2 dias, outra após 5 dias e a última após 8 semanas) a perda final não ultrapassará $10 \%$ e a tensão final será superior à tensão mínima exigida. Como se sabe, a madeira expande-se quando ganha umidade, e retrai-se quando perde, ocasionando os efeitos de ganho e perda de protensão, respectivamente. No entanto, com ensaios de laboratório e monitoramento periódico de pontes instaladas em diferentes condições ambientais, observou-se que as mudanças na tensão de protensão foram mínimas quando as lâminas de madeira já se encontravam secas no período da construção, mas foram maiores quando esta madeira secou com a ponte em serviço. Concluiu-se então, que os efeitos do ganho e da perda de protensão devidos à umidade não são importantes quando a madeira se encontra seca no momento da montagem da ponte. 


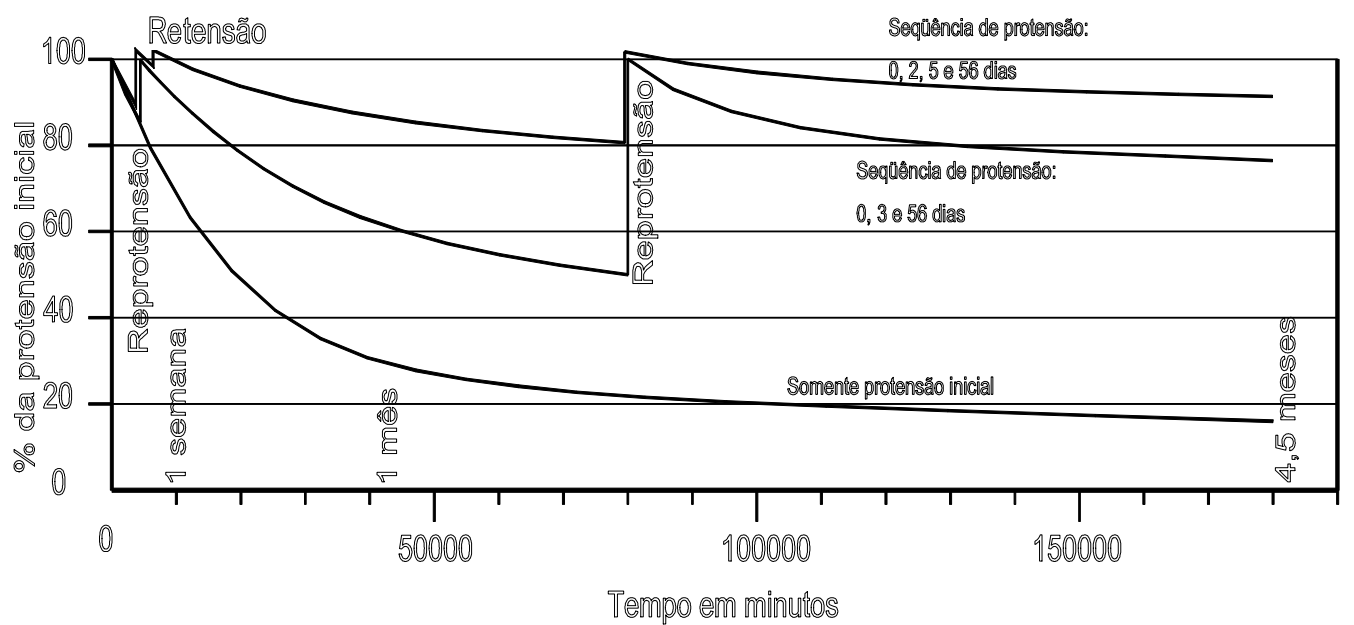

FIGURA 7 - Perda de Protensão e Sistemas de Retensão

(TAYLOR e CSAGOLY, 1979 apud RITTER, 1992)

Segundo CREWS (1998), as normas da OHBDC assumem que as perdas totais de protensão no tabuleiro não excedem $60 \%$ durante sua vida útil. Porém, resultados de ensaios indicam que, quando a tensão de protensão cai para 50 a $60 \%$ da tensão de projeto, há uma queda significante na rigidez transversal e na resistência ao atrito interlaminar. Para evitar este efeito, a protensão deve ser aplicada de modo que as perdas não tornem a tensão de protensão efetiva inferior à de projeto.

\subsection{5- Juntas de topo}

O sistema de pontes protendidas transversalmente com tabuleiro de altura constante utiliza peças de madeira serrada. Estas peças geralmente possuem largura igual a $5 \mathrm{~cm}$, altura de 20 a $40 \mathrm{~cm}$ e comprimento máximo em torno de $6 \mathrm{~m}$. Assim, quando o vão livre da ponte for superior a $6 \mathrm{~m}$, serão utilizadas juntas de topo no tabuleiro. Como consequiência, o projeto e a construção destas pontes tornam-se viáveis, sem afetar drasticamente as propriedades de resistência e rigidez da estrutura. Em OKIMOTO (1997), o efeito da presença e a freqüência de juntas de topo na rigidez longitudinal do tabuleiro foram verificados em ensaios de modelo reduzido. Para cada tensão de protensão, foram obtidas as equações para os valores de $\mathrm{C}_{\mathrm{bj}}$ (fator de redução da rigidez longitudinal do tabuleiro) em função da freqüência de juntas (J): 
$\operatorname{Para} \sigma_{\mathrm{N}}=300 \mathrm{kN} / \mathrm{m}^{2}$

$$
\mathrm{C}_{\mathrm{bj}}=1,06117-0,93587 \cdot \mathrm{J}^{-1}+0,2732 \cdot \mathrm{J}^{-2}
$$

$\operatorname{Para} \sigma_{\mathrm{N}}=700 \mathrm{kN} / \mathrm{m}^{2}$

$$
\mathrm{C}_{\mathrm{bj}}=1,06367-0,78911 \cdot \mathrm{J}^{-1}+0,17204 \cdot \mathrm{J}^{-2}
$$

Os valores de $\mathrm{C}_{\mathrm{bj}}$ em função da frequiência de juntas estão apresentados na tabela 1. Como as diferenças entre estes valores para as tensões estudadas não são significativas, adota-se os valores obtidos para $\sigma_{\mathrm{N}}=300 \mathrm{kN} / \mathrm{m}^{2}$, independente da tensão de projeto. De acordo com o autor, a freqüência ideal das juntas de topo é a cada 4 lâminas, ou seja, $\mathrm{C}_{\mathrm{bj}}=0,84$.

TABELA 1 - Valores de projeto para o fator de redução da rigidez longitudinal

\begin{tabular}{|c|c|c|c|}
\hline \multirow{2}{*}{$\begin{array}{l}\text { Freqüência } \\
\text { de Juntas }\end{array}$} & \multicolumn{2}{|c|}{ Fator $\mathrm{C}_{\mathrm{bj}}$} & \multirow{2}{*}{ Disposições mínimas } \\
\hline & $\sigma_{N}=300 \mathrm{kN} / \mathrm{m}^{2}$ & $\sigma_{N}=700 \mathrm{kN} / \mathrm{m}^{2}$ & \\
\hline cada 4 & 0,84 & 0,88 & \multirow{8}{*}{ Juntas alinhadas a cada 4 vigas } \\
\hline cada 5 & 0,88 & 0,91 & \\
\hline cada 6 & 0,91 & 0,94 & \\
\hline cada 7 & 0,93 & 0,95 & \\
\hline cada 8 & 0,95 & 0,97 & \\
\hline cada 9 & 0,96 & 0,98 & \\
\hline cada 10 & 0,97 & 0,99 & \\
\hline sem juntas & 1,00 & 1,00 & \\
\hline
\end{tabular}
(OKIMOTO, 1997)

\subsection{6- Modelos de cálculo}

De acordo com a bibliografia consultada, existem diversas maneiras de se abordar o cálculo das pontes protendidas transversalmente. Algumas são direcionadas para o dimensionamento, outras para a avaliação de resultados experimentais em trabalhos de pesquisa. 
CREWS (1998) aponta três métodos para a modelagem de tabuleiros protendidos de altura constante:

- Modelo de placa ortotrópica: para se analisar o tabuleiro como placa ortotrópica, deve-se conhecer as três propriedades elásticas do material: módulo de elasticidade na direção longitudinal $\mathrm{E}_{\mathrm{L}}$, módulo de elasticidade na direção transversal $\mathrm{E}_{\mathrm{T}} \mathrm{e}$ módulo de elasticidade transversal $\mathrm{G}_{\mathrm{LT}}$. Este modelo é melhor utilizado como ferramenta de pesquisa, por ser computacionalmente intensivo.

- Modelo de grelha: para se analisar o tabuleiro como grelha, também se deve conhecer $E_{L}, E_{T}$ e $G_{L T}$. Este modelo calcula com precisão os deslocamentos, as deformações e os momentos longitudinais do tabuleiro; no entanto, não fornece vantagem significativa para o projeto por ser mais complicado que o modelo de viga modificada.

- Modelo de viga modificada: para se analisar o tabuleiro como viga modificada, deve-se conhecer o módulo de elasticidade na direção longitudinal das lâminas de madeira $E_{L}$ e a largura de distribuição $D_{w}$ da viga. Na determinação de $D_{w}$, os resultados obtidos em ensaios de protótipos de tabuleiros utilizando carregamentos referentes aos estados limites últimos e de utilização realizados na Austrália foram comparados com a largura de distribuição estimada na edição de 1993 do OHBDC. Por fim, estes resultados foram calibrados com aqueles obtidos em ensaios de protótipos de tabuleiros utilizando carregamentos referentes ao estado limite de utilização realizados nos E.U.A. Este modelo de viga, apesar de simples, calcula os deslocamentos e a capacidade última de resistência do tabuleiro. É o modelo de cálculo mais indicado para a finalidade de projeto. 


\subsection{7- Derivações do sistema}

Além do sistema com tabuleiro de altura constante, constituído por peças de madeira serrada dispostas longitudinalmente ao sentido do tráfego (Figura 8), foram estudadas outras aplicações para o sistema protendido transversalmente.

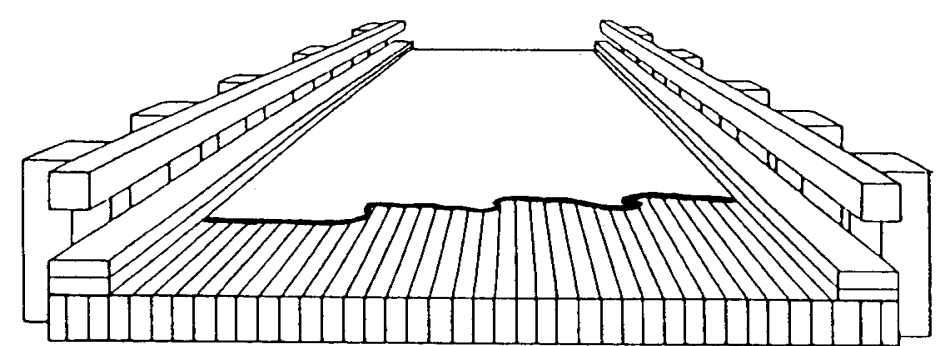

FIGURA 8 - Tabuleiro com seção transversal de altura constante (OKIMOTO, 1997)

A figura 9 mostra uma variação direta deste sistema, utilizando-se peças de MLC. Estas peças são constituídas de madeira serrada de menores dimensões, as quais possibilitam o alcance de maiores vãos.

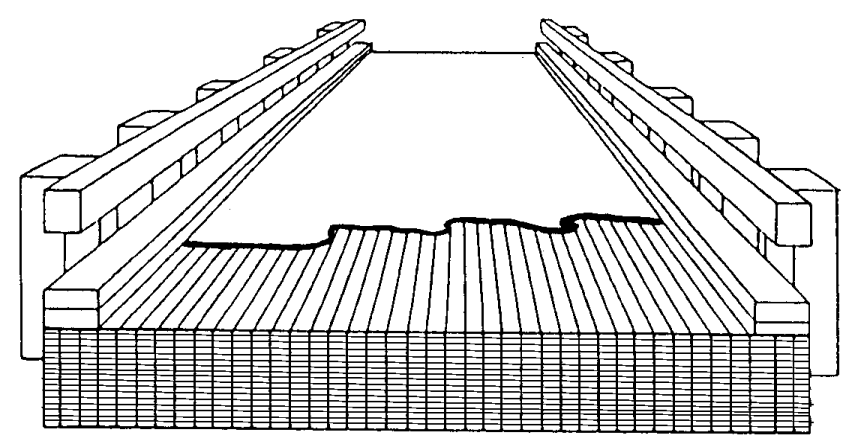

FIGURA 9 - Tabuleiro de altura constante com peças em MLC (OKIMOTO, 1997) 
O sistema tipo sanduíche é constituído por peças de madeira serrada de diferentes tamanhos, que são colocadas de modo a criar um mecanismo de travamento entre si (Figura 10). Este sistema utiliza duas linhas de protensão, uma para cada camada.

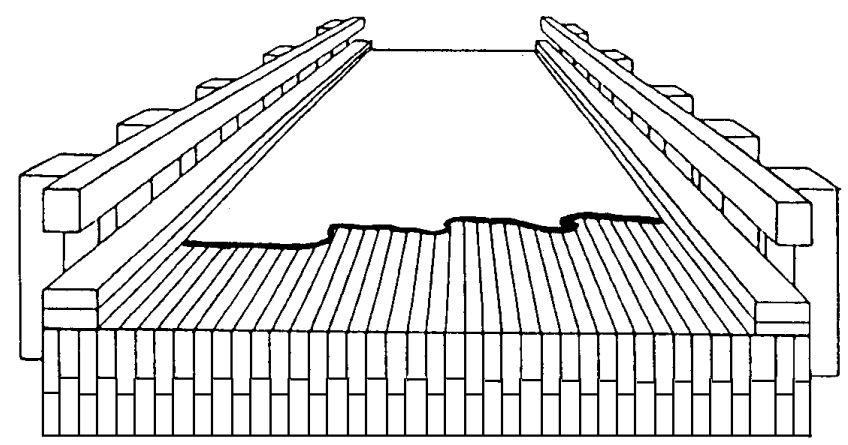

FIGURA 10 - Sistema sanduíche

(OKIMOTO, 1997)

Uma das variações do tabuleiro de altura constante é obtida com a introdução de vigas intermediárias de maior altura (Figura 11). Neste sistema, denominado ponte protendida formada por vigas- $\mathrm{T}$, o tabuleiro é constituído por peças de madeira serrada e as nervuras constituídas de madeira serrada, MLC ou LVL (lâminas de pequena espessura coladas com as fibras orientadas na mesma direção).

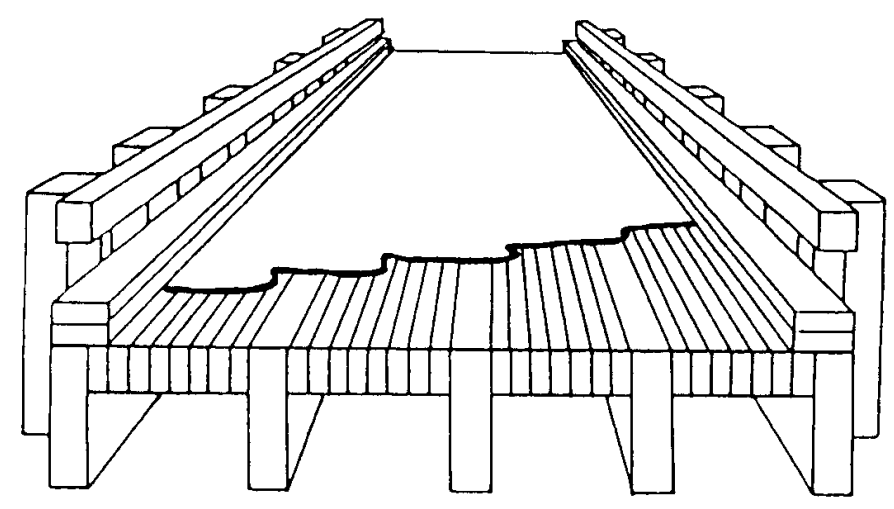

FIGURA 11 - Tabuleiro formado por vigas-T

(OKIMOTO, 1997) 
Outras possíveis variações são: treliças longitudinais protendidas transversalmente, tabuleiro com seção caixão e tabuleiro transversal com protensão longitudinal. No primeiro caso, as treliças são posicionadas ao longo do vão, dispostas continuamente uma ao lado da outra ou espaçadas (Figura 12). Neste sistema, a protensão é aplicada no tabuleiro e nos banzos superiores.

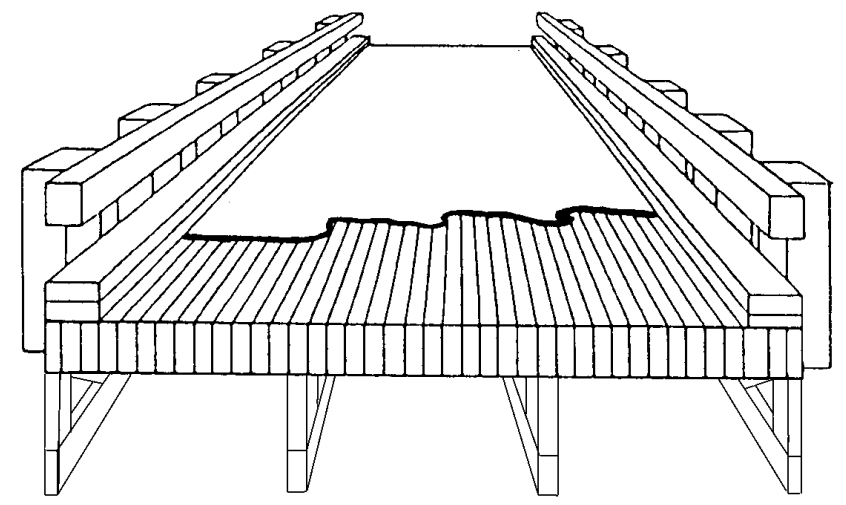

FIGURA 12 - Treliças longitudinais protendidas transversalmente.

(OKIMOTO, 1997)

Na seção caixão, apresentada na figura 13, as nervuras são constituídas de peças de madeira serrada, MLC, madeira compensada ou viga treliçada. Este sistema necessita de duas linhas de protensão, uma para cada tabuleiro.

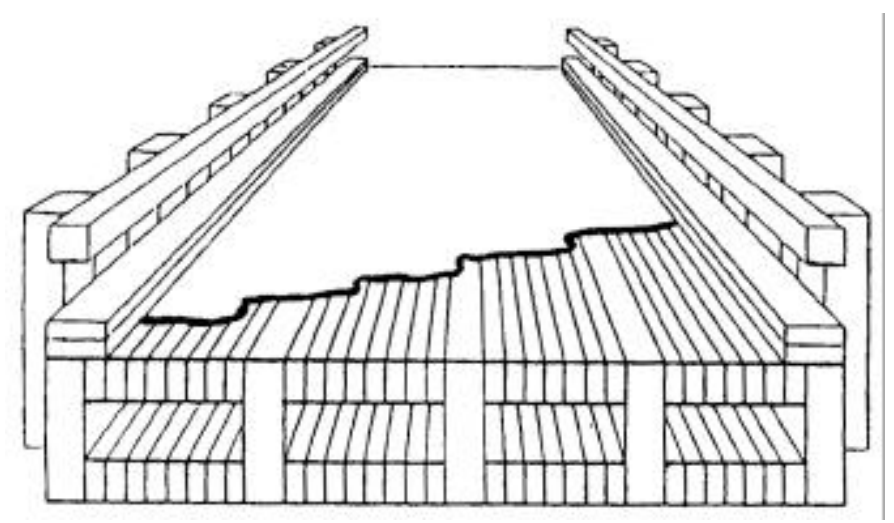

FIGURA 13 - Tabuleiro com seção caixão

(OKIMOTO, 1997) 
Por último, tem-se o sistema com tabuleiro protendido longitudinalmente, constituído por peças de madeira serrada dispostas transversalmente (Figura 14). Neste sistema, devem existir elementos de rigidez posicionados como vigas.

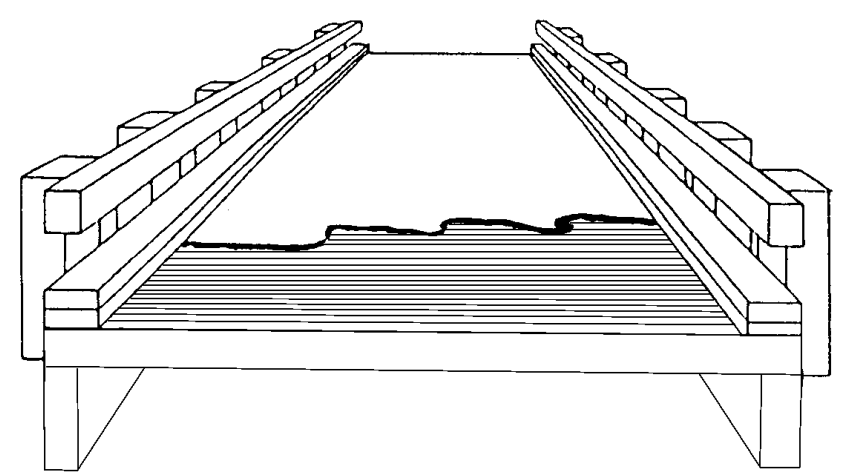

FIGURA 14 - Tabuleiro transversal com protensão longitudinal (OKIMOTO, 1997)

\section{3- Tabuleiros formados por vigas de seção transversal T}

A seguir são apresentadas as informações relacionadas ao sistema $\mathrm{T}$ das pontes de madeira protendidas transversalmente. Estas informações referem-se à construção pioneira, às variações do sistema construtivo, aos ensaios de outros protótipos e ao método WVU.

\subsection{1- Construção pioneira}

Segundo TAYLOR \& RITTER (1990), o sistema T das pontes de madeira protendidas transversalmente foi desenvolvido e testado em 1988 por DICKSON \& GANGARAO (1990) da West Virginia University, onde foram realizados ensaios de modelo em laboratório e a construção do primeiro protótipo formado por vigas-T. Este protótipo, denominado ponte "Barlow Drive" (Figura 15), foi construído em Spencer, com 22,3 m de vão e 5,3 m de largura, possuindo seis nervuras de LVL com seção transversal igual a 15,0 x 114,0 cm mais uma viga central constituída por duas peças com dimensões transversais 11,0 x $114,0 \mathrm{~cm}$ cada uma. 


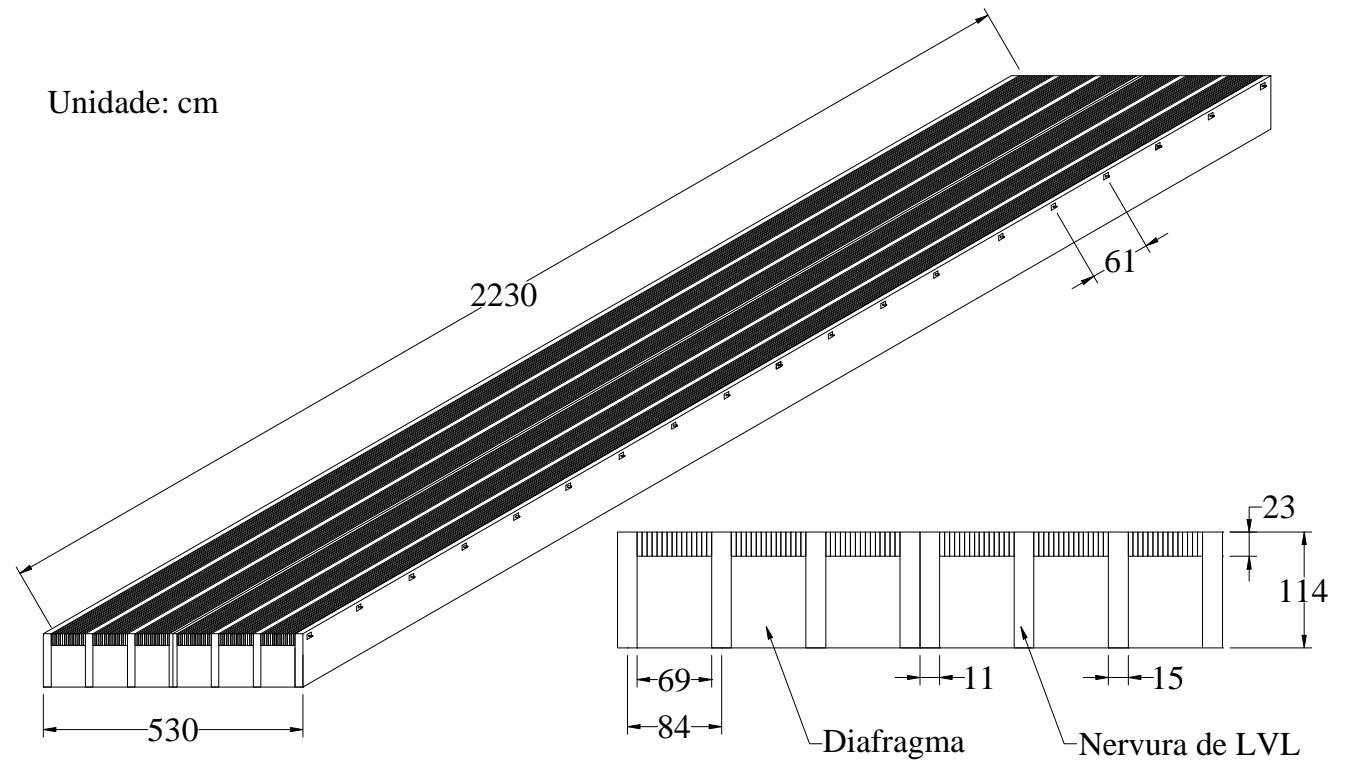

FIGURA 15 - Dimensões da Ponte "Barlow Drive"

Por se tratar de uma construção pioneira, foi desenvolvido um programa de ensaios em um modelo construído com 4,9 m de vão e 1,65 m de largura, possuindo três nervuras longitudinais com seção transversal igual a $9,0 \times 46,0 \mathrm{~cm}$ e altura do tabuleiro igual a $14 \mathrm{~cm}$ (Figura 16). Este modelo não foi construído em escala, mas o espaçamento entre as nervuras foi mantido igual ao da escala real.

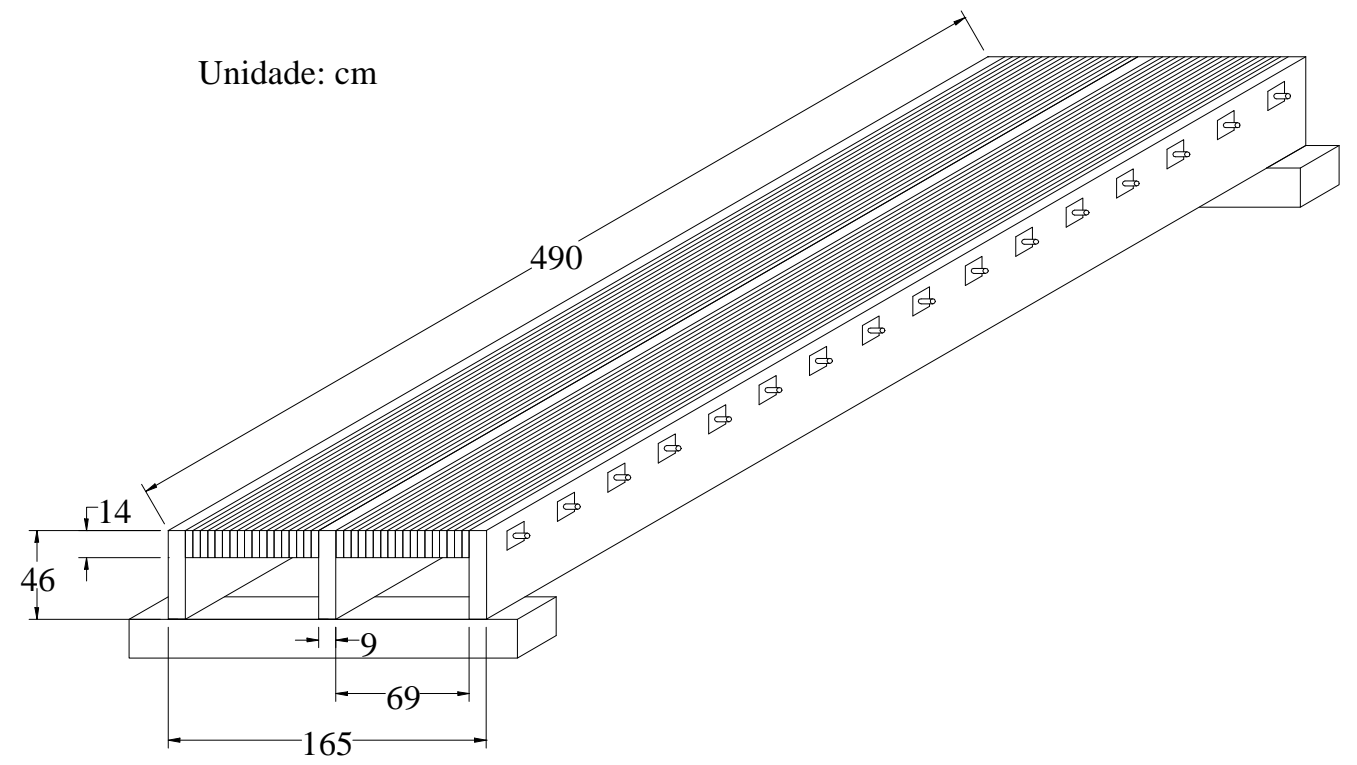

FIGURA 16 - Modelo ensaiado por DICKSON \& GANGARAO (1990) 
Estes ensaios foram realizados com os objetivos de:

- determinar experimentalmente a posição da linha neutra e verificar a composição do sistema T. Este ensaio consistiu em medir a deformação no topo e na parte inferior da viga-T, e os resultados indicaram composição total da viga-T central, ou seja, a linha neutra obtida experimentalmente praticamente coincidiu com a obtida teoricamente (Figura 17);

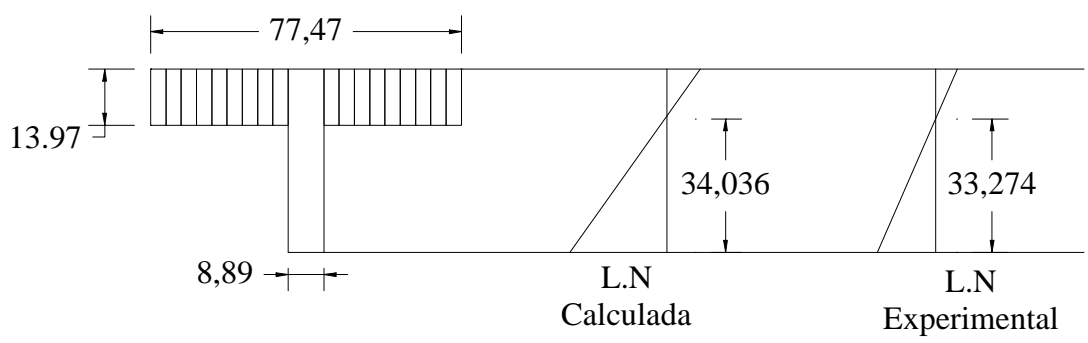

FIGURA 17 - Localização da linha neutra da viga-T central do modelo

- determinar a tensão de protensão necessária para impedir o deslizamento entre as lâminas adjacentes e a abertura destas lâminas no lado tracionado do tabuleiro. De acordo com os resultados, estimou-se que a tensão de protensão é igual a $12 \%$ da resistência à compressão admissível da madeira. Estes resultados obtidos também mostraram que o comportamento entre a força aplicada e o deslocamento do tabuleiro foi não-linear e que houve uma perda de quase $50 \%$ da tensão de protensão no período de 32 dias. No entanto, não foi possível estabelecer as parcelas devidas à deformação lenta da madeira e à perda de umidade ocorrida no tabuleiro do modelo, mas enfatizou-se a importância da manutenção da tensão de protensão;

- determinar a distribuição lateral das cargas quando a nervura central estiver carregada. De acordo com os resultados, a força aplicada à nervura diretamente carregada foi aproximadamente $2 / 3$ da carga total.

A ponte foi construída em duas partes, sendo cada uma protendida temporariamente por barras de aço colocadas a cada dois furos. Estas estruturas foram transportadas para Charleston, na Virgínia do oeste, onde cada metade foi erguida por um guindaste de $1.400 \mathrm{kN}$ e posicionada definitivamente sobre os apoios 
com o auxilio de outro guindaste de $800 \mathrm{kN}$. A protensão transversal da estrutura consistiu inicialmente em colocar barras de aço, atravessando a largura total da ponte, nos furos que ficaram vazios e posteriormente usar barras com o mesmo comprimento para substituir as temporárias. $\mathrm{Na}$ fase de acabamento, os guardacorpos foram instalados e a superfície de rolamento pavimentada com concreto asfáltico. A figura 18 apresenta a ponte "Barlow Drive" já finalizada.

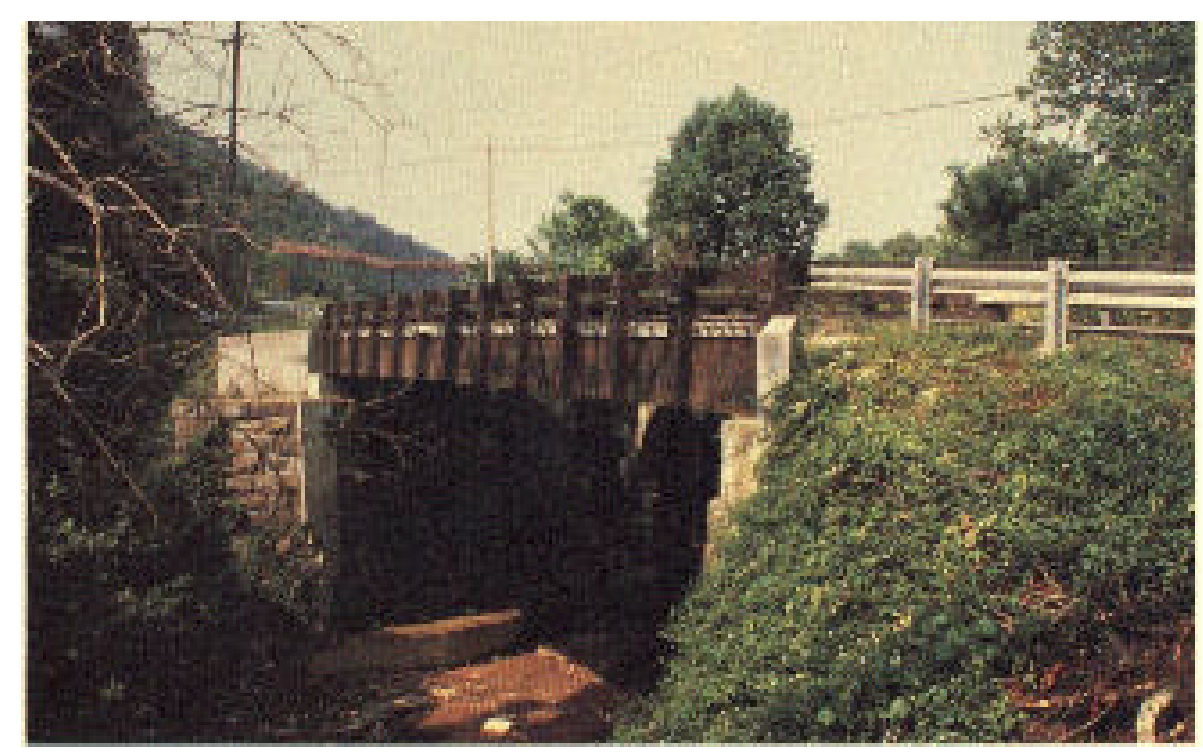

FIGURA 18 - Ponte "Barlow Drive"

(USDA Forest Service, 1995)

Esta ponte foi monitorada durante um período de seis meses, obtendo-se os seguintes resultados principais:

- o deslocamento máximo da nervura ocorreu na viga externa $\left(\delta_{\text {máx }}=2,13 \mathrm{~cm}\right)$, com valor mais baixo que o esperado $\left(\delta_{\text {esperado }}=\mathrm{L} / 865\right.$ ou $\left.2,58 \mathrm{~cm}\right)$. Esta rigidez imprevista foi devido à contribuição das duas nervuras centrais, do guarda-rodas e do guarda-corpo. Neste ensaio, a roda de um veículo-tipo de $231 \mathrm{kN}$ ficou encostada no guarda-rodas da ponte;

- o deslocamento máximo do tabuleiro foi igual a $0,51 \mathrm{~cm}$, não sendo observado nenhum deslizamento vertical entre as lâminas. Neste ensaio, uma carga de roda de 
$40 \mathrm{kN}$ foi posicionada no ponto médio da porção do tabuleiro entre duas nervuras adjacentes;

- esta ponte foi protendida inicialmente com valor igual a 1,02 $\mathrm{MPa}$ e retensionada duas vezes (a primeira após 8 dias e a segunda após 50 dias) com o mesmo valor da protensão inicial. De acordo com os resultados, houve uma perda da tensão de protensão de aproximadamente $50 \%$ após 5 meses de sua construção e uma perda de quase 32\% após 12 meses de sua construção. Esta perda de protensão menor foi devido a um extenso período de chuva antes das medições, que ocasionou ganho de umidade e expansão da madeira;

- a umidade da ponte variou entre 18 e $40 \%$, sendo que a maior variação ocorreu na parte superior das nervuras. A umidade do tabuleiro foi aproximadamente $22 \%$.

$\mathrm{O}$ alto custo da estrutura, aproximadamente US\$ $850 / \mathrm{m}^{2}$, foi devido à fabricação e transporte das vigas de LVL para o local de construção, ao aluguel dos guindastes, à mão-de-obra com a instalação e também ao projeto conservativo da ponte, que por se tratar de uma construção pioneira, não havia diretrizes a seguir.

\subsection{2- Variações construtivas do sistema $\mathrm{T}$}

A seguir estão apresentadas duas possíveis variações construtivas do sistema $\mathrm{T}$ das pontes de madeira protendidas transversalmente. Estas variações se referem ao sistema modular T e à utilização do LVL nas pontes de madeira.

Segundo DAVALOS, SALIM \& DICKSON (1993), o sistema T modular foi desenvolvido com o objetivo de superar as dificuldades na montagem de pontes protendidas formadas por vigas-T e, conseqüentemente, reduzir o custo total da estrutura. Com o novo sistema modular, é possível que uma ponte seja montada in loco em apenas 1 dia, enquanto que a montagem descrita para a ponte "Barlow Drive" exige de 3 a 4 semanas. Como exemplo de aplicação do novo sistema, os 
autores citam a ponte "Camp Arrowhead", projetada de acordo com o método WVU e formada por 5 módulos que se estendem ao longo de 18,9 m de vão (Figura 19).
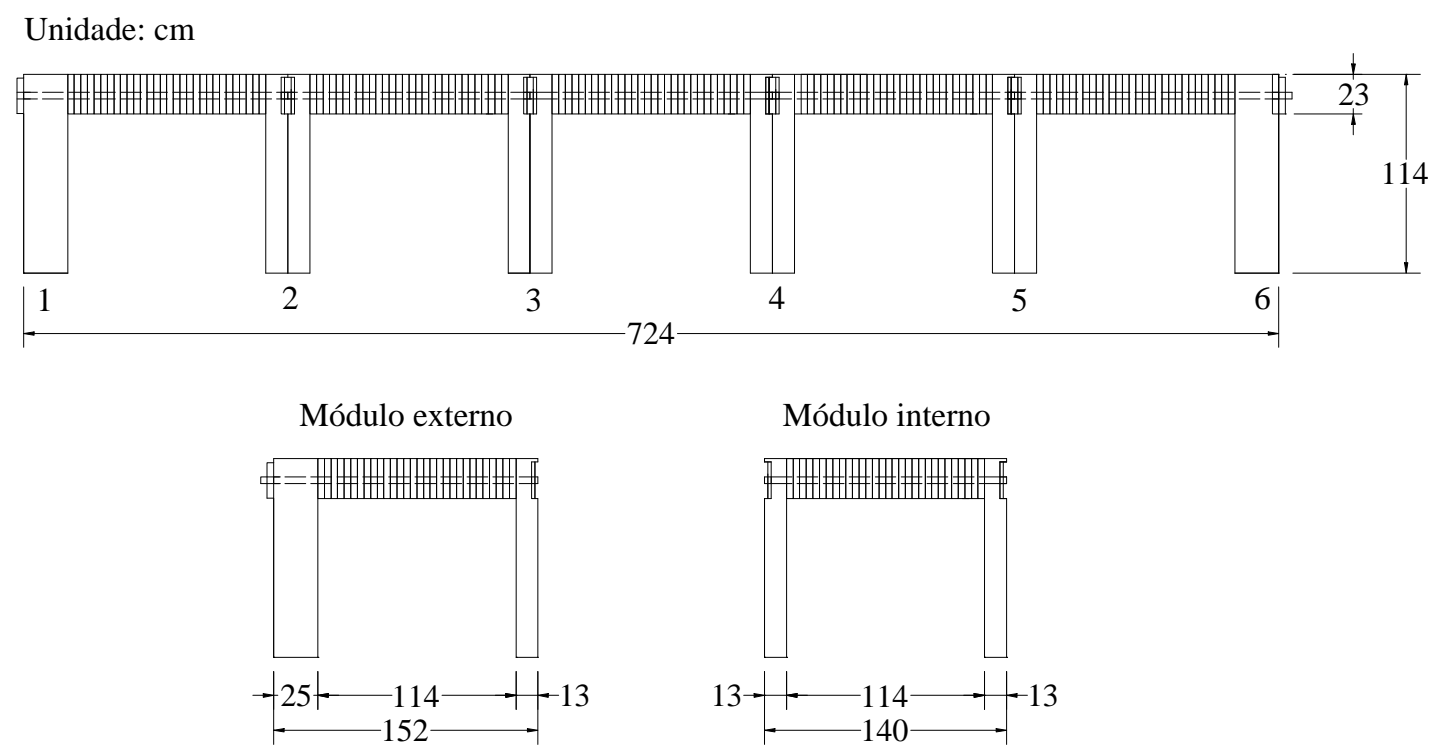

FIGURA 19 - Dimensões da Ponte "Camp Arrowhead"

Na construção desta ponte, cada módulo foi protendido por barras de aço temporárias colocadas a cada $61 \mathrm{~cm}$ e por outras barras permanentes colocadas a cada $183 \mathrm{~cm}$. No pátio de construção, os guarda-corpos e os guarda-rodas foram instalados nos módulos externos e todas as barras de protensão tracionadas três vezes para minimizar as perdas ao longo do tempo. Os módulos foram transportados para Cabell County, na Virgínia do oeste, erguidos por guindaste e posicionados definitivamente sobre os apoios. As barras de aço a cada $61 \mathrm{~cm}$ foram substituídas por outras que atravessaram a largura total da ponte e as barras a cada $183 \mathrm{~cm}$ retensionadas. Na fase de acabamento, a ponte foi fixada aos apoios e a superfície de rolamento pavimentada com concreto asfáltico. A figura 20 apresenta a ponte "Camp Arrowhead" já finalizada. 


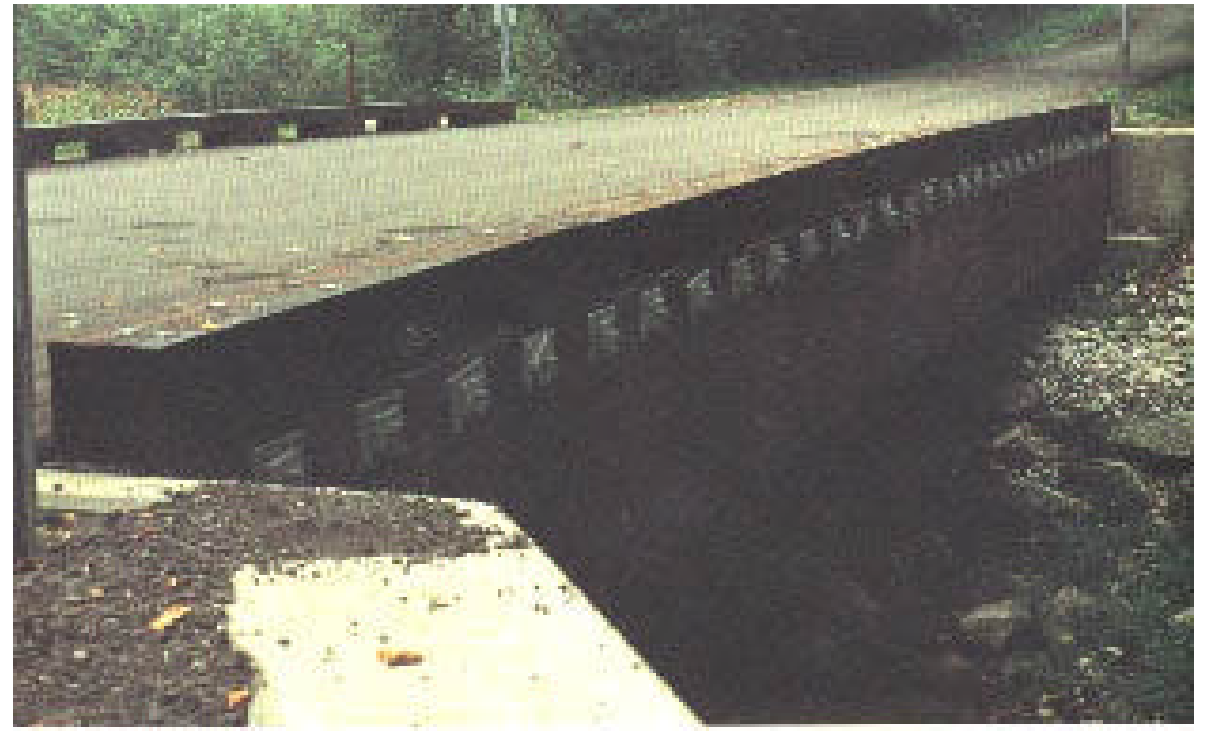

FIGURA 20 - Ponte "Camp Arrowhead"

(USDA Forest Service, 1995)

Esta ponte foi monitorada durante um período de quatro meses e os resultados dos ensaios (Tabela 2 e Tabela 3) foram comparados com aqueles obtidos pelos métodos dos elementos finitos e do WVU. Nos ensaios para determinar o deslocamento máximo da nervura, um veículo-tipo de $231 \mathrm{kN}$ foi posicionado na faixa de tráfego a jusante da ponte, e depois posicionado na faixa de tráfego a montante. Estes dois casos foram usados para simular o carregamento assimétrico, e, por superposição, simular o carregamento simétrico da ponte. Nos ensaios para determinar o deslocamento máximo do tabuleiro, uma carga de roda de $40 \mathrm{kN}$ foi posicionada no ponto médio da porção do tabuleiro entre as nervuras 3 e 4 . 
TABELA 2 - Tensões e deslocamentos máximos da porção do tabuleiro entre as nervuras 3 e 4

\begin{tabular}{|c|c|c|c|}
\cline { 2 - 4 } \multicolumn{1}{c|}{} & $\begin{array}{c}\text { Dados de } \\
\text { Campo }\end{array}$ & $\begin{array}{c}\text { Elementos } \\
\text { finitos }\end{array}$ & Método WVU \\
\hline Tensão máx.(MPa) & 0,324 & 0,315 & 0,381 \\
\hline Deslocamento máx. (cm) & 0,214 & 0,209 & 0,211 \\
\hline
\end{tabular}

TABELA 3 - Tensões e deslocamentos máximos das nervuras 3 e 4

\begin{tabular}{|c|c|c|c|c|}
\cline { 2 - 3 } \multicolumn{1}{c|}{} & \multicolumn{2}{c|}{ Dados de Campo } & Elementos & Método \\
\cline { 2 - 3 } & Nervura 3 & Nervura 4 & finitos & WVU \\
\hline Tensão máx.(MPa) & 5,01 & 5,27 & 5,72 & 6,47 \\
\hline Deslocamento máx. (cm) & 2,06 & 2,06 & 2,10 & 2,53 \\
\hline
\end{tabular}

Os autores concluíram que:

- a nova técnica de construção em módulos, além de mais eficiente, facilita a fabricação e o transporte da ponte, reduz os esforços com a mão-de-obra e a instalação e aumenta, significantemente, o controle de qualidade;

- o método WVU é um método simples e suficientemente preciso para prever as tensões e os deslocamentos dos sistemas $\mathrm{T}$, podendo ser utilizado como ferramenta de cálculo no projeto destas pontes.

O custo total da estrutura, incluindo projeto, fabricação do tabuleiro e das vigas, transporte e mão de obra com a instalação, foi aproximadamente US\$ 570/m².

Segundo RITTER et al (1996), o LVL é feito de folhas de madeira obtidas através de corte por rotação e coladas com adesivos impermeáveis, com as fibras orientadas na mesma direção. Geralmente, a espessura das folhas de madeira é de 2,5 a 6,4 mm e, como há pequenas frestas nestas folhas, o resultado é a penetração total de preservativos de madeira. Por ser um material manufaturado, pode ser produzido em variedades de tamanhos e formas. O LVL não é um material novo, ele originou 

TABELA 4 - Dimensões e detalhes da pontes (RITTER et al, 1996)

\begin{tabular}{|c|c|c|c|c|}
\hline $\begin{array}{c}\text { Nome da } \\
\text { Ponte }\end{array}$ & $\begin{array}{c}\text { Vão da Ponte } \\
(\mathrm{m})\end{array}$ & $\begin{array}{c}\text { Largura da } \\
\text { Ponte }(\mathrm{m})\end{array}$ & $\begin{array}{c}\text { Altura da } \\
\text { Nervura }(\mathrm{cm})\end{array}$ & $\begin{array}{c}\text { Viga Caixão } \\
\text { nas laterais }\end{array}$ \\
\hline Mill Creek & 9,1 & 7,3 & 40,6 & sim \\
\hline Pett Creek & 11,6 & 8,5 & 50,8 & sim \\
\hline Kenally Creek & 9,9 & 5,2 & 45,7 & não \\
\hline Franklin Road & 13,41 & 11,0 & 71,1 & sim \\
\hline Wardwell & 8,5 & 11,43 & 40,6 & sim \\
\hline South Canal & 7,92 & 4,88 & 35,6 & não \\
\hline
\end{tabular}

\subsection{3- Ensaios de outros protótipos}

GANGARAO \& LATHEEF (1991) apresentam análises experimentais e teóricas de sistemas com diversas seções transversais (seção bulbo T, seção caixão e seção formada por vigas-T). Nos ensaios, os modelos reduzidos em sistema $\mathrm{T}$ são submetidos a duas condições de carregamento, A e B (Figuras 22 e 23), sendo que a condição A foi aplicada para modelos com diafragmas e nervuras de LVL, e a condição B para modelos com e sem diafragmas e nervuras de MLC.

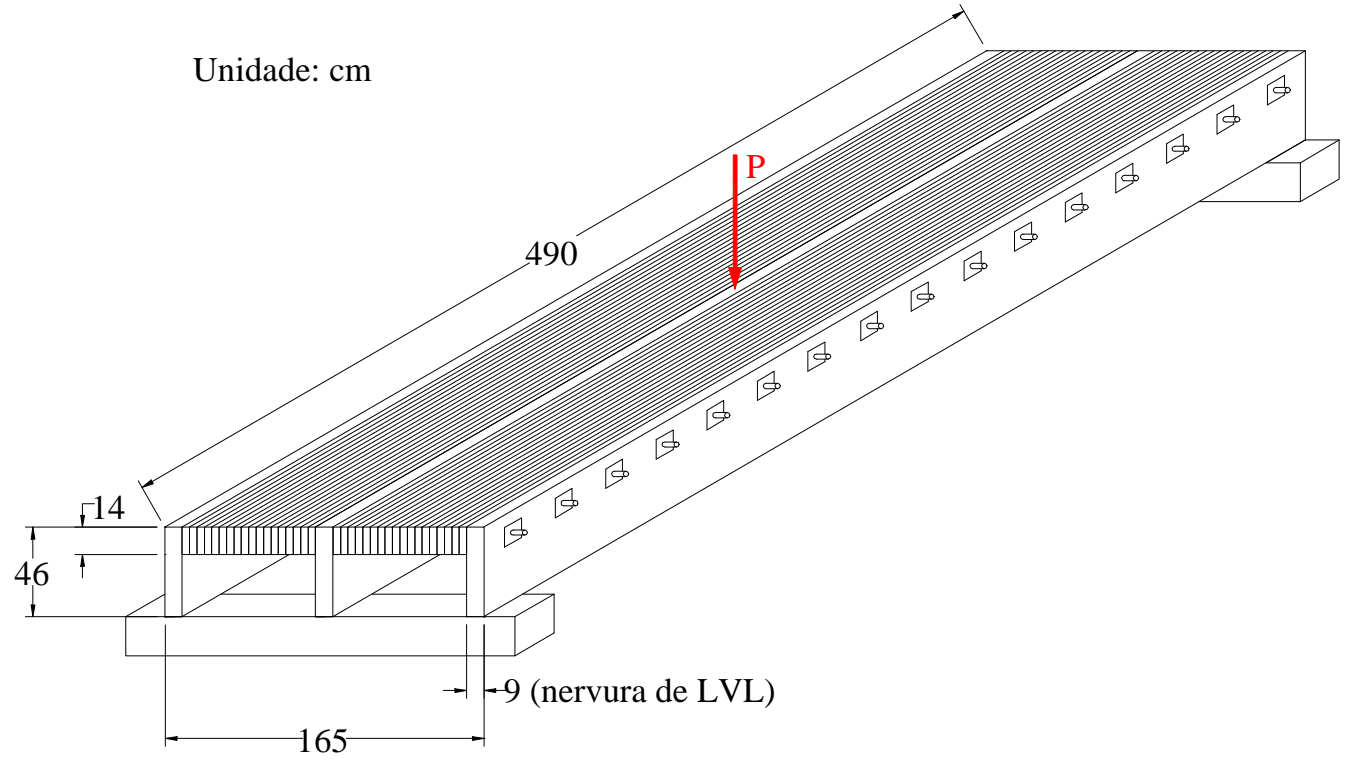

FIGURA 22 - Condição de carregamento A 


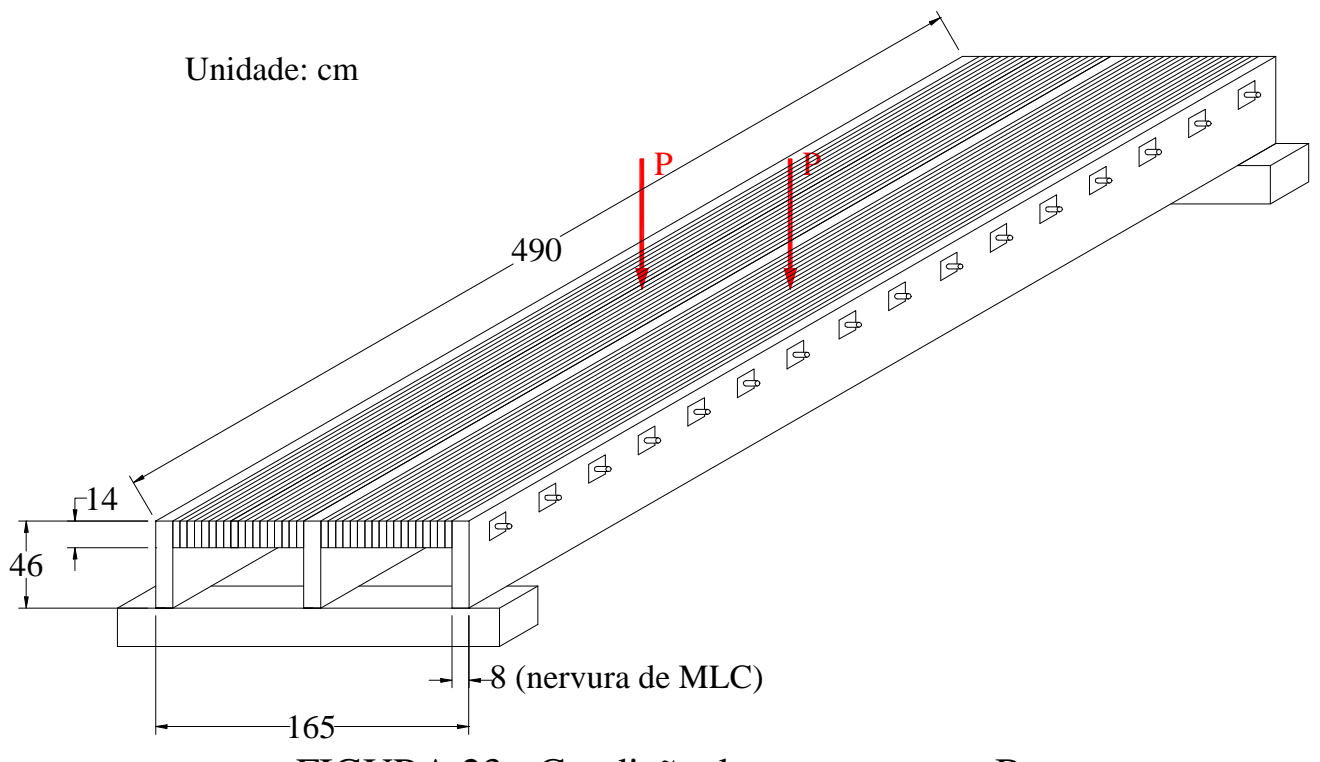

FIGURA 23 - Condição de carregamento B

Com estes ensaios, os autores concluíram que:

- não foram observados deslizamento vertical, nem separação na direção transversal das lâminas de madeira. Também não foi observada falha devida ao cisalhamento no tabuleiro e nas nervuras;

- para a condição de carregamento $\mathrm{B}$, a força aplicada à nervura central foi aproximadamente $50 \%$ da carga total para modelos sem diafragmas e $42 \%$ para modelos com diafragmas. No entanto, estas porcentagens podem ser maiores para sistemas T que tenham mais de três nervuras;

- os ensaios à flexão com forças no regime elástico-linear indicaram composição total da viga-T central.

BARGER Jr. et al (1993) também apresentam análises experimentais e teóricas de sistemas com seção transversal formada por vigas-T e seção caixão, com o objetivo de entender a rigidez transversal e a variação da distribuição lateral da carga destes sistemas. Nos ensaios, cada modelo reduzido em sistema T com três e quatro nervuras foi submetido a duas tensões de protensão: 0,345 $\mathrm{MPa}$ e 0,690 $\mathrm{MPa}$ 
e as nervuras interna e externa foram solicitadas por forças variando de 0 até 35,59 $\mathrm{kN}$ (Figuras 24 e 25).

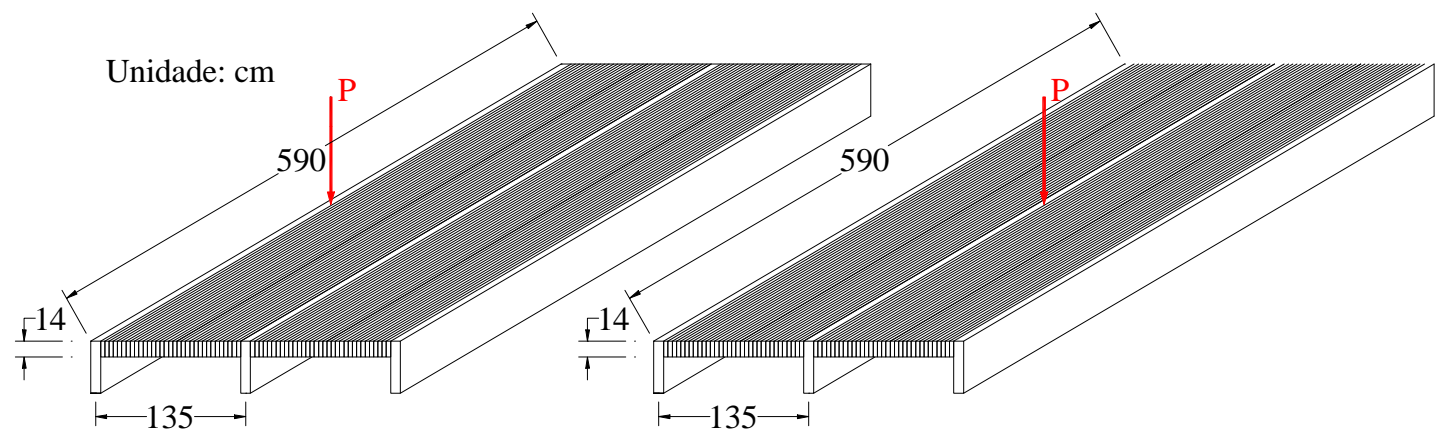

FIGURA 24 - Modelo com três nervuras sob força estática na nervura interna e externa

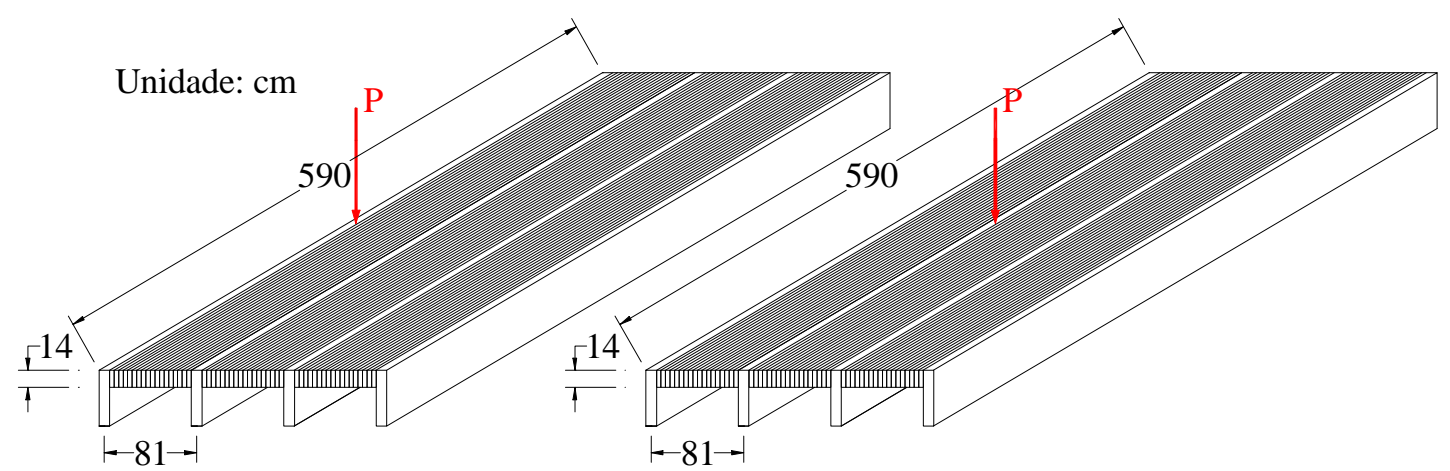

FIGURA 25 - Modelo com quatro nervuras sob força estática na nervura interna e externa

Com estes ensaios, os autores concluíram que:

- os ensaios para determinar o deslocamento das nervuras internas indicaram que o sistema T com três nervuras é mais flexível que o sistema T com quatro nervuras;

- os ensaios para determinar a deformação das nervuras internas indicaram que o sistema T é mais flexível quando submetido a uma tensão de protensão igual a 0,345 MPa que a uma tensão de protensão igual a 0,690 MPa; 
- os ensaios para determinar a deformação devida à compressão na face superior do tabuleiro indicaram que a distribuição não uniforme desta deformação é devida à menor capacidade dos tabuleiros protendidos de transmitir lateralmente o esforço cortante vertical entre as lâminas. Este fenômeno, denominado cisalhamento retardado, é responsável pela redução da largura da mesa de uma viga-T;

- uma nervura externa diretamente carregada absorve uma parcela de carga maior que uma nervura interna diretamente carregada. Desta forma, uma nervura externa é mais flexível que uma nervura interna.

\subsection{4- Método WVU}

DAVALOS \& SALIM (1992) apresentam o método WVU para o sistema T das pontes de madeira protendidas transversalmente. Este método de dimensionamento, baseado no fator de distribuição da carga $\mathrm{W}_{\mathrm{f}}$ e na largura efetiva da mesa de uma viga- $T$ interna $b_{e}$, reduz o projeto do sistema $T$ ao de uma viga- $T$. Esta viga é analisada usando-se as equações de flexão simples, considerando-se os efeitos globais [deslocamentos e tensões (de flexão e de cisalhamento) longitudinais máximos devidos à carga permanente e à carga móvel] e os efeitos locais [deslocamentos e tensões (de flexão e de cisalhamento) transversais máximos devidos à carga de roda aplicada na seção do tabuleiro entre duas nervuras adjacentes].

A distribuição da tensão de compressão na largura real da aba de uma viga-T é não-linear (Figura 26). Assim, com o objetivo de simplificar o cálculo dos deslocamentos e das tensões máximas desta viga, DAVALOS \& SALIM (1993) desenvolveram uma equação de regressão para calcular a largura efetiva da aba $B_{E}$ na qual se considera a distribuição de tensão constante e equivalente à distribuição real de tensão. 


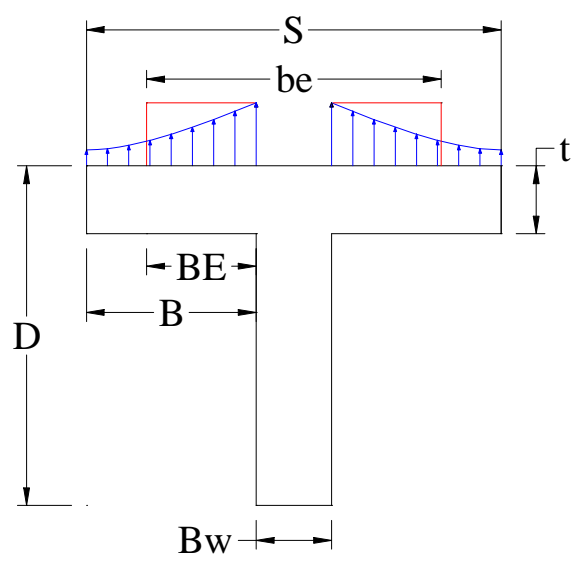

FIGURA 26 - Distribuição de tensão não-linear de uma viga-T isolada

Inicialmente, foi desenvolvida uma equação para se determinar a largura $B_{E}$ de uma viga-T isolada, admitindo-se a força resultante de tração na nervura igual à força resultante de compressão na mesa (Equação 13).

$$
\mathrm{B}_{\mathrm{E}}=\frac{1}{2} \cdot\left[\frac{\mathrm{B}_{\mathrm{w}} \cdot(\mathrm{D}-\mathrm{t})}{2 \cdot \mathrm{t}} \cdot\left(\frac{\sigma_{\mathrm{yt}}+\sigma_{\mathrm{yc}}}{\left(\sigma_{\mathrm{yc}}\right)_{\text {máx }}}\right)-\mathrm{B}_{\mathrm{w}}\right]
$$

onde:

$\sigma_{\mathrm{yc}}=$ tensão de compressão máxima na nervura da viga-T

$\sigma_{\mathrm{yt}}=$ tensão de tração máxima na nervura da viga-T

$\left(\sigma_{\text {yc }}\right)_{\text {máx }}=$ tensão de compressão máxima na aba da viga-T

Posteriormente, as variáveis que têm influência significativa na largura $B_{E}$ (altura do tabuleiro t, altura da nervura D, espaçamento entre nervuras $\mathrm{S}$, vão da ponte L, razão entre o módulo de elasticidade na direção longitudinal da nervura e o módulo de elasticidade na direção longitudinal das lâminas do tabuleiro $\mathrm{E}_{\mathrm{Ln}} / \mathrm{E}_{\mathrm{Lt}}$ ) foram combinadas entre si e as tensões, necessárias para se obter $\mathrm{B}_{\mathrm{E}}$ a partir de (13), calculadas pelo método dos elementos finitos. Com os valores de $\mathrm{B}_{\mathrm{E}}$, realizou-se um estudo paramétrico para se determinar as melhores combinações adimensionais entre as variáveis citadas. Com isto, foram identificadas as equações de regressão que possibilitam escrever as relações $\mathrm{B}_{\mathrm{E}} / \mathrm{B}$ em função das melhores combinações obtidas: $\mathrm{L} / \mathrm{B}, \mathrm{D} / \mathrm{t}$ e $\mathrm{E}_{\mathrm{L}, \mathrm{n}} / \mathrm{E}_{\mathrm{L}, \mathrm{t}}$. Estas variáveis foram selecionadas por um processo de eliminação regressiva, com nível de significância igual a 10\%. Finalmente, a equação 
de regressão foi obtida com os dados dos 125 modelos, analisados via elementos finitos, ajustados a uma linha reta (Equação 14).

$$
\mathrm{B}_{\mathrm{E}}=\mathrm{B} \cdot\left[0,4586+\frac{1}{198} \cdot\left(\frac{\mathrm{L}}{\mathrm{B}}\right) \cdot\left(\frac{\mathrm{D}-\mathrm{t}}{\mathrm{t}}\right) \cdot\left(\frac{\mathrm{E}_{\mathrm{L}, \mathrm{n}}}{\mathrm{E}_{\mathrm{L}, \mathrm{t}}}\right)\right]
$$

onde:

$\mathrm{B}=$ largura da aba de uma viga-T

Os autores concluíram que:

- a largura $\mathrm{B}_{\mathrm{E}}$ é proporcional à força aplicada;

- a largura $B_{E}$ é menor ou igual a $B$ quando $\left(\frac{L}{B}\right) \cdot\left(\frac{D-t}{t}\right) \cdot\left(\frac{E_{L, n}}{E_{L, t}}\right)$ é menor ou igual a 106

- a equação de regressão deve ser aplicada a sistemas T com vãos simplesmente apoiados de até $30 \mathrm{~m}$.

\section{4- Conclusões a respeito da revisão bibliográfica}

A análise da bibliografia permitiu a obtenção das seguintes conclusões principais:

- O sistema de madeira protendido transversalmente formado por vigas-T é interessante para a construção de pontes, tendo sido aceito como uma alternativa para aumentar o vão das pontes com seção transversal de altura constante. Esta aceitação pode ser observada pelo número expressivo de pontes construídas no Canadá e Estados Unidos utilizando este sistema. 
- O método WVU é simples em relação aos modelos de placa e de grelha, e suficientemente preciso para prever as tensões e os deslocamentos das pontes de madeira protendidas transversalmente formadas por vigas- $\mathrm{T}$.

- As nervuras destas pontes devem ser constituídas por peças de grandes seções e comprimentos, havendo a opção de construí-las com MLC ou LVL. No entanto, o LVL não é fabricado no Brasil, tornado-se viável a MLC. Para o tabuleiro, que pode ser constituído por peças com pequenas dimensões, é mais vantajosa a utilização de madeira serrada.

- Com base nas recomendações de OKIMOTO (1997), a tensão de projeto utilizada é igual a 0,7 MPa, os parâmetros elásticos são calculados pelas equações (9) e (10) e o fator de redução da rigidez longitudinal $\mathrm{C}_{\mathrm{bj}}$ calculado pela equação (11). 


\section{3- ANÁLISE NUMÉRICA DO SISTEMA T}

O procedimento de cálculo utilizado para a análise numérica do sistema $\mathrm{T}$ das pontes de madeira baseia-se no método WVU para o dimensionamento da altura e largura das nervuras, da altura do tabuleiro e do espaçamento entre nervuras. Para o desenvolvimento deste trabalho, o método WVU foi adaptado aos critérios da Associação Brasileira de Normas Técnicas, "NBR 7188/84 - Cargas Móveis em Pontes Rodoviárias e Passarelas de Pedestres" e "NBR 7190/97 - Projeto de Estruturas de Madeira”, e programado em software MATHCAD@

Este estudo é conduzido a partir da definição preliminar do vão, da largura e classe da ponte, das espécies e classes de resistência das madeiras utilizadas para as nervuras e o tabuleiro. São analisadas diversas configurações de pontes, variando-se a altura do tabuleiro, a largura das nervuras, o número de nervuras e determinando-se a altura das mesmas para cada configuração.

\section{1- Condições da análise numérica}

A seguir são apresentadas as informações relacionadas às condições da análise numérica. Estas informações referem-se à madeira utilizada e às características das pontes estudadas.

\subsection{1- Madeira utilizada}

No Brasil, a madeira é utilizada com frequiência para múltiplas finalidades, mas devido ao processo de extração irracional, grandes áreas são derrubadas para o aproveitamento de poucas espécies de interesse comercial. 
O reflorestamento é uma atividade que utiliza racionalmente a madeira na solução de problemas relacionados a coberturas (residenciais, comerciais, industriais), cimbramentos (para estruturas de concreto armado e protendido), transposição de obstáculos (pontes, viadutos, passarelas para pedestres), armazenamento (silos verticais e horizontais); na fabricação de componentes para a edificação, como painéis divisórios, portas, forros, pisos; nas indústrias de papel, lápis, embalagens; nos meios de transportes (barcos, carroçaria, vagões de trem), entre outros, e a opção prioritária brasileira envolve dois gêneros: Pinus e Eucalyptus. As principais vantagens da madeira oriunda do reflorestamento sobre as madeiras nativas são:

- as áreas e as explorações controladas, com períodos de corte predefinidos, e definição de áreas e espécies de acordo com o tipo de uso;

- as espécies mais utilizadas têm se adaptado às diferentes situações de clima e solo;

- os altos níveis de produtividade em decorrência do desenvolvimento de melhores práticas silviculturais, uso de sementes melhoradas, técnicas na produção de mudas e adequada fertilização.

Neste contexto, as madeiras de reflorestamento utilizadas nas simulações numéricas foram as espécies e as classes de resistência das madeiras comercialmente disponíveis, ou seja, nervuras de MLC de variedades Pinus ou Eucalipto Grandis, ambos Classe C 30, e tabuleiros de madeira serrada de variedades de Pinus Classe C 30 ou de Eucalipto Classes C 30 e C 40.

O Eucalipto Grandis combina as vantagens de ter resistência e densidade médias, ou seja, é suficientemente poroso e permeável para admitir uma boa colagem.

As tabelas 5 e 6 apresentam as classes de resistência correspondentes às coníferas e às dicotiledôneas. 
TABELA 5 - Classes de resistência para coníferas (NBR 7190/97)

\begin{tabular}{|c|c|c|c|c|}
\hline \multicolumn{5}{|c|}{ Coníferas } \\
\hline CLASSE & $\begin{array}{c}\mathrm{f}_{\mathrm{c} 0, \mathrm{k}} \\
(\mathrm{MPa})\end{array}$ & $\begin{array}{c}\mathrm{f}_{\mathrm{v} 0, \mathrm{k}} \\
(\mathrm{MPa})\end{array}$ & $\begin{array}{c}\mathrm{E}_{\mathrm{c} 0, \mathrm{~m}} \\
(\mathrm{MPa})\end{array}$ & $\begin{array}{c}\rho_{\text {aparente }} \\
\left(\mathrm{kg} / \mathrm{m}^{3}\right)\end{array}$ \\
\hline C 20 & 20 & 4 & 3500 & 500 \\
\hline C 25 & 25 & 5 & 8500 & 550 \\
\hline C 30 & 30 & 6 & 14500 & 600 \\
\hline
\end{tabular}

TABELA 6 - Classes de resistência para dicotiledôneas (NBR 7190/97)

\begin{tabular}{|c|c|c|c|c|}
\hline \multicolumn{5}{|c|}{ Dicotiledôneas } \\
\hline CLASSE & $\begin{array}{c}\mathrm{f}_{\mathrm{c} 0, \mathrm{k}} \\
(\mathrm{MPa})\end{array}$ & $\begin{array}{c}\mathrm{f}_{\mathrm{v} 0, \mathrm{k}} \\
(\mathrm{MPa})\end{array}$ & $\begin{array}{c}\mathrm{E}_{\mathrm{c} 0, \mathrm{~m}} \\
(\mathrm{MPa})\end{array}$ & $\begin{array}{c}\rho_{\text {aparente }} \\
\left(\mathrm{kg} / \mathrm{m}^{3}\right)\end{array}$ \\
\hline C 20 & 20 & 4 & 9500 & 650 \\
\hline C 30 & 30 & 5 & 14500 & 800 \\
\hline C 40 & 40 & 6 & 19500 & 950 \\
\hline C 60 & 60 & 8 & 24500 & 1000 \\
\hline
\end{tabular}

\subsection{2- Características das pontes}

As pontes analisadas numericamente são da classe 30 , por se tratar do emprego mais comum das pontes de madeira protendidas.

Os vãos utilizados para a análise destas pontes foram iguais a 10, 15, 20 e 25 m. O limite inferior é escolhido porque para vãos menores que $10 \mathrm{~m}$ empregam-se pontes com seção transversal de altura constante e o limite superior é o vão máximo empregado para as pontes de madeira formadas por vigas-T. Estas pontes têm uma ou duas faixas de tráfego, de larguras iguais a 5,5 e 10,0 m respectivamente.

As figuras 27 e 28 apresentam os desenhos esquemáticos de uma ponte com 5 nervuras e uma faixa de tráfego e de uma ponte com 9 nervuras e duas faixas de tráfego. 
Unidade: $\mathrm{cm}$

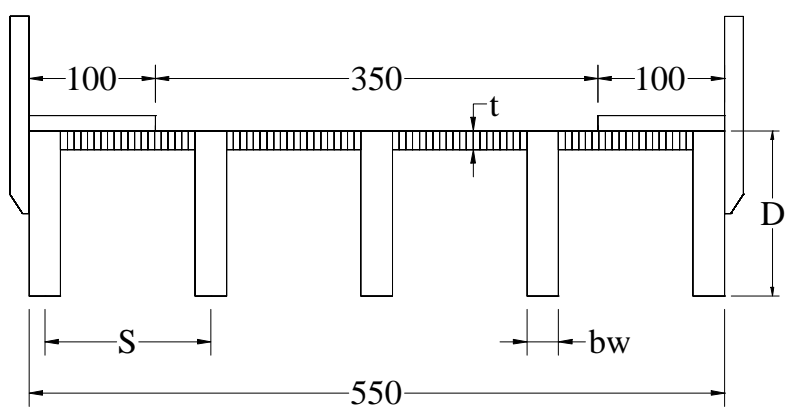

FIGURA 27 - Ponte com uma faixa de tráfego

\section{Unidade: $\mathrm{cm}$}

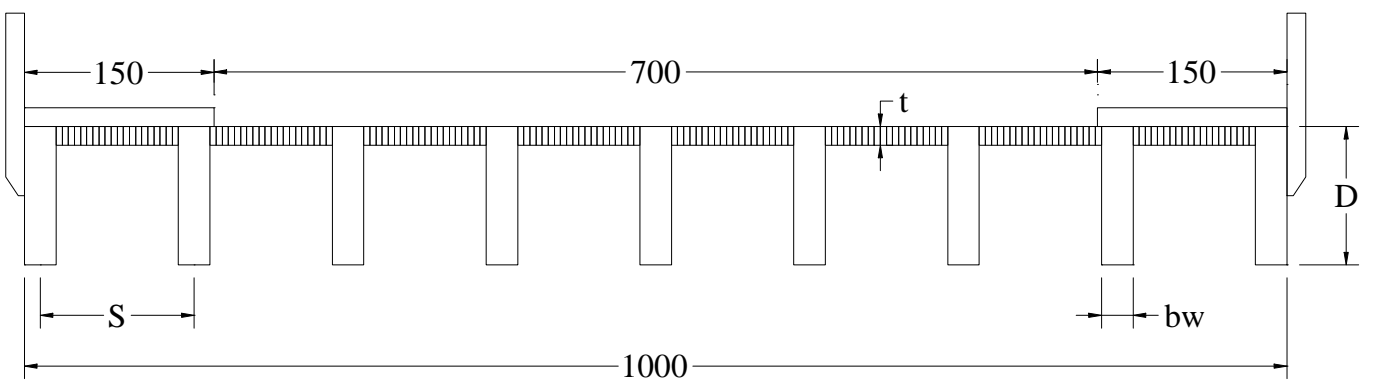

FIGURA 28 - Ponte com duas faixas de tráfego

Com relação às dimensões dos elementos estruturais, foram adotadas larguras das nervuras e alturas dos tabuleiros iguais a 15, 20 e $25 \mathrm{~cm}$. As dimensões menores que $15 \mathrm{~cm}$ tornam a seção transversal delgada em relação à altura da nervura, e as dimensões maiores que $25 \mathrm{~cm}$ dificultam a obtenção das peças de madeira serrada.

O espaçamento mínimo entre duas nervuras deve ser maior ou igual a $70 \mathrm{~cm}$, resultando em um número máximo de nervuras igual a 8 para pontes com uma faixa de tráfego e 14 para pontes com duas faixas de tráfego. O espaçamento máximo deve ser menor ou igual a $200 \mathrm{~cm}$, resultando em um número mínimo de nervuras igual a 8 para ponte com uma faixa de tráfego e 14 para ponte com duas faixas de tráfego.

\section{2- Procedimento de cálculo}

Neste tópico está descrito e exemplificado o procedimento de cálculo 
utilizado no dimensionamento das pontes de madeira formadas por vigas-T.

Após a definição do vão, da largura e da classe da ponte, das espécies e das classes de resistência das madeiras utilizadas para as nervuras e o tabuleiro, é calculado o módulo de elasticidade na direção transversal do tabuleiro.

O número mínimo de nervuras é determinado, segundo DAVALOS et al (1993), em função do deslocamento máximo da porção do tabuleiro entre duas nervuras adjacentes, sob a ação da carga de uma roda (Figura 29). Segundo GANGARAO \& RAJU (1992), este deslocamento deve ser menor ou igual a 0,5 cm para que não ocorra fissuração do pavimento asfáltico, sendo este o limite utilizado no presente trabalho. Deste modo, o espaçamento máximo entre nervuras deve ser menor ou igual a 2,0 m para que apenas uma roda se posicione entre duas nervuras.

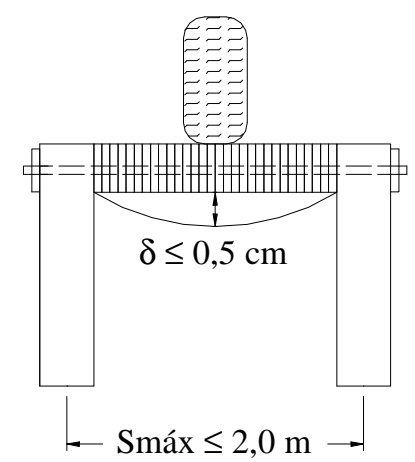

FIGURA 29 - Número mínimo de nervuras

O número máximo de nervuras é determinado, de modo que o espaçamento mínimo entre nervuras seja maior ou igual a $0,7 \mathrm{~m}$ (Figura 30). Este valor foi definido como premissa do trabalho, pois os espaçamentos menores que $0,7 \mathrm{~m}$ conduzem ao tabuleiro com altura constante.

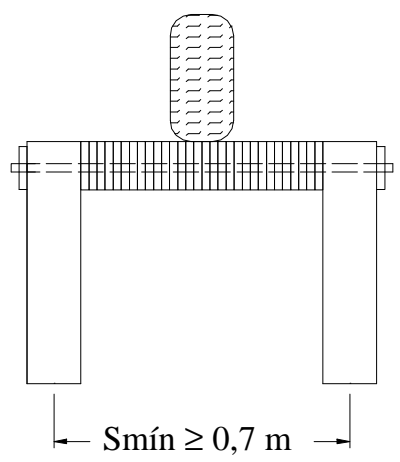

FIGURA 30 - Número máximo de nervuras 
Após a determinação do número de nervuras, são feitas as verificações dos efeitos localizados no tabuleiro e os cálculos da largura efetiva da mesa de uma viga$\mathrm{T}$ interna e do fator de distribuição da carga, que determina a parcela da carga transmitida para a nervura mais solicitada. A partir de então, o projeto do sistema $\mathrm{T}$ resume-se ao dimensionamento de uma viga-T. Com as equações de flexão simples, são calculados os momentos fletores e os esforços cortantes máximos devidos às ações permanentes e variáveis, e verificados os estados limites últimos e de utilização correspondentes. Por último, calcula-se o volume de madeira do tabuleiro e das nervuras, para efeito de comparação.

O fluxograma do método de cálculo proposto está apresentado figura 31 .

1 Dados de entrada (dimensões, classes botânicas e classes de resistência das madeiras, sistema de protensão)

2 Cálculo do módulo de elasticidade na direção transversal do tabuleiro

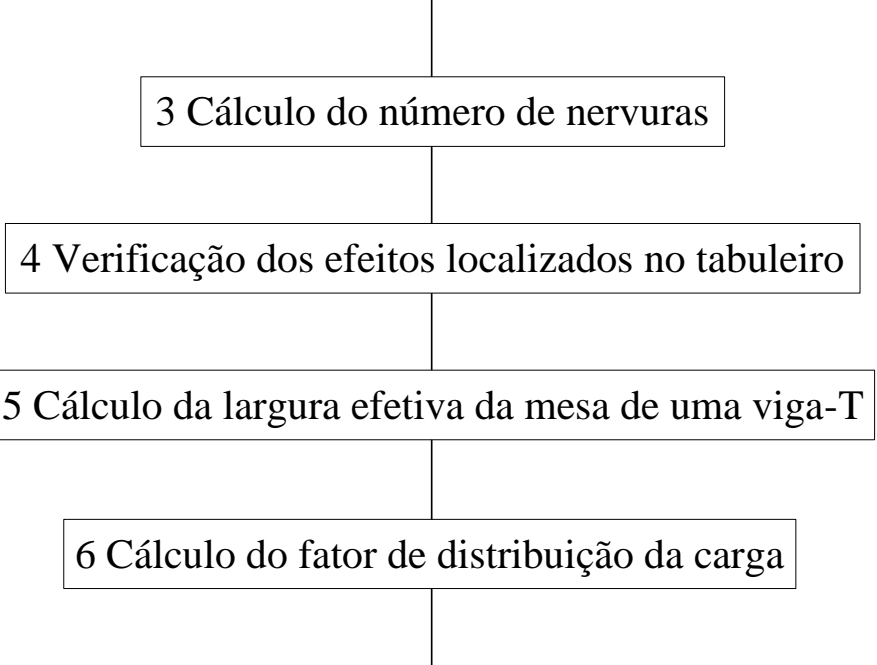

7 Determinação do valor de cálculo do momento fletor total

8 Determinação do valor de cálculo do esforço cortante total

9 Verificações dos estados limites últimos e de utilização

10 Cálculo do volume de madeira

FIGURA 31 - Fluxograma do método de cálculo 
3.2.1- Dados de entrada

A figura 32 apresenta o desenho esquemático de uma ponte formada por vigas-T, apresentando os parâmetros geométricos utilizados no cálculo:

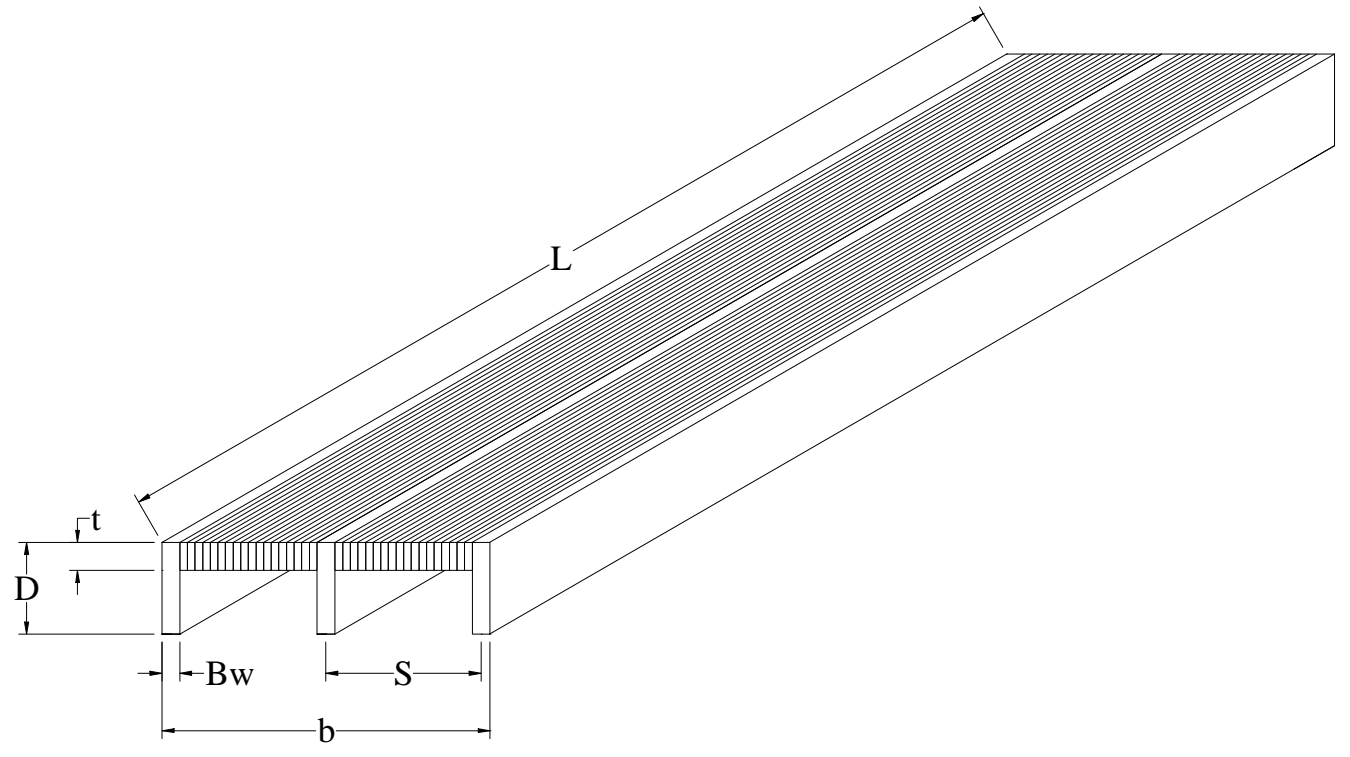

FIGURA 32 - Desenho esquemático de uma ponte formada por vigas-T

onde:

$\mathrm{L}=$ vão da ponte

$\mathrm{b}=$ largura da ponte

$\mathrm{t}=$ altura do tabuleiro

$\mathrm{D}=$ altura da nervura

$\mathrm{B}_{\mathrm{w}}=$ largura da nervura

$\mathrm{S}=$ espaçamento entre nervuras

3.2.2- Cálculo do módulo de elasticidade na direção transversal das lâminas do tabuleiro $\mathrm{E}_{\mathrm{T}}$

O parâmetro elástico $\mathrm{E}_{\mathrm{T}}$ é calculado a partir da relação dada por OKIMOTO (2000): 


$$
\frac{\mathrm{E}_{\mathrm{T}}}{\mathrm{E}_{\mathrm{L}, \mathrm{t}}}=0,018367-\left[2,0395 \cdot 10^{-5} \cdot \rho\right]+\sigma_{\mathrm{N}} \cdot\left(1,1728 \cdot 10^{-5}+1,795 \cdot 10^{-8} \cdot \rho\right)
$$

onde:

$\mathrm{E}_{\mathrm{L}, \mathrm{t}}=$ módulo de elasticidade na direção longitudinal das lâminas do tabuleiro

$\rho=$ densidade aparente da madeira do tabuleiro

$\sigma_{\mathrm{N}}=$ tensão de protensão no tabuleiro

3.2.3- Cálculo do número mínimo de nervuras $\left(\mathrm{n}_{\operatorname{mín}}\right)$

O número mínimo de nervuras é calculado de modo que o deslocamento da porção do tabuleiro entre duas nervuras adjacentes seja menor ou igual a $0,5 \mathrm{~cm}$. Com o número de nervuras mínimo, tem-se o espaçamento máximo entre nervuras.

O espaçamento máximo entre nervuras $S_{\text {máx }}$ é calculado pela equação 16:

$$
\delta=\frac{P \cdot\left(S_{\text {máx }}\right)^{3}}{4 \cdot K_{\delta} \cdot E_{T} \cdot t^{4}}=0,5
$$

sendo:

$$
\mathrm{K}_{\delta}=-10,9+7,8 \cdot\left(\frac{\mathrm{S}_{\mathrm{máx}}}{\mathrm{t}}\right)+0,27 \cdot\left(\frac{\mathrm{E}_{\mathrm{L}, \mathrm{t}}}{\mathrm{E}_{\mathrm{T}}}\right)
$$

onde:

$\mathrm{K}_{\delta}=$ parâmetro empírico para o deslocamento que considera a largura resistente do tabuleiro

$\mathrm{P}=$ carga do eixo do veículo-tipo classe $30(100 \mathrm{kN})$

O número de nervuras inicial $n_{\text {inicial }}$ é calculado a partir do $S_{\text {máx }}$ :

$$
\mathrm{n}_{\text {inicial }}=1+\frac{\mathrm{b}-\mathrm{B}_{\mathrm{W}}}{\mathrm{S}_{\text {máx }}}
$$


$\mathrm{O}$ número de nervuras mínimo $\mathrm{n}_{\text {mín }}$ é o primeiro inteiro maior ou igual a $\mathrm{n}_{\text {inicial. }}$. Em função de $\mathrm{n}_{\text {mín }}$ é calculado o espaçamento $\mathrm{S}$ :

$$
\mathrm{S}=\frac{\mathrm{b}-\mathrm{B}_{\mathrm{W}}}{\mathrm{n}-1}
$$

Na seqüência, calcula-se a tensão máxima $\sigma_{\text {máx,d }}$ pela equação 20 :

$$
\sigma_{\text {máx }, \mathrm{d}}=1,4 \cdot\left(\frac{3 \cdot \mathrm{P} \cdot \mathrm{S}}{2 \cdot \mathrm{K}_{\sigma} \cdot \mathrm{t}^{3}}+\sigma_{\mathrm{N}}\right) \leq \mathrm{f}_{\mathrm{c} 90, \mathrm{~d}}
$$

sendo:

$$
\mathrm{K}_{\sigma}=3+3,1 \cdot\left(\frac{\mathrm{S}}{\mathrm{t}}\right)+0,15 \cdot\left(\frac{\mathrm{E}_{\mathrm{L}, \mathrm{t}}}{\mathrm{E}_{\mathrm{T}}}\right)
$$

onde:

$\mathrm{K}_{\sigma}=$ parâmetro empírico para a tensão que considera a largura resistente do tabuleiro

Esta tensão deve ser menor ou igual à resistência de cálculo da madeira do tabuleiro à compressão perpendicular às fibras $\mathrm{f}_{\mathrm{c} 90, \mathrm{~d}}$. Caso esta condição não seja atendida, aumenta-se o número de nervuras.

3.2.4- Cálculo da largura efetiva da mesa de uma viga-T interna $\left(b_{e}\right)$

A largura efetiva da aba $\mathrm{B}_{\mathrm{E}}$ é calculada pela equação 22:

$$
\mathrm{B}_{\mathrm{E}}=\mathrm{B} \cdot\left[0,4586+\frac{1}{198} \cdot\left(\frac{\mathrm{L}}{\mathrm{B}}\right) \cdot\left(\frac{\mathrm{D}-\mathrm{t}}{\mathrm{t}}\right) \cdot\left(\frac{\mathrm{E}_{\mathrm{L}, \mathrm{n}}}{\mathrm{E}_{\mathrm{L}, \mathrm{t}}}\right)\right]
$$

sendo:

$$
\mathrm{B}=0,5 \cdot\left(\mathrm{S}-\mathrm{B}_{\mathrm{W}}\right)
$$

onde:

$\mathrm{B}=$ largura da aba de uma viga-T

$\mathrm{E}_{\mathrm{L}, \mathrm{n}}=$ módulo de elasticidade na direção longitudinal da nervura 
A largura efetiva da mesa $b_{e}$ é o menor valor entre os dados abaixo:

$$
\begin{aligned}
& \mathrm{b}_{\mathrm{e}}=2,0 \cdot \mathrm{B}_{\mathrm{E}}+\mathrm{B}_{\mathrm{W}} \\
& \mathrm{b}_{\mathrm{e}}=\mathrm{S} \\
& \mathrm{b}_{\mathrm{e}}=\frac{\mathrm{L}}{8}
\end{aligned}
$$

A figura 33 apresenta os parâmetros geométricos de uma viga-T interna.

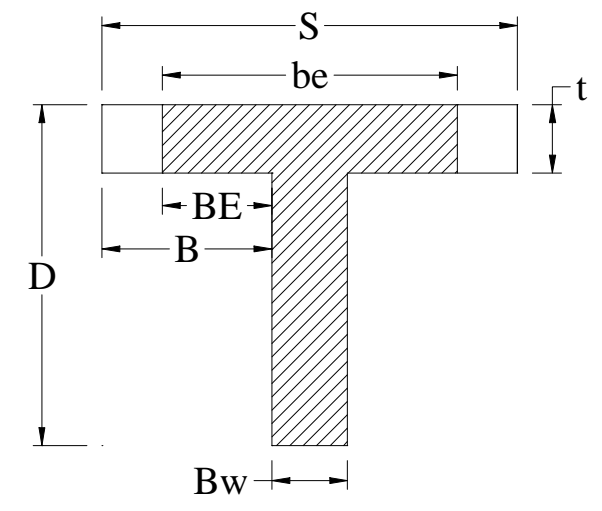

FIGURA 33 - Viga-T interna efetiva

No caso de espécies de madeiras diferentes no tabuleiro e na nervura, deve-se efetuar uma transformação da viga-T, tomando como base o módulo de elasticidade na direção longitudinal da nervura:

$$
\mathrm{b}_{\mathrm{t}}=\frac{\mathrm{E}_{\mathrm{L}, \mathrm{t}}}{\mathrm{E}_{\mathrm{L}, \mathrm{n}}} \cdot\left(\mathrm{b}_{\mathrm{e}}-\mathrm{B}_{\mathrm{W}}\right)
$$

sendo:

$$
\mathrm{b}_{\mathrm{eti}}=\left(\mathrm{b}_{\mathrm{t}}+\mathrm{B}_{\mathrm{W}}\right)
$$

onde:

$b_{\text {eti }}=$ largura efetiva transformada da mesa de uma viga- $T$ interna

$\mathrm{b}_{\mathrm{t}}=$ largura efetiva transformada da aba de uma viga-T interna

A figura 34 apresenta os parâmetros geométricos de uma viga-T interna transformada. 


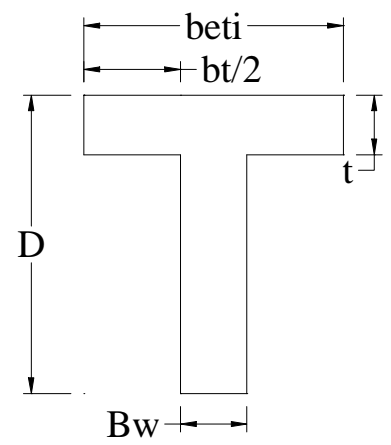

FIGURA 34 - Viga-T interna transformada

O momento de inércia da viga-T interna $\mathrm{I}_{\mathrm{i}}$ é calculado pela equação 29:

$$
I_{i}=\left[\frac{B_{W} \cdot D^{3}}{12}+A_{n} \cdot\left(y_{i}-y_{n}\right)^{2}\right]+2 \cdot\left[\frac{\frac{b_{t}}{2} \cdot t^{3}}{12}+A_{\text {bal }} \cdot\left(y_{i}-y_{b a l}\right)^{2}\right]
$$

onde:

$A_{\text {bal }}=$ área da aba de uma viga-T interna

$\mathrm{A}_{\mathrm{n}}=$ área da nervura

$\mathrm{y}_{\mathrm{bal}}=$ localização da linha neutra da aba

$\mathrm{y}_{\mathrm{i}}=$ localização da linha neutra da viga-T interna

$\mathrm{y}_{\mathrm{n}}=$ localização da linha neutra da nervura

A figura 35 apresenta os parâmetros geométricos de uma viga-T externa efetiva.

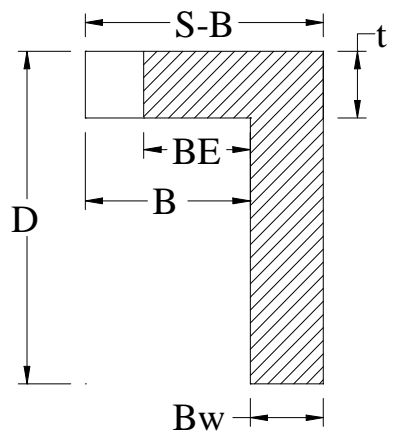

FIGURA 35 - Viga-T externa efetiva 
A viga-T é transformada tomando como base o módulo de elasticidade na direção longitudinal da nervura:

$$
\mathrm{b}_{\mathrm{tex}}=\frac{\mathrm{E}_{\mathrm{L}, \mathrm{t}}}{\mathrm{E}_{\mathrm{L}, \mathrm{n}}} \cdot \mathrm{B}_{\mathrm{E}}
$$

onde:

$\mathrm{b}_{\mathrm{tex}}=$ largura efetiva transformada da aba de uma viga-T externa

A figura 36 apresenta os parâmetros geométricos de uma viga-T externa transformada.

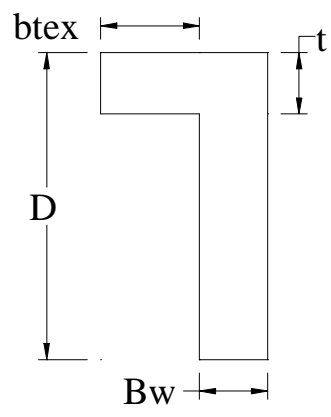

FIGURA 36 - Viga-T externa transformada

O momento de inércia da viga-T externa $\mathrm{I}_{\mathrm{ex}}$ é calculado pela equação 31:

$$
I_{e x}=\left[\frac{B_{W} \cdot D^{3}}{12}+A_{n} \cdot\left(y_{e x}-y_{n}\right)^{2}\right]+\left[\frac{b_{t e x} \cdot t^{3}}{12}+A_{b a l x} \cdot\left(y_{e x}-y_{b a l}\right)^{2}\right]
$$

onde:

$\mathrm{A}_{\text {balx }}=$ área da aba de uma viga-T externa

$\mathrm{y}_{\mathrm{ex}}=$ localização da linha neutra da viga-T externa

3.2.5- Cálculo do fator de distribuição da carga $\left(\mathrm{W}_{\mathrm{f}}\right)$ 
$\mathrm{O}$ fator $\mathrm{W}_{\mathrm{f}}$, calculado pela equação 32 , indica a porcentagem da carga móvel posicionada na faixa ocupada pelo veículo-tipo que é absorvida pela nervura mais solicitada de uma ponte com duas faixas de tráfego:

$$
\mathrm{W}_{\mathrm{f}}=\frac{1+\mathrm{C}_{0}}{\mathrm{n} \cdot \mathrm{C}_{0}+\frac{2}{\pi} \cdot(\mathrm{n}-1)}
$$

sendo:

$$
\begin{aligned}
& \mathrm{C}_{0}=\frac{\left(\mathrm{b}-\mathrm{B}_{\mathrm{w}}\right)}{\pi} \cdot \frac{\mathrm{D}_{\mathrm{T}}}{\mathrm{B}_{\mathrm{e}}} \cdot \frac{\left[8 \cdot(\lambda)^{2}+1\right]}{(\lambda)^{4}} \\
& \mathrm{D}_{\mathrm{T}}=\mathrm{E}_{\mathrm{T}} \cdot \frac{\mathrm{t}^{3}}{12} \\
& \lambda=\frac{\left(\mathrm{b}-\mathrm{B}_{\mathrm{W}}\right)}{\mathrm{L}} \\
& \mathrm{B}_{\mathrm{e}}=\mathrm{E}_{\mathrm{L}, \mathrm{n}} \cdot \mathrm{Iex}
\end{aligned}
$$

onde:

$\mathrm{B}_{\mathrm{e}}=$ rigidez à flexão longitudinal de uma viga-T externa

$\mathrm{C}_{0}=$ coeficiente de deslocamento de uma viga- $\mathrm{T}$ externa

$\mathrm{D}_{\mathrm{T}}=$ rigidez à flexão transversal do tabuleiro

$\lambda=$ relação entre a largura e o vão da ponte

Para pontes com uma faixa de tráfego, o fator $\mathrm{W}_{\mathrm{f}}$ é multiplicado por 1,6 (DAVALOS, GANGARAO \& SALIM 1993).

3.2.6- Determinação do valor de cálculo do momento fletor total $\left(\mathrm{Md}_{\mathrm{T}}\right)$

$\mathrm{O}$ valor de cálculo do momento fletor total $\mathrm{Md}_{\mathrm{T}}$ é a soma dos momentos devidos à carga permanente $\mathbf{M}_{\text {máx.cp }}$ e à carga móvel $\mathbf{M}_{\text {máx.cm: }}$

$$
\mathrm{Md}_{\mathrm{T}}=\gamma_{\mathrm{G}} \cdot \mathrm{M}_{\text {máx.cp }}+\gamma_{\mathrm{Q}} \cdot \mathrm{M}_{\text {máx.cm }}+0,75 \cdot \gamma_{\mathrm{Q}} \cdot\left[(\phi-1) \cdot \mathrm{M}_{\text {máx.cm }}\right]
$$

sendo:

$$
\phi=1+\left(\frac{\alpha}{40+L}\right)
$$


onde:

$\alpha=$ coeficiente para pontes rodoviárias com revestimento de concreto asfáltico $\phi=$ coeficiente de impacto

$\gamma_{\mathrm{G}}=$ coeficiente de ponderação para estados limites últimos (ações permanentes de grande variabilidade)

$\gamma_{\mathrm{Q}}=$ coeficiente de ponderação para estados limites últimos (ações variáveis)

a- $\mathrm{O}$ momento fletor máximo devido à carga móvel $\mathrm{M}_{\text {máx.cm, em função da força }}$ concentrada de projeto $\mathrm{P}_{\mathrm{d}}$, é calculado pela equação 39 (Figura 37):

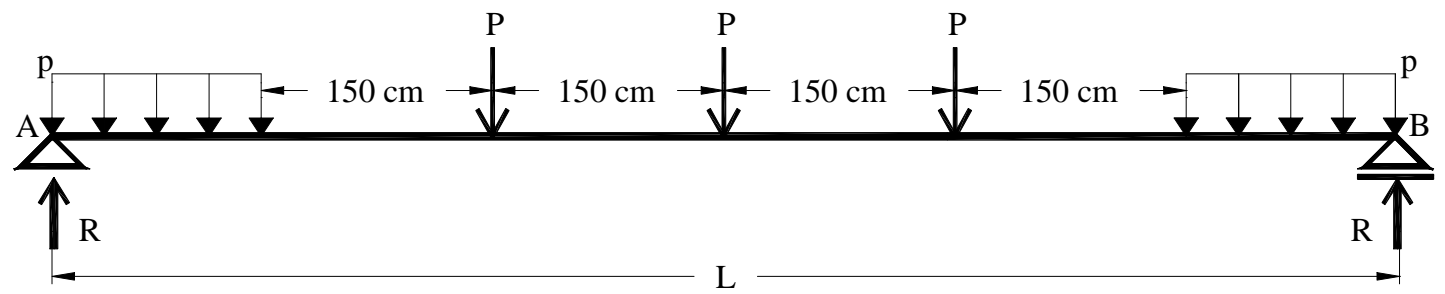

FIGURA 37 - Viga-T interna solicitada pela carga móvel

$$
\mathrm{M}_{\text {máx.cm }}=\left(\frac{\mathrm{P}_{\mathrm{d}} \cdot \mathrm{L}}{4}\right)
$$

sendo:

$$
\begin{aligned}
& P_{d}=N_{L} \cdot W_{f} \cdot P_{e} \\
& P_{e}=\frac{4 \cdot M_{\text {máx.m }}}{L}
\end{aligned}
$$

onde:

$\mathrm{M}_{\text {máx.m }}=$ momento fletor máximo devido à carga móvel

$\mathrm{N}_{\mathrm{L}}=$ número de faixas de tráfego

$\mathrm{p}=$ força uniformemente distribuída na faixa ocupada pelo veículo-tipo $\left(5.10^{-3} \mathrm{MPa}\right)$

$\mathrm{P}=$ carga do eixo do veículo-tipo classe $30(100 \mathrm{kN})$

$\mathrm{P}_{\mathrm{e}}=$ força concentrada, posicionada no ponto médio do vão, que produz um momento equivalente ao $\mathrm{M}_{\text {máx.m }}$

$\mathrm{P}_{\mathrm{d}}=$ força concentrada de projeto 
b- Momento fletor máximo devido à carga permanente total $\mathbf{M}_{\text {máx.cp }}$ é calculado pela equação 42 (Figura 38):

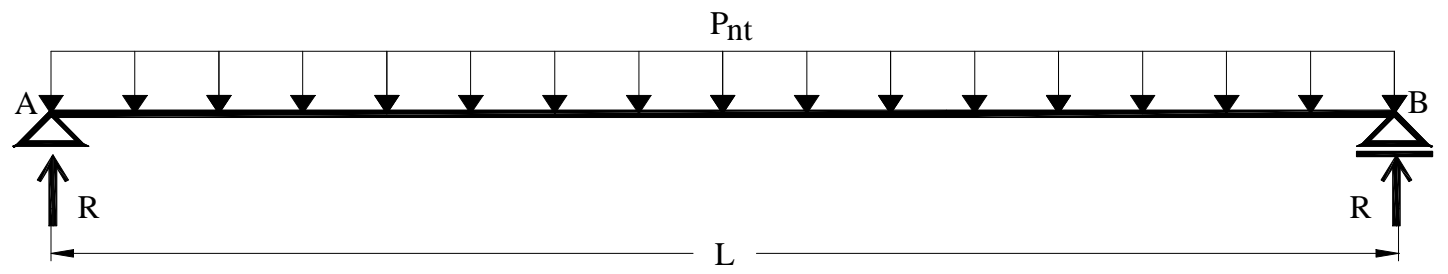

FIGURA 38 - Viga-T interna solicitada pela carga permanente

$$
\mathrm{M}_{\text {máx.cp }}=\frac{\mathrm{P}_{\mathrm{nt}} \cdot \mathrm{L}^{2}}{8}
$$

A carga permanente total $\mathrm{P}_{\mathrm{nt}}$ é a soma dos pesos-próprios das barras de protensão $P_{b p}$, da nervura $P_{n}$, da porção do tabuleiro entre duas nervuras $P_{t}$ e do revestimento asfáltico sobre uma seção do tabuleiro $\mathrm{P}_{\text {asf. }}$. Os pesos-próprios citados estão linearmente distribuídos ao longo do vão:

$$
\mathrm{P}_{\mathrm{nt}}=\mathrm{P}_{\mathrm{bp}}+\mathrm{P}_{\mathrm{n}}+\mathrm{P}_{\mathrm{t}}+\mathrm{P}_{\mathrm{asf}}
$$

sendo:

$$
\begin{aligned}
& P_{b p}=\frac{P_{b}}{s \cdot n} \\
& P_{n}=\left(9,81 \cdot \rho \cdot A_{n}\right) \\
& P_{t}=\left(9,81 \cdot \rho \cdot A_{t}\right) \\
& P_{a s f}=\gamma_{a s f} \cdot A_{\text {asf }}
\end{aligned}
$$

onde:

$\mathrm{A}_{\mathrm{t}}=$ área do tabuleiro entre duas nervuras

$\mathrm{A}_{\mathrm{asf}}=$ área do revestimento asfáltico sobre uma seção do tabuleiro

$\mathrm{P}_{\mathrm{b}}=$ peso-próprio de uma barra de protensão

$\gamma_{\text {asf }}=$ peso específico do asfalto

3.2.7- Determinação do valor de cálculo do esforço cortante total $\left(\mathrm{Vd}_{\mathrm{T}}\right)$ 
O valor de cálculo do esforço cortante total $\mathrm{Vd}_{\mathrm{T}}$ é a soma dos esforços cortantes devidos à carga permanente $\mathrm{V}_{\mathrm{cp}}$ e à carga móvel $\mathrm{V}_{\mathrm{cm}}$, calculados na distância x' = 2.D do apoio (Figura 39):

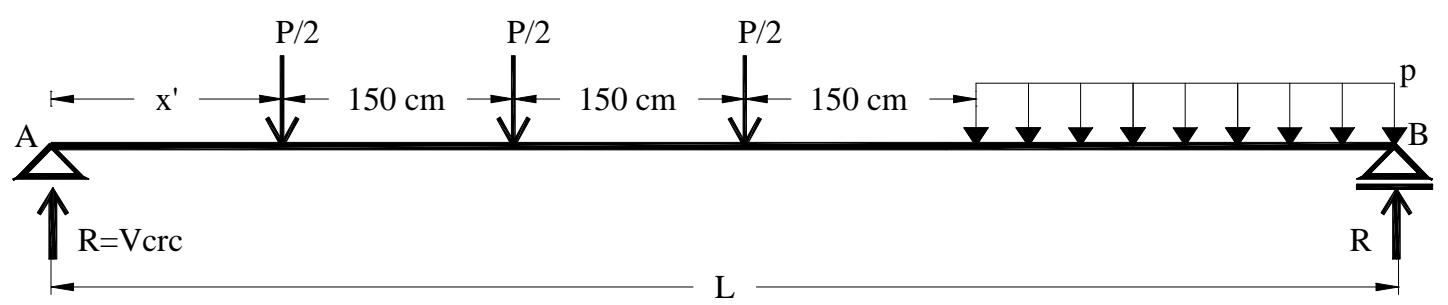

FIGURA 39 - Viga-T interna solicitada pela carga móvel

$$
\mathrm{Vd}_{\mathrm{T}}=\gamma_{\mathrm{G}} \cdot \mathrm{V}_{\mathrm{cp}}+\gamma_{\mathrm{Q}} \cdot \mathrm{V}_{\mathrm{cm}}+0,75 \cdot \gamma_{\mathrm{Q}} \cdot\left[(\phi-1) \cdot \mathrm{V}_{\mathrm{cm}}\right]
$$

sendo:

$$
\begin{aligned}
& \mathrm{V}_{\mathrm{cp}}=\frac{\mathrm{P}_{\mathrm{nt}}}{2} \cdot\left(\mathrm{L}-2 \cdot \mathrm{x}^{\prime}\right) \\
& \mathrm{V}_{\mathrm{cm}}=\frac{1}{2} \cdot\left(0,6 \cdot \mathrm{V}_{\mathrm{crc}}+\mathrm{V}_{\mathrm{crd}}\right) \\
& \mathrm{V}_{\mathrm{crd}}=\mathrm{N}_{\mathrm{L}} \cdot \mathrm{W}_{\mathrm{f}} \cdot \mathrm{V}_{\mathrm{crc}}
\end{aligned}
$$

onde:

$\mathrm{D}=$ altura da nervura

$\mathrm{V}_{\mathrm{cm}}=$ esforço cortante devido à carga móvel

$\mathrm{V}_{\mathrm{cp}}=$ esforço cortante devido à carga permanente

$\mathrm{V}_{\text {crc }}=$ esforço cortante na distância $\mathrm{x}$ devido às cargas de rodas concentradas, sem distribuição de carga

$\mathrm{V}_{\text {crd }}=$ esforço cortante na distância $\mathrm{x}$ devido às cargas de rodas distribuídas

$\mathrm{x}^{\prime}=$ duas vezes a altura da nervura

\subsection{8- Verificações}

a- Verificação da viga-T, considerando-se a teoria elementar de vigas

a.1- Verificação das tensões normais 
Os valores de cálculo das tensões de tração e compressão paralelas às fibras da viga-T $\sigma$ são calculados pela equação 52:

$$
\sigma=\frac{\mathrm{Md}_{\mathrm{T}} \cdot \mathrm{c}}{\mathrm{I}_{\mathrm{i}}}
$$

onde:

$\mathrm{c}=$ distância da linha neutra até a parte tracionada ou comprimida de uma viga-T

As tensões de tração e compressão $\sigma$ devem ser menores ou iguais à resistência de cálculo da madeira da nervura à tração na flexão $\mathrm{f}_{\mathrm{t} 0, \mathrm{~d}}$ e à resistência de cálculo da madeira do tabuleiro à compressão paralela às fibras $\mathrm{f}_{\mathrm{c} 0, \mathrm{~d}}$, respectivamente.

a.2- Verificação das tensões de cisalhamento

O valor de cálculo da tensão de cisalhamento da viga-T $\tau$ é calculado pela equação 53:

$$
\tau=\frac{\mathrm{M}_{\mathrm{S}} \cdot \mathrm{Vd}_{\mathrm{T}}}{\mathrm{B}_{\mathrm{w}} \cdot \mathrm{I}}
$$

A tensão de cisalhamento $\tau$ deve ser menor ou igual à resistência de cálculo da madeira da nervura ao cisalhamento paralelo às fibras $f_{\mathrm{v} 0, \mathrm{~d}}$.

a.3- Verificação dos deslocamentos

$\mathrm{O}$ deslocamento total $\delta_{\mathrm{T}}$ é a soma dos deslocamentos devidos à carga permanente $\delta_{\mathrm{cp}}$ e à carga móvel $\delta_{\mathrm{cm}}$ :

$$
\delta_{\mathrm{T}}=\delta_{\mathrm{cp}}+\psi_{2} \cdot \delta_{\mathrm{cm}}
$$

a.3.1- O deslocamento devido à carga móvel é a soma dos deslocamentos devidos ao veículo-tipo e à força uniformemente distribuída na faixa ocupada por este veículo (Figura 40): 


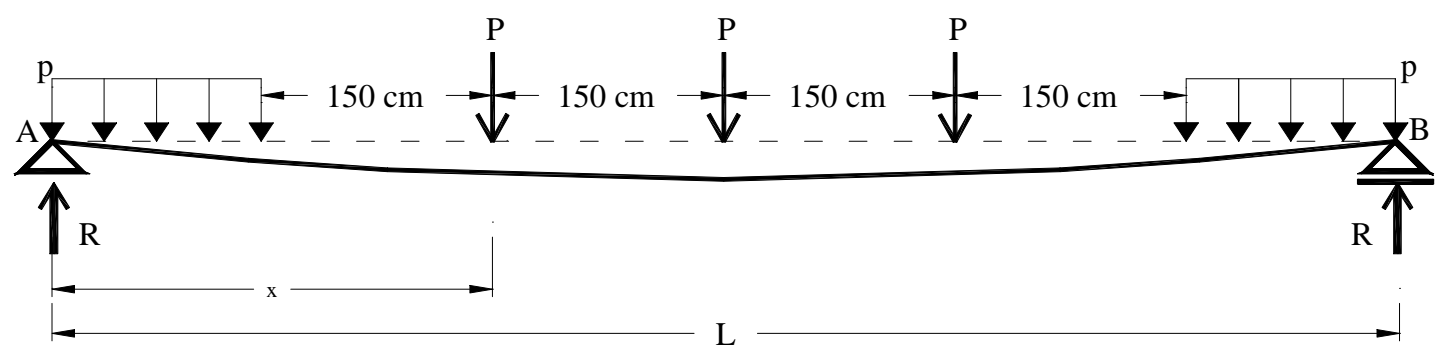

FIGURA 40 - Viga-T interna solicitada pela carga móvel

$$
\delta_{\mathrm{cm}}=\delta_{\mathrm{cm} 1}+\delta_{\mathrm{cm} 2}
$$

sendo:

$$
\begin{aligned}
& \delta_{\mathrm{cm} 1}=\frac{\mathrm{P}_{\delta} \cdot \mathrm{L}^{3}}{48 \cdot \mathrm{E}_{\mathrm{L}, \mathrm{n}} \cdot \mathrm{Ii}}+\frac{\mathrm{P}_{\delta} \cdot \mathrm{x}}{24 \cdot \mathrm{E}_{\mathrm{L}, \mathrm{n}} \cdot \mathrm{Ii}} \cdot\left(3 \cdot \mathrm{L}^{2}-4 \cdot \mathrm{x}^{2}\right) \\
& \delta_{\mathrm{cm} 2}=2 \cdot\left\{\frac{\mathrm{p} \cdot 300 \cdot \mathrm{z}^{2}}{24 \cdot \mathrm{L} \cdot \mathrm{E}_{\mathrm{L}, \mathrm{n}} \cdot \mathrm{Ii}} \cdot\left[-\mathrm{z}^{2} \cdot \mathrm{L}+2 \cdot \mathrm{L}^{3}+\mathrm{z}^{2} \cdot \frac{\mathrm{L}}{2}-\frac{3}{2} \cdot \mathrm{L}^{3}+2 \cdot\left(\frac{\mathrm{L}}{2}\right)^{3}\right]\right\} \\
& \mathrm{P}_{\delta}=\mathrm{N}_{\mathrm{L}} \cdot \mathrm{W}_{\mathrm{f}} \cdot \mathrm{P} \\
& \mathrm{z}=\frac{(\mathrm{L}-600)}{2} \\
& \mathrm{x}=\mathrm{z}+150
\end{aligned}
$$

onde:

$\mathrm{P}_{\delta}=$ carga de eixo $\mathrm{P}$ modificada pelo fator de distribuição $\mathrm{W}_{\mathrm{f}}$ e pelo número de faixas de tráfego $\mathrm{N}_{\mathrm{L}}$

$\mathrm{x}=$ distância entre o apoio e a primeira carga de eixo $\mathrm{P}$

a.3.2- O deslocamento devido à carga permanente é calculado pela equação 61:

$$
\delta_{\mathrm{cp}}=\frac{5 \cdot \mathrm{P}_{\mathrm{nt}} \cdot \mathrm{L}^{4}}{384 \cdot \mathrm{E}_{\mathrm{L}, \mathrm{n}} \cdot \mathrm{Ii}} .
$$

onde:

$\psi_{2}=$ fator de combinação e de utilização para cargas móveis em pontes rodoviárias

O deslocamento total $\delta_{\mathrm{T}}$ deve ser menor ou igual a $\mathrm{L} / 200$ 
b- Verificação do puncionamento no tabuleiro

O esforço cortante devido ao puncionamento, calculado pela equação 62, é a força que provoca o deslizamento relativo entre as lâminas do tabuleiro:

$$
\mathrm{V}=\frac{\mathrm{P}}{2 \cdot \mathrm{S}} \cdot\left(\mathrm{S}-\frac{\mathrm{a}+\mathrm{B}_{\mathrm{W}}}{2}\right)
$$

onde:

$\mathrm{a}=$ largura de contato do pneu

$b_{1}=$ comprimento efetivo do pneu

O esforço cortante resistente é calculado pela equação 63:

$$
\mathrm{V}_{\mathrm{res}}=\sigma_{\mathrm{N}} \cdot \mathrm{b}_{1} \cdot \mathrm{t} \cdot \mu_{\mathrm{s}}
$$

onde:

$\mu_{\mathrm{S}}=$ coeficiente de atrito estático igual a 0,35

$\mathrm{O}$ esforço cortante $\mathrm{V}$ deve ser menor ou igual ao esforço cortante resistente $\mathrm{V}_{\text {res. }}$

\subsection{9- Cálculo do volume de madeira}

a- $\mathrm{O}$ volume de madeira laminada colada das nervuras $\mathrm{V}_{\text {nervura }}$ é calculado pela equação 64:

$$
\mathrm{V}_{\text {nervura }}=\mathrm{n} \cdot\left(\mathrm{B}_{\mathrm{W}} \cdot \mathrm{D} \cdot \mathrm{L}\right)
$$

b- $O$ volume de madeira serrada do tabuleiro $V_{\text {tabuleiro }}$ é calculado pela equação 65 :

$$
\mathrm{V}_{\text {tabuleiro }}=\left[\mathrm{b}-\left(\mathrm{n} \cdot \mathrm{B}_{\mathrm{W}}\right)\right] \cdot \mathrm{t} \cdot \mathrm{L}
$$




\section{3-Descrição e resultados da análise numérica}

A seguir são descritos os métodos das análises efetuadas numericamente e apresentados os resultados correspondentes. Estas análises referem-se ao dimensionamento das pontes formadas com vigas-T; ao estudo das influências da altura do tabuleiro e da largura das nervuras, e da espécie de madeira do tabuleiro e das nervuras na altura $\mathrm{D}$.

As pontes formadas com vigas-T foram dimensionadas para vãos $\mathrm{L}$ iguais a $10,15,20$ e $25 \mathrm{~m}$, larguras b iguais a 5,5 (1 faixa de tráfego) e 10,0 m ( 2 faixas de tráfego), larguras das nervuras $B_{w}$ e alturas dos tabuleiros t iguais a 15, 20 e $25 \mathrm{~cm}$ e número de nervuras n variando de 4 até 8 ( 1 faixa de tráfego) e de 7 até 14 (2 faixas de tráfego), conforme descrito no item 3.1.2.

O estudo das influências da altura do tabuleiro e da largura das nervuras, da espécie de madeira do tabuleiro e das nervuras na altura $\mathrm{D}$ foram realizados a partir dos resultados numéricos do dimensionamento de pontes com os mesmos parâmetros supracitados, porém fixando-se o vão L em 15 m.

\subsection{1- Dimensionamento das pontes formadas por vigas- $\mathrm{T}$}

Com o objetivo de se conhecer as dimensões das seções transversais das pontes formadas com vigas- $\mathrm{T}$, as alturas $\mathrm{D}$ foram calculadas considerando-se a madeira Classe C 30 - Conífera para as nervuras e o tabuleiro, e as combinações das variações de $L, b, B_{w}$, t, e n, conforme descritos no item 3.3.

Com os resultados obtidos, foram montadas as tabelas 7 e 8 , que apresentam, respectivamente, as alturas das nervuras e os volume totais de madeira para a ponte com 1 faixa de tráfego. Estes resultados também podem ser visualizados nas figuras 41 e 42.

Os resultados referentes às pontes com 2 faixas de tráfego são apresentados nas tabelas 10 e 11 e nas figuras 43 e 44. 
TABELA 7 - Alturas das nervuras D para pontes com 1 faixa de tráfego $\left(B_{w}, t, D\right.$ em cm)

\begin{tabular}{|c|c|c|c|c|c|c|c|c|c|c|c|c|c|c|c|c|}
\hline \multirow{2}{*}{$\mathrm{n}$} & \multicolumn{16}{|c|}{ VÃOS DAS PONTES } \\
\hline & \multicolumn{4}{|c|}{$L=10 \mathrm{~m}$} & \multicolumn{4}{|c|}{$L=15 \mathrm{~m}$} & \multicolumn{4}{|c|}{$L=20 m$} & \multicolumn{4}{|c|}{$L=25 \mathrm{~m}$} \\
\hline \multirow{4}{*}{4} & $B_{w}$ & 15 & 20 & 25 & $B_{1}$ & 15 & 20 & 25 & $B_{w}$ & 15 & 20 & 25 & $B_{w}$ & 15 & 20 & 25 \\
\hline & 15 & - & - & - & 15 & - & - & - & 15 & - & - & - & 15 & - & - & - \\
\hline & 20 & 145 & 128 & 117 & 20 & 192 & 170 & 154 & 20 & 241 & 213 & 193 & 20 & 289 & 256 & 233 \\
\hline & 25 & 145 & 128 & 116 & 25 & 192 & 169 & 153 & 25 & 239 & 210 & 191 & 25 & 286 & 252 & 229 \\
\hline \multirow{4}{*}{5} & $B_{w}$ & 15 & 20 & 25 & $\mathrm{~B}_{1}$ & 15 & 20 & 25 & $B_{w}$ & 15 & 20 & 25 & $B_{w}$ & 15 & 20 & 25 \\
\hline & 15 & 126 & 112 & 102 & 15 & 171 & 151 & 138 & 15 & 215 & 191 & 174 & 15 & 260 & 231 & 211 \\
\hline & 20 & 126 & 112 & 102 & 20 & 169 & 150 & 136 & 20 & 212 & 188 & 171 & 20 & 255 & 226 & 206 \\
\hline & 25 & 126 & 112 & 102 & 25 & 168 & 148 & 135 & 25 & 210 & 185 & 168 & 25 & 251 & 222 & 202 \\
\hline \multirow{4}{*}{6} & $B_{w}$ & 15 & 20 & 25 & & 15 & 20 & 25 & $\mathrm{~B}_{\mathrm{w}}$ & 15 & 20 & 25 & $B_{w}$ & 15 & 20 & 25 \\
\hline & 15 & 114 & 101 & 92 & 15 & 155 & 138 & 126 & 15 & 196 & 174 & 159 & 15 & 237 & 211 & 193 \\
\hline & 20 & 114 & 101 & 92 & 20 & 154 & 136 & 124 & 20 & 193 & 171 & 156 & 20 & 232 & 206 & 188 \\
\hline & 25 & 114 & 101 & 92 & 25 & 152 & 134 & 122 & 25 & 190 & 168 & 153 & 25 & 227 & 201 & 183 \\
\hline \multirow{4}{*}{7} & $B_{w}$ & 15 & 20 & 25 & B & 15 & 20 & 25 & $\mathrm{~B}_{\mathrm{v}}$ & 15 & 20 & 25 & $B_{w}$ & 15 & 20 & 25 \\
\hline & 15 & 106 & 94 & 85 & 15 & 144 & 128 & 117 & 15 & 182 & 162 & 148 & 15 & 220 & 196 & 179 \\
\hline & 20 & 105 & 93 & 85 & 20 & 142 & 126 & 115 & 20 & 178 & 158 & 144 & 20 & 214 & 190 & 174 \\
\hline & 25 & 105 & 93 & 85 & 25 & 140 & 124 & 113 & 25 & 175 & 155 & 141 & 25 & 209 & 185 & 169 \\
\hline \multirow{4}{*}{8} & $B_{w}$ & 15 & 20 & 25 & $\mathrm{~B}_{1}$ & 15 & 20 & 25 & $B_{w}$ & 15 & 20 & 25 & $B_{w}$ & 15 & 20 & 25 \\
\hline & 15 & 99 & 88 & 80 & 15 & 135 & 120 & 110 & 15 & 170 & 152 & 139 & 15 & 206 & 184 & 169 \\
\hline & 20 & 98 & 87 & 79 & 20 & 133 & 118 & 108 & 20 & 166 & 148 & 135 & 20 & 200 & 178 & 164 \\
\hline & 25 & 98 & 86 & 79 & 25 & 131 & 116 & 105 & 25 & 163 & 144 & 132 & 25 & 195 & 173 & 159 \\
\hline
\end{tabular}


TABELA 8 - Volumes de madeiras $\mathrm{V}$ para pontes com 1 faixa de tráfego $\left(B_{w}, t\right.$ em cm, $V$ em m $\left.{ }^{3}\right)$

\begin{tabular}{|c|c|c|c|c|c|c|c|c|c|c|c|c|c|c|c|c|}
\hline \multirow{2}{*}{$\mathrm{n}$} & \multicolumn{16}{|c|}{ VÃOS DAS PONTES } \\
\hline & \multicolumn{4}{|c|}{$L=10 \mathrm{~m}$} & \multicolumn{4}{|c|}{$L=15 \mathrm{~m}$} & \multicolumn{4}{|c|}{$L=20 \mathrm{~m}$} & \multicolumn{4}{|c|}{$L=25 \mathrm{~m}$} \\
\hline \multirow{4}{*}{4} & $B_{w}$ & 15 & 20 & 25 & $B_{w}$ & 15 & 20 & 25 & $B_{w}$ & 15 & 20 & 25 & $B_{w}$ & 15 & 20 & 25 \\
\hline & 15 & - & - & - & 15 & - & - & - & 15 & - & - & - & 15 & - & - & - \\
\hline & 20 & 19 & 20 & 21 & 20 & 32 & 35 & 37 & 20 & 49 & 53 & 57 & 20 & 68 & 75 & 81 \\
\hline & 25 & 21 & 22 & 23 & 25 & 36 & 38 & 40 & 25 & 53 & 57 & 61 & 25 & 74 & 80 & 85 \\
\hline \multirow{4}{*}{5} & $B_{w}$ & 15 & 20 & 25 & $B_{w}$ & 15 & 20 & 25 & & 15 & 20 & 25 & $\mathrm{~B}_{\mathrm{w}}$ & 15 & 20 & 25 \\
\hline & 15 & 17 & 18 & 19 & 15 & 30 & 33 & 35 & 15 & 47 & 52 & 56 & 15 & 67 & 75 & 82 \\
\hline & 20 & 19 & 20 & 21 & 20 & 33 & 36 & 38 & 20 & 51 & 56 & 60 & 20 & 72 & 79 & 86 \\
\hline & 25 & 21 & 22 & 23 & 25 & 37 & 39 & 41 & 25 & 55 & 60 & 63 & 25 & 77 & 84 & 90 \\
\hline \multirow{4}{*}{6} & $\mathrm{~B}_{\mathrm{w}}$ & 15 & 20 & 25 & $B_{w}$ & 15 & 20 & 25 & $B_{w}$ & 15 & 20 & 25 & $B_{w}$ & 15 & 20 & 25 \\
\hline & 15 & 17 & 19 & 20 & 15 & 31 & 35 & 37 & 15 & 49 & 55 & 60 & 15 & 71 & 79 & 87 \\
\hline & 20 & 19 & 21 & 22 & 20 & 35 & 37 & 40 & 20 & 53 & 58 & 63 & 20 & 75 & 83 & 91 \\
\hline & 25 & 22 & 23 & 24 & 25 & 38 & 40 & 42 & 25 & 57 & 62 & 66 & 25 & 80 & 87 & 94 \\
\hline \multirow{4}{*}{7} & & 15 & 20 & 25 & $B_{w}$ & 15 & 20 & 25 & $B_{w}$ & 15 & 20 & 25 & $B_{w}$ & 15 & 20 & 25 \\
\hline & 15 & 18 & 19 & 21 & 15 & 33 & 36 & 39 & 15 & 52 & 58 & 63 & 15 & 74 & 84 & 92 \\
\hline & 20 & 20 & 21 & 22 & 20 & 36 & 39 & 41 & 20 & 55 & 61 & 65 & 20 & 78 & 87 & 95 \\
\hline & 25 & 22 & 23 & 24 & 25 & 39 & 41 & 44 & 25 & 59 & 64 & 68 & 25 & 83 & 90 & 97 \\
\hline \multirow{4}{*}{8} & $B_{w}$ & 15 & 20 & 25 & $B_{w}$ & 15 & 20 & 25 & $B_{w}$ & 15 & 20 & 25 & $B_{w}$ & 15 & 20 & 25 \\
\hline & 15 & 18 & 20 & 21 & 15 & 34 & 38 & 41 & 15 & 54 & 60 & 66 & 15 & 78 & 88 & 98 \\
\hline & 20 & 20 & 22 & 23 & 20 & 37 & 40 & 43 & 20 & 57 & 63 & 68 & 20 & 82 & 91 & 100 \\
\hline & 25 & 23 & 24 & 25 & 25 & 40 & 42 & 45 & 25 & 61 & 66 & 70 & 25 & 85 & 94 & 101 \\
\hline
\end{tabular}



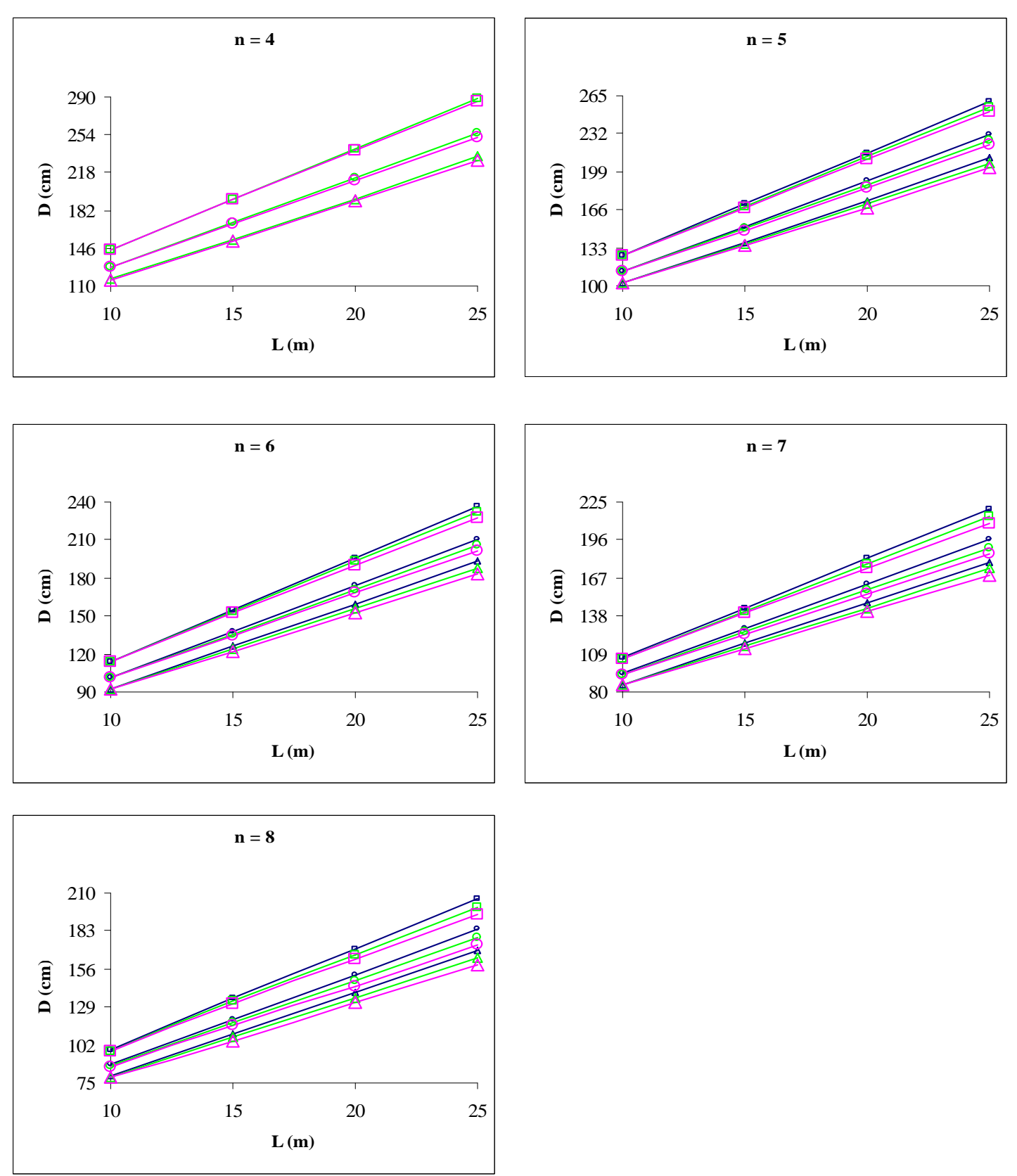

$\longrightarrow \mathrm{t}=15 \mathrm{~cm}, \mathrm{Bw}=15 \mathrm{~cm} \longrightarrow \mathrm{t}=15 \mathrm{~cm}, \mathrm{Bw}=20 \mathrm{~cm} \longrightarrow \mathrm{t}=15 \mathrm{~cm}, \mathrm{Bw}=25 \mathrm{~cm}$

$\square \mathrm{t}=20 \mathrm{~cm}, \mathrm{Bw}=15 \mathrm{~cm} \rightleftharpoons \mathrm{\odot}=20 \mathrm{~cm}, \mathrm{Bw}=20 \mathrm{~cm} \longrightarrow \triangle \mathrm{t}=20 \mathrm{~cm}, \mathrm{Bw}=25 \mathrm{~cm}$

$\square \mathrm{t}=25 \mathrm{~cm}, \mathrm{Bw}=15 \mathrm{~cm} \triangle \mathrm{C}=25 \mathrm{~cm}, \mathrm{Bw}=20 \mathrm{~cm} \triangle \triangle \mathrm{t}=25 \mathrm{~cm}, \mathrm{Bw}=25 \mathrm{~cm}$

FIGURA 41 - Gráficos D x L para pontes com 1 faixa de tráfego 

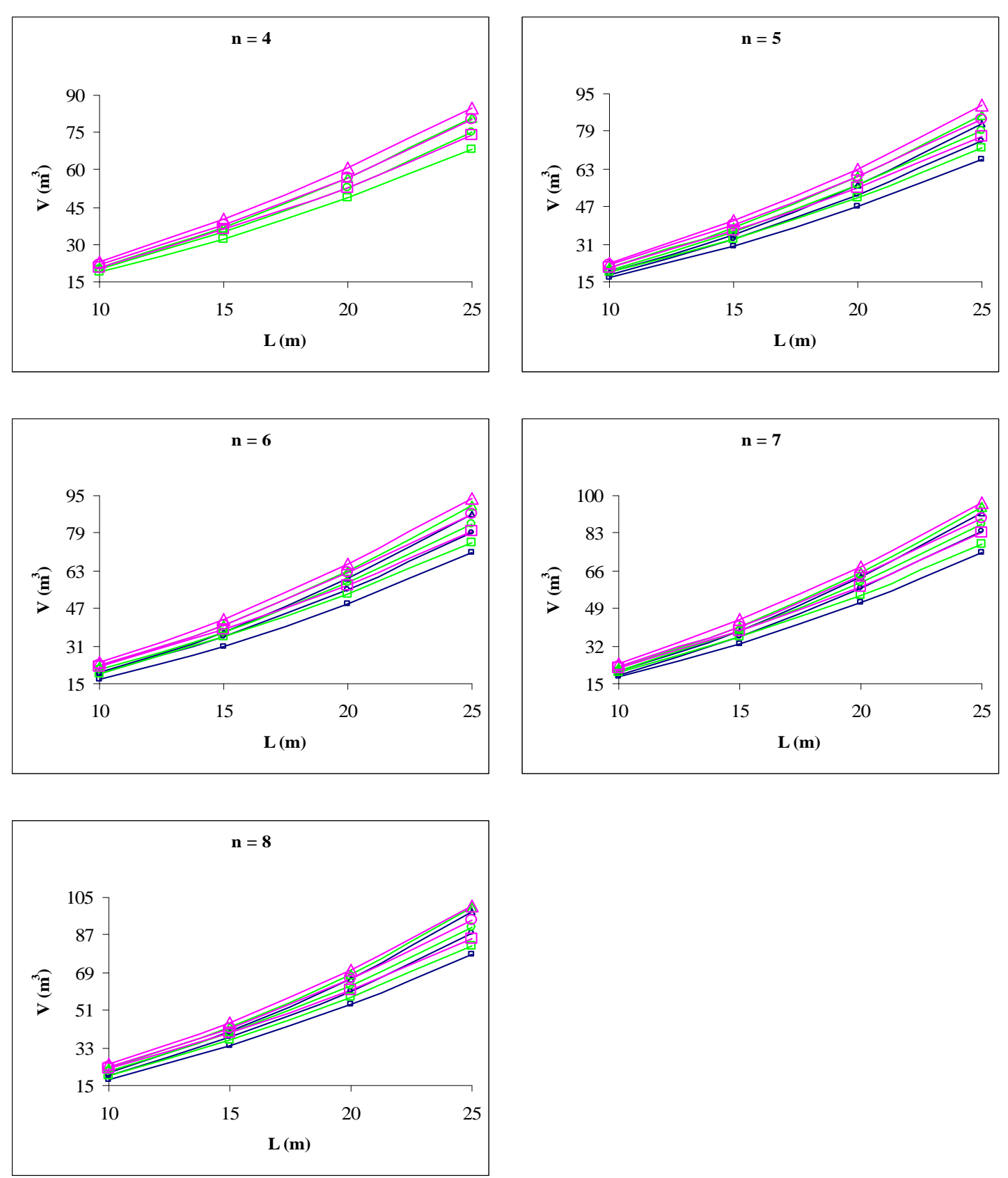

$\longrightarrow \mathrm{t}=15 \mathrm{~cm}, \mathrm{Bw}=15 \mathrm{~cm} \longrightarrow \mathrm{t}=15 \mathrm{~cm}, \mathrm{Bw}=20 \mathrm{~cm} \longrightarrow \mathrm{t}=15 \mathrm{~cm}, \mathrm{Bw}=25 \mathrm{~cm}$
$\square \mathrm{t}=20 \mathrm{~cm}, \mathrm{Bw}=15 \mathrm{~cm} \longrightarrow \mathrm{C}=20 \mathrm{~cm}, \mathrm{Bw}=20 \mathrm{~cm} \triangle \triangle \mathrm{t}=20 \mathrm{~cm}, \mathrm{Bw}=25 \mathrm{~cm}$
$\square \mathrm{t}=25 \mathrm{~cm}, \mathrm{Bw}=15 \mathrm{~cm} \longrightarrow \mathrm{C}=25 \mathrm{~cm}, \mathrm{Bw}=20 \mathrm{~cm} \triangle \triangle \mathrm{t}=25 \mathrm{~cm}, \mathrm{Bw}=25 \mathrm{~cm}$

FIGURA 42 - Gráficos V x L para pontes com 1 faixa de tráfego 
TABELA 9 - Alturas das nervuras D para pontes com 2 faixas de tráfego

$\left(B_{w}, t, D\right.$ em cm)

\begin{tabular}{|c|c|c|c|c|c|c|c|c|c|c|c|c|c|c|c|c|}
\hline \multirow{2}{*}{$\mathrm{n}$} & \multicolumn{16}{|c|}{ VÃOS DAS PONTES } \\
\hline & \multicolumn{4}{|c|}{$L=10 \mathrm{~m}$} & \multicolumn{4}{|c|}{$L=15 \mathrm{~m}$} & \multicolumn{4}{|c|}{$L=20 \mathrm{~m}$} & \multicolumn{4}{|c|}{$L=25 \mathrm{~m}$} \\
\hline \multirow{4}{*}{7} & $t B_{w}$ & 15 & 20 & 25 & $\mathrm{t}$ & 15 & 20 & 25 & $t B_{w}$ & 15 & 20 & 25 & $t B_{w}$ & 15 & 20 & 25 \\
\hline & 15 & - & - & - & 15 & - & - & - & 15 & - & - & - & 15 & - & - & - \\
\hline & 20 & 118 & 104 & 95 & 20 & 157 & 139 & 127 & 20 & 198 & 175 & 160 & 20 & 239 & 212 & 194 \\
\hline & 25 & 119 & 105 & 96 & 25 & 158 & 140 & 128 & 25 & 198 & 176 & 160 & 25 & 239 & 212 & 193 \\
\hline \multirow{4}{*}{8} & $t \mathrm{~B}_{\mathrm{w}}$ & 15 & 20 & 25 & $\mathrm{t}$ & 15 & 20 & 25 & $t v^{B_{w}}$ & 15 & 20 & 25 & $t \mathrm{~B}_{\mathrm{w}}$ & 15 & 20 & 25 \\
\hline & 15 & & & - & 15 & - & - & - & 15 & . & - & - & 15 & & - & - \\
\hline & 20 & 110 & 97 & 89 & 20 & 147 & 130 & 119 & 20 & 185 & 164 & 150 & 20 & 224 & 199 & 182 \\
\hline & 25 & 111 & 98 & 89 & 25 & 148 & 131 & 119 & 25 & 186 & 164 & 150 & 25 & 224 & 198 & 181 \\
\hline \multirow{4}{*}{9} & $\mathrm{t}^{\mathrm{B}_{\mathrm{w}}}$ & 15 & 20 & 25 & $\mathrm{t}$ & 15 & 20 & 25 & $t \mathrm{~B}_{\mathrm{w}}$ & 15 & 20 & 25 & $t \mathrm{~B}_{\mathrm{w}}$ & 15 & 20 & 25 \\
\hline & 15 & 102 & 90 & 83 & 15 & 139 & 123 & 113 & 15 & 176 & 156 & 143 & 15 & 213 & 190 & 174 \\
\hline & 20 & 103 & 92 & 8 & 20 & 139 & 123 & 112 & 20 & 175 & 155 & 142 & 20 & 212 & 188 & 173 \\
\hline & 25 & 104 & 92 & 84 & 25 & 139 & 123 & 112 & 25 & 175 & 155 & 142 & 25 & 211 & 188 & 172 \\
\hline \multirow{4}{*}{10} & $t \mathrm{~B}_{\mathrm{w}}$ & 15 & 20 & 25 & $\mathrm{t}$ & 15 & 20 & 25 & $t \mathrm{~B}_{\mathrm{w}}$ & 15 & 20 & 25 & $t \mathrm{~B}_{\mathrm{w}}$ & 15 & 20 & 25 \\
\hline & 15 & 97 & 86 & $7 \varepsilon$ & 15 & 132 & 117 & 107 & 15 & 168 & 149 & 136 & 15 & 203 & 181 & 166 \\
\hline & 20 & 98 & 87 & 7 & 20 & 132 & 117 & 10 & 20 & 67 & 149 & 135 & 20 & 02 & 180 & 165 \\
\hline & 25 & 99 & 88 & 80 & 25 & 132 & 117 & & 25 & & 148 & 135 & 25 & 201 & 179 & 164 \\
\hline \multirow{4}{*}{11} & $t \mathrm{~B}_{\mathrm{w}}$ & 15 & 20 & 25 & $\mathrm{t}$ & 15 & 20 & 25 & $\mathrm{t}^{\mathrm{B}_{\mathrm{w}}}$ & 15 & 20 & 25 & $\mathrm{~B}_{\mathrm{w}}$ & 15 & 20 & 25 \\
\hline & 15 & 93 & 82 & & 15 & 127 & 112 & 10 & 15 & & 143 & 131 & 15 & 195 & 174 & 160 \\
\hline & 20 & 93 & 83 & 7 & 20 & 126 & 112 & 10 & 20 & 159 & 142 & 130 & 20 & 193 & 172 & 158 \\
\hline & 25 & 94 & 84 & 76 & 25 & 127 & 112 & 102 & 25 & 159 & 141 & 129 & 25 & 192 & 171 & 157 \\
\hline \multirow{4}{*}{12} & $t B_{w}$ & 15 & 20 & 25 & $\mathrm{~B}_{\mathrm{v}}$ & 15 & 20 & 25 & $B_{w}$ & 15 & 20 & 25 & $t$ & 15 & 20 & 25 \\
\hline & 15 & 89 & 79 & & 15 & 122 & 108 & 99 & 15 & 154 & 138 & 126 & 15 & 188 & 168 & 154 \\
\hline & 20 & 89 & 80 & & 20 & 121 & 108 & 94 & 20 & & 136 & 125 & 20 & 18 & 166 & 152 \\
\hline & 25 & 90 & 80 & 73 & 25 & 121 & 108 & 98 & 25 & 153 & 136 & 124 & 25 & 185 & 165 & 151 \\
\hline \multirow{4}{*}{13} & $t \mathrm{~B}_{\mathrm{w}}$ & 15 & 20 & 25 & $t$ & 15 & 20 & 25 & $\mathrm{t}^{\mathrm{B}_{\mathrm{w}}}$ & 15 & 20 & 25 & $t \sqrt{B_{w}}$ & 15 & 20 & 25 \\
\hline & 15 & 86 & 76 & & 15 & 117 & 104 & 96 & 15 & 149 & 133 & 122 & 15 & 181 & 162 & 149 \\
\hline & 20 & 86 & 77 & 7 & 20 & 117 & 104 & 95 & 20 & 18 & 132 & 121 & 20 & 179 & 160 & 147 \\
\hline & 25 & 87 & 77 & 70 & 25 & 117 & 104 & 95 & 25 & 147 & 131 & 120 & 25 & 178 & 159 & 146 \\
\hline \multirow{4}{*}{14} & $\mathrm{t}^{\mathrm{B}_{\mathrm{w}}}$ & 15 & 20 & 25 & $t B_{v}$ & 15 & 20 & 25 & $\mathrm{~B}_{\mathrm{w}}$ & 15 & 20 & 25 & $t B_{w}$ & 15 & 20 & 25 \\
\hline & 15 & 83 & 74 & 6 & 15 & 114 & 101 & 93 & 15 & 144 & 129 & 118 & 15 & 176 & 157 & 145 \\
\hline & 20 & 83 & 74 & 6 & 20 & 113 & 101 & 92 & 20 & 143 & 128 & 117 & 20 & 174 & 155 & 143 \\
\hline & 25 & 84 & 74 & 68 & 25 & 113 & 100 & 92 & 25 & 142 & 127 & 116 & 25 & 172 & 154 & 141 \\
\hline
\end{tabular}


TABELA 10 - Volumes de madeiras V para pontes com 2 faixas de tráfego $\left(B_{w}, \mathrm{t} \mathrm{em} \mathrm{cm,} V\right.$ em m$\left.{ }^{3}\right)$

\begin{tabular}{|c|c|c|c|c|c|c|c|c|c|c|c|c|c|c|c|c|}
\hline \multirow{2}{*}{$\mathrm{n}$} & \multicolumn{16}{|c|}{ VÃOS DAS PONTES } \\
\hline & \multicolumn{4}{|c|}{$L=10 \mathrm{~m}$} & \multicolumn{4}{|c|}{$L=15 \mathrm{~m}$} & \multicolumn{4}{|c|}{$L=20 \mathrm{~m}$} & \multicolumn{4}{|c|}{$L=25 \mathrm{~m}$} \\
\hline \multirow{4}{*}{7} & $t B_{w}$ & 15 & 20 & 25 & $\mathrm{t}$ & 15 & 20 & 25 & $\mathrm{t}^{\mathrm{B}_{\mathrm{w}}}$ & 15 & 20 & 25 & $\mathrm{t}$ & 15 & 20 & 25 \\
\hline & 15 & - & - & - & 15 & - & - & - & 15 & - & - & - & 15 & - & - & - \\
\hline & 20 & 30 & 32 & 33 & 20 & 52 & 55 & 58 & 20 & 77 & 83 & 89 & 20 & 107 & 117 & 126 \\
\hline & 25 & 35 & 36 & 37 & 25 & 58 & 62 & 65 & 25 & 86 & 92 & 97 & 25 & 119 & 128 & 136 \\
\hline \multirow{4}{*}{8} & $t$ & 15 & 20 & 25 & $\mathrm{t}$ & 15 & 20 & 25 & $\mathrm{t}$ & 15 & 20 & 25 & $\mathrm{t} \mathrm{B}_{\mathrm{w}}$ & 15 & 20 & 25 \\
\hline & 15 & - & - & - & 15 & & - & & 15 & & - & - & 15 & & - & - \\
\hline & 20 & 31 & 32 & 34 & 20 & 53 & 56 & 60 & 20 & 80 & 86 & 92 & 20 & 111 & 122 & 131 \\
\hline & 25 & 35 & 37 & 38 & 25 & 60 & 63 & 66 & 25 & 89 & 94 & 100 & 25 & 122 & 132 & 141 \\
\hline \multirow{4}{*}{9} & $\mathrm{t} \mathrm{B}_{\mathrm{w}}$ & 15 & 20 & 25 & $t$ & 15 & 20 & 25 & $t$ & 15 & 20 & 25 & $\mathrm{t}$ & 15 & 20 & 25 \\
\hline & 15 & 27 & 29 & 30 & 15 & 48 & 52 & 56 & 15 & 73 & 81 & 88 & 15 & 104 & & 127 \\
\hline & 20 & 31 & 33 & 34 & 20 & 54 & 58 & 6 & 20 & 82 & 89 & 95 & 20 & 115 & 126 & 136 \\
\hline & 25 & 36 & 37 & 38 & 25 & 61 & 64 & 67 & 25 & 91 & 97 & 103 & 25 & 125 & 136 & 145 \\
\hline \multirow{4}{*}{10} & $t \mathrm{~B}_{\mathrm{w}}$ & 15 & 20 & 25 & $t$ & 15 & 20 & 25 & $t^{B_{u}}$ & 15 & 20 & 25 & $\mathrm{t}$ & 15 & 20 & 25 \\
\hline & 15 & 27 & 29 & 31 & 15 & 49 & 53 & 5 & 15 & 76 & 84 & 91 & 15 & 108 & 121 & 132 \\
\hline & 20 & 3 & 33 & 35 & 20 & 55 & 59 & & 20 & 84 & 92 & 98 & 20 & 118 & 130 & 141 \\
\hline & 25 & 36 & 38 & 39 & 25 & 62 & 65 & & 25 & 93 & 99 & 105 & 25 & 129 & 140 & 149 \\
\hline \multirow{4}{*}{11} & $t$ & 15 & 20 & 25 & $t$ & 15 & 20 & 25 & $\mathrm{t}^{\mathrm{B}_{\mathrm{u}}}$ & 15 & 20 & 25 & $\mathrm{t}$ & 15 & 20 & 25 \\
\hline & 15 & 2 & 30 & 32 & 15 & 50 & 55 & & 15 & 78 & 86 & 94 & 15 & 112 & 125 & 137 \\
\hline & 20 & 3 & 34 & 3. & 20 & 56 & 60 & 6 & 20 & 86 & 94 & 101 & 20 & 121 & 134 & 145 \\
\hline & 25 & 36 & 38 & 39 & 25 & 63 & 66 & os & 25 & 94 & 101 & 107 & 25 & 131 & 143 & 153 \\
\hline \multirow{4}{*}{12} & $t B_{w}$ & 15 & 20 & 25 & $\mathrm{t}$ & 15 & 20 & 25 & $\mathrm{t}^{\mathrm{B}_{\mathrm{u}}}$ & 15 & 20 & 25 & $t$ & 15 & 20 & 25 \\
\hline & 15 & 2 & 30 & 32 & 15 & 51 & 56 & 6 & 15 & 80 & 89 & 97 & 15 & 115 & 129 & 142 \\
\hline & 20 & 3 & 34 & & 20 & 5 & 62 & & 20 & & 96 & 103 & 20 & 125 & 138 & 149 \\
\hline & 25 & 37 & 38 & 39 & 25 & 63 & 67 & & 25 & 96 & 103 & 109 & 25 & 135 & 147 & 157 \\
\hline \multirow{4}{*}{13} & $t$ & 15 & 20 & 25 & $\mathrm{t}$ & 15 & 20 & 25 & $\mathrm{t}^{\mathrm{B}_{\mathrm{u}}}$ & 15 & 20 & 25 & $\mathrm{t}$ & 15 & 20 & 25 \\
\hline & 15 & 29 & 31 & 33 & 15 & 52 & 57 & & 15 & 82 & 91 & 100 & 15 & 118 & 133 & 146 \\
\hline & 20 & 33 & 35 & 36 & 20 & 58 & 63 & & 20 & 0 & 98 & 106 & 20 & 128 & 141 & 153 \\
\hline & 25 & 37 & 39 & 40 & 25 & 64 & 68 & 72 & 25 & 98 & 105 & 112 & 25 & 137 & 150 & 161 \\
\hline \multirow{4}{*}{14} & $t \mathrm{~B}_{\mathrm{w}}$ & 15 & 20 & 25 & $t$ & 15 & 20 & 25 & $\mathrm{t}^{\mathrm{B}_{\mathrm{u}}}$ & 15 & 20 & 25 & $t$ & 15 & 20 & 25 \\
\hline & 15 & 29 & 32 & 33 & 15 & 54 & 59 & 6. & 15 & 84 & 94 & 102 & 15 & 122 & 137 & 151 \\
\hline & 20 & 3. & 35 & 37 & 20 & 5 & 64 & 6 & 20 & 92 & 100 & 108 & 20 & 131 & 145 & 158 \\
\hline & 25 & 37 & 39 & 40 & 25 & 65 & 69 & 73 & 25 & 99 & 107 & 114 & 25 & 140 & 153 & 164 \\
\hline
\end{tabular}




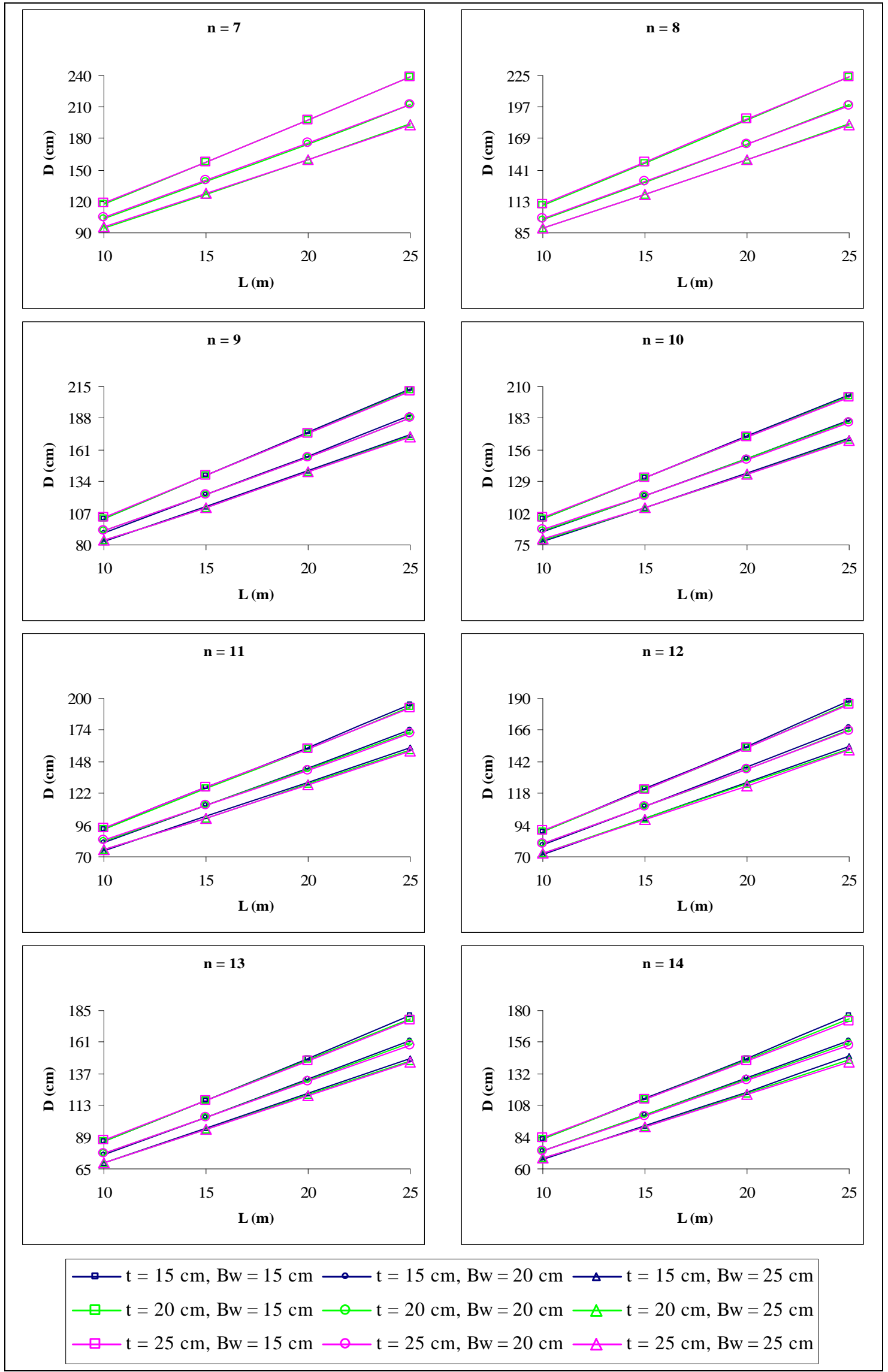

FIGURA 43 - Gráficos D x L para pontes com 2 faixas de tráfego 


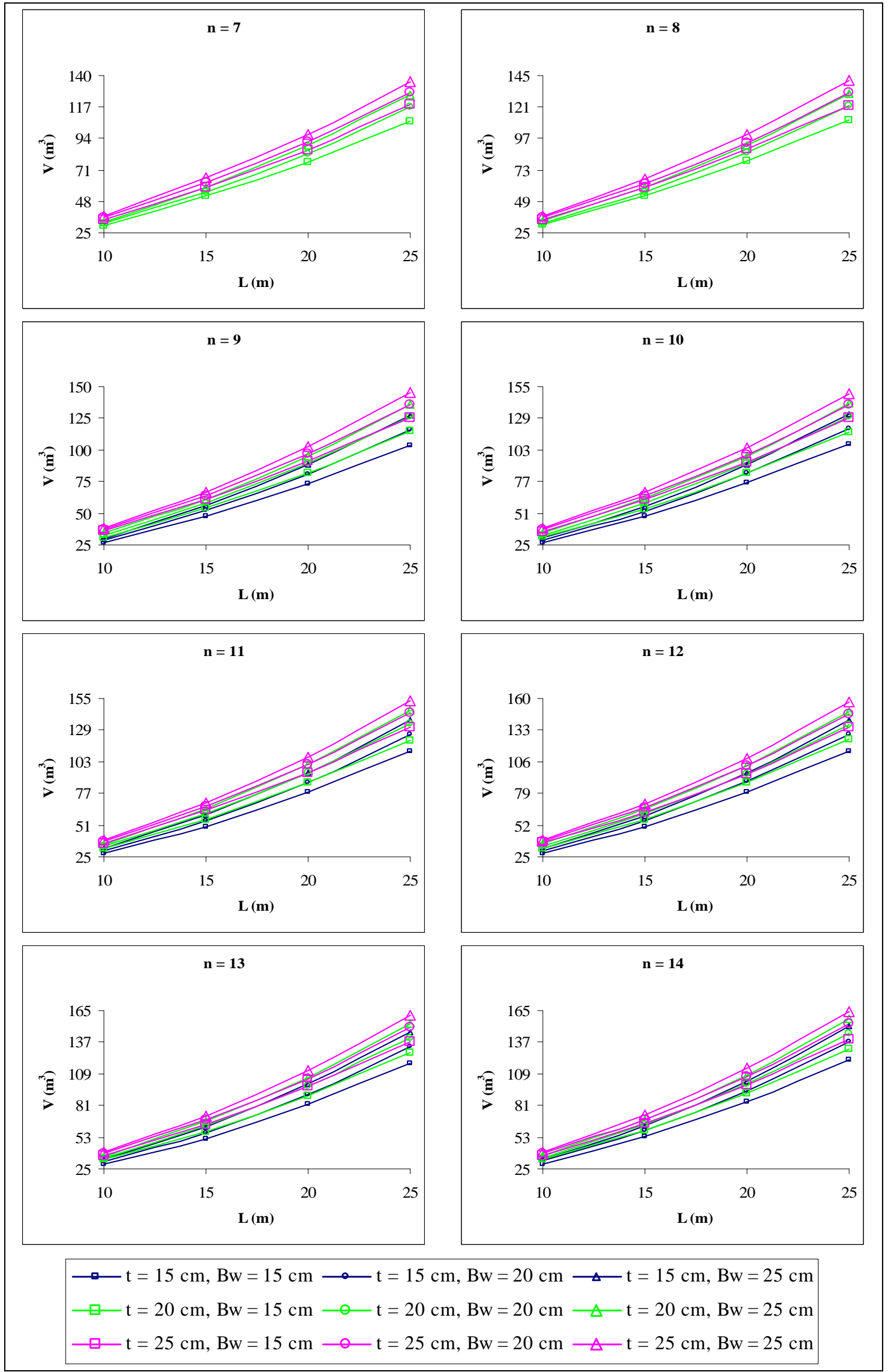

FIGURA 44 - Gráficos V x L para pontes com 2 faixas de tráfego 
3.3.2- Influência da altura do tabuleiro e da largura das nervuras na altura D

Com o objetivo de se verificar a influência da largura $B_{w}$ e da altura t na altura D, estas alturas foram calculadas para pontes com as mesmas características (largura da ponte, número de nervuras e madeira Classe C 30 - Conífera para as nervuras e o tabuleiro), e então comparadas inicialmente fixando-se a largura $B_{w} e$ variando-se a altura t e, posteriormente, fixando-se a altura t e variando-se a largura $\mathrm{B}_{\mathrm{w}}$.

Com os resultados obtidos, foram montadas as tabelas 11 e 12 , que apresentam, respectivamente, as alturas das nervuras para as pontes com 1 e 2 faixas de tráfego. Estes resultados também podem ser visualizados na figura 45 .

TABELA 11 - Alturas D para pontes com 1 faixa de tráfego $\left(\mathrm{B}_{\mathrm{w}}, \mathrm{t}, \mathrm{D}\right.$ em cm)

\begin{tabular}{|c|c|c|c|c|}
\hline \multirow[t]{5}{*}{$\mathrm{n}$} & \multicolumn{4}{|c|}{$\begin{array}{l}\text { TABULEIRO E NERVURAS } \\
\text { CLASSE C } 30 \text { (CONÍFERA) }\end{array}$} \\
\hline & $\mathrm{t}$ & 15 & 20 & 25 \\
\hline & 15 & - & - & - \\
\hline & 20 & 192 & 170 & 154 \\
\hline & 25 & 192 & 169 & 153 \\
\hline \multirow{4}{*}{5} & $\mathrm{t}$ & 15 & 20 & 25 \\
\hline & 15 & 171 & 151 & 138 \\
\hline & 20 & 169 & 150 & 136 \\
\hline & 25 & 168 & 148 & 135 \\
\hline \multirow{4}{*}{6} & $\mathrm{t}$ & 15 & 20 & 25 \\
\hline & 15 & 155 & 138 & 126 \\
\hline & 20 & 154 & 136 & 124 \\
\hline & 25 & 152 & 134 & 122 \\
\hline \multirow{4}{*}{7} & $\mathrm{t}$ & 15 & 20 & 25 \\
\hline & 15 & 144 & 128 & 117 \\
\hline & 20 & 142 & 126 & 115 \\
\hline & 25 & 140 & 124 & 113 \\
\hline \multirow{4}{*}{8} & $\mathrm{t}$ & 15 & 20 & 25 \\
\hline & 15 & 135 & 120 & 110 \\
\hline & 20 & 133 & 118 & 108 \\
\hline & 25 & 131 & 116 & 105 \\
\hline
\end{tabular}


TABELA 12 - Alturas D para pontes com 2 faixas de tráfego $\left(\mathrm{B}_{\mathrm{w}}, \mathrm{t}, \mathrm{D} \mathrm{em} \mathrm{cm}\right)$

\begin{tabular}{|c|c|c|c|c|}
\hline $\mathrm{n}$ & \multicolumn{4}{|c|}{$\begin{array}{l}\text { TABULEIRO E NERVURAS } \\
\text { CLASSE C } 30 \text { (CONÍFERA) }\end{array}$} \\
\hline \multirow[b]{2}{*}{7} & $t$ & 15 & 20 & 25 \\
\hline & $\begin{array}{l}15 \\
20 \\
25\end{array}$ & $\begin{array}{c}- \\
157 \\
158\end{array}$ & $\begin{array}{c}- \\
139 \\
140\end{array}$ & $\begin{array}{c}- \\
127 \\
128\end{array}$ \\
\hline \multirow[b]{2}{*}{8} & $\mathrm{t}$ & 15 & 20 & 25 \\
\hline & $\begin{array}{l}15 \\
20 \\
25\end{array}$ & $\begin{array}{c}- \\
147 \\
148 \\
\end{array}$ & $\begin{array}{c}- \\
130 \\
131\end{array}$ & $\begin{array}{c}- \\
119 \\
119\end{array}$ \\
\hline \multirow[b]{2}{*}{9} & $\mathrm{t}$ & 15 & 20 & 25 \\
\hline & $\begin{array}{l}15 \\
20 \\
25\end{array}$ & $\begin{array}{l}139 \\
139 \\
139 \\
\end{array}$ & $\begin{array}{l}123 \\
123 \\
123\end{array}$ & $\begin{array}{l}13 \\
112 \\
112\end{array}$ \\
\hline \multirow[b]{2}{*}{10} & $\mathrm{t}$ & 15 & 20 & 25 \\
\hline & $\begin{array}{l}15 \\
20 \\
25\end{array}$ & $\begin{array}{l}132 \\
132 \\
132 \\
\end{array}$ & $\begin{array}{l}117 \\
117 \\
117\end{array}$ & $\begin{array}{l}107 \\
107 \\
107\end{array}$ \\
\hline \multirow[b]{2}{*}{11} & $\mathrm{t}$ & 15 & 20 & 25 \\
\hline & $\begin{array}{l}15 \\
20 \\
25 \\
\end{array}$ & $\begin{array}{l}127 \\
126 \\
127 \\
\end{array}$ & $\begin{array}{l}112 \\
112 \\
112 \\
\end{array}$ & $\begin{array}{l}103 \\
102 \\
102 \\
\end{array}$ \\
\hline \multirow[b]{2}{*}{12} & $\mathrm{t}$ & 15 & 20 & 25 \\
\hline & $\begin{array}{l}15 \\
20 \\
25\end{array}$ & $\begin{array}{l}122 \\
121 \\
121\end{array}$ & $\begin{array}{l}108 \\
108 \\
108\end{array}$ & $\begin{array}{l}99 \\
99 \\
98\end{array}$ \\
\hline \multirow[b]{2}{*}{13} & $\mathrm{t}$ & 15 & 20 & 25 \\
\hline & $\begin{array}{l}15 \\
20 \\
25\end{array}$ & $\begin{array}{l}117 \\
117 \\
117 \\
\end{array}$ & $\begin{array}{l}104 \\
104 \\
104 \\
\end{array}$ & $\begin{array}{l}96 \\
95 \\
95\end{array}$ \\
\hline \multirow[b]{2}{*}{14} & $\mathrm{t}$ & 15 & 20 & 25 \\
\hline & $\begin{array}{l}15 \\
20 \\
25\end{array}$ & $\begin{array}{l}114 \\
113 \\
113\end{array}$ & $\begin{array}{l}101 \\
101 \\
100\end{array}$ & $\begin{array}{l}93 \\
92 \\
92\end{array}$ \\
\hline
\end{tabular}




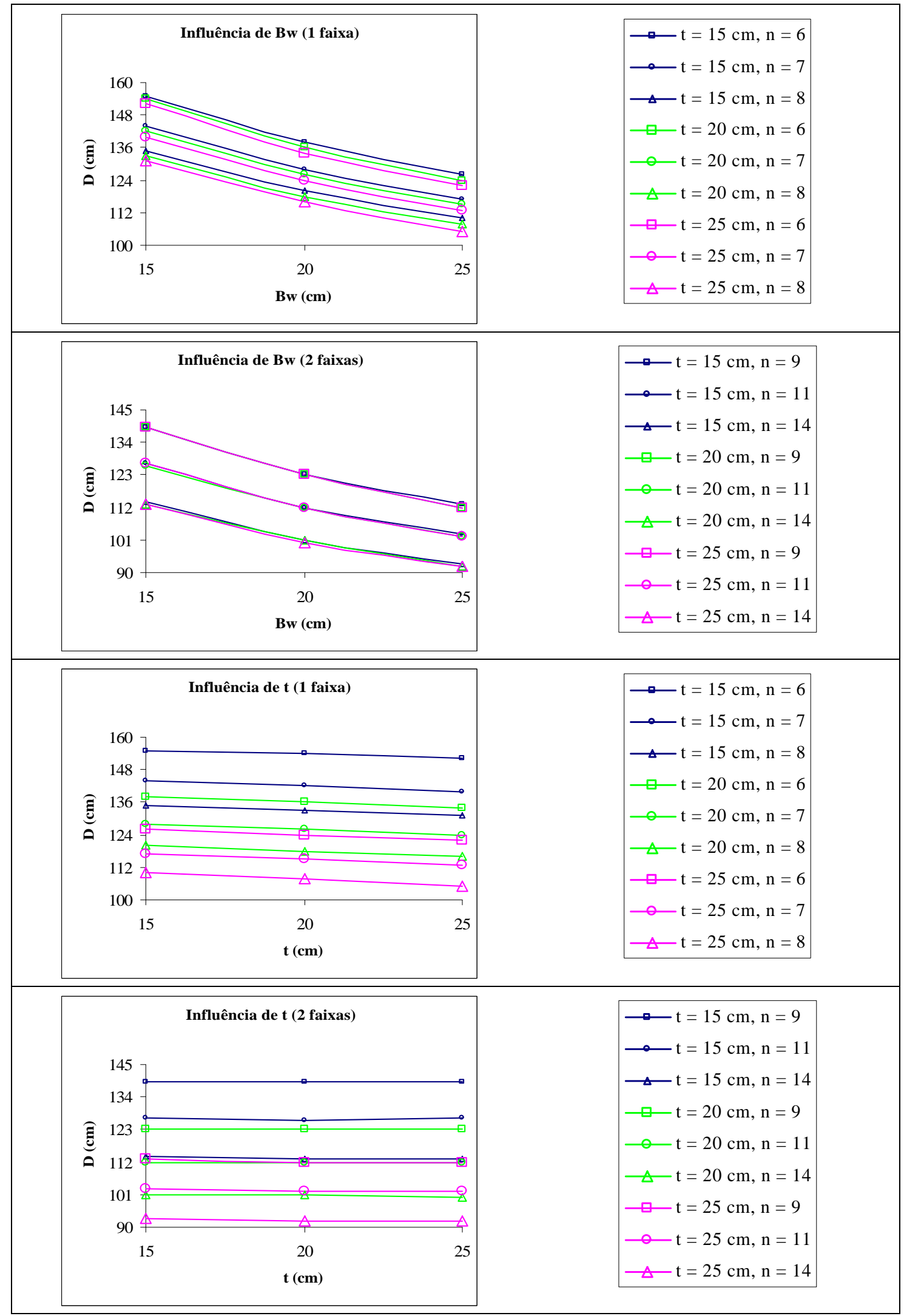

FIGURA 45 - Gráficos D x $\mathrm{B}_{\mathrm{w}}$ e D x t para pontes com 1 e 2 faixas de tráfego 
3.3.3- Influência da espécie de madeira do tabuleiro na altura D

Com o objetivo de se verificar a influência da espécie de madeira do tabuleiro na altura $\mathrm{D}$, estas alturas foram calculadas para pontes com as mesmas características (largura da ponte, largura das nervuras, altura do tabuleiro, número de nervuras e madeira Classe C 30 - Conífera para as nervuras), e então comparadas entre si, mudando-se apenas a madeira do tabuleiro (Classe C 30 - Conífera, Classe C 30 Dicotiledônea e Classe C 40 - Dicotiledônea).

Com os resultados obtidos, foram montadas as tabelas 13 e 14, que apresentam, respectivamente, as alturas das nervuras e os volume totais de madeiras para a ponte com 1 faixa de tráfego. Os resultados referentes às pontes com 2 faixas de tráfego são apresentados nas tabelas 15 e 16.

Estes resultados também podem ser visualizados nas figuras 46 e 47. 
TABELA 13 - Alturas das nervuras D para pontes com 1 faixa de tráfego $\left(B_{w}, t, D\right.$ em cm)

\begin{tabular}{|c|c|c|c|c|c|c|c|c|c|c|c|c|}
\hline \multirow[b]{2}{*}{$n$} & \multicolumn{12}{|c|}{ CLASSES DE RESISTENNCIA DAS MADEIRAS DO TABULEIRO } \\
\hline & \multicolumn{4}{|c|}{$\begin{array}{l}\text { CLASSE C } 30 \\
\text { (CONÍFERA) }\end{array}$} & \multicolumn{4}{|c|}{$\begin{array}{c}\text { CLASSE C } 30 \\
\text { (DICOTILEDÔNEA) }\end{array}$} & \multicolumn{4}{|c|}{$\begin{array}{c}\text { CLASSE C } 40 \\
\text { (DICOTILEDÔNEA) }\end{array}$} \\
\hline \multirow{4}{*}{4} & $\mathrm{t}$ & 15 & 20 & 25 & $\mathrm{t}$ & 15 & 20 & 25 & $\mathrm{~B}_{\mathrm{v}}$ & 15 & 20 & 25 \\
\hline & 15 & - & - & - & 15 & - & - & - & 15 & - & - & - \\
\hline & 20 & 192 & 170 & 154 & 20 & 194 & 171 & 155 & 20 & 192 & 169 & 153 \\
\hline & 25 & 192 & 169 & 153 & 25 & 194 & 171 & 155 & 25 & 192 & 170 & 154 \\
\hline \multirow{4}{*}{5} & $\mathrm{t}$ & 15 & 20 & 25 & & 15 & 20 & 25 & & 15 & 20 & 25 \\
\hline & 15 & 171 & 151 & 138 & 15 & 172 & 152 & 139 & 15 & 169 & 149 & 136 \\
\hline & 20 & 169 & 150 & 136 & 20 & 171 & 151 & 137 & 20 & 168 & 148 & 135 \\
\hline & 25 & 168 & 148 & 135 & 25 & 170 & 150 & 136 & 25 & 168 & 148 & 135 \\
\hline \multirow{4}{*}{6} & $B_{w}$ & 15 & 20 & 25 & & 15 & 20 & 25 & & 15 & 20 & 25 \\
\hline & 15 & 155 & 138 & 126 & 15 & 156 & 139 & 127 & 15 & 153 & 136 & 124 \\
\hline & 20 & 154 & 136 & 124 & 20 & 155 & 137 & 125 & 20 & 152 & 135 & 123 \\
\hline & 25 & 152 & 134 & 122 & 25 & 154 & 136 & 124 & 25 & 152 & 134 & 121 \\
\hline \multirow{4}{*}{7} & $t$ & 15 & 20 & 25 & $\mathrm{t}$ & 15 & 20 & 25 & $\mathrm{t}$ & 15 & 20 & 25 \\
\hline & 15 & 144 & 128 & 117 & 15 & 145 & 129 & 117 & 15 & 142 & 126 & 115 \\
\hline & 20 & 142 & 126 & 115 & 20 & 143 & 127 & 116 & 20 & 141 & 124 & 113 \\
\hline & 25 & 140 & 124 & 113 & 25 & 142 & 125 & 114 & 25 & 139 & 123 & 112 \\
\hline \multirow{4}{*}{8} & $\mathrm{t}$ & 15 & 20 & 25 & $\mathrm{t}$ & 15 & 20 & 25 & $\mathrm{~B}_{\mathrm{v}}$ & 15 & 20 & 25 \\
\hline & 15 & 135 & 120 & 110 & 15 & 136 & 121 & 110 & 15 & 133 & 118 & 108 \\
\hline & 20 & 133 & 118 & 108 & 20 & 134 & 119 & 108 & 20 & 131 & 116 & 106 \\
\hline & 25 & 131 & 116 & 105 & 25 & 132 & 117 & 107 & 25 & 130 & 115 & 104 \\
\hline
\end{tabular}


TABELA 14 - Volumes de madeiras V para pontes com 1 faixa de tráfego $\left(B_{w}, t\right.$ em cm, $V$ em m $\left.{ }^{3}\right)$

\begin{tabular}{|c|c|c|c|c|c|c|c|c|c|c|c|c|}
\hline \multirow[b]{2}{*}{$\mathrm{n}$} & \multicolumn{12}{|c|}{ CLASSES DE RESISTENNCIA DAS MADEIRAS DO TABULEIRO } \\
\hline & \multicolumn{4}{|c|}{$\begin{array}{l}\text { CLASSE C } 30 \\
\text { (CONÍFERA) }\end{array}$} & \multicolumn{4}{|c|}{$\begin{array}{c}\text { CLASSE C } 30 \\
\text { (DICOTILEDÔNEA) }\end{array}$} & \multicolumn{4}{|c|}{$\begin{array}{c}\text { CLASSE C } 40 \\
\text { (DICOTILEDÔNEA) }\end{array}$} \\
\hline \multirow{4}{*}{4} & $\mathrm{t}_{\mathrm{w}}$ & 15 & 20 & 25 & $\mathrm{t} \mathrm{B}_{\mathrm{w}}$ & 15 & 20 & 25 & $\mathrm{~B}_{\mathrm{u}}$ & 15 & 20 & 25 \\
\hline & 15 & - & - & - & 15 & - & - & - & 15 & - & - & - \\
\hline & 20 & 32 & 35 & 37 & 20 & 32 & 35 & 37 & 20 & 32 & 34 & 36 \\
\hline & 25 & 36 & 38 & 40 & 25 & 36 & 38 & 40 & 25 & 36 & 38 & 40 \\
\hline \multirow{4}{*}{5} & $B_{n}$ & 15 & 20 & 25 & & 15 & 20 & 25 & & 15 & 20 & 25 \\
\hline & 15 & 30 & 33 & 35 & 15 & 30 & 33 & 36 & 15 & 30 & 32 & 35 \\
\hline & 20 & 33 & 36 & 38 & 20 & 33 & 36 & 38 & 20 & 33 & 36 & 38 \\
\hline & 25 & 37 & 39 & 41 & 25 & 37 & 39 & 41 & 25 & 37 & 39 & 41 \\
\hline \multirow{4}{*}{6} & $\mathrm{t}$ & 15 & 20 & 25 & $t \mathrm{~B}_{\mathrm{w}}$ & 15 & 20 & 25 & $\mathrm{t}$ & 15 & 20 & 25 \\
\hline & 15 & 31 & 35 & 37 & 15 & 31 & 35 & 38 & 15 & 31 & 34 & 37 \\
\hline & 20 & 35 & 37 & 40 & 20 & 35 & 38 & 40 & 20 & 34 & 37 & 40 \\
\hline & 25 & 38 & 40 & 42 & 25 & 38 & 41 & 43 & 25 & 38 & 40 & 42 \\
\hline \multirow{4}{*}{7} & & 15 & 20 & 25 & $\mathrm{~B}_{\mathrm{w}}$ & 15 & 20 & 25 & & 15 & 20 & 25 \\
\hline & 15 & 33 & 36 & 39 & 15 & 33 & 36 & 39 & 15 & 32 & 36 & 39 \\
\hline & 20 & 36 & 39 & 41 & 20 & 36 & 39 & 42 & 20 & 36 & 38 & 41 \\
\hline & 25 & 39 & 41 & 44 & 25 & 39 & 42 & 44 & 25 & 39 & 41 & 43 \\
\hline \multirow{4}{*}{8} & $\mathrm{~B}_{\mathrm{u}}$ & 15 & 20 & 25 & $\mathrm{t}_{\mathrm{w}}$ & 15 & 20 & 25 & & 15 & 20 & 25 \\
\hline & 15 & 34 & 38 & 41 & 15 & 34 & 38 & 41 & 15 & 34 & 37 & 40 \\
\hline & 20 & 37 & 40 & 43 & 20 & 37 & 40 & 43 & 20 & 36 & 40 & 42 \\
\hline & 25 & 40 & 42 & 45 & 25 & 40 & 43 & 45 & 25 & 40 & 42 & 44 \\
\hline
\end{tabular}


TABELA 15 - Alturas das nervuras D para pontes com 2 faixas de tráfego $\left(B_{w}, t, D\right.$ em cm)

\begin{tabular}{|c|c|c|c|c|c|c|c|c|c|c|c|c|}
\hline \multirow[b]{2}{*}{$\mathrm{n}$} & \multicolumn{12}{|c|}{ CLASSES DE RESISTENNCIA DAS MADEIRAS DO TABULEIRO } \\
\hline & \multicolumn{4}{|c|}{$\begin{array}{l}\text { CLASSE C } 30 \\
\text { (CONÍFERA) }\end{array}$} & \multicolumn{4}{|c|}{$\begin{array}{c}\text { CLASSE C } 30 \\
\text { (DICOTILEDÔNEA) }\end{array}$} & \multicolumn{4}{|c|}{$\begin{array}{c}\text { CLASSE C } 40 \\
\text { (DICOTILEDÔNEA) }\end{array}$} \\
\hline \multirow{4}{*}{7} & $\mathrm{~B}_{\mathrm{w}}$ & 15 & 20 & 25 & $B_{w}$ & 15 & 20 & 25 & $B_{w}$ & 15 & 20 & 25 \\
\hline & 15 & - & - & - & 15 & - & - & - & 15 & - & - & - \\
\hline & 20 & 157 & 139 & 127 & 20 & 159 & 141 & 128 & 20 & 158 & 140 & 127 \\
\hline & 25 & 158 & 140 & 128 & 25 & 160 & 142 & 129 & 25 & 160 & 142 & 129 \\
\hline \multirow{4}{*}{8} & $\mathrm{~B}_{\mathrm{w}}$ & 15 & 20 & 25 & & 15 & 20 & 25 & & 15 & 20 & 25 \\
\hline & 15 & - & - & - & 15 & - & - & - & 15 & - & - & - \\
\hline & 20 & 147 & 130 & 119 & 20 & 149 & 132 & 120 & 20 & 147 & 130 & 119 \\
\hline & 25 & 148 & 131 & 119 & 25 & 150 & 132 & 121 & 25 & 149 & 132 & 120 \\
\hline \multirow{4}{*}{9} & & 15 & 20 & 25 & & 15 & 20 & 25 & & 15 & 20 & 25 \\
\hline & 15 & 139 & 123 & 113 & 15 & 140 & 124 & 113 & 15 & 138 & 122 & 111 \\
\hline & 20 & 139 & 123 & 112 & 20 & 140 & 124 & 113 & 20 & 139 & 123 & 112 \\
\hline & 25 & 139 & 123 & 112 & 25 & 141 & 125 & 114 & 25 & 140 & 124 & 113 \\
\hline \multirow{4}{*}{10} & $\mathrm{~B}_{\mathrm{w}}$ & 15 & 20 & 25 & & 15 & 20 & 25 & & 15 & 20 & 25 \\
\hline & 15 & 132 & 117 & 107 & 15 & 133 & 118 & 108 & 15 & 131 & 116 & 106 \\
\hline & 20 & 132 & 117 & 107 & 20 & 134 & 118 & 108 & 20 & 132 & 117 & 106 \\
\hline & 25 & 132 & 117 & 107 & 25 & 134 & 119 & 108 & 25 & 133 & 118 & 107 \\
\hline \multirow{4}{*}{11} & $B_{w}$ & 15 & 20 & 25 & & 15 & 20 & 25 & & 15 & 20 & 25 \\
\hline & 15 & 127 & 112 & 103 & 15 & 128 & 113 & 104 & 15 & 126 & 111 & 102 \\
\hline & 20 & 126 & 112 & 102 & 20 & 128 & 113 & 103 & 20 & 126 & 112 & 102 \\
\hline & 25 & 127 & 112 & 102 & 25 & 128 & 114 & 104 & 25 & 127 & 112 & 102 \\
\hline \multirow{4}{*}{12} & $\mathrm{~B}_{\mathrm{w}}$ & 15 & 20 & 25 & & 15 & 20 & 25 & & 15 & 20 & 25 \\
\hline & 15 & 122 & 108 & 99 & 15 & 123 & 109 & 100 & 15 & 121 & 107 & 98 \\
\hline & 20 & 121 & 108 & 99 & 20 & 123 & 109 & 99 & 20 & 121 & 107 & 98 \\
\hline & 25 & 121 & 108 & 98 & 25 & 123 & 109 & 99 & 25 & 122 & 108 & 98 \\
\hline \multirow{4}{*}{13} & $B_{w}$ & 15 & 20 & 25 & & 15 & 20 & 25 & & 15 & 20 & 25 \\
\hline & 15 & 117 & 104 & 96 & 15 & 118 & 105 & 96 & 15 & 116 & 103 & 95 \\
\hline & 20 & 117 & 104 & 95 & 20 & 118 & 105 & 96 & 20 & 117 & 103 & 94 \\
\hline & 25 & 117 & 104 & 95 & 25 & 118 & 105 & 96 & 25 & 117 & 104 & 94 \\
\hline \multirow{4}{*}{14} & $\mathrm{~B}_{\mathrm{w}}$ & 15 & 20 & 25 & & 15 & 20 & 25 & & 15 & 20 & 25 \\
\hline & 15 & 114 & 101 & 93 & 15 & 114 & 102 & 93 & 15 & 11 & 100 & 92 \\
\hline & 20 & 113 & 101 & 92 & 20 & 114 & 102 & 93 & 20 & 113 & 100 & 92 \\
\hline & 25 & 113 & 100 & 92 & 25 & 114 & 102 & 93 & 25 & 113 & 100 & 91 \\
\hline
\end{tabular}


TABELA 16 - Volumes de madeiras V para pontes com 2 faixas de tráfego $\left(\mathrm{B}_{\mathrm{w}}, \mathrm{t}\right.$ em $\mathrm{cm}, \mathrm{V} \mathrm{em} \mathrm{\textrm {m } ^ { 3 } )}$

\begin{tabular}{|c|c|c|c|c|c|c|c|c|c|c|c|c|}
\hline \multirow[b]{2}{*}{$\mathrm{n}$} & \multicolumn{12}{|c|}{ CLASSES DE RESISTENNCIA DAS MADEIRAS DO TABULEIRO } \\
\hline & \multicolumn{4}{|c|}{$\begin{array}{l}\text { CLASSE C } 30 \\
\text { (CONÍFERA) }\end{array}$} & \multicolumn{4}{|c|}{$\begin{array}{c}\text { CLASSE C } 30 \\
\text { (DICOTILEDÔNEA) }\end{array}$} & \multicolumn{4}{|c|}{$\begin{array}{c}\text { CLASSE C 40 } \\
\text { (DICOTILEDÔNEA) }\end{array}$} \\
\hline \multirow{4}{*}{7} & $B_{w}$ & 15 & 20 & 25 & $B_{u}$ & 15 & 20 & 25 & & 15 & 20 & 25 \\
\hline & 15 & - & - & - & 15 & - & - & - & 15 & - & - & - \\
\hline & 20 & 52 & 55 & 58 & 20 & 52 & 55 & 58 & 20 & 52 & 55 & 58 \\
\hline & 25 & 58 & 62 & 65 & 25 & 59 & 62 & 65 & 25 & 59 & 62 & 65 \\
\hline \multirow{4}{*}{8} & $B_{w}$ & 15 & 20 & 25 & & 15 & 20 & 25 & & 15 & 20 & 25 \\
\hline & 15 & - & - & - & 15 & - & - & - & 15 & - & - & - \\
\hline & 20 & 53 & 56 & 60 & 20 & 53 & 57 & 60 & 20 & 53 & 56 & 60 \\
\hline & 25 & 60 & 63 & 66 & 25 & 60 & 63 & 66 & 25 & 60 & 63 & 66 \\
\hline \multirow{4}{*}{9} & $B_{w}$ & 15 & 20 & 25 & $t$ & 15 & 20 & 25 & & 15 & 20 & 25 \\
\hline & 15 & 48 & 52 & 56 & 15 & 48 & 52 & 56 & 15 & 47 & 51 & 55 \\
\hline & 20 & 54 & 58 & 61 & 20 & 54 & 58 & 61 & 20 & 54 & 58 & 61 \\
\hline & 25 & 61 & 64 & 67 & 25 & 61 & 65 & 68 & 25 & 61 & 64 & 67 \\
\hline \multirow{4}{*}{10} & $B_{w}$ & 15 & 20 & 25 & & 15 & 20 & 25 & & 15 & 20 & 25 \\
\hline & 15 & 49 & 53 & 57 & 15 & 49 & 53 & 57 & 15 & 49 & 53 & 57 \\
\hline & 20 & 55 & 59 & 63 & 20 & 56 & 59 & 63 & 20 & 55 & 59 & 62 \\
\hline & 25 & 62 & 65 & 68 & 25 & 62 & 66 & 69 & 25 & 62 & 65 & 68 \\
\hline \multirow{4}{*}{11} & $\mathrm{~B}_{\mathrm{w}}$ & 15 & 20 & 25 & $B_{u}$ & 15 & 20 & 25 & & 15 & 20 & 25 \\
\hline & 15 & 50 & 55 & 59 & 15 & 50 & 55 & 59 & 15 & 50 & 54 & 58 \\
\hline & 20 & 56 & 60 & 64 & 20 & 57 & 61 & 64 & 20 & 56 & 60 & 64 \\
\hline & 25 & 63 & 66 & 69 & 25 & 63 & 67 & 70 & 25 & 63 & 66 & 69 \\
\hline \multirow{4}{*}{12} & $B_{w}$ & 15 & 20 & 25 & & 15 & 20 & 25 & & 15 & 20 & 25 \\
\hline & 15 & 51 & 56 & 60 & 15 & 52 & 56 & 61 & 15 & 51 & 56 & 60 \\
\hline & 20 & 57 & 62 & 66 & 20 & 58 & 62 & 66 & 20 & 57 & 61 & 65 \\
\hline & 25 & 63 & 67 & 70 & 25 & 64 & 68 & 71 & 25 & 64 & 67 & 70 \\
\hline \multirow{4}{*}{13} & $B_{w}$ & 15 & 20 & 25 & $\mathrm{t}$ & 15 & 20 & 25 & & 15 & 20 & 25 \\
\hline & 15 & 52 & 57 & 62 & 15 & 53 & 58 & 62 & 15 & 52 & 57 & 62 \\
\hline & 20 & 58 & 63 & 67 & 20 & 59 & 63 & 67 & 20 & 58 & 62 & 66 \\
\hline & 25 & 64 & 68 & 72 & 25 & 65 & 69 & 72 & 25 & 64 & 68 & 71 \\
\hline \multirow{4}{*}{14} & $B_{w}$ & 15 & 20 & 25 & $B_{n}$ & 15 & 20 & 25 & & 15 & 20 & 25 \\
\hline & 15 & 54 & 59 & 63 & 15 & 54 & 59 & 63 & 15 & 53 & 58 & 63 \\
\hline & 20 & 59 & 64 & 68 & 20 & 60 & 64 & 68 & 20 & 59 & 64 & 68 \\
\hline & 25 & 65 & 69 & 73 & 25 & 66 & 70 & 73 & 25 & 65 & 69 & 72 \\
\hline
\end{tabular}



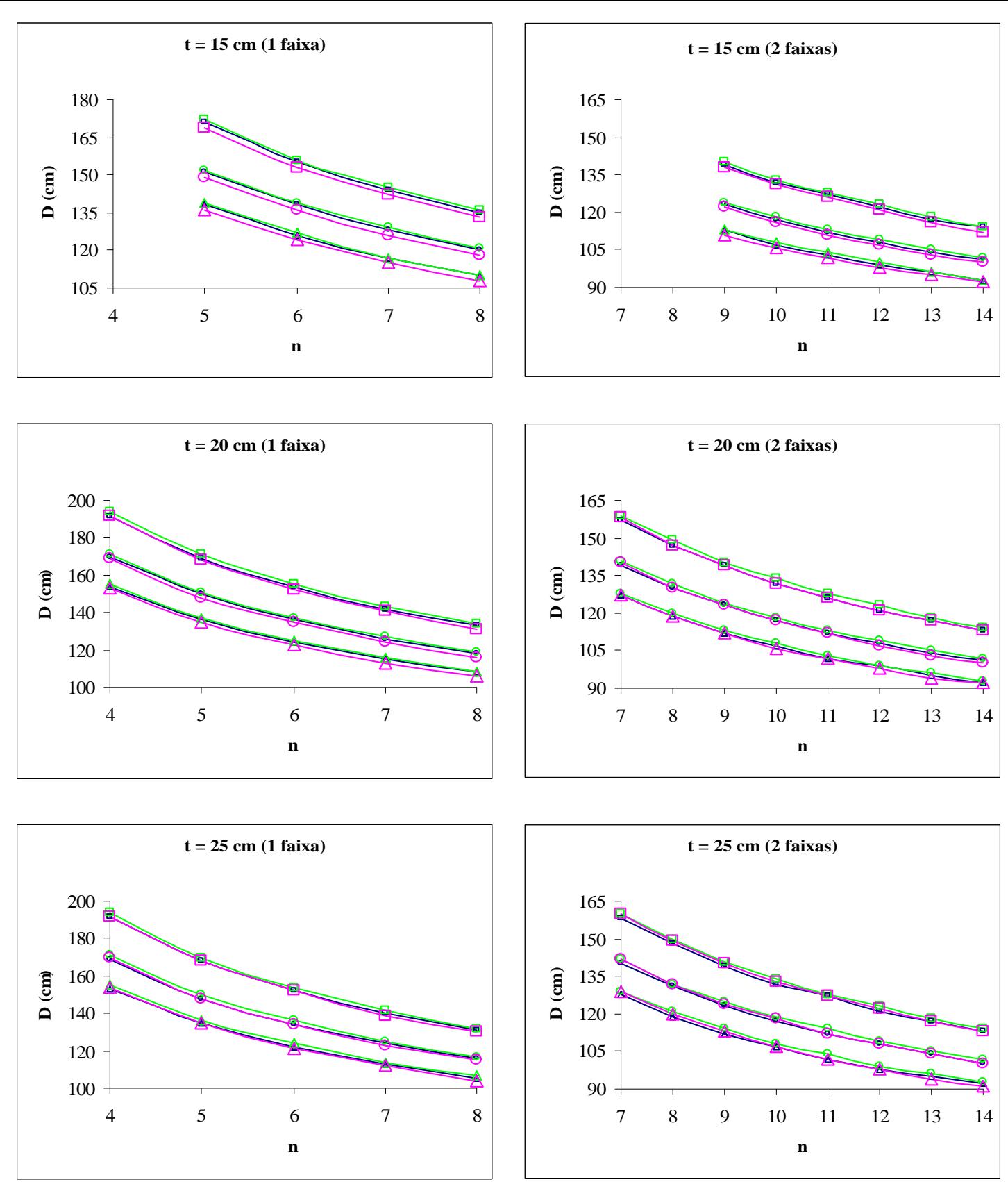

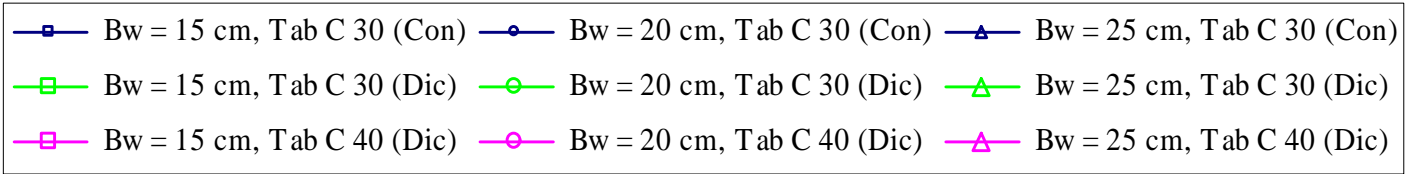

FIGURA 46 - Gráficos D x n para pontes com 1 e 2 faixas de tráfego 

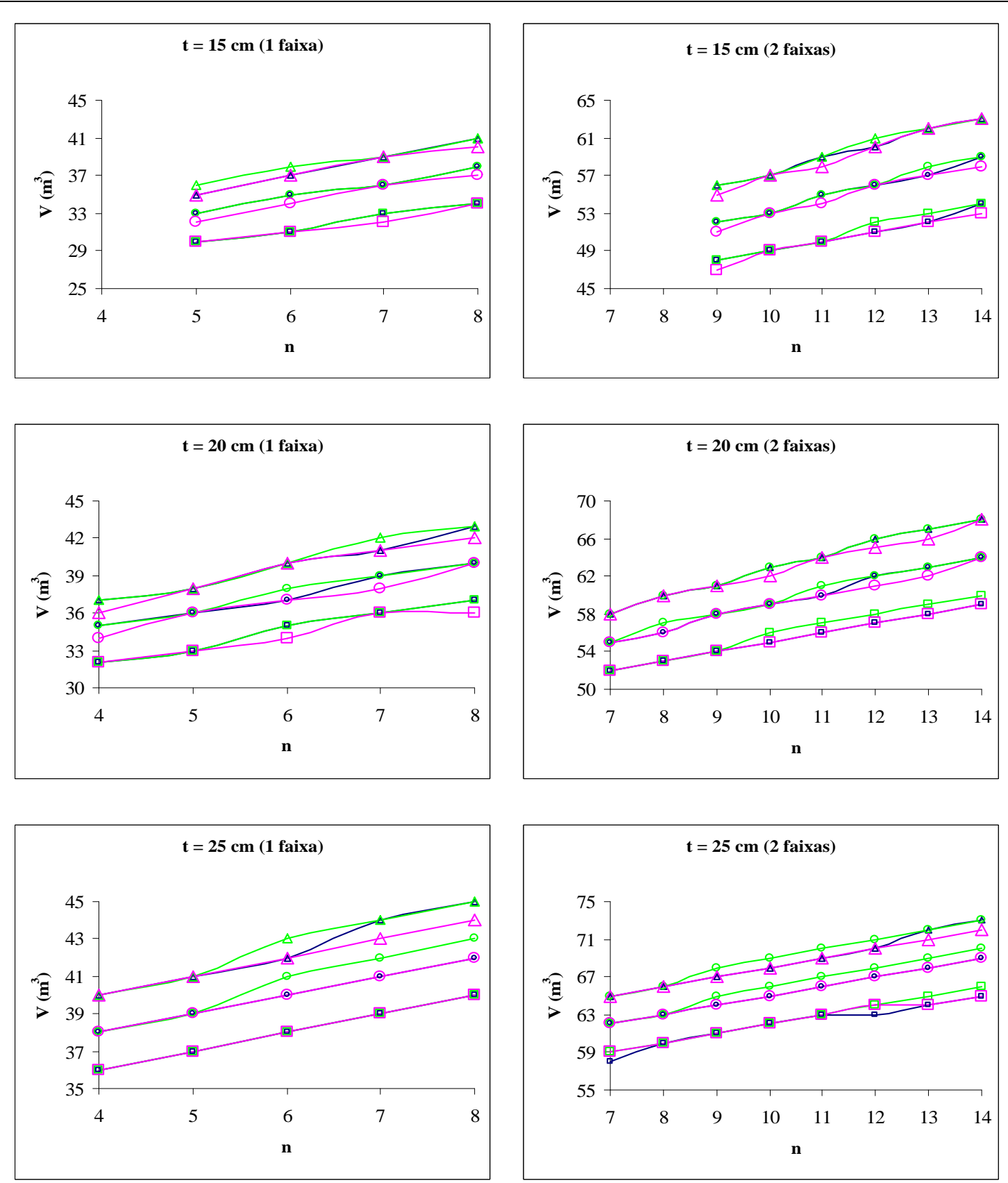

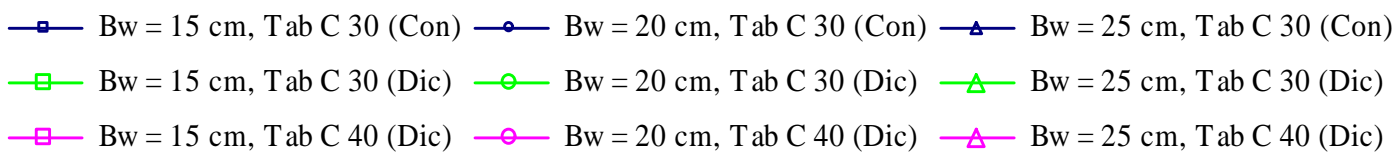

FIGURA 47 - Gráficos V x n para pontes com 1 e 2 faixas de tráfego 
3.3.4- Influência da espécie de madeira das nervuras na altura D

Com o objetivo de se verificar a influência da espécie de madeira das nervuras na altura $\mathrm{D}$, estas alturas foram calculadas para pontes com as mesmas características (largura, largura das nervuras, altura do tabuleiro, número de nervuras e madeira Classe C 30 - Conífera para o tabuleiro), e então comparadas entre si, mudando-se apenas a madeira das nervuras (Classe C 30 - Conífera e Classe C 30 Dicotiledônea).

Com os resultados obtidos, foram montadas as tabelas 17 e 18, que apresentam, respectivamente, as alturas das nervuras e os volume totais de madeiras para a ponte com 1 faixa de tráfego. Os resultados referentes às pontes com 2 faixas de tráfego são apresentados nas tabelas 19 e 20.

Estes resultados também podem ser visualizados nas figuras 48 a 49 . 
TABELA 17 - Alturas das nervuras D para pontes com 1 faixa de tráfego $\left(B_{w}, t, D\right.$ em cm)

\begin{tabular}{|c|c|c|c|c|c|c|c|c|}
\hline \multirow{2}{*}{$\mathrm{n}$} & \multicolumn{8}{|c|}{ CLASSES DE RESISTÊNCIA DAS MADEIRAS DAS NERVURAS } \\
\hline & \multicolumn{4}{|c|}{ CLASSE C 30 (CONÍFERA) } & \multicolumn{4}{|c|}{ CLASSE C 30 (DICOTILEDÔNEA) } \\
\hline \multirow{4}{*}{4} & $\mathrm{t}$ & 15 & 20 & 25 & $\mathrm{t}$ & 15 & 20 & 25 \\
\hline & 15 & - & - & - & 15 & - & - & - \\
\hline & 20 & 192 & 170 & 154 & 20 & 194 & 171 & 156 \\
\hline & 25 & 192 & 169 & 153 & 25 & 193 & 170 & 155 \\
\hline \multirow{4}{*}{5} & $\mathrm{t}$ & 15 & 20 & 25 & $\mathrm{t}$ & 15 & 20 & 25 \\
\hline & 15 & 171 & 151 & 138 & 15 & 172 & 153 & 140 \\
\hline & 20 & 169 & 150 & 136 & 20 & 171 & 151 & 138 \\
\hline & 25 & 168 & 148 & 135 & 25 & 170 & 150 & 136 \\
\hline \multirow{4}{*}{6} & $\mathrm{t}$ & 15 & 20 & 25 & $t$ & 15 & 20 & 25 \\
\hline & 15 & 155 & 138 & 126 & 15 & 157 & 139 & 127 \\
\hline & 20 & 154 & 136 & 124 & 20 & 155 & 138 & 126 \\
\hline & 25 & 152 & 134 & 122 & 25 & 154 & 136 & 124 \\
\hline \multirow{4}{*}{7} & $\mathrm{t}$ & 15 & 20 & 25 & $\mathrm{t}$ & 15 & 20 & 25 \\
\hline & 15 & 144 & 128 & 117 & 15 & 145 & 129 & 118 \\
\hline & 20 & 142 & 126 & 115 & 20 & 143 & 127 & 116 \\
\hline & 25 & 140 & 124 & 113 & 25 & 142 & 126 & 115 \\
\hline \multirow{4}{*}{8} & $\mathrm{t}$ & 15 & 20 & 25 & $\mathrm{t}$ & 15 & 20 & 25 \\
\hline & 15 & 135 & 120 & 110 & 15 & 136 & 122 & 111 \\
\hline & 20 & 133 & 118 & 108 & 20 & 134 & 119 & 109 \\
\hline & 25 & 131 & 116 & 105 & 25 & 132 & 117 & 107 \\
\hline
\end{tabular}


TABELA 18 - Volumes de madeiras V para pontes com 1 faixa de tráfego $\left(B_{w}, t e m ~ c m, V ~ e m ~ m^{3}\right)$

\begin{tabular}{|c|c|c|c|c|c|c|c|c|}
\hline \multirow{2}{*}{$\mathrm{n}$} & \multicolumn{8}{|c|}{ CLASSES DE RESISTÊNCIA DAS MADEIRAS DAS NERVURAS } \\
\hline & \multicolumn{4}{|c|}{ CLASSE C 30 (CONÍFERA) } & \multicolumn{4}{|c|}{ CLASSE C 30 (DICOTILEDÔNEA) } \\
\hline \multirow{4}{*}{4} & $\mathrm{t}$ & 15 & 20 & 25 & & 15 & 20 & 25 \\
\hline & 15 & - & - & - & 15 & - & - & - \\
\hline & 20 & 32 & 35 & 37 & 20 & 32 & 35 & 37 \\
\hline & 25 & 36 & 38 & 40 & 25 & 36 & 38 & 40 \\
\hline \multirow{4}{*}{5} & $\mathrm{t}$ & 15 & 20 & 25 & $\mathrm{t}$ & 15 & 20 & 25 \\
\hline & 15 & 30 & 33 & 35 & 15 & 30 & 33 & 36 \\
\hline & 20 & 33 & 36 & 38 & 20 & 33 & 36 & 39 \\
\hline & 25 & 37 & 39 & 41 & 25 & 37 & 39 & 41 \\
\hline \multirow{4}{*}{6} & $\mathrm{t}$ & 15 & 20 & 25 & $\mathrm{t}$ & 15 & 20 & 25 \\
\hline & 15 & 31 & 35 & 37 & 15 & 32 & 35 & 38 \\
\hline & 20 & 35 & 37 & 40 & 20 & 35 & 38 & 40 \\
\hline & 25 & 38 & 40 & 42 & 25 & 38 & 41 & 43 \\
\hline \multirow{4}{*}{7} & $t$ & 15 & 20 & 25 & $\mathrm{t}$ & 15 & 20 & 25 \\
\hline & 15 & 33 & 36 & 39 & 15 & 33 & 36 & 39 \\
\hline & 20 & 36 & 39 & 41 & 20 & 36 & 39 & 42 \\
\hline & 25 & 39 & 41 & 44 & 25 & 39 & 42 & 44 \\
\hline \multirow{4}{*}{8} & $\mathrm{t}$ & 15 & 20 & 25 & & 15 & 20 & 25 \\
\hline & 15 & 34 & 38 & 41 & 15 & 34 & 38 & 41 \\
\hline & 20 & 37 & 40 & 43 & 20 & 37 & 40 & 43 \\
\hline & 25 & 40 & 42 & 45 & 25 & 40 & 43 & 45 \\
\hline
\end{tabular}


TABELA 19 - Alturas das nervuras D para pontes com 2 faixas de tráfego $\left(B_{w}, t, D\right.$ em cm)

\begin{tabular}{|c|c|c|c|c|c|c|c|c|}
\hline \multirow{2}{*}{$\mathrm{n}$} & \multicolumn{8}{|c|}{ CLASSES DE RESISTENNCIA DAS MADEIRAS DAS NERVURAS } \\
\hline & \multicolumn{4}{|c|}{ CLASSE C 30 (CONÍFERA) } & \multicolumn{4}{|c|}{ CLASSE C 30 (DICOTILEDÔNEA) } \\
\hline \multirow{4}{*}{7} & $\mathrm{t}$ & 15 & 20 & 25 & $\mathrm{t}$ & 15 & 20 & 25 \\
\hline & 15 & - & - & - & 15 & - & - & - \\
\hline & 20 & 157 & 139 & 127 & 20 & 159 & 140 & 128 \\
\hline & 25 & 158 & 140 & 128 & 25 & 159 & 141 & 129 \\
\hline \multirow{4}{*}{8} & $\mathrm{t}$ & 15 & 20 & 25 & $\mathrm{t}$ & 15 & 20 & 25 \\
\hline & 15 & - & - & - & 15 & - & - & - \\
\hline & 20 & 147 & 130 & 119 & 20 & 149 & 132 & 120 \\
\hline & 25 & 148 & 131 & 119 & 25 & 149 & 132 & 121 \\
\hline \multirow{4}{*}{9} & $\mathrm{t}$ & 15 & 20 & 25 & $\mathrm{t}$ & 15 & 20 & 25 \\
\hline & 15 & 139 & 123 & 113 & 15 & 140 & 125 & 114 \\
\hline & 20 & 139 & 123 & 112 & 20 & 140 & 125 & 114 \\
\hline & 25 & 139 & 123 & 112 & 25 & 141 & 125 & 114 \\
\hline \multirow{4}{*}{10} & $\mathrm{t}$ & 15 & 20 & 25 & $\mathrm{t}$ & 15 & 20 & 25 \\
\hline & 15 & 132 & 117 & 107 & 15 & 134 & 119 & 109 \\
\hline & 20 & 132 & 117 & 107 & 20 & 134 & 119 & 109 \\
\hline & 25 & 132 & 117 & 107 & 25 & 134 & 119 & 108 \\
\hline \multirow{4}{*}{11} & $\mathrm{t}$ & 15 & 20 & 25 & $\mathrm{t}$ & 15 & 20 & 25 \\
\hline & 15 & 127 & 112 & 103 & 15 & 128 & 114 & 104 \\
\hline & 20 & 126 & 112 & 102 & 20 & 128 & 114 & 104 \\
\hline & 25 & 127 & 112 & 102 & 25 & 128 & 114 & 104 \\
\hline \multirow{4}{*}{12} & $\mathrm{t}$ & 15 & 20 & 25 & $\mathrm{t}$ & 15 & 20 & 25 \\
\hline & 15 & 122 & 108 & 99 & 15 & 123 & 110 & 101 \\
\hline & 20 & 121 & 108 & 99 & 20 & 123 & 109 & 100 \\
\hline & 25 & 121 & 108 & 98 & 25 & 123 & 109 & 100 \\
\hline \multirow{4}{*}{13} & $\mathrm{t}$ & 15 & 20 & 25 & $\mathrm{t}$ & 15 & 20 & 25 \\
\hline & 15 & 117 & 104 & 96 & 15 & 119 & 106 & 97 \\
\hline & 20 & 117 & 104 & 95 & 20 & 118 & 106 & 97 \\
\hline & 25 & 117 & 104 & 95 & 25 & 118 & 105 & 96 \\
\hline \multirow{4}{*}{14} & & 15 & 20 & 25 & $\mathrm{t}$ & 15 & 20 & 25 \\
\hline & 15 & 114 & 101 & 93 & 15 & 115 & 103 & 94 \\
\hline & 20 & 113 & 101 & 92 & 20 & 115 & 102 & 94 \\
\hline & 25 & 113 & 100 & 92 & 25 & 114 & 102 & 93 \\
\hline
\end{tabular}


TABELA 20 - Volume de madeira $\mathrm{V}$ para pontes com 2 faixas de tráfego $\left(B_{\mathrm{w}}, \mathrm{t}\right.$ em $\mathrm{cm}, \mathrm{V}$ em m$\left.{ }^{3}\right)$

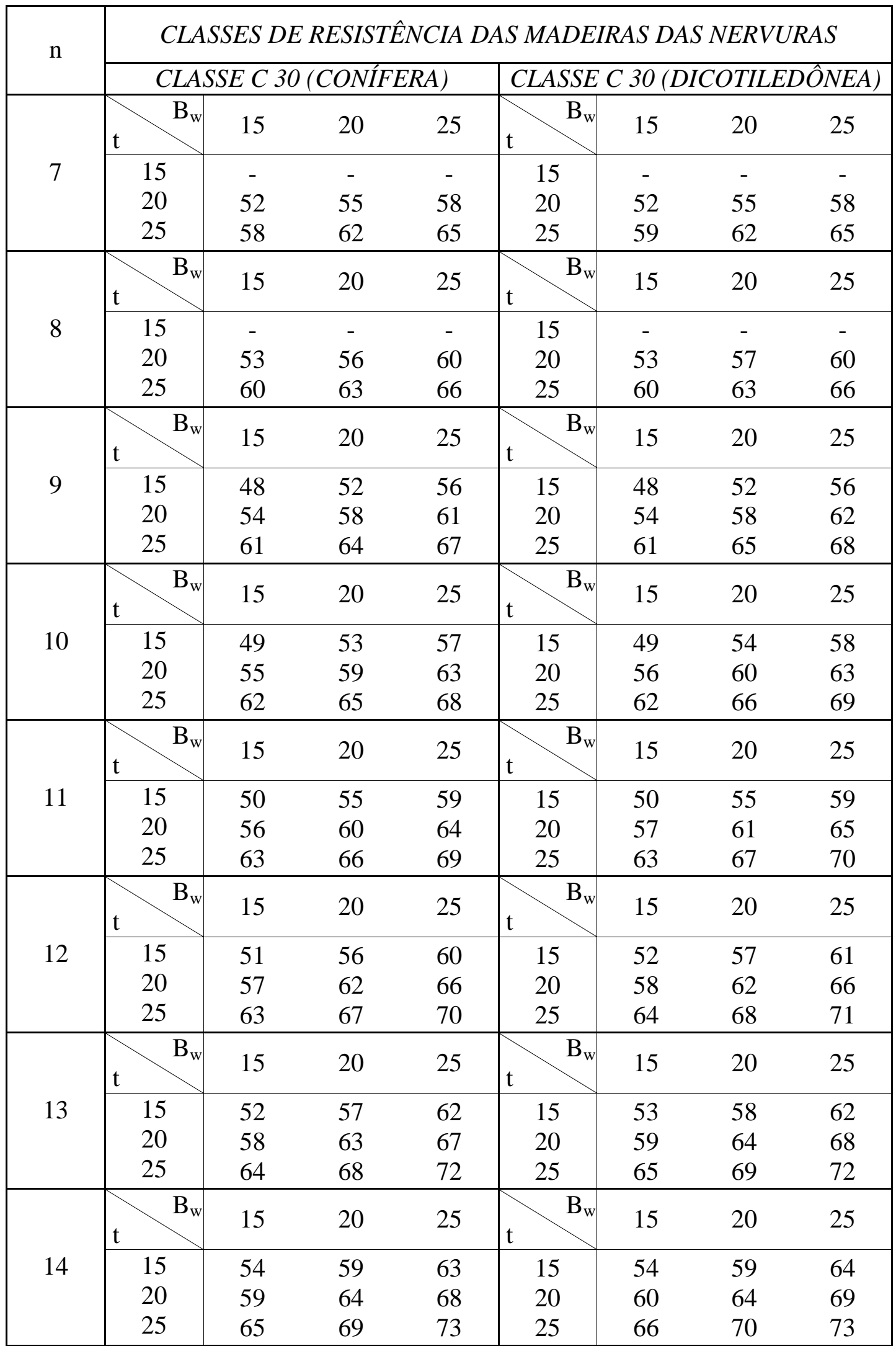



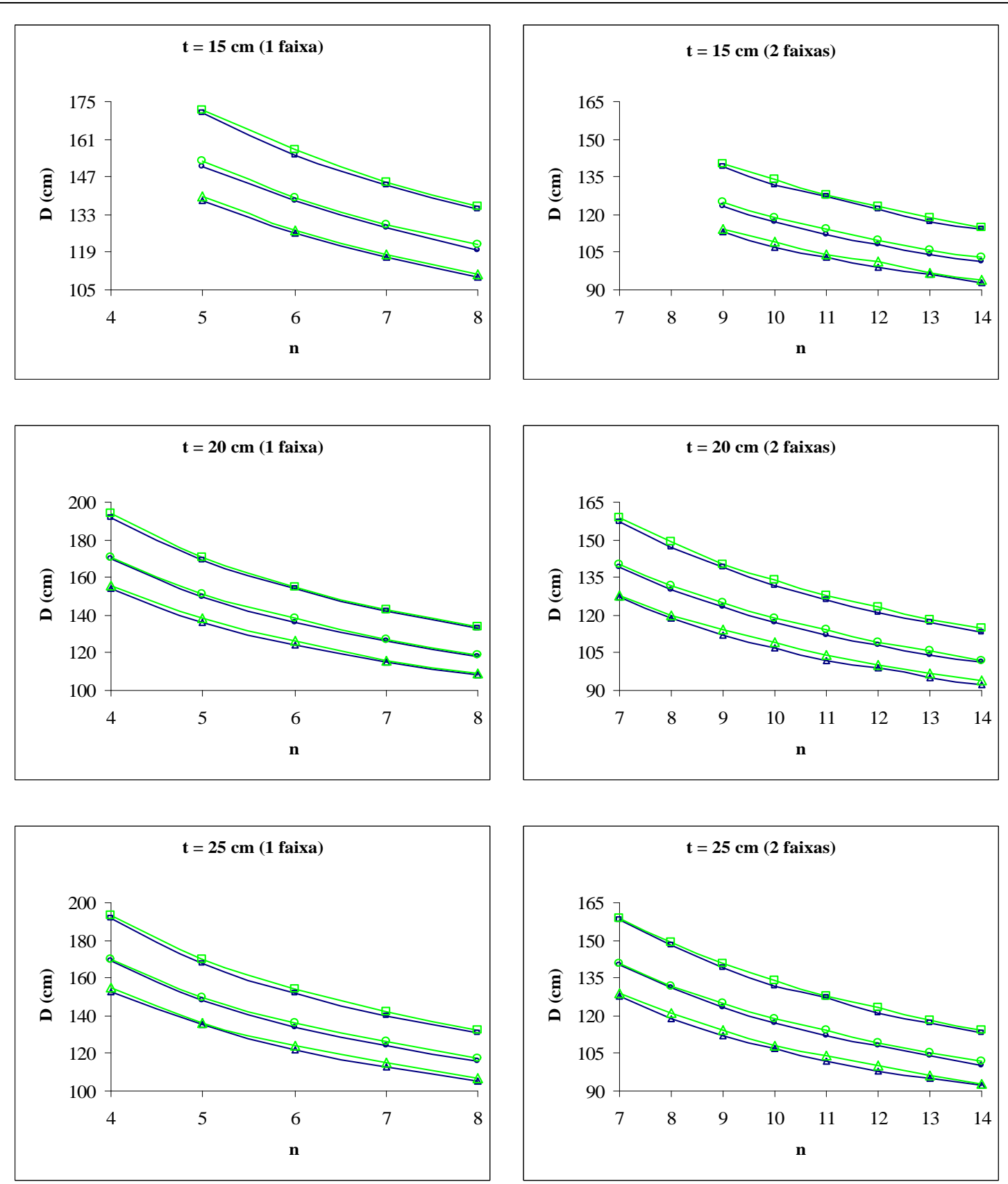

$\longrightarrow \mathrm{Bw}=15 \mathrm{~cm}$, Tab C $30(\mathrm{Con}) \multimap \mathrm{Bw}=20 \mathrm{~cm}$, Tab C $30(\mathrm{Con}) \multimap \mathrm{Bw}=25 \mathrm{~cm}, \mathrm{Tab} \mathrm{C} 30(\mathrm{Con})$
$\square \mathrm{Bw}=15 \mathrm{~cm}$, Tab C $30(\mathrm{Dic})-\mathrm{Bw}=15 \mathrm{~cm}$, Tab C $30(\mathrm{Dic})-\triangle \mathrm{Bw}=15 \mathrm{~cm}, \mathrm{Tab} C 30(\mathrm{Dic})$

FIGURA 48 - Gráficos D x n para pontes com 1 e 2 faixas de tráfego 

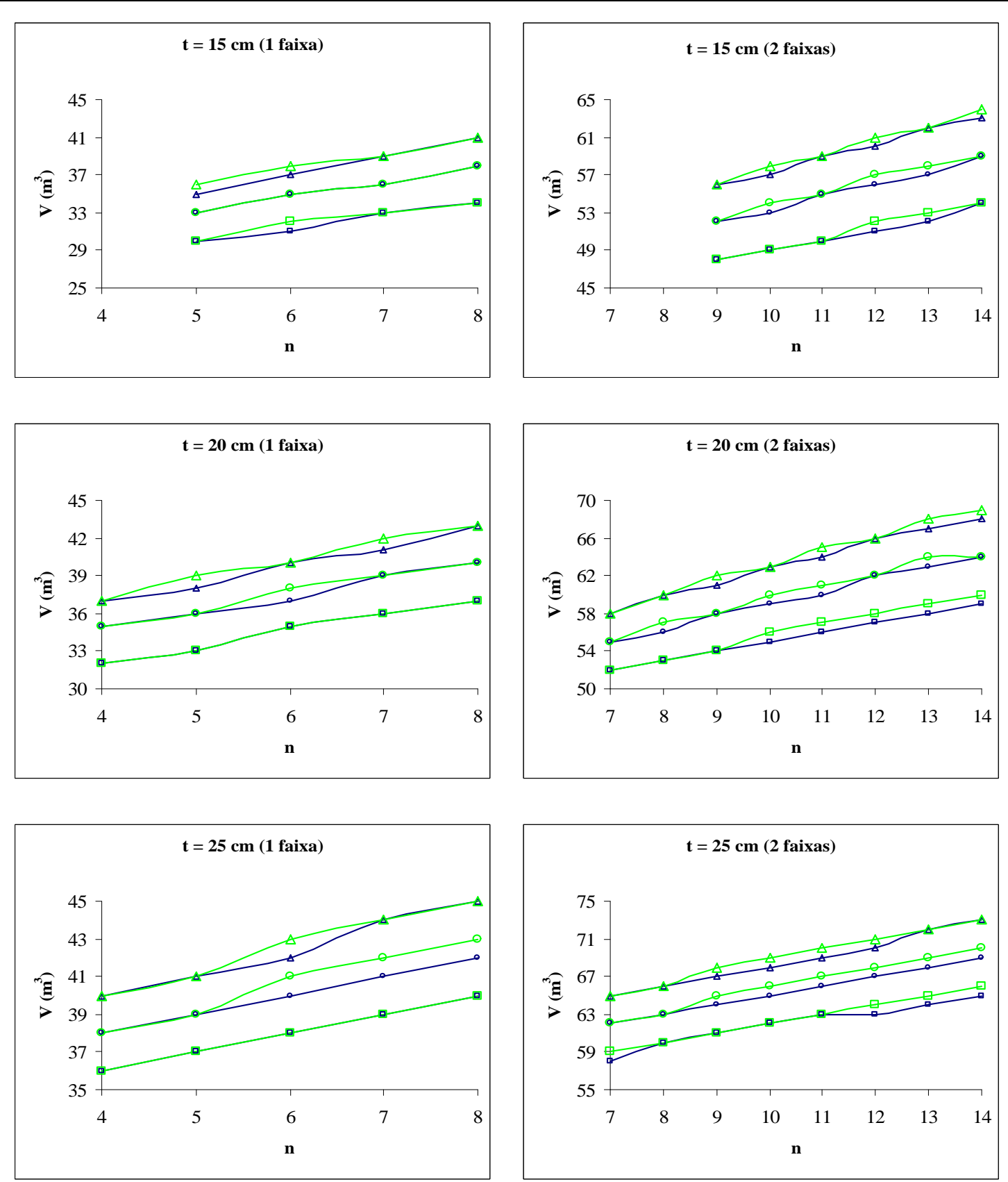

$\rightarrow \mathrm{Bw}=15 \mathrm{~cm}, \mathrm{Tab} \mathrm{C} 30(\mathrm{Con}) \multimap \mathrm{Bw}=20 \mathrm{~cm}, \mathrm{Tab} \mathrm{C} 30(\mathrm{Con}) \multimap \mathrm{Bw}=25 \mathrm{~cm}, \mathrm{Tab} \mathrm{C} 30(\mathrm{Con})$ $\square \mathrm{Bw}=15 \mathrm{~cm}, \mathrm{Tab} \mathrm{C} 30$ (Dic) $\multimap \mathrm{Bw}=15 \mathrm{~cm}, \mathrm{Tab}$ C 30 (Dic) $\triangle \mathrm{Bw}=15 \mathrm{~cm}, \mathrm{Tab} \mathrm{C} 30$ (Dic)

FIGURA 49 - Gráficos V x n para pontes com 1 e 2 faixas de tráfego 


\section{4-Discussões sobre a análise numérica}

No processo de dimensionamento das nervuras, o fator limitante foi o estado limite último de tração nas fibras inferiores das nervuras, para todas as situações analisadas. O critério estipulado pela NBR 7190/97, para o estado limite de utilização, conduz a resultados distintos dos que eram obtidos anteriormente à implantação desta norma, quando se observava que o fator limitante era o deslocamento vertical da estrutura. Deste modo, podem-se esperar reduções significativas na altura das nervuras ao se utilizar resistências de cálculo à tração superiores às empregadas neste trabalho, por meio de critérios de dimensionamento que permitam considerar a maior resistência à tração da madeira.

No processo de avaliação da influência dos fatores geométricos, observa-se que a variação da altura do tabuleiro de 15 a $25 \mathrm{~cm}$ conduz a reduções de, no máximo, 3\% para a altura das nervuras, e que a variação da largura das nervuras de 15 a $25 \mathrm{~cm}$ conduz a reduções de, no máximo, $12 \%$ para a altura das mesmas.

Em relação à influência da madeira do tabuleiro (conífera C 30 ou dicotiledônea C 30 ou C 40) na altura das nervuras, observa-se uma ligeira vantagem para as coníferas quando são comparadas espécies de madeira com a mesma resistência à compressão paralela às fibras e o mesmo módulo de elasticidade na direção longitudinal (Classe C 30). Isto ocorre porque a distribuição lateral das cargas é mais favorável (menor $\mathrm{W}_{\mathrm{f}}$ ) devido ao efeito da protensão na rigidez à flexão transversal ser mais eficiente para madeiras de menor densidade. Deste modo, ocorre uma diminuição de, no máximo, $2 \%$ para a altura das nervuras. A utilização de espécies de madeira com maior módulo de elasticidade na direção longitudinal (Classe C 40) conduz a uma diminuição de, no máximo, 3\% para a altura das nervuras.

Dentro das premissas estabelecidas neste trabalho, os gráficos apresentados na figura 51 possibilitam visualizar, com boa aproximação, as dimensões necessárias para as nervuras, variando-se a sua quantidade e o vão da ponte. Estes gráficos foram elaborados fixando-se a altura do tabuleiro $(\mathrm{t}=20 \mathrm{~cm})$ e a classe de resistência da madeira (Classe C 30 - Conífera). 


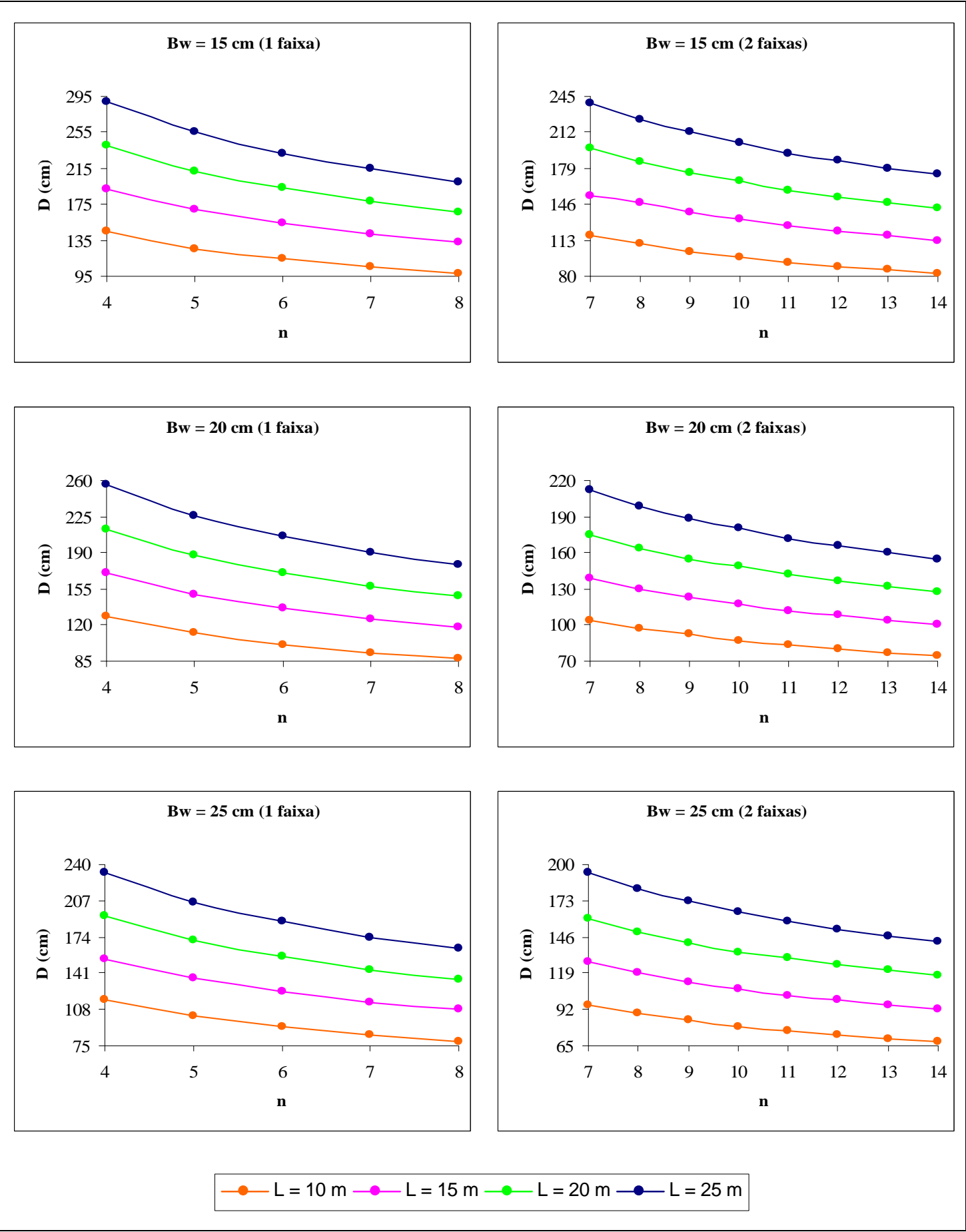

FIGURA 50 - Dimensões das nervuras para pontes com 1 e 2 faixas de tráfego

As alturas mínimas do tabuleiro, para espaçamento entre nervuras variando de 70 até $200 \mathrm{~cm}$, podem ser visualizadas na figura 51 para as três classes de resistência das madeiras analisadas. Estas alturas foram determinadas em função do deslocamento vertical da porção do tabuleiro entre duas nervuras adjacentes, sob a ação da carga de uma roda na posição mais desfavorável $(0,5 \mathrm{~cm})$. 


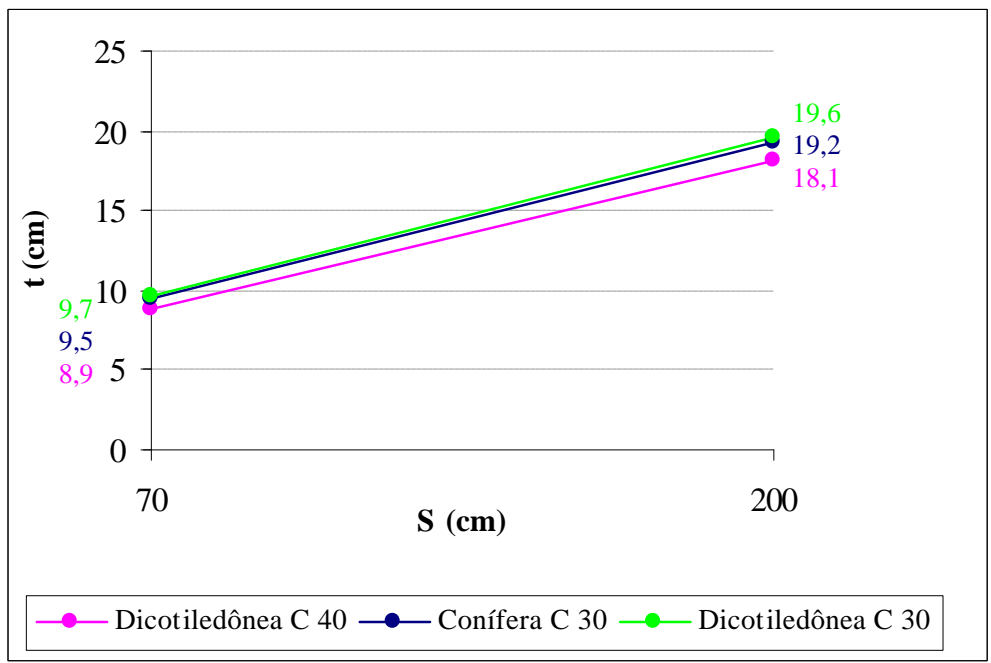

FIGURA 51 - Altura do tabuleiro em função do espaçamento entre nervuras

Finalizando, deve ser considerado que as estruturas mais eficientes, em termos de consumo de madeira, são aquelas que apresentam nervuras com maior altura. Entretanto, devido ao custo de fabricação da madeira laminada colada ser muito superior ao da madeira serrada utilizada no tabuleiro, a definição da geometria mais eficiente depende da análise de custos e da possível limitação na altura das vigas laminadas.

\section{5- Exemplo do método de cálculo}

No apêndice 1 está apresentado um exemplo do procedimento de cálculo, programado em MATHCAD@, para uma ponte com $2 \mathrm{~m}$ de vão e 1,1 m de largura (1 faixa de tráfego). 


\section{4- EXPERIMENTAÇÃO DO MODELO REDUZIDO}

Neste capítulo está descrito o ensaio estático de um modelo reduzido de ponte formada por vigas-T. Estes ensaios foram realizados com o objetivo de se avaliar o modelo teórico utilizado no dimensionamento destas pontes, principalmente quanto à comparação entre as rigidezes à flexão longitudinal experimental e teórica da seção transversal e ao fator de distribuição da carga $\left(\mathrm{W}_{\mathrm{f}}\right)$.

\section{1- Características do modelo reduzido}

A estrutura avaliada é uma ponte classe 30 com comprimento L igual a $10 \mathrm{~m}$, uma faixa de tráfego com largura b igual a 5,5 m e madeira classe C 30 (conífera) para as nervuras e o tabuleiro. O dimensionamento utilizando o procedimento de cálculo baseado no método WVU conduziu a uma ponte formada por 6 nervuras com largura $B_{w}$ igual a $25 \mathrm{~cm}$, altura $D$ igual a $100 \mathrm{~cm}$ e espaçamento entre os eixos igual a $105 \mathrm{~cm}$, e tabuleiro com 80 lâminas de espessura igual a $5 \mathrm{~cm}$ e altura t igual a 25 $\mathrm{cm}$.

A análise experimental desta ponte foi efetuada por meio de um modelo reduzido na escala 1:5, cujas dimensões estão apresentadas na figura 52.

Este modelo foi construído utilizando a espécie Pinus Hondurensis (Pinus caribaea var. hondurensis) para as nervuras e a espécie Pinus Taeda (Pinus taeda) para as lâminas do tabuleiro. 


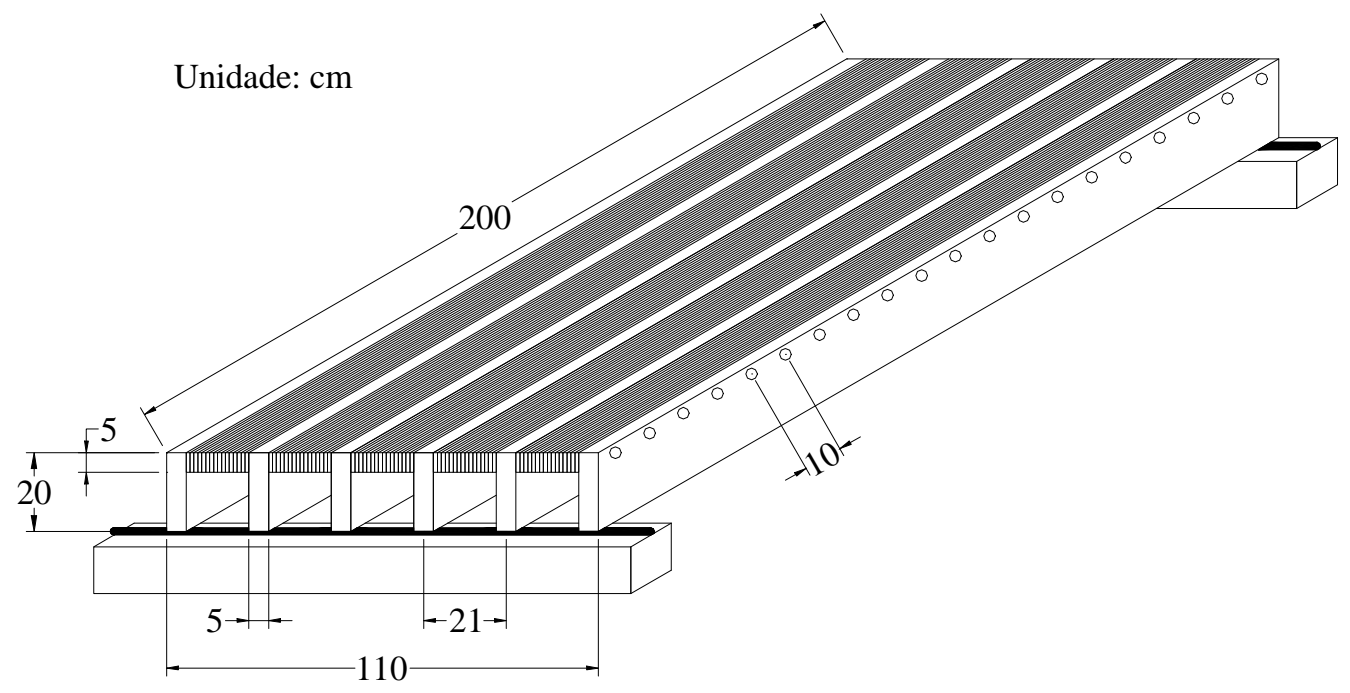

FIGURA 52 - Dimensões do modelo reduzido

4.1.1- Caracterização das nervuras

O módulo de elasticidade de cada nervura, cujas dimensões nominais são $5 \times 20 \times 200 \mathrm{~cm}$, foi determinado experimentalmente por meio de ensaio à flexão. Este ensaio foi realizado aplicando-se uma força concentrada no meio do vão, conforme mostrado na figura 53.

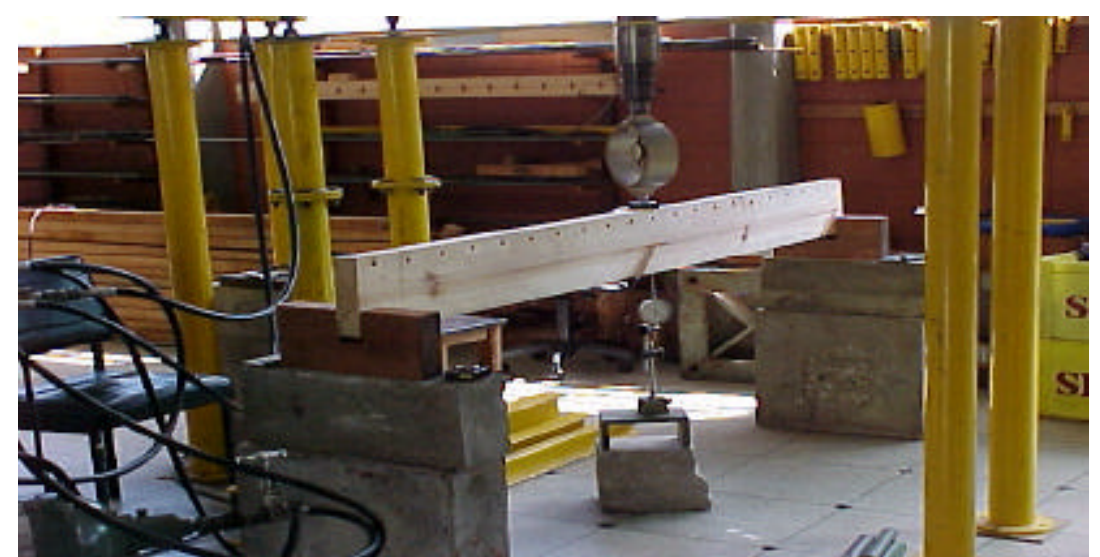

FIGURA 53 - Ensaio de caracterização das nervuras

O deslocamento vertical no meio do vão da peça $\delta_{\mathrm{cN}}$ foi medido a cada incremento de $0,916 \mathrm{kN}$ na força aplicada $\mathrm{P}_{\mathrm{cN}}(10$ leituras de 0 até $8,244 \mathrm{kN})$, por meio de relógio comparador marca MITUTOYO (resolução de 0,01 mm e curso de 
$50 \mathrm{~mm}$ ). Os ensaios foram realizados com uma repetição para cada nervura, e o módulo de elasticidade da mesma $\mathrm{E}_{\mathrm{L}, \mathrm{n}}$ foi calculado pela equação 66 , substituindo-se o coeficiente angular $\mathrm{k}$ na equação 67 :

$$
\mathrm{E}_{\mathrm{L}, \mathrm{n}}=\frac{\mathrm{k} \cdot \mathrm{L}^{3}}{48 \cdot \mathrm{I}}
$$

sendo:

$$
\begin{aligned}
& \mathrm{E}_{\mathrm{L}, \mathrm{n}}=\frac{\mathrm{P} \cdot \mathrm{L}^{3}}{48 \cdot \delta \cdot \mathrm{I}} \\
& \mathrm{k}=\frac{\mathrm{P}}{\delta}
\end{aligned}
$$

$\mathrm{O}$ coeficiente $\mathrm{k}$ foi obtido a partir da regressão linear do conjunto de pontos $\left(\mathrm{P}_{\mathrm{cN}}, \delta_{\mathrm{cN}}\right)$.

onde:

$\mathrm{I}$ = momento de inércia da nervura

$\mathrm{L}=$ vão da nervura $(200 \mathrm{~cm})$

$\mathrm{P}=$ força concentrada aplicada no meio do vão da nervura

$\delta=$ deslocamento vertical no meio do vão da nervura

Os valores iniciais não foram considerados na regressão linear para evitar as interferências dos baixos valores de força.

Os valores de $\mathrm{E}_{\mathrm{L}, \mathrm{n}}$ estão apresentados na tabela 21 .

TABELA 21 - Módulos de elasticidade na direção longitudinal $\mathrm{E}_{\mathrm{L}, \mathrm{n}}$ das nervuras

\begin{tabular}{|c|c|}
\hline Nervura & $\mathrm{E}_{\mathrm{L}, \mathrm{n}}(\mathrm{MPa})$ \\
\hline $\mathrm{A}$ & 6523 \\
\hline $\mathrm{B}$ & 7744 \\
\hline $\mathrm{C}$ & 5236 \\
\hline $\mathrm{D}$ & 7216 \\
\hline $\mathrm{E}$ & 6940 \\
\hline $\mathrm{F}$ & 5172 \\
\hline
\end{tabular}


4.1.2- Caracterização das lâminas do tabuleiro

O módulo de elasticidade de cada lâmina, cujas dimensões nominais são $1 \times 5 \times 200 \mathrm{~cm}$, foi determinado experimentalmente por meio de ensaio à flexão. Este ensaio foi realizado aplicando-se uma força concentrada no meio do vão, conforme mostrado na figura 54.

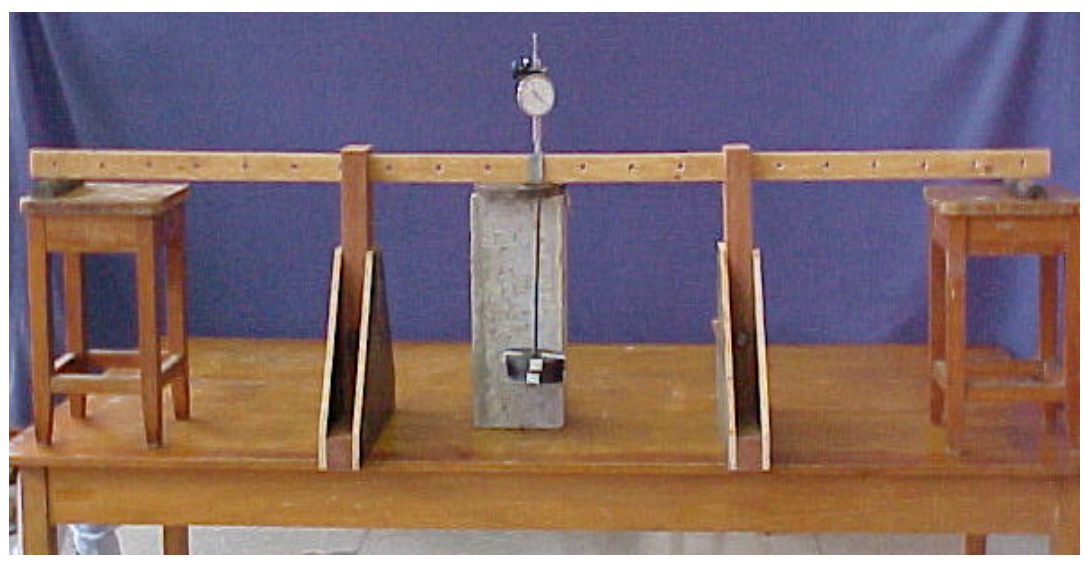

FIGURA 54 - Ensaio de caracterização das lâminas do tabuleiro

O deslocamento vertical no meio do vão da peça $\delta_{\mathrm{cT}}$ foi medido a cada incremento de $15 \mathrm{~N}$ na força aplicada $\mathrm{P}_{\text {ст }}$ (3 leituras de 5 até $35 \mathrm{~N}$ ), por meio de relógio comparador marca MITUTOYO ( resolução de $0,01 \mathrm{~mm}$ e curso de $50 \mathrm{~mm}$ ).

Os ensaios foram realizados com uma repetição para cada lâmina, e o módulo de elasticidade da mesma $\mathrm{E}_{\mathrm{L}, \mathrm{t}}$ foi calculado no intervalo 5 - $35 \mathrm{~N}$, substituindo-se $\mathrm{P}$ por $\Delta \mathrm{P}$ e $\delta$ por $\Delta \delta$ na equação abaixo:

$$
\mathrm{E}_{\mathrm{L}, \mathrm{t}}=\frac{\mathrm{P} \cdot \mathrm{L}^{3}}{48 \cdot \delta \cdot \mathrm{I}}
$$

onde:

$\mathrm{I}$ = momento de inércia da lâmina

$\mathrm{L}=$ vão da lâmina

$\mathrm{P}=$ força concentrada aplicada no meio do vão da lâmina

$\delta=$ deslocamento vertical no meio do vão da lâmina 
Os deslocamentos medidos para as forças iguais a $5 \mathrm{~N}, 20 \mathrm{~N}$ e $35 \mathrm{~N}$ permitiram verificar a linearidade entre a força aplicada e o deslocamento medido, no intervalo utilizado para o cálculo do módulo de elasticidade.

Os valores de $\mathrm{E}_{\mathrm{L}, \mathrm{t}}$ estão apresentados na tabela 22.

TABELA 22 - Módulos de elasticidade na direção longitudinal das lâminas do tabuleiro $\mathrm{E}_{\mathrm{L}, \mathrm{t}}$

\begin{tabular}{|c|c|c|c|c|c|c|c|}
\hline $\begin{array}{c}\mathrm{N}^{\circ} \mathrm{da} \\
\text { lâmina }\end{array}$ & $\begin{array}{c}\mathrm{E}_{\mathrm{L}, \mathrm{t}} \\
(\mathrm{MPa})\end{array}$ & $\begin{array}{c}\mathrm{N}^{\circ} \mathrm{da} \\
\text { lâmina }\end{array}$ & $\begin{array}{c}\mathrm{E}_{\mathrm{L}, \mathrm{t}} \\
(\mathrm{MPa})\end{array}$ & $\begin{array}{c}\mathrm{N}^{\circ} \mathrm{da} \\
\text { lâmina }\end{array}$ & $\begin{array}{c}\mathrm{E}_{\mathrm{L}, \mathrm{t}} \\
(\mathrm{MPa})\end{array}$ & $\begin{array}{c}\mathrm{N}^{\circ} \mathrm{da} \\
\text { lâmina }\end{array}$ & $\begin{array}{c}\mathrm{E}_{\mathrm{L}, \mathrm{t}} \\
(\mathrm{MPa})\end{array}$ \\
\hline 1 & 10123 & 21 & 9418 & 41 & 7611 & 61 & 7768 \\
\hline 2 & 7067 & 22 & 7370 & 42 & 9099 & 62 & 9746 \\
\hline 3 & 7778 & 23 & 11606 & 43 & 10318 & 63 & 9282 \\
\hline 4 & 5490 & 24 & 7656 & 44 & 8283 & 64 & 7048 \\
\hline 5 & 7890 & 25 & 8781 & 45 & 9974 & 65 & 9480 \\
\hline 6 & 8829 & 26 & 10154 & 46 & 8726 & 66 & 8238 \\
\hline 7 & 9795 & 27 & 7363 & 47 & 7661 & 67 & 8702 \\
\hline 8 & 7624 & 28 & 7506 & 48 & 9429 & 68 & 6424 \\
\hline 9 & 6168 & 29 & 8379 & 49 & 11866 & 69 & 10254 \\
\hline 10 & 9992 & 30 & 6797 & 50 & 10617 & 70 & 10690 \\
\hline 11 & 6416 & 31 & 6986 & 51 & 8450 & 71 & 12242 \\
\hline 12 & 7034 & 32 & 8848 & 52 & 10558 & 72 & 11315 \\
\hline 13 & 7608 & 33 & 8328 & 53 & 9021 & 73 & 8080 \\
\hline 14 & 7054 & 34 & 6661 & 54 & 12483 & 74 & 6400 \\
\hline 15 & 8106 & 35 & 9373 & 55 & 9856 & 75 & 7326 \\
\hline 16 & 9547 & 36 & 6946 & 56 & 11984 & 76 & 7571 \\
\hline 17 & 7394 & 37 & 7557 & 57 & 12291 & 77 & 10514 \\
\hline 18 & 7099 & 38 & 7523 & 58 & 8904 & 78 & 6507 \\
\hline 19 & 6693 & 39 & 7842 & 59 & 6106 & 79 & 8938 \\
\hline 20 & 8533 & 40 & 11510 & 60 & 7939 & 80 & 6374 \\
\hline
\end{tabular}


4.1.3- Classificação das nervuras e das lâminas do tabuleiro

As classes de resistência das nervuras e das lâminas foram determinadas experimentalmente por meio de ensaio de compressão paralela às fibras.

Os resultados indicaram que as nervuras e as lâminas do tabuleiro pertencem à classe C 30 (conífera).

\section{2- Montagem do modelo}

A seguir são descritas as etapas realizadas na montagem do modelo. Estas etapas referem-se à distribuição das nervuras e das lâminas do tabuleiro, aos apoios do modelo, ao sistema de protensão, aos dispositivos utilizados na experimentação e às formas de aplicação das forças.

\subsection{1- Distribuição das nervuras e das lâminas do tabuleiro}

A distribuição adequada das nervuras e das lâminas do tabuleiro tem como objetivo uniformizar a rigidez longitudinal do modelo.

As nervuras foram distribuídas o mais simetricamente possível em relação ao eixo longitudinal do modelo reduzido, posicionando-se externamente as nervuras com os módulos de elasticidade $\mathrm{E}_{\mathrm{L}, \mathrm{n}}$ maiores (Tabela 23 e Figura 55).

TABELA 23 - Distribuição final das nervuras

\begin{tabular}{|c|c|c|}
\hline $\begin{array}{c}\text { Nervura } \\
\text { (numeração } \\
\text { inicial) }\end{array}$ & $\begin{array}{c}\text { Nervura } \\
\text { (numeração } \\
\text { definitiva) }\end{array}$ & $\begin{array}{c}\text { Módulo de } \\
\text { elasticidade } \mathrm{E}_{\mathrm{L}, \mathrm{n}} \\
\text { (MPa) }\end{array}$ \\
\hline B & 1 & 7744 \\
\hline A & 2 & 6523 \\
\hline C & 3 & 5236 \\
\hline F & 4 & 5172 \\
\hline E & 5 & 6940 \\
\hline D & 6 & 7216 \\
\hline
\end{tabular}




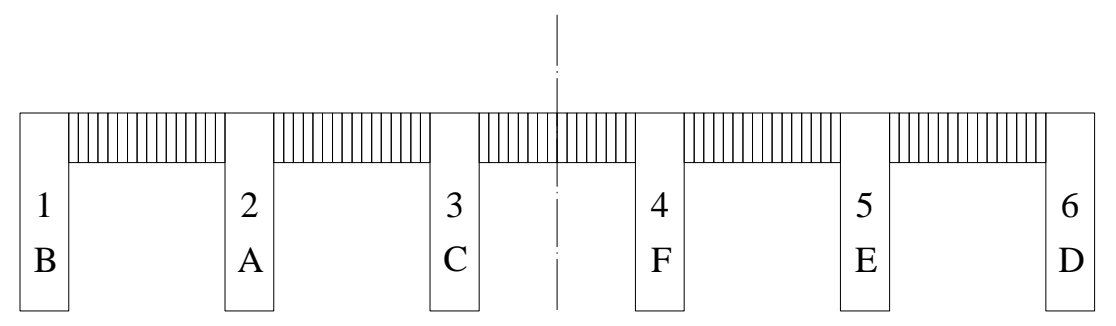

FIGURA 55 - Distribuição das nervuras no modelo reduzido

A distribuição das lâminas do tabuleiro se fez em conjuntos de 4 peças (Figura 56), de modo que as médias dos módulos de elasticidade na direção longitudinal de cada conjunto fossem próximas entre si e também próximas da média do módulo de elasticidade de todas as lâminas.

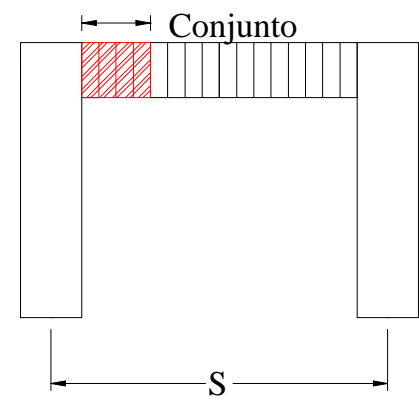

FIGURA 56 - Conjunto de lâminas formado por quatro peças

Neste contexto, define-se o procedimento para a distribuição das lâminas:

- Inicialmente, os módulos de elasticidade das lâminas do tabuleiro $\mathrm{E}_{\mathrm{L}, \mathrm{t}}$ foram colocados em ordem crescente e divididos em 4 grupos $\left(1^{\circ}\right.$ grupo: $1^{a}$ à $20^{a}$ lâmina, $2^{a}$ grupo: $21^{\mathrm{a}}$ à $40^{\mathrm{a}}$ lâmina, $3^{\circ}$ grupo: $41^{\mathrm{a}}$ à $60^{\mathrm{a}}$ lâmina e $4^{\circ}$ grupo: $61^{\mathrm{a}}$ à $80^{\mathrm{a}}$ lâmina).

- Posteriormente, foram formados conjuntos de 4 peças, sendo que a primeira peça pertencia ao $1^{\circ}$ grupo, a segunda peça pertencia ao $3^{\circ}$ grupo, a terceira peça pertencia ao $2^{\circ}$ grupo e a quarta peça pertencia ao $4^{\circ}$ grupo. Em resumo, cada conjunto foi formado seguindo a regra (i, 61 - i, $20+$ i, 81 - i), com i variando de 1 até 20 (Tabela 24 e Figura 57). 
TABELA 24 - Distribuição final das lâminas do tabuleiro

\begin{tabular}{|c|c|c|c|c|c|c|c|}
\hline Conj. & $\begin{array}{l}\mathrm{N}^{\circ} \mathrm{da} \\
\text { lâmina }\end{array}$ & $\begin{array}{c}\mathrm{E}_{\mathrm{L}, \mathrm{t}} \\
(\mathrm{MPa})\end{array}$ & $\begin{array}{c}\mathrm{E}_{\mathrm{L}, \text { tmédio }} \\
(\mathrm{MPa})\end{array}$ & Conj. & $\begin{array}{l}\mathrm{N}^{\circ} \mathrm{da} \\
\text { lâmina }\end{array}$ & $\begin{array}{c}E_{\mathrm{L}, \mathrm{t}} \\
(\mathrm{MPa})\end{array}$ & $\begin{array}{l}\mathrm{E}_{\mathrm{L}, \text { tmédio }} \\
(\mathrm{MPa})\end{array}$ \\
\hline \multirow{4}{*}{1} & 4 & 5490 & \multirow{4}{*}{8771} & \multirow{4}{*}{11} & 30 & 6797 & \multirow{4}{*}{8480} \\
\hline & 62 & 9746 & & & 58 & 8904 & \\
\hline & 22 & 7370 & & & 47 & 7661 & \\
\hline & 54 & 12483 & & & 52 & 10558 & \\
\hline \multirow{4}{*}{2} & 59 & 6106 & \multirow{4}{*}{8834} & \multirow{4}{*}{12} & 36 & 6946 & \multirow{4}{*}{8517} \\
\hline & 16 & 9547 & & & 32 & 8848 & \\
\hline & 17 & 7394 & & & 61 & 7765 & \\
\hline & 57 & 12291 & & & 77 & 10514 & \\
\hline \multirow{4}{*}{3} & 9 & 6168 & \multirow{4}{*}{8848} & \multirow{4}{*}{13} & 31 & 6986 & \multirow{4}{*}{8478} \\
\hline & 65 & 9480 & & & 6 & 8829 & \\
\hline & 28 & 7506 & & & 3 & 7778 & \\
\hline & 71 & 12242 & & & 43 & 10318 & \\
\hline \multirow{4}{*}{4} & 80 & 6374 & \multirow{4}{*}{8827} & \multirow{4}{*}{14} & 12 & 7034 & \multirow{4}{*}{8477} \\
\hline & 48 & 9429 & & & 25 & 8781 & \\
\hline & 38 & 7523 & & & 39 & 7842 & \\
\hline & 56 & 11984 & & & 69 & 10254 & \\
\hline \multirow{4}{*}{5} & 74 & 6400 & \multirow{4}{*}{8811} & \multirow{4}{*}{15} & 64 & 7048 & \multirow{4}{*}{8454} \\
\hline & 21 & 9418 & & & 46 & 8726 & \\
\hline & 37 & 7557 & & & 5 & 7890 & \\
\hline & 49 & 11866 & & & 26 & 10154 & \\
\hline \multirow{4}{*}{6} & 11 & 6416 & \multirow{4}{*}{8743} & \multirow{4}{*}{16} & 14 & 7054 & \multirow{4}{*}{8454} \\
\hline & 35 & 9373 & & & 67 & 8702 & \\
\hline & 76 & 7571 & & & 60 & 7939 & \\
\hline & 23 & 11606 & & & 1 & 10123 & \\
\hline & 68 & 6424 & & & 2 & 7067 & \\
\hline 7 & 63 & 9282 & 8706 & 17 & 20 & 8533 & 8418 \\
\hline & 13 & 7608 & 0100 & 17 & 73 & 8080 & \\
\hline & 40 & 11510 & & & 10 & 9992 & \\
\hline & 78 & 6507 & & & 18 & 7099 & \\
\hline 8 & 42 & 9099 & 8634 & 18 & 51 & 8450 & 8407 \\
\hline & 41 & 7611 & & & 15 & 8106 & \\
\hline & 72 & 11315 & & & 45 & 9974 & \\
\hline & 34 & 6661 & & & 75 & 7326 & \\
\hline 9 & 53 & 9021 & 8499 & 19 & 29 & 8379 & 8450 \\
\hline & 8 & 7624 & & & 66 & 8238 & \\
\hline & 70 & 10690 & & & 55 & 9856 & \\
\hline & 19 & 6693 & & & 27 & 7363 & \\
\hline 10 & 79 & 8938 & 8477 & 20 & 33 & 8328 & 8442 \\
\hline 10 & 24 & 7656 & $84 / 1$ & 20 & 44 & 8283 & $0+42$ \\
\hline & 50 & 10618 & & & 7 & 9795 & \\
\hline & & & & & & Média & 8586 \\
\hline & & & & & & $\begin{array}{l}\text { Desvio } \\
\text { Padrão }\end{array}$ & 16,350 \\
\hline
\end{tabular}




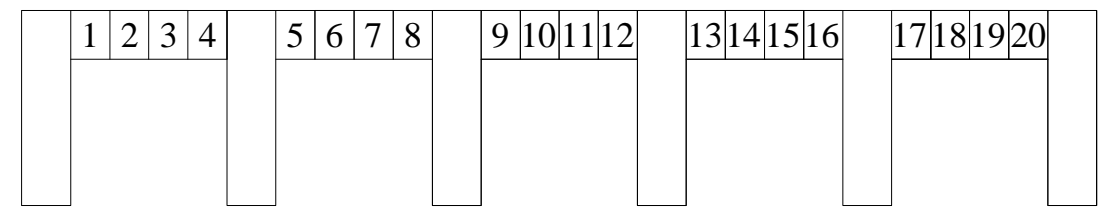

FIGURA 57 - Distribuição dos conjuntos de lâminas no modelo reduzido

- Por último, as médias dos módulos de elasticidade de cada conjunto foram calculadas e comparadas entre si e com a média do módulo de elasticidade de todas as lâminas. Com estes valores pôde-se verificar se o procedimento usado para distribuir as lâminas do tabuleiro é adequado.

As médias dos módulos de elasticidade na direção longitudinal de cada conjunto estão próximas entre si e também próximas da média do módulo de elasticidade de todas as lâminas (desvio/média $=0,2 \%)$. Deste modo, conclui-se que o procedimento usado para distribuir as lâminas do tabuleiro é adequado.

\subsection{2- Apoios do modelo}

O modelo reduzido foi apoiado sobre um sistema composto de perfis metálicos e roletes de aço montados sobre a laje de reação. Estes roletes permitem a rotação no ponto de apoio e não impedem o deslocamento horizontal do modelo (Figura 58).

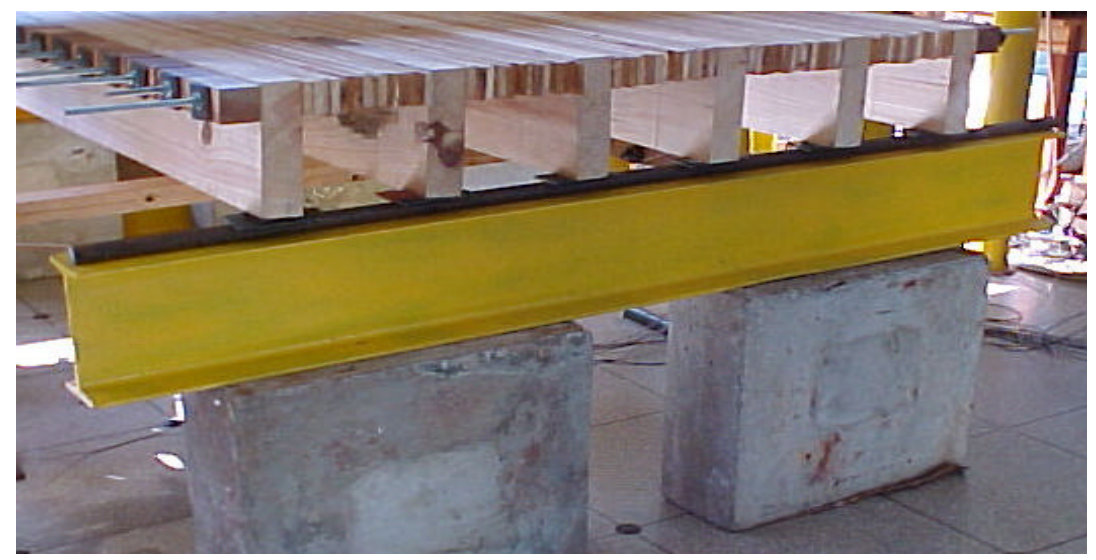

FIGURA 58 - Detalhe do apoio do modelo 


\subsection{3- Sistema de protensão}

O sistema de protensão foi constituído por 21 barras de aço espaçadas $10 \mathrm{~cm}$ entre si e com diâmetros nominais igual a $9,5 \mathrm{~mm}$.

Para a aplicação da força de protensão no modelo, as barras de aço foram tensionadas pelo rosqueamento manual das porcas sextavadas e então ancoradas por um conjunto de placa de ancoragem de aço comum e bloco de distribuição de madeira. Para estabelecer a tensão de protensão no tabuleiro igual a $0,7 \mathrm{MPa}$, cada barra estava tensionada de modo a aplicar uma força de 3,5 kN em uma área de 50 $\mathrm{cm}^{2}$ (distância entre as barras igual a $10 \mathrm{~cm}$ e altura do tabuleiro igual a $5 \mathrm{~cm}$ ).

O controle da força de protensão foi feito por meio de 11 células de cargas dispostas em barras alternadas (Figura 59), utilizando-se um indicador de deformações do modelo KYOWA SM - 60B (precisão de $5 \times 10^{-6}$ ) acoplado a uma caixa comutadora para 24 pontos modelo KYOWA SS24R. As células de carga foram previamente calibradas, ou seja, uma força igual a 3,5 $\mathrm{kN}$ foi aplicada para se conhecer a leitura da deformação correspondente.

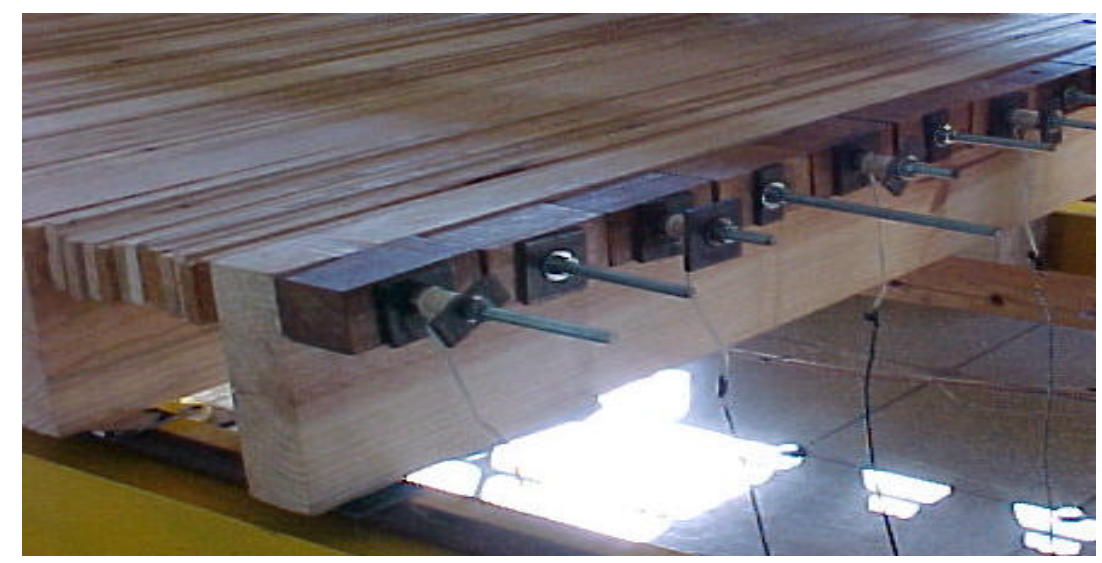

FIGURA 59 - Disposição das células de carga

4.2.4- Dispositivos utilizados na experimentação

4.2.4.1- Dispositivos para aplicação das forças 
A aplicação das forças no modelo foi feita com um cilindro hidráulico por intermédio de perfis "I" e chapas de aço.

As forças aplicadas foram medidas com um anel dinamométrico (capacidade nominal de $50 \mathrm{kN}$ ), fixado na extremidade do cilindro hidráulico (capacidade nominal de $100 \mathrm{kN}$ ), e distribuídas para duas chapas de aço através de um perfil "I" metálico. Cada chapa possui uma área de $32 \mathrm{~cm}^{2}$ equivalente à área de contato de uma roda do veículo-tipo classe 30 e um espaçamento entre as mesmas de $40 \mathrm{~cm}$ equivalente à distância entre os centros destas rodas.

\subsubsection{2- Equipamentos utilizados para medir deslocamentos}

Os deslocamentos verticais das nervuras foram medidos por intermédio de transdutores (LVDT) modelo HP DCDT 500 (precisão de 0,001 mm e amplitude igual a $\pm 12,7 \mathrm{~mm}$ ), e registrados por uma unidade de aquisição de dados modelo HP 3497A acoplada ao micro computador modelo HP 9825T.

Os transdutores foram instalados em 6 pontos do modelo reduzido, possibilitando que os deslocamentos verticais fossem medidos no ponto médio do vão de cada nervura (Figura 60).

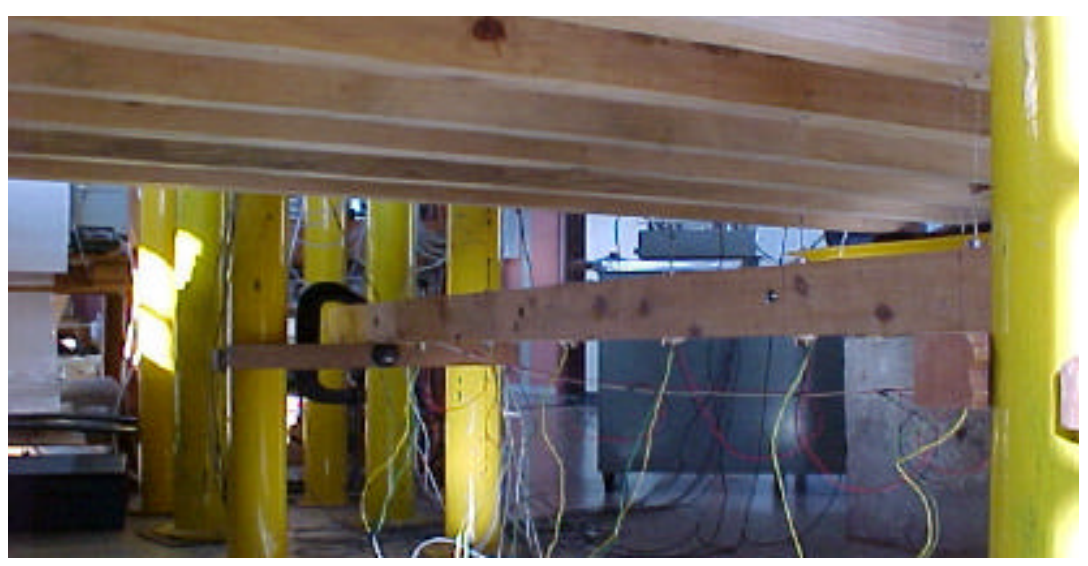

FIGURA 60 - Medida dos deslocamentos verticais no meio do vão das nervuras

\subsection{5- Formas de aplicação das forças}


Com o objetivo de se obter a rigidez efetiva do modelo, foi realizado um ensaio preliminar aplicando-se uma força no meio do vão do modelo e distribuída ao longo da largura (Figura 61).

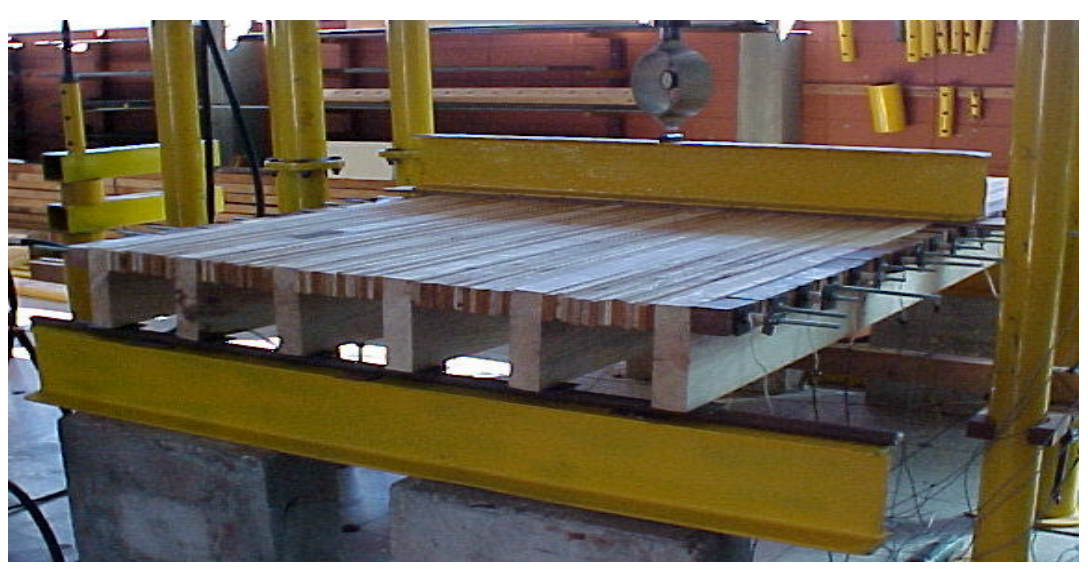

FIGURA 61 - Força uniformemente distribuída

Posteriormente, os ensaios foram realizados simulando a atuação de um eixo do veículo-tipo. Para isto, foram aplicadas duas forças concentradas no meio do vão do modelo e em várias posições ao longo de sua largura (Figura 62).

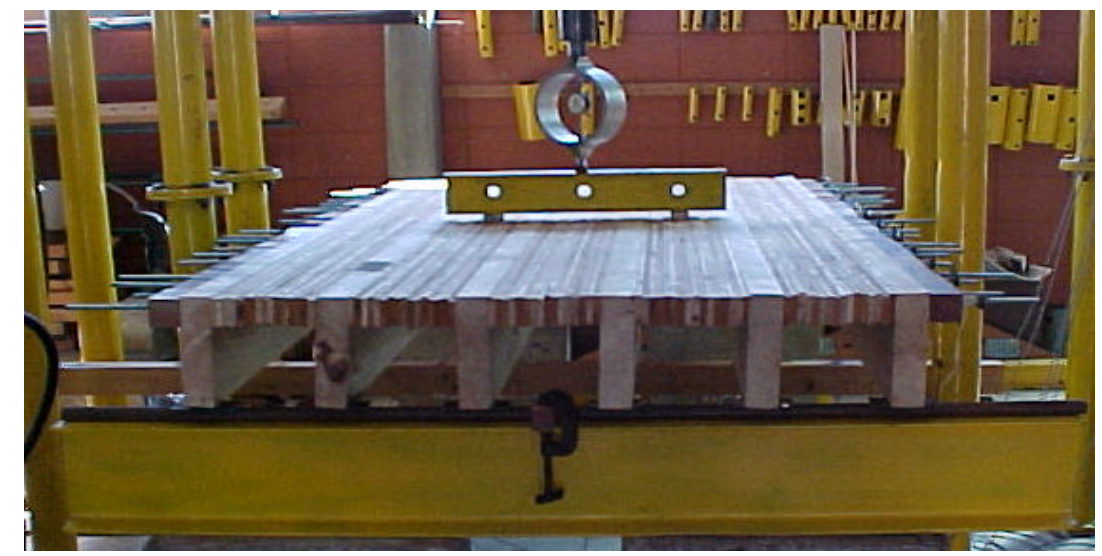

FIGURA 62 - Simulação de um eixo centrado

Para a aplicação das cargas não centradas, optou-se pela utilização de uma viga bi-apoiada devido à impossibilidade de se deslocar lateralmente o cilindro hidráulico (Figura 63). 


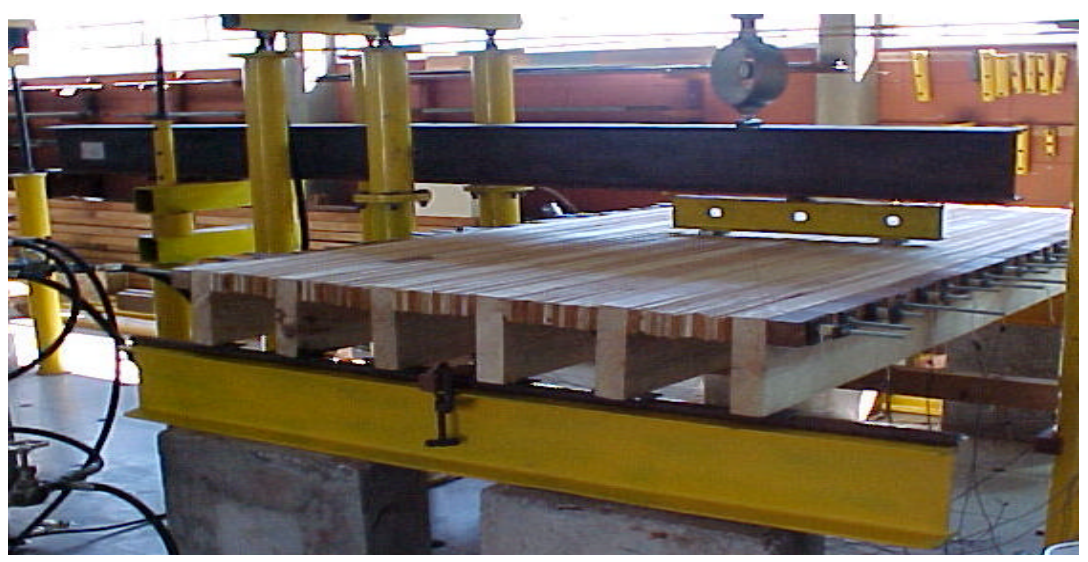

FIGURA 63 - Simulação de um eixo não centrado

Em cada ensaio, os deslocamentos verticais foram medidos a cada incremento de 4,58 $\mathrm{kN}$ na força aplicada, até o valor máximo de 45,8 kN para o carregamento distribuído; 4,25 na força aplicada, até o valor máximo de $34 \mathrm{kN}$ para o carregamento de um eixo com a roda externa na nervura 2 ou 5; 3,84 na força aplicada, até o valor máximo de $23 \mathrm{kN}$ para o carregamento centrado de um eixo e o carregamento de um eixo com a roda externa na nervura 1 ou 6 . Todos os ensaios foram realizados com uma repetição para cada carregamento.

Para se ter noção da magnitude da força aplicada no modelo em relação à carga móvel, foram determinados os momentos fletores no meio do vão da estrutura real, acrescidos do efeito do impacto, devidos ao carregamento móvel na faixa ocupada pelo veículo-tipo $\mathrm{M}_{\text {real }}=78120 \mathrm{kN}$.cm e ao carregamento móvel em toda a largura da ponte $\mathrm{M}_{\text {real }}=81995 \mathrm{kN} . \mathrm{cm}$.

Os momentos fletores equivalentes no modelo, em termos de se obter tensões normais da mesma magnitude, são determinados dividindo-se os momentos fletores na estrutura real pelo cubo do fator de redução de escala $\left(\mathrm{M}_{\text {modelo }}=\mathrm{M}_{\text {real }} / 5^{3}\right)$, sendo $\mathrm{M}_{\text {modelo }}=625 \mathrm{kN} . \mathrm{cm}$ e $\mathrm{M}_{\text {modelo }}=656 \mathrm{kN} . \mathrm{cm}$. Estes momentos são provocados por forças concentradas iguais a $12,5 \mathrm{kN}$ e $13,12 \mathrm{kN}$, respectivamente.

\section{3- Resultados obtidos e análises}

A seguir são apresentados os resultados experimentais dos ensaios estáticos do modelo reduzido de ponte com seção-T e as análises numéricas correspondentes. 
Estes resultados são a média dos valores observados no primeiro ciclo de leituras e na sua repetição. É importante salientar que não ocorreram diferenças significativas entre os valores do primeiro ciclo em relação aos da repetição.

\subsection{1- Resultados}

Para cada carregamento, foi efetuada a regressão linear entre as forças aplicadas e os deslocamentos correspondentes, obtendo-se a equação abaixo:

$$
\delta(\mathrm{mm})=\mathrm{a}+\mathrm{b} \cdot \mathrm{P}(\mathrm{kN})
$$

As tabelas 25 a 30 apresentam os resultados obtidos para todos os ensaios, os valores das constantes a e b e o coeficiente de correlação obtidos em cada regressão.

TABELA 25 - Força uniformemente distribuída - (I)

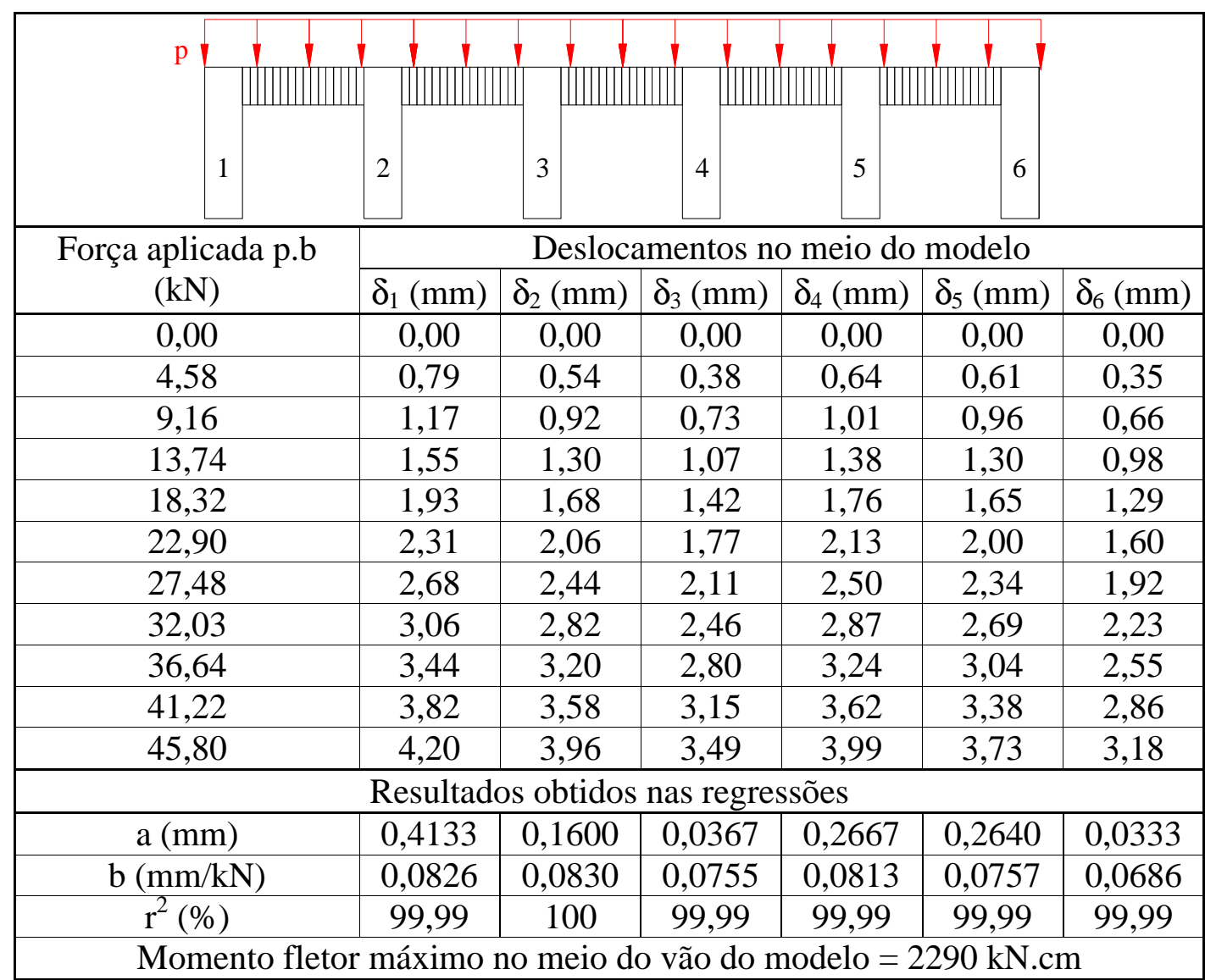


TABELA 26 - Carregamento de um eixo com a roda externa na nervura 1 - (II)

\begin{tabular}{|c|c|c|c|c|c|c|}
\hline & \\
& & & \\
\hline
\end{tabular}

TABELA 27 - Carregamento de um eixo com a roda externa na nervura 2 - (III)

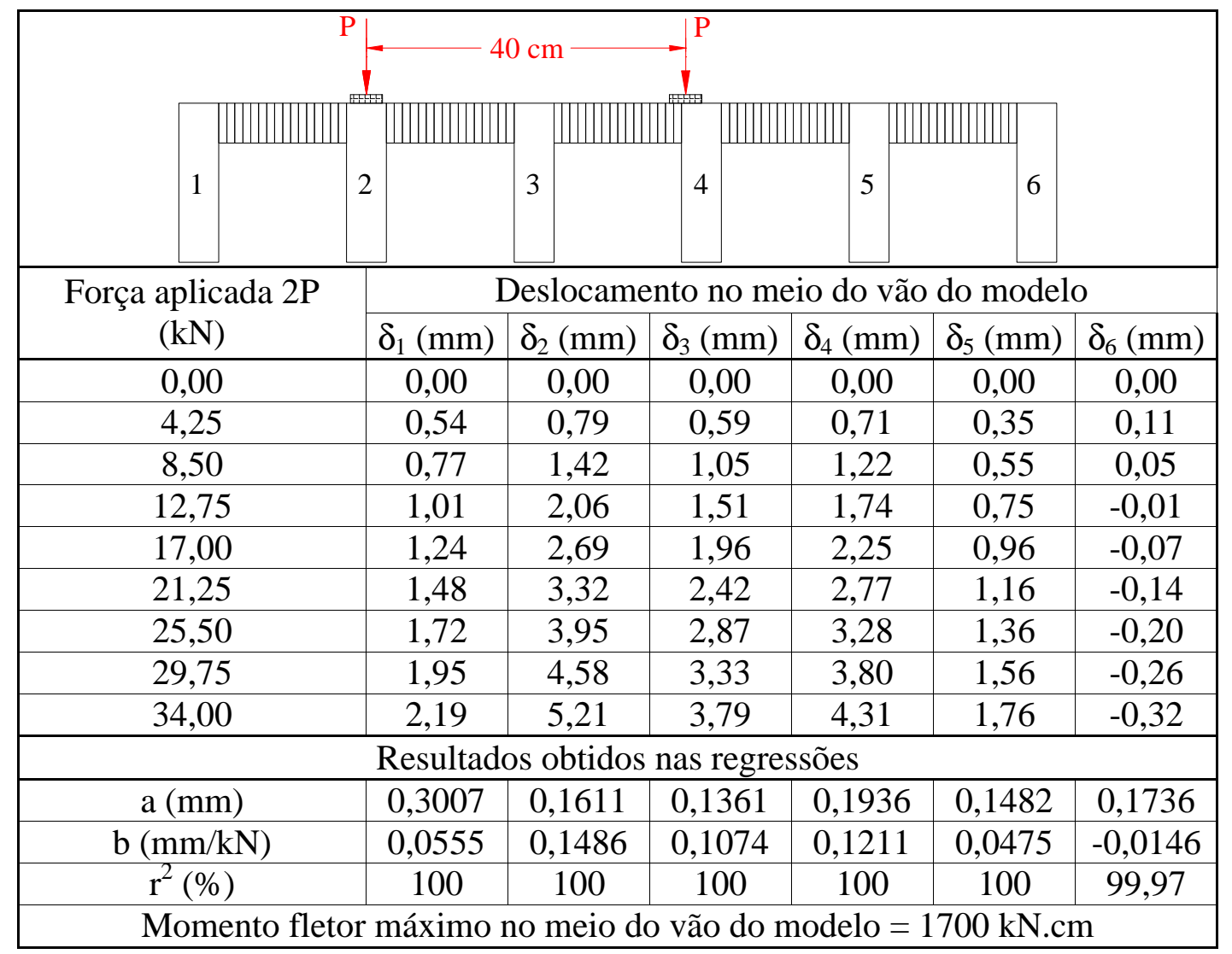


TABELA 28 - Carregamento de um eixo com a roda externa na nervura 5 - (IV)

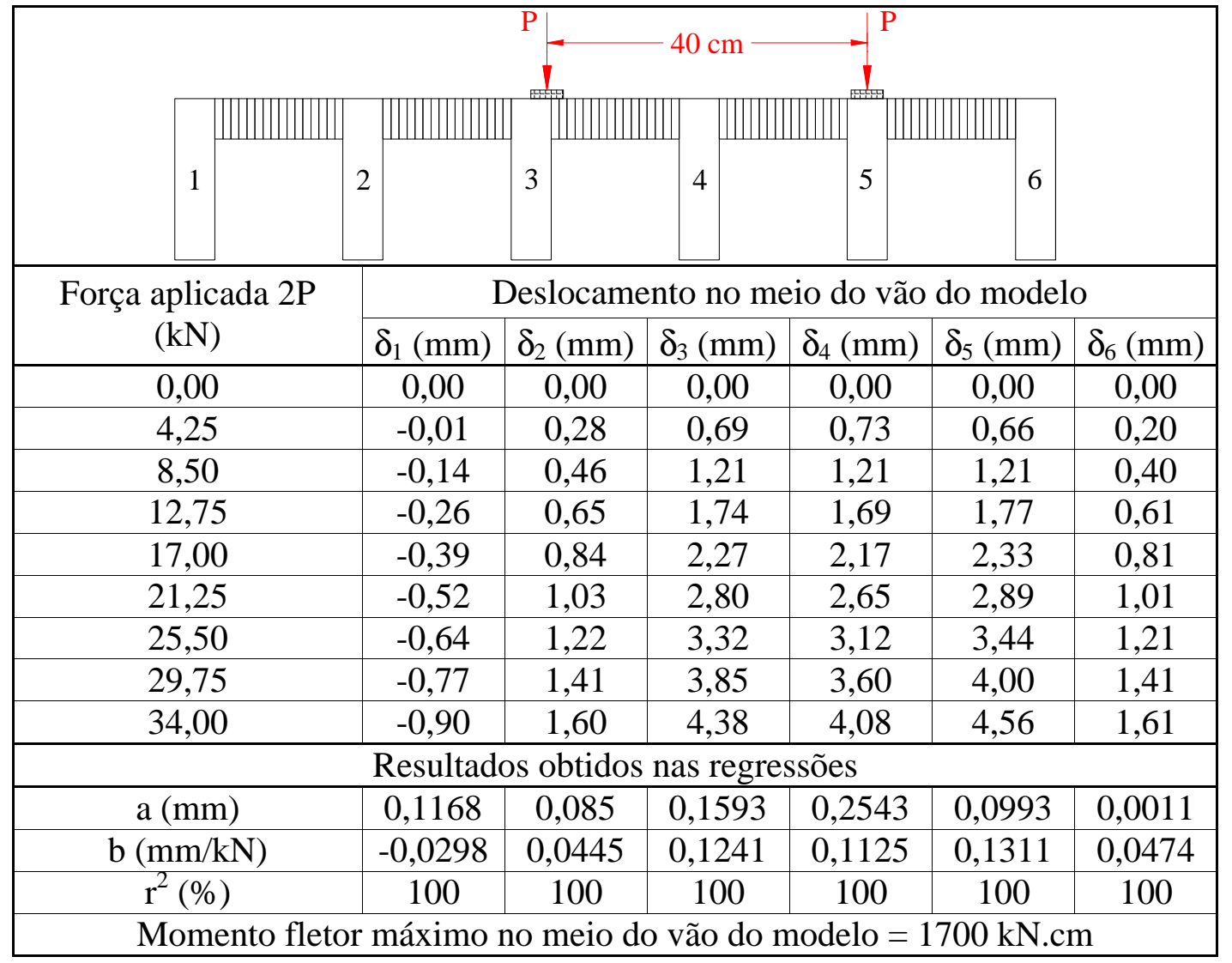

TABELA 29 - Carregamento de um eixo com a roda externa na nervura 6 - (V)

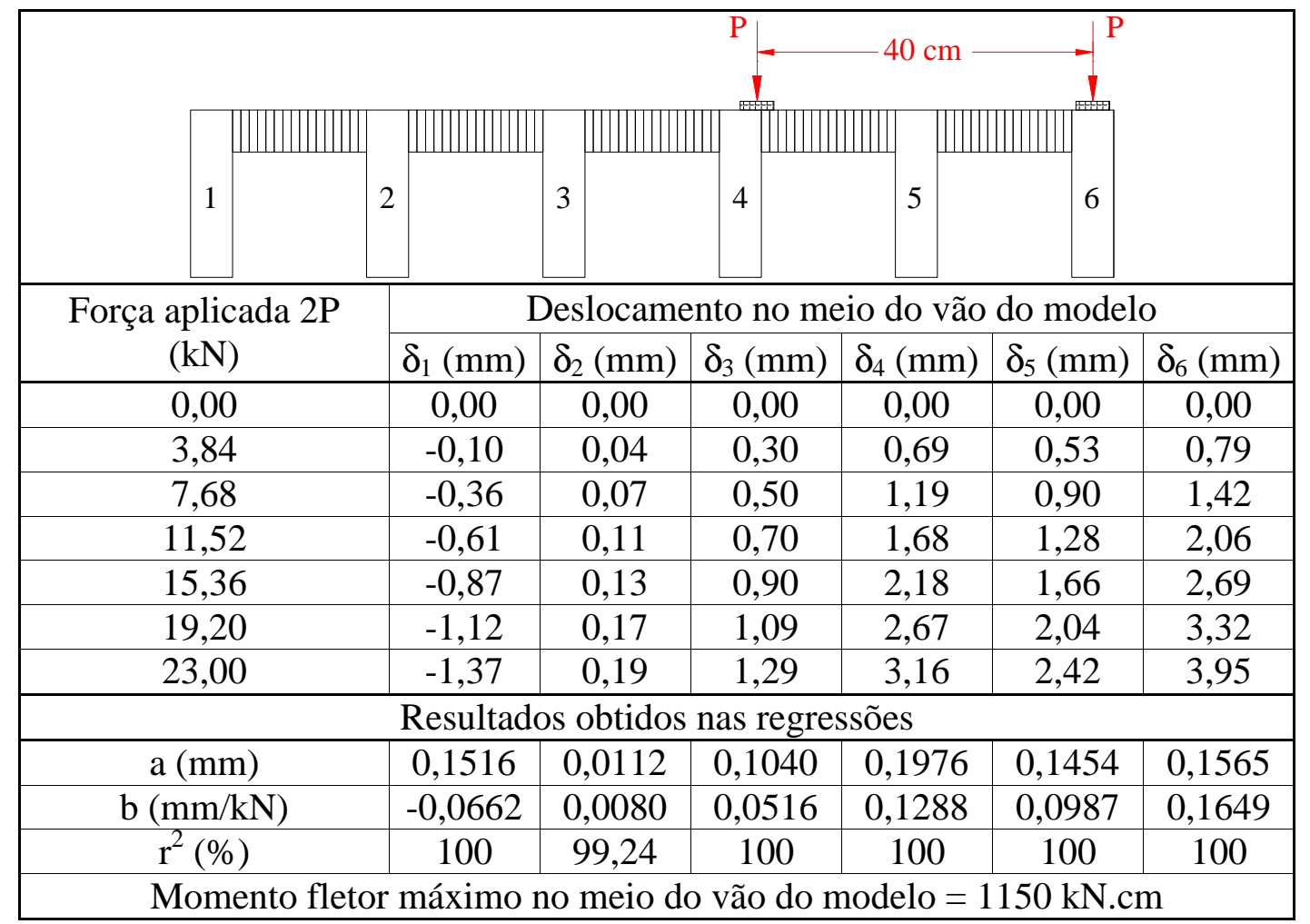


TABELA 30 - Carregamento centrado de um eixo - (VI)

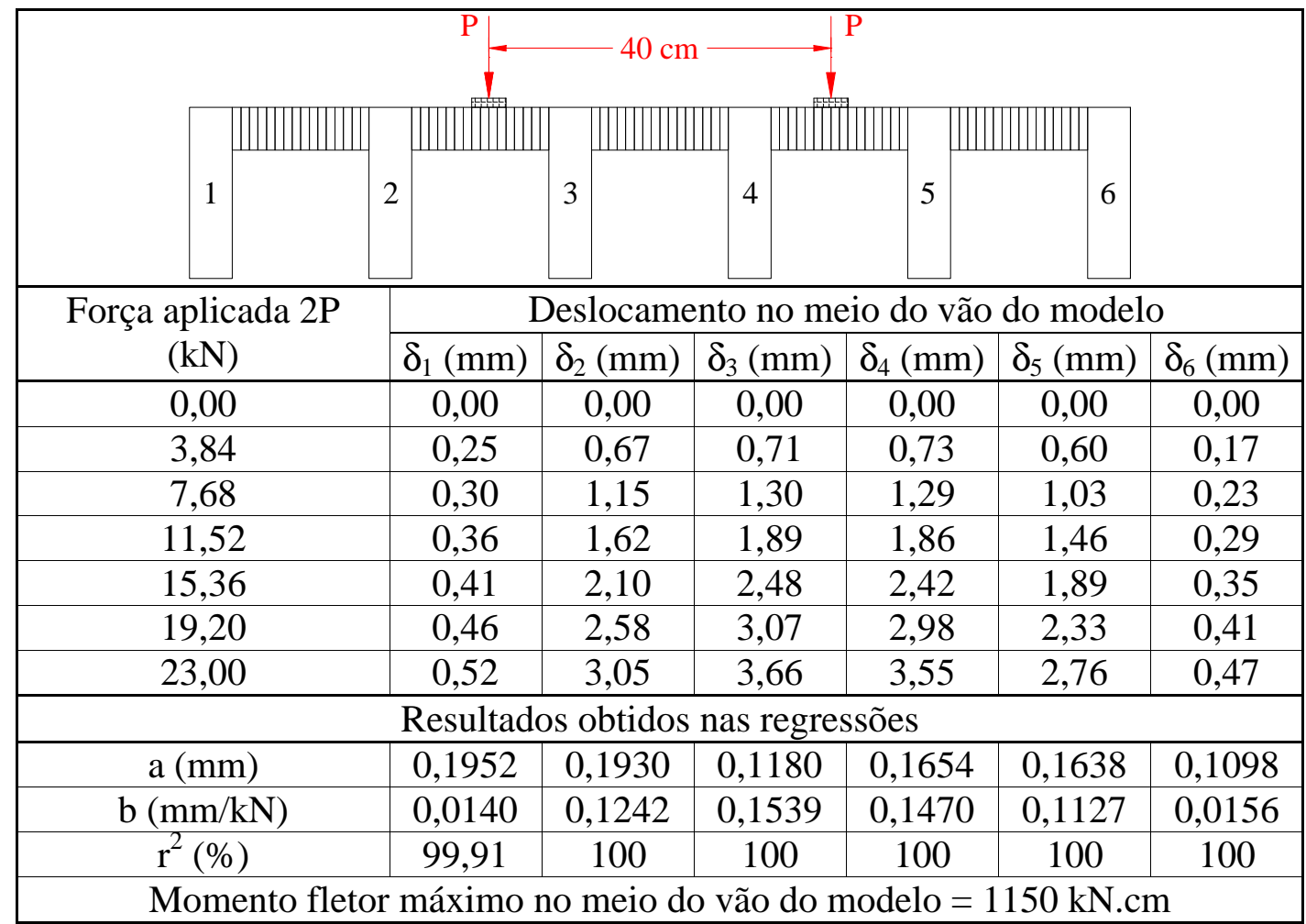

Para uma melhor visualização dos resultados experimentais obtidos, são apresentados para todas as situações de carregamento, os gráficos que relacionam deslocamentos das nervuras versus forças aplicadas (Figura 64) e as linhas elásticas transversais correspondentes às forças máximas aplicadas de cada carregamento (Figura 65). 


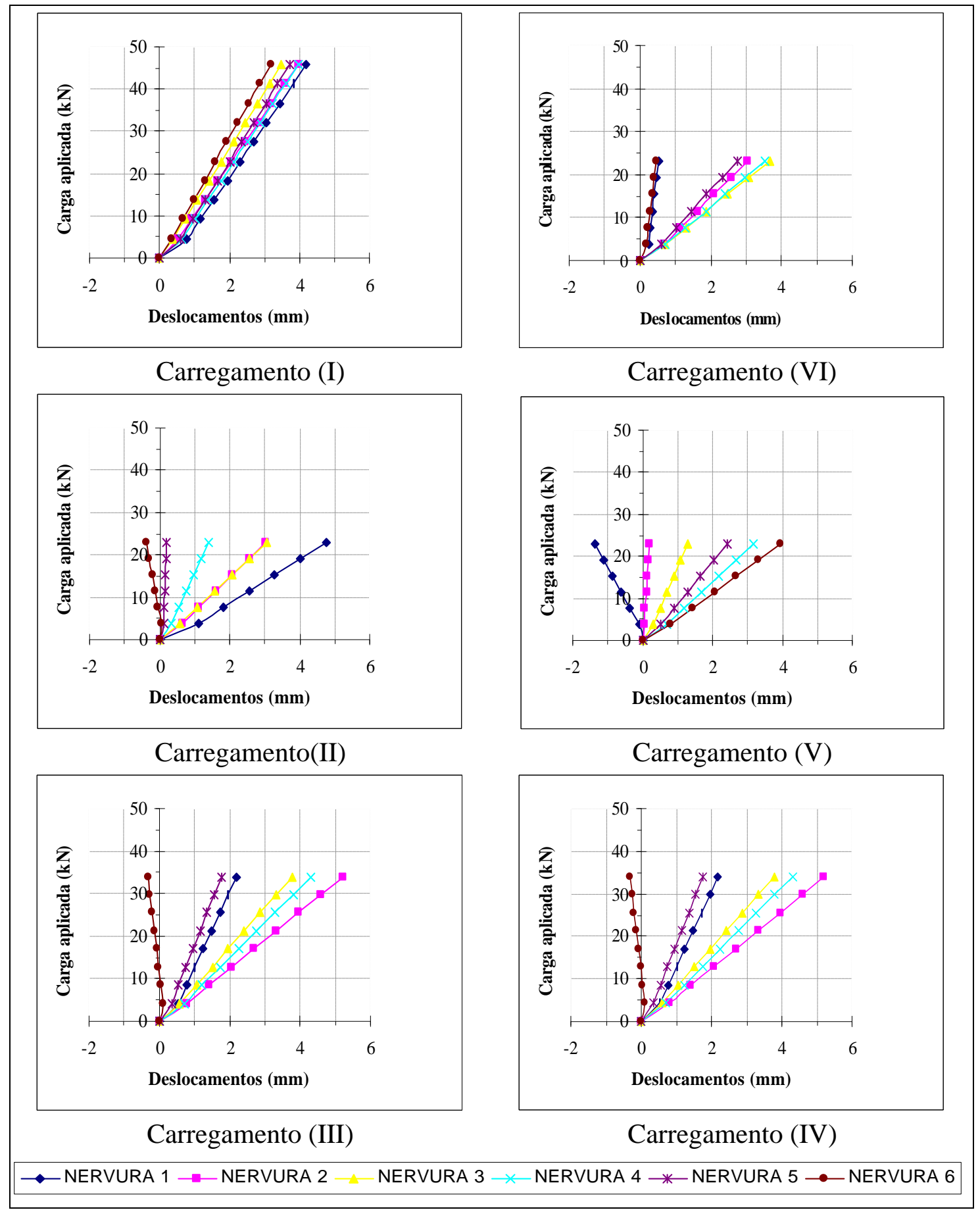

FIGURA 64 - Gráficos $\delta$ X P para os carregamentos correspondentes

Os gráficos apresentadas acima permitem observar que o modelo reduzido comportou-se de modo elástico-linear. 


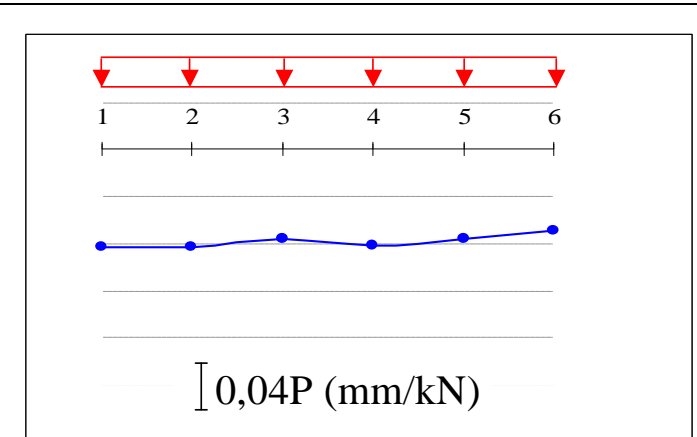

Carregamento (I)

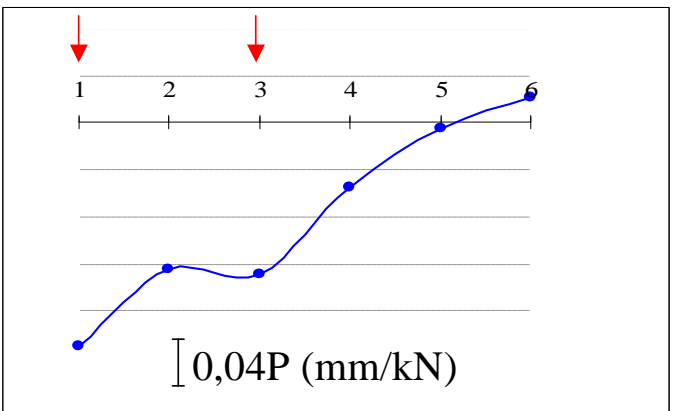

Carregamento (II)

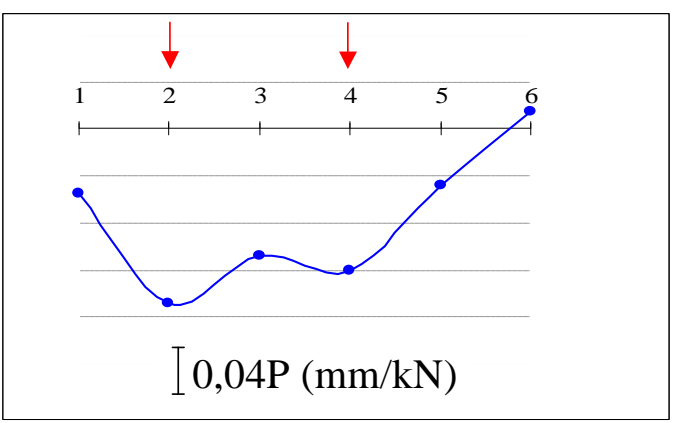

Carregamento (III)

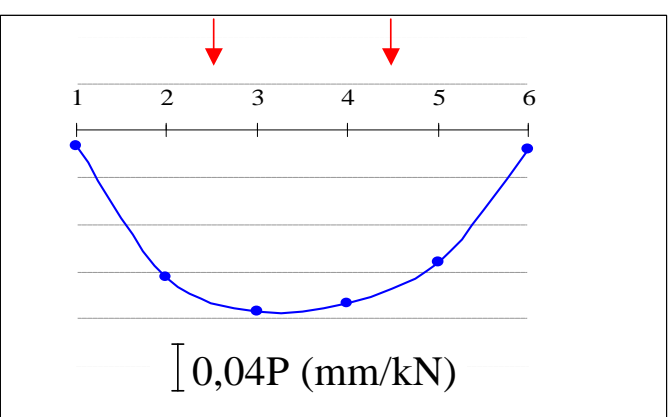

Carregamento (VI)

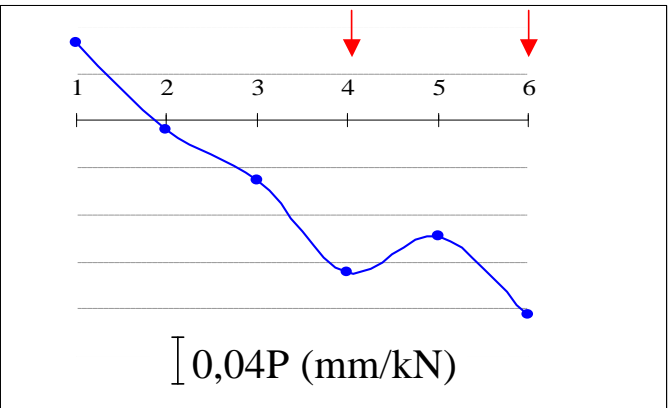

Carregamento (V)

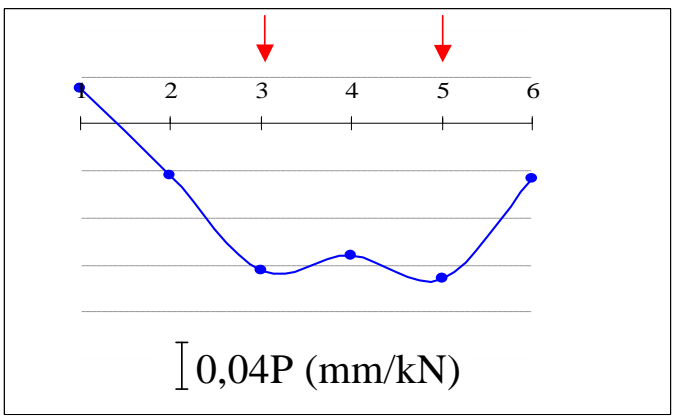

Carregamento (IV)

FIGURA 65 - Linhas elásticas transversais para os carregamentos correspondentes

4.3.2- Análise da rigidez à flexão longitudinal do modelo

Este item apresenta a comparação entre as rigidezes à flexão longitudinal experimental e teórica (método WVU) do modelo.

A rigidez à flexão longitudinal experimental $(\mathrm{E} \cdot \mathrm{I})_{\text {experimental }}$ foi calculada com base nos resultados do carregamento em que a força é uniformemente distribuída no meio do vão e ao longo da largura do modelo. Para este carregamento, 
não há influência da rigidez à flexão transversal e a ponte se comporta como um conjunto de vigas longitudinais. Então:

$$
(\mathrm{E} \cdot \mathrm{I})_{\text {exp erimental }}=\frac{\mathrm{P} \cdot \mathrm{L}^{3}}{48 \cdot \delta}
$$

onde:

$\mathrm{L}=$ vão do modelo reduzido $(200 \mathrm{~cm})$

$\mathrm{P}=$ força total aplicada no meio do vão do modelo reduzido

$\delta=$ deslocamento no meio do vão do modelo reduzido para a força uniformemente distribuída

A relação $\mathrm{P} / \delta$ foi tomada como o inverso da média dos valores "b" apresentados na tabela 25:

$$
\frac{\mathrm{P}}{\delta}=128,56 \mathrm{kN} / \mathrm{cm}
$$

Substituindo este valor na equação 71 tem-se:

$$
(\mathrm{E} \cdot \mathrm{I})_{\text {exp erimental }}=\frac{128,56 \cdot 200^{3}}{48}=21.426 .667 \mathrm{kN} . \mathrm{cm}^{2}
$$

A rigidez à flexão longitudinal teórica $(\mathrm{E} \cdot \mathrm{I})_{\text {teórica }}$ foi calculada a partir da soma dos momentos de inércia transformados das vigas do modelo reduzido.

Inicialmente, as larguras efetivas das abas de cada viga- $\mathrm{T}$ do modelo foram determinadas de acordo com o método WVU, seguindo o procedimento de cálculo apresentado no item 3.2.4.

Posteriormente, a seção transversal do modelo foi uniformizada adotando-se um valor único para o módulo de elasticidade na direção longitudinal das nervuras e das lâminas do tabuleiro $\left(\mathrm{E}_{\text {adotado }}=1000 \mathrm{kN} / \mathrm{cm}^{2}\right)$, e as larguras transformadas das nervuras e das abas foram determinadas seguindo o procedimento de cálculo apresentado no item 3.2.4. 
Por último, foram determinados os momentos de inércia, para cada uma destas vigas, em relação ao eixo horizontal que passa pelo CG da seção transformada total do modelo.

A tabela 31 e a figura 66 apresentam as dimensões das vigas-T transformadas:

TABELA 31 - Valores geométricos, efetivos e transformados das nervuras e abas

\begin{tabular}{|c|c|c|c|c|c|c|c|}
\hline \multirow{2}{*}{$\begin{array}{c}\text { Vigas } \\
\text { Externas }\end{array}$} & \multicolumn{2}{|c|}{$\begin{array}{c}\text { Valores } \\
\text { Geométricos }\end{array}$} & \multicolumn{2}{|c|}{ Valores Efetivos } & \multicolumn{3}{|c|}{ Valores Transformados } \\
\cline { 2 - 8 } & $\begin{array}{c}\mathrm{B}_{\mathrm{w}} \\
(\mathrm{cm})\end{array}$ & $\begin{array}{c}\mathrm{B} \\
(\mathrm{cm})\end{array}$ & $\begin{array}{c}\mathrm{B}_{\mathrm{w}} \\
(\mathrm{cm})\end{array}$ & $\begin{array}{c}\mathrm{B}_{\mathrm{E}} \\
(\mathrm{cm})\end{array}$ & $\begin{array}{c}\mathrm{B}_{\mathrm{w}, \text { transformado }} \\
(\mathrm{cm})\end{array}$ & $\begin{array}{c}\mathrm{b}_{\text {tex }} \\
(\mathrm{cm})\end{array}$ & $\begin{array}{c}\mathrm{I}_{\text {transformado }} \\
\left(\mathrm{cm}^{4}\right)\end{array}$ \\
\hline 1 & 5 & 8 & 5 & 6,34 & 3,87 & 5,58 & 3793 \\
\hline 6 & 5 & 8 & 5 & 6,26 & 3,61 & 5,29 & 3548 \\
\hline $\begin{array}{c}\text { Vigas } \\
\text { Internas }\end{array}$ & $\begin{array}{c}\mathrm{B}_{\mathrm{w}} \\
(\mathrm{cm})\end{array}$ & $\begin{array}{c}\mathrm{B} \\
(\mathrm{cm})\end{array}$ & $\begin{array}{c}\mathrm{B}_{\mathrm{w}} \\
(\mathrm{cm})\end{array}$ & $\begin{array}{c}\mathrm{B}_{\mathrm{E}} \\
(\mathrm{cm})\end{array}$ & $\begin{array}{c}\mathrm{B}_{\mathrm{w}, \text { transformado }} \\
(\mathrm{cm})\end{array}$ & $\begin{array}{c}\mathrm{b}_{\mathrm{t}} / 2 \\
(\mathrm{~cm})\end{array}$ & $\begin{array}{c}\mathrm{I}_{\text {transformado }} \\
\left(\mathrm{cm}^{4}\right)\end{array}$ \\
\hline 2 & 5 & 8 & 5 & 5,91 & 3,26 & 6,84 & 3912 \\
\hline 3 & 5 & 8 & 5 & 5,52 & 2,62 & 6,05 & 3242 \\
\hline 4 & 5 & 8 & 5 & 5,52 & 2,59 & 5,98 & 3204 \\
\hline 5 & 5 & 8 & 5 & 6,16 & 3,47 & 6,93 & 4093 \\
\hline
\end{tabular}

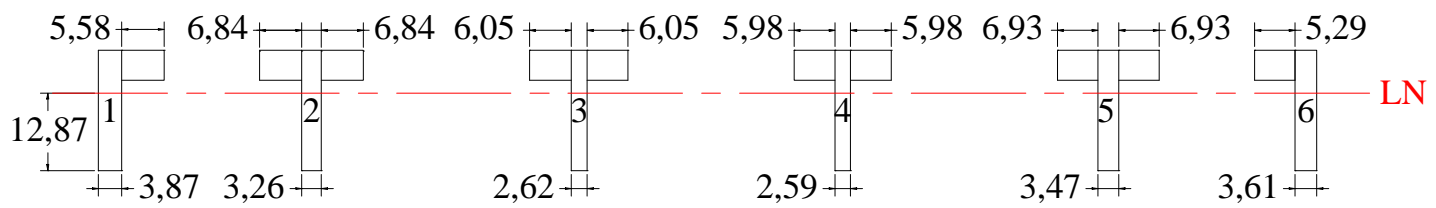

FIGURA 66 - Vigas-T transformadas

A rigidez à flexão longitudinal da seção transversal transformada é dada por:

$\mathrm{I}_{\text {transformada }}=\sum\left[\mathrm{I}_{\mathrm{i}}+\mathrm{A}_{\mathrm{i}} \cdot\left(\mathrm{y}_{\mathrm{CG}}-\mathrm{y}_{\mathrm{i}}\right)^{2}\right]=(21792+258)=22050 \mathrm{~cm}^{4}$

$(\mathrm{E} \cdot \mathrm{I})_{\text {transformada }}=1000 \cdot 22050=22.050 .000 \mathrm{kN} . \mathrm{cm}^{2}$

Comparando o valor teórico com o experimental, observa-se que este é cerca de $97 \%$ do valor do primeiro, indicando uma composição da seção transversal com uma eficiência praticamente equivalente à prevista pelo método WVU. 


\subsection{3- Análise do fator de distribuição da carga $\left(\mathrm{W}_{\mathrm{f}}\right)$}

Este item apresenta a comparação entre os fatores de distribuição da carga experimental e teórica (método WVU) do modelo.

Para o cálculo do fator $\mathrm{W}_{\mathrm{f}}$ experimental do modelo, determinou-se a parcela de carga absorvida por cada nervura $\left(\mathrm{P}_{\mathrm{i}}\right)$ quando foram aplicados os carregamentos em que a roda do eixo ficou sobre uma das nervuras externas. Estes carregamentos são as situações mais desfavoráveis em termos de distribuição transversal das cargas.

No cálculo de $\mathrm{P}_{\mathrm{i}}$ foi feita uma simplificação na qual admitiu-se que cada nervura absorveu uma parcela de carga proporcional ao produto do deslocamento desta nervura por sua rigidez à flexão.

Deste modo, $\mathrm{W}_{\mathrm{f}}$ experimental foi determinado pela relação entre a parcela de carga máxima $\left(\mathrm{P}_{\mathrm{i}, \text { máx }}\right)$ e o somatório das parcelas de carga $\left(\Sigma \mathrm{P}_{\mathrm{i}}\right)$ de cada nervura:

$$
\mathrm{W}_{\mathrm{f}}=\frac{\mathrm{P}_{\mathrm{i}, \mathrm{máx}}}{\sum \mathrm{P}_{\mathrm{i}}}
$$

sendo:

$$
\mathrm{P}_{\mathrm{i}}=\frac{48 \cdot \delta_{\mathrm{i}} \cdot \mathrm{E}_{\text {adotado }} \cdot \mathrm{I}_{\mathrm{i}, \text { transformada }}}{\mathrm{L}^{3}}
$$

Substituindo $P_{i}$ na equação 72 tem-se:

$$
\mathrm{W}_{\mathrm{f}}=\frac{\mathrm{I}_{\mathrm{i}, \text { transformada }} \cdot \delta_{\mathrm{i}}}{\sum\left(\mathrm{I}_{\mathrm{i}, \text { transformada }} \cdot \delta_{\mathrm{i}}\right)}
$$

onde:

$\mathrm{I}_{\mathrm{i}, \text { transformada }}=$ momento de inércia da viga- $\mathrm{T}$ i transformada, sendo $\mathrm{i}=1,2, \ldots, 6$

$\delta_{\mathrm{i}}=$ deslocamento no meio do vão da nervura $\mathrm{i}$, sendo $\mathrm{i}=1,2, \ldots, 6$

Inicialmente, calculou-se o fator $\left(\mathrm{W}_{\mathrm{f} 1}\right)$ com os resultados apresentados na tabela 26 , caso em que a roda ficou sobre a nervura externa 1 :

$$
\mathrm{W}_{\mathrm{f} 1}=\frac{\mathrm{I}_{1, \text { transformada }} \cdot \delta_{1}}{\sum\left(\mathrm{I}_{\mathrm{i}, \text { transformada }} \cdot \delta_{\mathrm{i}}\right)}=\frac{3793 \cdot 0,475}{4376} \cdot 100=41 \%
$$


Posteriormente, calculou-se o fator $\left(\mathrm{W}_{\mathrm{f} 6}\right)$ com os resultados apresentados na tabela 29 , caso em que a roda ficou sobre a nervura externa 6 :

$$
\mathrm{W}_{\mathrm{f} 6}=\frac{\mathrm{I}_{6, \text { transformada }} \cdot \delta_{6}}{\sum\left(\mathrm{I}_{\mathrm{i}, \text { transformada }} \cdot \delta_{\mathrm{i}}\right)}=\frac{3548 \cdot 0,395}{3377} \cdot 100=41 \%
$$

E, finalmente, calculou-se o fator de distribuição da carga $\left(\mathrm{W}_{\mathrm{f}}\right)$ :

$$
\mathrm{W}_{\mathrm{f}}=\frac{\mathrm{W}_{\mathrm{f} 1}+\mathrm{W}_{\mathrm{f} 6}}{2} \Rightarrow \mathrm{W}_{\mathrm{f}}=41 \%
$$

$\mathrm{O}$ fator $\mathrm{W}_{\mathrm{f}}$ teórico do modelo foi determinado de acordo com o método WVU, seguindo o procedimento de cálculo apresentado no item 3.2.5, conforme descrito abaixo:

$$
\mathrm{W}_{\mathrm{f}}=\frac{1+\mathrm{C}_{0}}{\mathrm{n} \cdot \mathrm{C}_{0}+\frac{2}{\pi} \cdot(\mathrm{n}-1)}
$$

sendo:

$$
\begin{aligned}
& \mathrm{C}_{0}=\frac{\left(\mathrm{b}-\mathrm{B}_{\mathrm{w}}\right)}{\pi} \cdot \frac{\mathrm{D}_{\mathrm{T}}}{\mathrm{B}_{\mathrm{e}}} \cdot \frac{\left[8 \cdot(\lambda)^{2}+1\right]}{(\lambda)^{4}} \\
& \mathrm{D}_{\mathrm{T}}=\mathrm{E}_{\mathrm{T}} \cdot \frac{\mathrm{t}^{3}}{12} \\
& \lambda=\frac{\left(\mathrm{b}-\mathrm{B}_{\mathrm{W}}\right)}{\mathrm{L}} \\
& \mathrm{B}_{\mathrm{e}}=\mathrm{E}_{\mathrm{L}, \mathrm{n}} \cdot \mathrm{Iex}
\end{aligned}
$$

Calculando, tem-se que:

$$
\begin{aligned}
& \mathrm{D}_{\mathrm{T}}=18,78 \cdot \frac{5^{3}}{12}=196 \mathrm{kN} . \mathrm{cm} \\
& \lambda=\frac{(110-5)}{200}=0,525 \\
& \mathrm{~B}_{\mathrm{e}}=647,2 \cdot 5814=3.762 .821 \mathrm{kN} . \mathrm{cm}^{2}
\end{aligned}
$$




$$
\begin{aligned}
& \mathrm{C}_{0}=\frac{(110-5)}{\pi} \cdot \frac{196}{3.762 .821} \cdot \frac{\left[8 \cdot(0,525)^{2}+1\right]}{(0,525)^{4}}=0,0734 \\
& \mathrm{~W}_{\mathrm{f}}=\frac{1+0,0734}{6 \cdot 0,0734+\frac{2}{\pi} \cdot(6-1)} \cdot 1,6=47 \%
\end{aligned}
$$

Comparando o valor teórico com o experimental, observa-se que este $\left(\mathrm{W}_{\mathrm{f}}=\right.$ $41 \%)$ é ligeiramente menor que o obtido pelo método WVU $\left(\mathrm{W}_{\mathrm{f}}=47 \%\right)$, indicando que a parcela de carga absorvida pela nervura mais solicitada do modelo é menor que a parcela de carga determinada pelo método WVU. 


\section{4- CONCLUSÕES}

$\mathrm{O}$ desenvolvimento do sistema $\mathrm{T}$ das pontes de madeira protendidas transversalmente surgiu devido à necessidade de se construir pontes que vencessem vãos maiores que os alcançados pelas pontes com tabuleiros protendidos de altura constante. O procedimento de cálculo, utilizado na determinação das dimensões efetivas das pontes formadas por vigas-T, possibilitou efetuar a análise numérica destas pontes para diversas situações de projeto.

Estas pontes classe 30 foram dimensionadas para vãos iguais a 10, 15, 20 e 25 m, larguras iguais a 5,5 (1 faixa de tráfego) e 10,0 m (2 faixas de tráfego), larguras das nervuras e alturas dos tabuleiros iguais a 15, 20 e $25 \mathrm{~cm}$, número de nervuras variando de 4 até 8 (1 faixa de tráfego) e de 7 até 14 (2 faixas de tráfego), e espaçamento entre nervuras variando de 70 até $200 \mathrm{~cm}$.

A partir das discussões desenvolvidas ao longo do trabalho, conclui-se que:

- No processo de dimensionamento das nervuras realizado na análise numérica, o fator limitante foi o estado limite último de tração nas fibras inferiores das nervuras, para todas as situações analisadas. Deste modo, podem-se esperar reduções significativas na altura das nervuras ao se utilizar resistências de cálculo à tração superiores às empregadas neste trabalho, por meio de critérios de dimensionamento que permitam considerar a maior resistência à tração da madeira.

- A altura do tabuleiro não influencia de maneira significativa na altura das nervuras, pois a variação da altura do tabuleiro de 15 a $25 \mathrm{~cm}$ conduz a reduções de, no máximo, $3 \%$ para a altura das nervuras. 
- A largura das nervuras influencia de maneira significativa na altura das mesmas, pois a variação desta largura de 15 a $25 \mathrm{~cm}$ conduz a reduções de, no máximo, 12\% para a sua altura.

- Em relação ao tabuleiro, observa-se que a utilização de madeira conífera C $30 \mathrm{ou}$ dicotiledônea C 30 ou C 40 não influencia de maneira significativa na altura das nervuras. Para as madeiras classe C 30, que apresentam o mesmo módulo de elasticidade na direção longitudinal, observa-se uma melhor distribuição transversal das cargas para as coníferas devido à protensão transversal proporcionar um maior módulo de elasticidade na direção transversal para estas madeiras; para as madeiras classe C 40, que apresentam maior módulo de elasticidade na direção longitudinal, observa-se uma diminuição de, no máximo, $3 \%$ para a altura das nervuras.

- Na análise experimental do modelo foram obtidos valores para a rigidez à flexão longitudinal e para o fator de distribuição da carga muito próximos dos valores teóricos determinados pelo método WVU, indicando que o método possibilita um dimensionamento adequado para as pontes de madeira protendidas transversalmente formadas por vigas-T. 


\section{6- REFERÊNCIAS BIBLIOGRÁFICAS}

ASSOCIAÇÃO BRASILEIRA DE NORMAS TÉCNICAS (1984). NBR 7188 Cargas Móveis em Pontes Rodoviárias e Passarelas de Pedestres. Rio de Janeiro. ASSOCIAÇÃO BRASILEIRA DE NORMAS TÉCNICAS (1997). NBR 7190 Projeto de Estruturas em Madeira. Rio de Janeiro.

BARGER JR., L. S.; LOPEZ-ANIDO, R.; GANGARAO, H. V. S. (1993). Experimental Evaluation of Stressed Timber Bridge Systems. In: TRANSPORTATION RESEARCH RECORD, TRB, n.1426. Washington, D.C. National Research Council, p.57-61.

CREWS, K. (1998). International Guidelines for Design of Stress Laminated Timber Bridge Decks. World Conference on Timber Engineering-WCTE, 5., artigo 4, v.1. Swiss Federal, editado por J. Natterer e J.-L. Sandoz. LausanneSuíça.

DAVAlOS, J. F; SALIM, H. A. (1992). Design of Stress-Laminated T-System Timber Bridges. National Hardwood Timber Bridge Conference 1992, Timber Bridge Information Resource Center-TBIRC, USDA-FS-Northeastern Area.

DAVAlOS, J. F; SALIM, H. A. (1993). Effective Flange Width for StressLaminated T-Systems Timber Bridges. Journal of the Structural Engineering, v.119, n.3, p.938-953.

DAVAlOS, J. F.; SALIM, H. A.; DICKSON, B. (1993). Development and Field Testing of the Camp Arrowhead Modular Stress-Laminated T-System Timber Bridge. Annual Meeting, TRB, 72., National Research Council, Washington, D.C., n.93-0663.

DIAS, A. A. (1998). Tabuleiros de Pontes de Madeira Protendidos Transversalmente com Seção Transversal T. In: ENCONTRO BRASILEIRO EM MADEIRAS E 
ESTRUTURAS DE MADEIRA, 4., São Carlos, 1998. Anais. São Carlos, Escola de Engenharia de São Carlos, 1998, v.2, p.325-334.

DICKSON, B.; GANGARAO, H. V. S. (1990). Development and Testing of an Experimental Stressed-Timber T-Beam Bridge. In: TRANSPORTATION RESEARCH RECORD, TRB, National Research Council, Washington, D.C., v.2, n.1275, p.67-75.

GANGARAO, H. V. S.; LATHEEF, I. (1991). System Innovation and Experimental Evaluation of Stressed-Timber Bridges. In: INTERNATIONAL TIMBER ENGINEERING CONFERENCE, Trada, London, U.K., 1991. Proceedings. v.3, p.3327-3334.

GANGARAO, H. V. S.; RAJU, P. R. (1992). Transverse Wheel Load Distribution for Deck-Stringer Bridges. In: NSF WORKSHOP ON BRIDGE ENGINEERING RESEARCH IN PROGRESS, 3., La Jolla, CA, 1992. Proceedings. University of CA, p.109-112.

OKIMOTO, F. S. (1997). Pontes Protendidas de Madeira: parâmetros elásticos para o projeto. São Carlos. Dissertação (Mestrado) - Escola de Engenharia de São Carlos, Universidade de São Paulo.

PRATA, D. G. (1994). Sistemas Estruturais para Pontes de Madeira. São Carlos. Tese (Doutorado) - Escola de Engenharia de São Carlos, Universidade de São Paulo.

RITTER, M. A. (1992). Timber Bridges: Design, Construction, Inspection, and Maintenance. U.S. Department of Agriculture Forest Service, Washington, D.C.

RITTER, M.; LEE, P. H.; KAINZ, J.; MEYER, C. (1996). An Evaluation of StressLaminated T-Beam Bridges Constructed of Laminated Veneer Lumber. In: NATIONAL CONFERENCE ON WOOD TRANSPORTATION STRUCTURES. U.S. Department of Agriculture Forest Service, p.92-103.

TAYLOR, R.; RITTER, M. (1990). Development of Longer Span Wood Bridges. In: INTERNATIONAL CONFERENCE ON SHORT AND MEDIUM SPAN BRIDGES, Toronto, Canadá, 1990. Proceedings. v.2, p.391-492.

USDA (1995), Forest Service, Modern Timber Bridges of West Virginia. Volume 1. Editor Barry Dickson, Constructed Facilities Center, West Virginia University, U.S.A. 
APÊNDICE 1 - PROGRAMA PARA O CÁlCULO E 0 DIMENSIONAMENTO DE PONTES DE MADEIRA PROTENDIDAS TRANSVERSALMENTE FORMADAS POR VIGAS-T 
Projeto de Ponte Protendida de Madeira - Classe 30

1) Dados (Unidades: $\mathrm{cm}, \mathrm{kg}, \mathrm{kN}$ )

\subsection{Do Projeto}

${ }^{*}$ Vão......................................... $\quad \mathrm{L}_{\mathrm{p}}:=200 \quad \mathrm{~cm}$ Estrutura bi-apoiada

${ }^{*}$ Largura ................................. b $\mathrm{b}:=110 \mathrm{~cm} \begin{aligned} & \text { (Uma faixa de tráfego, dois } \\ & \text { passeios) }\end{aligned}$

*Altura do tabuleiro ...................... $\mathrm{t}:=5 \quad \mathrm{~cm}$

Índice de variável

$\mathrm{k}:=0,1 . .2$

Largura da nervura, $\mathrm{k} \ldots \ldots \ldots \ldots \ldots \ldots . . . . . . . . . \mathrm{B}_{\mathrm{w}}:=\left(\begin{array}{l}3 \\ 4 \\ 5\end{array}\right) \mathrm{cm}$

*Número de faixas de tráfego.......... $\mathrm{N}_{\mathrm{L}}:=1$

*Largura de

contato do pneu

$\mathrm{a}:=8 \quad \mathrm{~cm}$

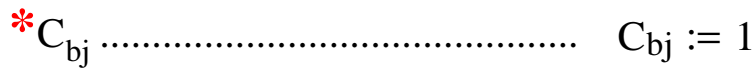

Comprimento

efetivo do pneu.

$\mathrm{b}_{1}:=30 \quad \mathrm{~cm}$

Carga de Roda do eixo traseiro....... P := $2 \quad \mathrm{kN}$

Carga uniformemente distribuída ao longo da faixa de tráfego........... p :=5 $10^{-4} \mathrm{kN} / \mathrm{cm}^{2}$ 
Nível de protensão no tabuleiro....... $\sigma_{\mathrm{N}}:=700 \cdot 10^{-4} \mathrm{kN} / \mathrm{cm}^{2}$

Coeficiente de atrito estático

$$
\mu_{S}:=0.35
$$

Proteção: Madeira tratada com creosoto

Capa asfáltica

$\mathrm{c}_{\mathrm{asf}}:=1 \mathrm{~cm}$

$\gamma_{\text {asf }}:=24 \cdot 10^{-6} \mathrm{kN} / \mathrm{cm}^{3}$

Coeficiente

para pontes rodoviárias

com revestimento de

concreto asfáltico

$\alpha:=12$

Fator de combinação e de utilização para cargas móveis

em pontes rodoviárias $\psi_{2}:=0.2$

\subsection{Da Madeira}

Classe: C20, C25, C30 (Coníferas)

Classe: C20, C30, C40, C60 (Dicotiledôneas)

Umidade: estável em 12\% (Padrão NBR 7190/86).

Caso1 := "Tabuleiro de coníferas e nervuras de dicotiledoneas"

Caso2 := "Tabuleiro e nervuras de dicotiledoneas"

Caso3 := "Tabuleiro e nervuras de coníferas"

Caso4 := "Tabuleiro de dicotiledoneas e nervuras de coníferas"

* Caso := Caso3

* $\mathrm{C}_{\text {tabuleiro }}:=$ "C $30 "$

* $\mathrm{C}_{\text {nervura }}:=$ "C $30 "$ 


\subsection{Do Sistema de Protensão}

\subsubsection{Barras}

Sistema comercial Dywidag

Aço ST 85/105: $\quad \mathrm{f}_{\mathrm{yST}}:=85 \quad \mathrm{kN} / \mathrm{cm}^{2}$

Diâmetro

$\phi_{\mathrm{b}}:=0.9525 \mathrm{~cm}$ (duplofiletado)

Comprimento

$l_{b}:=b+6$

$\mathrm{l}_{\mathrm{b}}=116 \mathrm{~cm}$

Peso de 1 barra...... $\mathrm{P}_{\mathrm{b}}:=77 \cdot 10^{-6} \cdot\left[\pi \cdot\left(\frac{\phi_{\mathrm{b}}}{2}\right)^{2}, \mathrm{l}_{\mathrm{b}}\right] \quad \mathrm{P}_{\mathrm{b}}=0.0064 \quad \mathrm{kN}$

Espaçamento

entre as barras.

$$
\mathrm{s}:=\frac{\mathrm{f}_{\mathrm{yST}}}{1.1 \cdot 2.5 \cdot \sigma_{\mathrm{N}} \cdot \mathrm{t}} \cdot\left[\pi \cdot\left(\frac{\phi_{\mathrm{b}}}{2}\right)^{2}\right] \quad \mathrm{s}=62.9271 \mathrm{~cm}
$$

2) Especificação dos dados da madeira para as classes utilizadas

Obs: $\mathrm{f}_{\mathrm{c} 0 . \mathrm{k}}, \mathrm{f}_{\mathrm{v} 0 . \mathrm{k}}$ e $\mathrm{E}_{\mathrm{co} . \mathrm{m}}\left(\mathrm{kN} / \mathrm{cm}^{2}\right)$

$\rho\left(\mathrm{kg} / \mathrm{cm}^{3}\right)$

\section{DADOS CONÍFERAS}

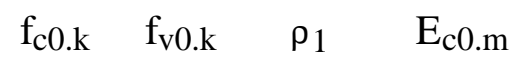

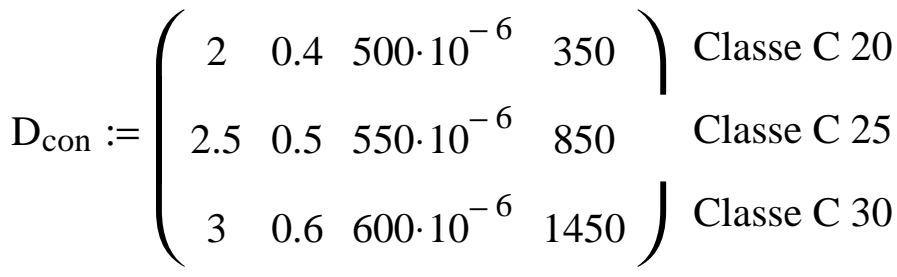

\section{DADOS DICOTILEDÔNEAS}

$\mathrm{f}_{\mathrm{c} 0 . \mathrm{k}} \quad \mathrm{f}_{\mathrm{v} 0 . \mathrm{k}} \quad \rho_{2} \quad \mathrm{E}_{\mathrm{c} 0 . \mathrm{m}}$

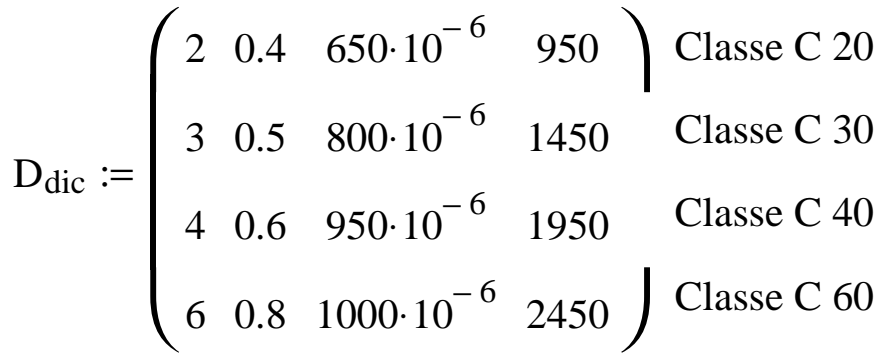




$$
\begin{aligned}
& \mathrm{i}:=0 . .2 \quad \mathrm{f}_{\mathrm{c} 0 . \mathrm{k} 1_{\mathrm{i}}}:=\mathrm{D}_{\mathrm{con}_{\mathrm{i}, 0}} \\
& \mathrm{j}:=0 . .3 \quad \mathrm{f}_{\mathrm{c} 0 . \mathrm{k} 2}{ }_{\mathrm{j}}:=\mathrm{D}_{\mathrm{dic}_{\mathrm{j}, 0}} \\
& \mathrm{f}_{\mathrm{v} 0 . \mathrm{k} 1_{\mathrm{i}}}:=\mathrm{D}_{\text {con }_{\mathrm{i}, 1}} \\
& \mathrm{f}_{\mathrm{v} 0 . \mathrm{k} 2} \mathrm{j}_{\mathrm{j}}:=\mathrm{D}_{\mathrm{dic}}{ }_{\mathrm{j}, 1} \\
& \mathrm{f}_{\mathrm{c} 90 . \mathrm{k} 1_{\mathrm{i}}}:=0.25 \cdot \mathrm{D}_{\mathrm{con}_{\mathrm{i}, 0}} \\
& \mathrm{f}_{\mathrm{c} 90 . \mathrm{k} 2} \mathrm{j}_{\mathrm{j}}:=0.25 \cdot \mathrm{D}_{\mathrm{dic}}{ }_{\mathrm{j}, 0} \\
& \mathrm{f}_{\mathrm{t} 0 . \mathrm{k} 1_{\mathrm{i}}}:=\frac{\mathrm{D}_{\mathrm{con}_{\mathrm{i}, 0}}}{0.77} \\
& \mathrm{f}_{\mathrm{t} 0 . \mathrm{k} 2 \mathrm{j}}:=\frac{\mathrm{D}_{\mathrm{dic}}{ }_{\mathrm{j}, 0}}{0.77} \\
& \rho_{1_{i}}:=\mathrm{D}_{\text {con }_{i, 2}} \\
& \rho_{2_{j}}:=\mathrm{D}_{\mathrm{dic}_{\mathrm{j}, 2}} \\
& \mathrm{E}_{\mathrm{c} 0 . \mathrm{m} 1_{\mathrm{i}}}:=\mathrm{D}_{\mathrm{con}_{\mathrm{i}, 3}} \\
& \mathrm{E}_{\mathrm{c} 0 . \mathrm{m} 2} \mathrm{j}:=\mathrm{D}_{\mathrm{dic}_{\mathrm{j}, 3}}
\end{aligned}
$$

Nervura Tabuleiro

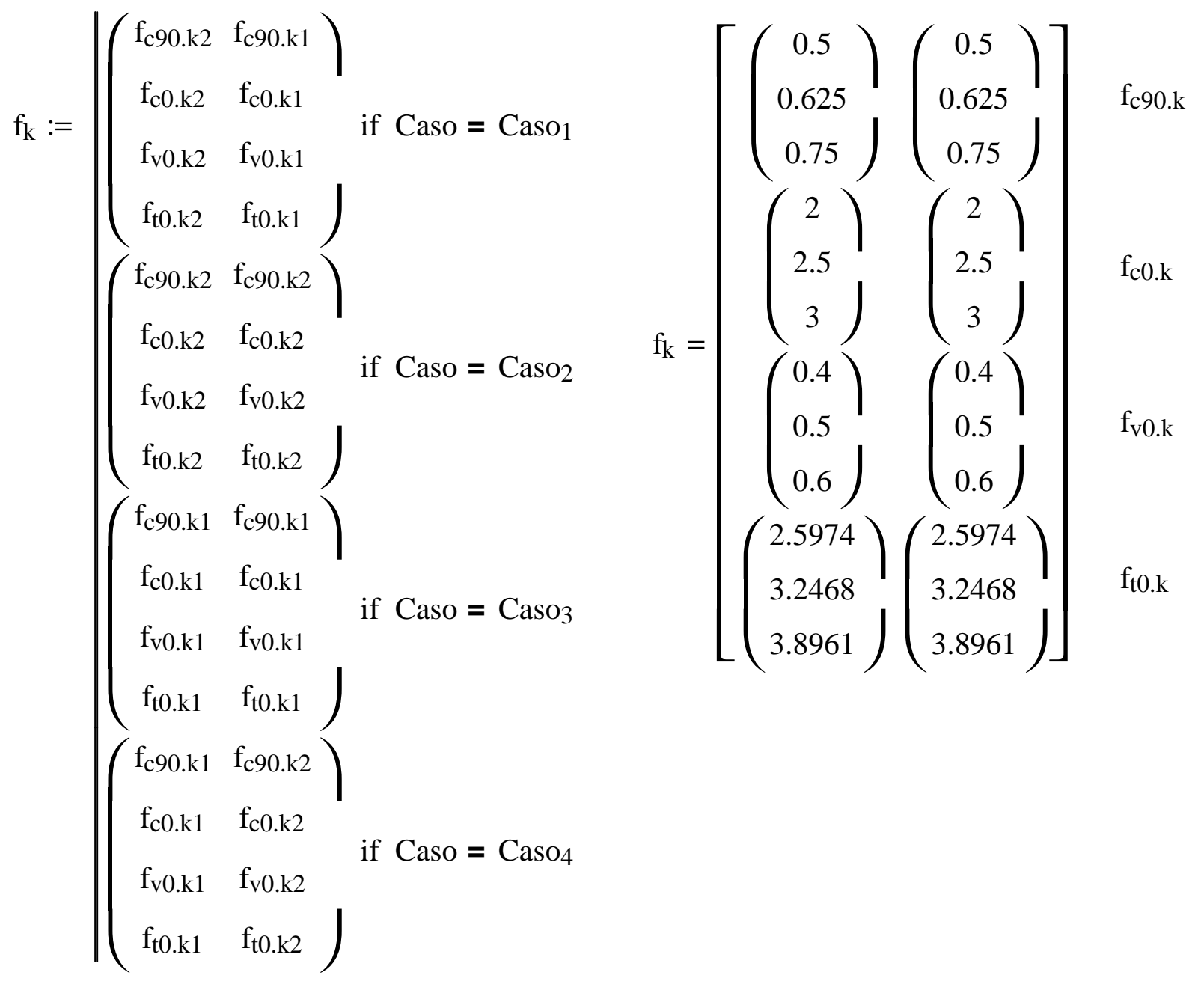


- Valores de Cálculo

$$
\mathrm{k}_{\text {mod.1 }}:=0.7 \quad \mathrm{k}_{\bmod .2}:=1.0 \quad \mathrm{k}_{\bmod .3}:=0.8
$$

$\mathrm{k}_{\text {mod }}:=\mathrm{k}_{\bmod .1} \cdot \mathrm{k}_{\bmod .2} \cdot \mathrm{k}_{\bmod .3} \quad \mathrm{k}_{\bmod }=0.56$

$\mathrm{E}_{\mathrm{c} 0 . \mathrm{efN}}:=\mid \begin{array}{ll}\mathrm{k}_{\mathrm{mod}} \cdot \mathrm{E}_{\mathrm{c} 0 . \mathrm{m} 1} & \text { if Caso }=\mathrm{Caso}_{3} \\ \mathrm{k}_{\mathrm{mod}} \cdot \mathrm{E}_{\mathrm{c} 0 . \mathrm{m} 1} & \text { if Caso }=\mathrm{CasO} 4 \\ \mathrm{k}_{\mathrm{mod}} \cdot \mathrm{E}_{\mathrm{c} 0 . \mathrm{m} 2} & \text { otherwise }\end{array}$

$\mathrm{E}_{\mathrm{c} 0 . \mathrm{efT}}:=\mid \begin{array}{ll}\mathrm{k}_{\mathrm{mod}} \cdot \mathrm{E}_{\mathrm{c} 0 . \mathrm{m} 2} & \text { if } \text { Caso }=\mathrm{Caso} 2 \\ \mathrm{k}_{\mathrm{mod}} \cdot \mathrm{E}_{\mathrm{c} 0 . \mathrm{m} 2} & \text { if Caso }=\mathrm{Caso}_{4} \\ \mathrm{k}_{\mathrm{mod}} \cdot \mathrm{E}_{\mathrm{c} 0 . \mathrm{m} 1} & \text { otherwise }\end{array}$

\section{Ner Tab}

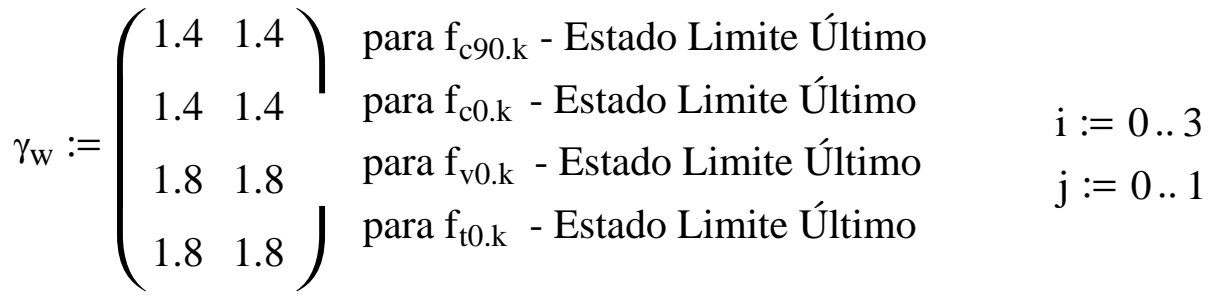

$f_{d_{i, j}}:=k_{\bmod } \cdot \frac{f_{k_{i, j}}}{\gamma_{w_{i, j}}}$

Portanto:
$\mathrm{E}_{\mathrm{c} 0 . \mathrm{efN}}=\left(\begin{array}{c}196 \\ 476 \\ 812\end{array}\right) \quad \mathrm{kN} / \mathrm{cm}^{2}$
$\mathrm{E}_{\mathrm{c} 0 . \mathrm{efT}}=\left(\begin{array}{c}196 \\ 476 \\ 812\end{array}\right) \mathrm{kN} / \mathrm{cm}^{2}$
$\mathrm{E}_{\mathrm{L} . \mathrm{n}}:=\mathrm{E}_{\mathrm{c} 0 . \mathrm{efN}}$
$\mathrm{E}_{\mathrm{L} . \mathrm{t}}:=\mathrm{C}_{\mathrm{bj}} \cdot \mathrm{E}_{\mathrm{c} 0 . \mathrm{efT}}$ 
3) Cálculo do módulo de elasticidade do tabuleiro na direção transversal $\mathrm{E}_{\mathrm{T}}$

$$
\mathrm{r}:=\mid \begin{array}{ll}
3 & \text { if } \text { Caso }=\mathrm{Caso}_{2} \\
3 & \text { if } \text { Caso }=\mathrm{Caso}_{4} \\
2 & \text { otherwise }
\end{array} \quad \mathrm{i}:=0 . . \mathrm{r}
$$

$\mathrm{a}-$

$$
\begin{aligned}
& \operatorname{aux}_{\mathrm{i}}:=\mid \begin{array}{l}
\sigma_{\mathrm{N}} \cdot 10^{4} \cdot\left(1.17275 \cdot 10^{-5}+1.795 \cdot 10^{-8} \cdot \rho_{2} \cdot 10^{6}\right), \text { if Caso = Caso } 2 \\
\sigma_{\mathrm{N}} \cdot 10^{4} \cdot\left(1.17275 \cdot 10^{-5}+1.795 \cdot 10^{-8} \cdot \rho_{2} \cdot 10^{6}\right) \\
\sigma_{\mathrm{N}^{*}} \cdot 10^{4} \cdot\left(1.17275 \cdot 10^{-5}+1.795 \cdot 10^{-8} \cdot \rho_{1_{i}} \cdot 10^{6}\right)
\end{array} \\
& \mathrm{E}_{\mathrm{T}_{\mathrm{i}}}:=\mid \begin{array}{l}
\left(0.0183673-2.0395 \cdot 10^{-5} \cdot \rho_{2} \cdot 10^{6}+\operatorname{aux}_{\mathrm{i}}\right) \cdot \mathrm{E}_{\mathrm{L.t}} \cdot 10^{4} \text { if Caso = Caso2 } \\
\left(0.0183673-2.0395 \cdot 10^{-5} \cdot \rho_{2} \cdot 10^{6}+\operatorname{aux}_{\mathrm{i}}\right) \cdot \mathrm{E}_{\mathrm{L} . \mathrm{i}_{\mathrm{i}}} \cdot 10^{4} \text { if Caso = Caso4 } \\
\left(0.0183673-2.0395 \cdot 10^{-5} \cdot \rho_{1} \cdot 10^{6}+\operatorname{aux}_{\mathrm{i}}\right) \cdot \mathrm{E}_{\mathrm{L} . \mathrm{t}_{\mathrm{i}}} \cdot 10^{4} \text { otherwise }
\end{array} \\
& \mathrm{E}_{\mathrm{T}_{\mathrm{i}}}:=\mathrm{E}_{\mathrm{T}_{\mathrm{i}}} \cdot 10^{-4}
\end{aligned}
$$

4) Cálculo do número de nervuras

Cálculo de S a partir da verificação do deslocamento local máximo da porção do tabuleiro entre duas nervuras adjacentes.

$$
\delta=\frac{\mathrm{P} \cdot(\mathrm{S})^{3}}{4 \cdot \mathrm{K}_{\delta} \cdot \mathrm{E}_{\mathrm{T}} \cdot \mathrm{t}^{4}}
$$

$\operatorname{com} \mathrm{K}_{\delta}=-10.9+7.8 \cdot\left(\frac{\mathrm{S}}{\mathrm{t}}\right)+0.27 \cdot\left(\frac{\mathrm{E}_{\mathrm{L} . \mathrm{t}}}{\mathrm{E}_{\mathrm{T}}}\right)$

Pelo arranjo da equação de deslocamento $\delta$ na forma polinomial $\mathrm{p}(\mathrm{S})$, e admitindo-se o limite superior para o $\delta$ :

$$
\delta_{\text {sup }}:=0.5 \quad \mathrm{~cm}
$$


É calculado os espaçamentos máximos $\mathrm{S}$ entre nervuras, a partir das raízes $\mathrm{r}_{0}, \mathrm{r}_{1}, \mathrm{r}_{2}$ do polinômio $p(S)$.

$\mathrm{r}:=\mid \begin{array}{ll}3 & \text { if } \text { Caso }=\mathrm{Caso}_{2} \\ 3 & \text { if } \text { Caso }=\text { Caso } 4 \\ 2 & \text { otherwise }\end{array} \quad \mathrm{i}:=0 . . \mathrm{r}$

Cálculos para o $\delta_{\text {sup }}$

$\Psi:=4 \cdot \delta_{\text {sup }} \cdot \mathrm{E}_{\mathrm{T}} \cdot \mathrm{t}^{4} \quad \mathrm{a}_{1}:=\mathrm{P} \quad \mathrm{a}_{2}:=0 \quad \mathrm{a}_{3}:=-7.8 \cdot \frac{\Psi}{\mathrm{t}} \quad \mathrm{a}_{\mathrm{i}_{\mathrm{i}}}:=\left(-0.27 \cdot \Psi_{\mathrm{i}} \cdot \frac{\mathrm{E}_{\mathrm{L} \cdot \mathrm{t}_{\mathrm{i}}}}{\mathrm{E}_{\mathrm{T}_{\mathrm{i}}}}\right)+10.9 \cdot \Psi_{\mathrm{i}}$ $\mathrm{j}:=0 . .2 \quad$.....índice do vetor raiz do polinômio

$$
\begin{array}{ll}
\operatorname{pol}(\mathrm{S}):=\left(\mathrm{a}_{1} \cdot \mathrm{S}^{3}+\mathrm{a}_{3} \cdot \mathrm{S}+\mathrm{a}_{4}\right) \quad \operatorname{resw}_{\mathrm{i}}:=\text { for } \mathrm{z} \in 0 . . \mathrm{i} \\
& \begin{array}{l}
\mathrm{a}_{4} \leftarrow \mathrm{a}_{\mathrm{z}} \\
\mathrm{a}_{3} \leftarrow \mathrm{a}_{3} \\
\mathrm{z} \leftarrow\left(\begin{array}{c}
\mathrm{a}_{4} \\
\mathrm{a}_{3} \\
\mathrm{a}_{2} \\
\mathrm{a}_{1}
\end{array}\right) \\
\mathrm{v} \leftarrow \operatorname{polyroots}(\mathrm{v})
\end{array}
\end{array}
$$$$
\operatorname{resw}^{\mathrm{T}}=\left[\left(\begin{array}{c}
-65.48 \\
-0.65 \\
66.13
\end{array}\right)\left(\begin{array}{c}
-101.27 \\
-0.78 \\
102.05
\end{array}\right)\left(\begin{array}{c}
-131.15 \\
-0.92 \\
132.07
\end{array}\right)\right]
$$$$
\left.\mathrm{r}_{0}:=\mathrm{resw}_{0} \quad \mathrm{r}_{1}:=\mathrm{resw}_{1}:=\mathrm{resw}_{2} \quad \mathrm{r}_{3}:=\mid \begin{array}{l}
\mathrm{resw}_{3} \text { if Caso }=\mathrm{Caso}_{2} \\
0 \\
0 \\
0
\end{array}\right) \text { otherwise }
$$

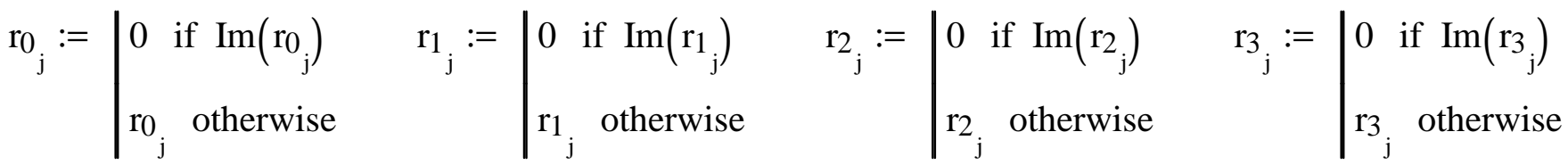


Seleção da maior raiz positiva do vetor resw, para $\delta_{\text {sup }}$

$$
S_{\text {máx } 0}:=\mid \begin{array}{ll}
\mathrm{r}_{0} \text { if }\left(\mathrm{r}_{0} \geq \mathrm{r}_{0}\right) \cdot\left(\mathrm{r}_{0} \geq \mathrm{r}_{0}\right) \\
\mathrm{r}_{0} \text { if }\left(\mathrm{r}_{0} \geq \mathrm{r}_{0}\right) \cdot\left(\mathrm{r}_{0} \geq \mathrm{r}_{0}\right) \\
\left.\mathrm{r}_{2}\right) \text { if }\left(\mathrm{r}_{0} \geq \mathrm{r}_{0}\right) \cdot\left(\mathrm{r}_{0_{2}} \geq \mathrm{r}_{0}\right)
\end{array}
$$$$
S_{\text {máx } 1}:=\mid \begin{array}{ll}
r_{1} \text { if }\left(r_{1_{0}} \geq r_{1}\right) \cdot\left(r_{1} \geq r_{1}\right) \\
r_{1} \text { if }\left(r_{1} \geq r_{1}\right) \cdot\left(r_{1} \geq r_{1}\right) \\
r_{1} \text { if }\left(r_{1_{2}} \geq r_{0}\right) \cdot\left(r_{1} \geq r_{1}\right)
\end{array}
$$

$\mathrm{S}_{\text {máx0 }}=66.1302 \quad \mathrm{~cm}$

$$
\mathrm{S}_{\text {máx1 }}=102.0538 \quad \mathrm{~cm}
$$

$$
S_{\operatorname{máx} 2}:=\mid \begin{array}{ll}
\mathrm{r}_{2} & \text { if }\left(\mathrm{r}_{0} \geq \mathrm{r}_{2}\right) \cdot\left(\mathrm{r}_{0} \geq \mathrm{r}_{2}\right) \\
\mathrm{r}_{2} & \text { if }\left(\mathrm{r}_{2} \geq \mathrm{r}_{2}\right) \cdot\left(\mathrm{r}_{2} \geq \mathrm{r}_{2}\right) \\
\mathrm{r}_{2} & \text { if }\left(\mathrm{r}_{2} \geq \mathrm{r}_{2}\right) \cdot\left(\mathrm{r}_{2} \geq \mathrm{r}_{2}\right)
\end{array}
$$

$$
S_{\text {máx3 }}:=\mid \begin{array}{ll}
r_{3} & \text { if }\left(r_{3} \geq r_{3}\right) \cdot\left(r_{3} \geq r_{3}\right) \\
r_{3} & \text { if }\left(r_{3_{0}} \geq r_{3}\right) \cdot\left(r_{3} \geq r_{3}\right) \\
r_{3} & \text { if }\left(r_{3} \geq r_{3}\right) \cdot\left(r_{3} \geq r_{3}\right)
\end{array}
$$

$\mathrm{S}_{\operatorname{máx} 2}=132.0696 \mathrm{zm}$

$\mathrm{S}_{\operatorname{máx} 3}=0$

$\mathrm{cm}$

$$
\begin{aligned}
& \mathrm{S}_{\text {máx }}:=\text { if Caso = } \mathrm{Caso}_{2} \\
& \mathrm{~S}_{\text {máx0 }} \text { if } \mathrm{C}_{\text {tabuleiro }}=\text { "C20" } \\
& \mathrm{S}_{\text {máx1 }} \text { if } \mathrm{C}_{\text {tabuleiro }}=\text { "C30" } \\
& \mathrm{S}_{\text {máx2 }} \text { if } \mathrm{C}_{\text {tabuleiro }}=\text { "C40" } \\
& \text { - } \mathrm{S}_{\mathrm{máx} 3} \text { if } \mathrm{C}_{\text {tabuleiro }}=\text { "C60" } \\
& \text { if } \mathrm{Caso}=\mathrm{Caso}_{4} \\
& \text { | } \mathrm{S}_{\text {máx0 }} \text { if } \mathrm{C}_{\text {tabuleiro }}=\text { "C20" } \\
& \mathrm{S}_{\text {máx1 }} \text { if } \mathrm{C}_{\text {tabuleiro }}=\text { "C30" } \\
& \mathrm{S}_{\text {máx2 }} \text { if } \mathrm{C}_{\text {tabuleiro }}=\text { "C40" } \\
& \mathrm{S}_{\text {máx3 }} \text { if } \mathrm{C}_{\text {tabuleiro }}=\text { "C60" } \\
& \text { otherwise } \\
& \| \mathrm{S}_{\text {máx0 }} \text { if } \mathrm{C}_{\text {tabuleiro }}=\text { "C20" } \\
& \mathrm{S}_{\text {máx1 }} \text { if } \mathrm{C}_{\text {tabuleiro }}=\text { "C25" } \\
& \mathrm{S}_{\text {máx2 }} \text { if } \mathrm{C}_{\text {tabuleiro }}=\text { "C30" }
\end{aligned}
$$

Portanto, o espaçamento máximo entre nervuras, para a $\mathrm{C}_{\text {tabuleiro }}=$ "C30"

é: $\quad S_{\text {máx }}=132.0696 \mathrm{~cm}$ 
A partir do valor $\mathrm{S}_{\text {máx }}$ é calculado o número mínimo de nervuras.

$\mathrm{n}_{\text {min }}:=1+\frac{\mathrm{b}-\mathrm{B}_{\mathrm{w}}}{\mathrm{S}_{\text {máx }}}$

$\mathrm{n}_{\min }=\left(\begin{array}{c}1.8102 \\ 1.8026 \\ 1.795\end{array}\right)$

$\mathrm{n}:=\max \left(\mathrm{n}_{\min }\right)$

$\mathrm{n}:=\operatorname{ceil}(\mathrm{n})$

Portanto, o número de nervuras é $\mathrm{n}:=6$

Em função do $n$ serão calculados os espaçamentos $S$ correspondentes aos valores de $B_{w}$

$$
\begin{aligned}
\mathrm{S}_{\mathrm{k}} & :=\frac{\mathrm{b}-\mathrm{B}_{\mathrm{w}_{\mathrm{k}}}}{\mathrm{n}-1} \\
\mathrm{~S} & =\left(\begin{array}{c}
21.4 \\
21.2 \\
21
\end{array}\right) \mathrm{cm}
\end{aligned}
$$

VerificaçãoS $_{\mathrm{k}}:=\mid \begin{array}{ll}\text { "O.K" } & \text { if } 14<\mathrm{S}_{\mathrm{k}}<40 \\ \text { "Não" } & \text { otherwise }\end{array}$

VerificaçãoS $=\left(\begin{array}{c}\text { "O.K" } \\ \text { "O.K" } \\ \text { "O.K" }\end{array}\right)$ 
5) Verificação dos efeitos localizados no tabuleiro

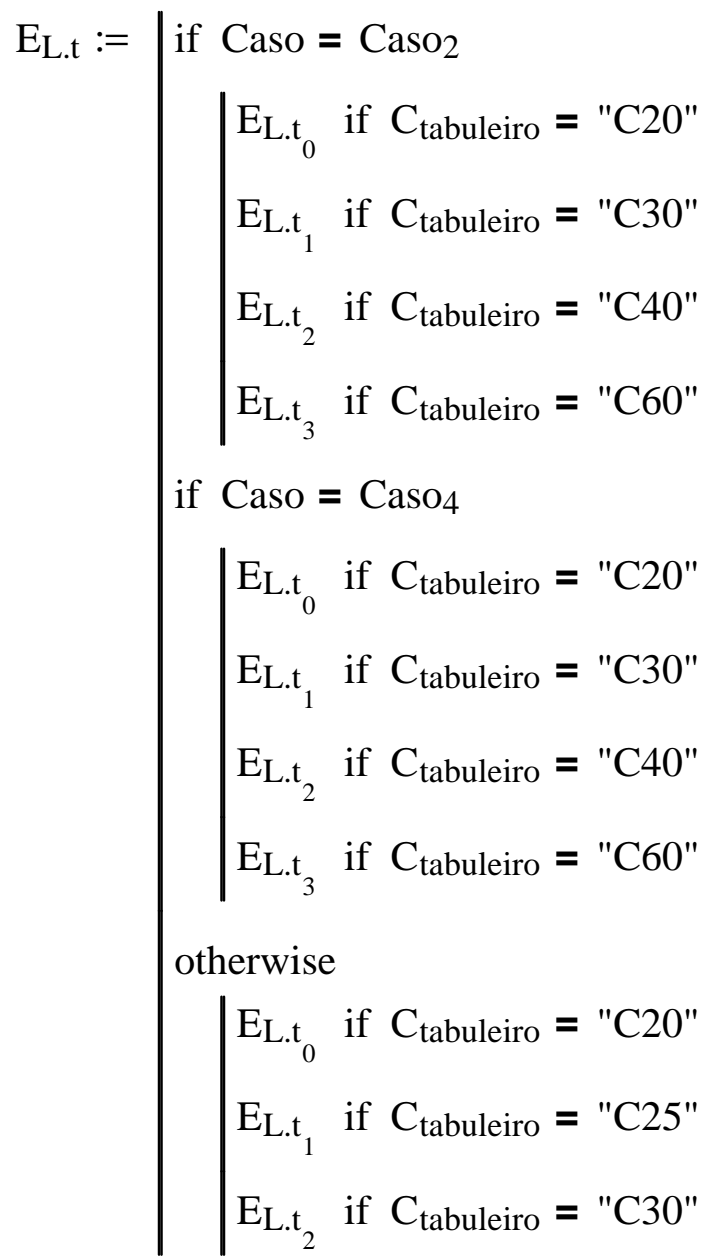

$\mathrm{E}_{\mathrm{L} . \mathrm{t}}=812 \quad \mathrm{kN} / \mathrm{cm}^{2}$

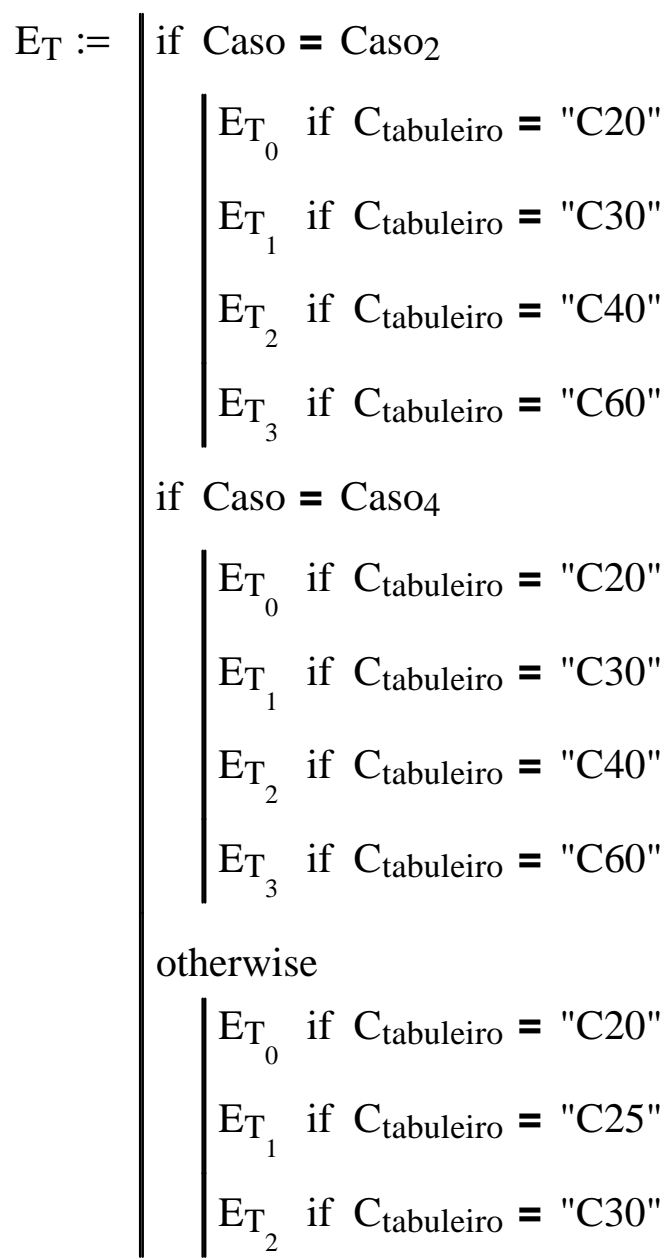

$\mathrm{E}_{\mathrm{T}}=17.7654 \quad \mathrm{kN} / \mathrm{cm}^{2}$ 


$$
\begin{aligned}
& E_{\mathrm{L} . n}:=\| \begin{array}{l}
\text { if } \text { Caso }=\mathrm{Caso}_{3} \\
\mathrm{E}_{\mathrm{L} . \mathrm{n}_{0}} \text { if } \mathrm{C}_{\text {nervura }}=\text { "C20" } \\
\mathrm{E}_{\mathrm{L} \mathrm{n}_{1}} \text { if } \mathrm{C}_{\text {nervura }}=\text { "C25" } \\
\mathrm{E}_{\mathrm{L} . \mathrm{n}_{2}} \text { if } \mathrm{C}_{\text {nervura }}=\text { "C } 30 "
\end{array} \\
& \text { if } \mathrm{Caso}=\mathrm{Caso}_{4} \\
& \mid \begin{array}{l}
\mathrm{E}_{\mathrm{L} \cdot \mathrm{n}_{0}} \text { if } \mathrm{C}_{\text {nervura }}=" \mathrm{C} 20 " \\
\mathrm{E}_{\mathrm{L} \cdot \mathrm{n}_{1}} \text { if } \mathrm{C}_{\text {nervura }}=" \mathrm{C} 25 " \\
\mathrm{E}_{\mathrm{L} \cdot \mathrm{n}_{2}} \text { if } \mathrm{C}_{\text {nervura }}=" \mathrm{C} 30 "
\end{array} \\
& \text { otherwise } \\
& \mid \begin{array}{l}
\mathrm{E}_{\mathrm{L} \cdot \mathrm{n}_{0}} \text { if } \mathrm{C}_{\text {nervura }}=" \mathrm{C} 20 " \\
\mathrm{E}_{\mathrm{L} \cdot \mathrm{n}_{1}} \text { if } \mathrm{C}_{\text {nervura }}=" \mathrm{C} 30 " \\
\mathrm{E}_{\mathrm{L} \cdot \mathrm{n}_{2}} \text { if } \mathrm{C}_{\text {nervura }}=" \mathrm{C} 40 " \\
\mathrm{E}_{\mathrm{L} \cdot \mathrm{n}_{3}} \text { if } \mathrm{C}_{\text {nervura }}=" \mathrm{C} 60 "
\end{array}
\end{aligned}
$$

$\mathrm{E}_{\mathrm{L} . \mathrm{n}}=812 \quad \mathrm{kN} / \mathrm{cm}^{2}$

a-Cálculo do deslocamento local máximo, $\delta_{\text {máx }}$

$$
\begin{aligned}
& \mathrm{K}_{\delta_{\mathrm{k}}}:=-10.9+7.8 \cdot\left(\frac{\mathrm{S}_{\mathrm{k}}}{\mathrm{t}}\right)+0.27 \cdot\left(\frac{\mathrm{E}_{\mathrm{L} . \mathrm{t}}}{\mathrm{E}_{\mathrm{T}}}\right) \\
& \delta_{\text {máx }_{\mathrm{k}}}:=\frac{\mathrm{P} \cdot\left(\mathrm{S}_{\mathrm{k}}\right)^{3}}{4 \cdot \mathrm{K}_{\delta_{\mathrm{k}}} \cdot \mathrm{E}_{\mathrm{T}} \cdot \mathrm{t}^{4}} \\
& \delta_{\text {localmáx }_{\mathrm{k}}}:=\left.\right|_{\text {"O.K" }} \text { if } \delta_{\text {máx }} \leq 0.5 \\
& \text { "Não" otherwise }
\end{aligned}
$$


b-Cálculo da tensão transversal local máxima, $\sigma_{\text {máx }}$

$$
\mathrm{K}_{\sigma_{\mathrm{k}}}:=3+3.1 \cdot\left(\frac{\mathrm{S}_{\mathrm{k}}}{\mathrm{t}},+0.15 \cdot\left(\frac{\mathrm{E}_{\mathrm{L} . \mathrm{t}}}{\mathrm{E}_{\mathrm{T}}}, \quad \sigma_{\text {máx }_{\mathrm{k}}}:=1.4 \cdot\left(\frac{3 \cdot \mathrm{P} \cdot \mathrm{S}_{\mathrm{k}}}{2 \cdot \mathrm{K}_{\sigma_{\mathrm{k}}} \cdot \mathrm{t}^{3}}+\sigma_{\mathrm{N}}\right)\right.\right.
$$

Resistência à compressão perpendicular às fibras ( $\left.f_{\mathrm{c} 90 . \mathrm{k}}\right), \mathrm{R}_{\mathrm{cperpendicular}}$

$$
\begin{aligned}
& \mathrm{f}_{\mathrm{c}}:=\mathrm{f}_{\mathrm{d}_{0,1}}
\end{aligned}
$$

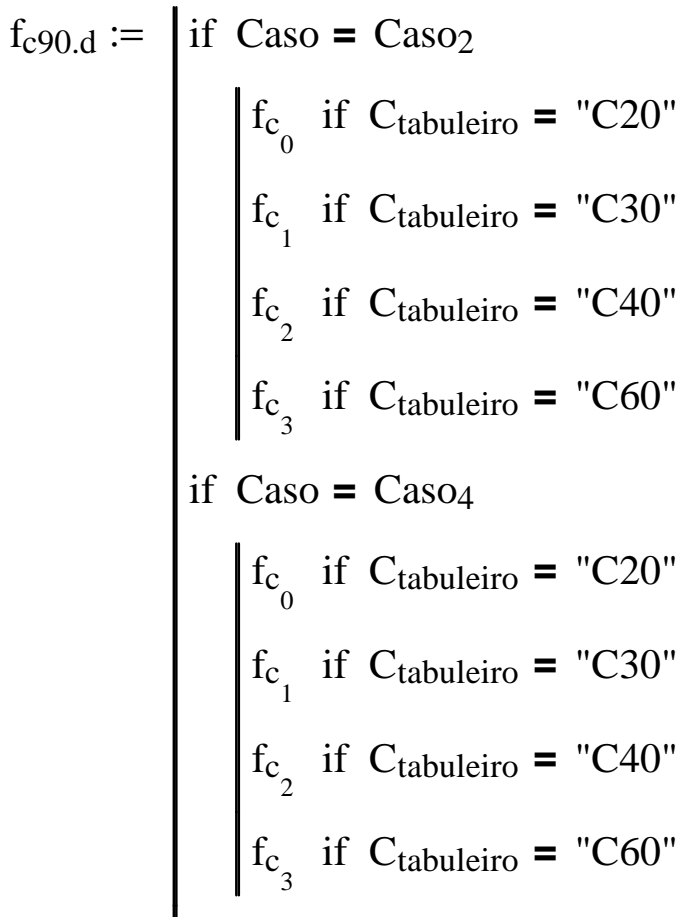

$$
\begin{aligned}
& \text { otherwise } \\
& \mid \begin{array}{l}
\mathrm{f}_{\mathrm{c}_{0}} \text { if } \mathrm{C}_{\text {tabuleiro }}=" \mathrm{C} 20 " \\
\mathrm{f}_{\mathrm{C}_{1}} \text { if } \mathrm{C}_{\text {tabuleiro }}=" \mathrm{C} 25 " \\
\mathrm{f}_{\mathrm{C}_{2}} \text { if } \mathrm{C}_{\text {tabuleiro }}=" \mathrm{C} 30 "
\end{array}
\end{aligned}
$$

$\mathrm{f}_{\mathrm{c} 90 . \mathrm{d}}=0.3 \quad \mathrm{kN} / \mathrm{cm}^{2}$

$$
\mathrm{R}_{\text {cperpendicular }}:=\mid \begin{array}{ll}
\text { "O.K" } & \text { if } \sigma_{\text {máx }_{k}} \leq \mathrm{f}_{\mathrm{c} 90 . \mathrm{d}} \\
\text { "Não" } & \text { otherwise }
\end{array}
$$


6) - Cálculo da largura efetiva da mesa de uma viga $\mathrm{T}\left(\mathrm{b}_{\mathrm{e}}\right)$

- Largura efetiva da aba $\left(\mathrm{B}_{\mathrm{E}}\right)$

$\mathrm{B}_{\mathrm{k}}:=\frac{1}{2} \cdot\left(\mathrm{S}_{\mathrm{k}}-\mathrm{B}_{\mathrm{w}_{\mathrm{k}}}\right) \quad \mathrm{D}:=\left(\begin{array}{c}22 \\ 20 \\ 18\end{array}\right) \mathrm{cm}$
$\mathrm{B}_{\mathrm{k}}:=\mathrm{B}_{\mathrm{k}} \cdot\left[0.4586+\frac{1}{198} \cdot\left(\frac{\mathrm{L}_{\mathrm{p}}}{\mathrm{B}_{\mathrm{k}}}\right) \cdot\left(\frac{\left.\mathrm{D}_{\mathrm{k}}-\mathrm{t}\right)}{\mathrm{t}}\right) \cdot \frac{\mathrm{E}_{\mathrm{L} \cdot \mathrm{n}}}{\mathrm{E}_{\mathrm{L} . \mathrm{t}}}\right]$

Verificação da condição $\frac{\mathrm{B}_{\mathrm{E}}}{\mathrm{B}} \leq 1 \quad \operatorname{rel}_{\mathrm{k}}:=\frac{\mathrm{B}_{\mathrm{k}}}{\mathrm{B}_{\mathrm{k}}} \quad \mathrm{rel}=\left(\begin{array}{c}0.8319 \\ 0.811 \\ 0.7869\end{array}\right)$

A largura efetiva da mesa é tomada como o menor entre os valores dos casos a, b, c:

$\mathrm{a}-\mathrm{b}_{\mathrm{k}} \leq 2.0 \cdot \mathrm{B}_{\mathrm{k}}+\mathrm{B}_{\mathrm{w}_{\mathrm{k}}} \quad \mathrm{b}_{\mathrm{ea}}:=2 \cdot \mathrm{B}_{\mathrm{k}}+\mathrm{B}_{\mathrm{w}_{\mathrm{k}}}$

$\mathrm{b}_{\mathrm{ea} 0}:=\mathrm{b}_{\mathrm{ea}} \quad \mathrm{b}_{\mathrm{ea} 1}:=\mathrm{b}_{\mathrm{ea}} \quad \mathrm{b}_{\mathrm{ea} 2}:=\mathrm{b}_{\mathrm{ea}}$

$\mathrm{b}-\mathrm{b}_{\mathrm{e}_{\mathrm{k}}} \leq \mathrm{S}_{\mathrm{k}} \quad \mathrm{b}_{\mathrm{eb}}:=\mathrm{S}_{\mathrm{k}}$

$b_{\mathrm{eb} 0}:=\mathrm{b}_{\mathrm{eb}} \quad \mathrm{b}_{\mathrm{eb} 1}:=\mathrm{b}_{\mathrm{eb}} \quad \mathrm{b}_{1} \quad:=\mathrm{b}_{\mathrm{eb}}$

$c-b_{e c} \leq \frac{L_{p}}{8} \quad b_{e c}:=\frac{L_{p}}{8}$

$b_{\mathrm{ec} 0}:=\mathrm{bec}_{0} \quad \mathrm{~b}_{\mathrm{ec} 1}:=\mathrm{b}_{\mathrm{ec}} \quad \mathrm{b}_{1} \quad:=\mathrm{b}_{\mathrm{ec}}$

$b_{e} 0:=\left|\begin{array}{l}b_{e a} \text { if }\left(b_{e a} \leq b_{e b 0}\right) \cdot\left(b_{e a} \leq b_{e c}\right) \\ b_{e b 0} \text { if }\left(b_{e b 0} \leq b_{e a 0}\right) \cdot\left(b_{e b 0} \leq b_{e c 0}\right) \\ b_{e c 0} \text { if }\left(b_{e c 0} \leq b_{e a 0}\right) \cdot\left(b_{e c 0} \leq b_{e b 0}\right)\end{array} \quad b_{e 1}:=\right| \begin{aligned} & b_{e a 1} \text { if }\left(b_{e a 1} \leq b_{e b 1}\right) \cdot\left(b_{e a 1} \leq b_{e c 1}\right) \\ & b_{e b 1} \text { if }\left(b_{e b 1} \leq b_{e a 1}\right) \cdot\left(b_{e b 1} \leq b_{e c 1}\right) \\ & b_{e c 1} \text { if }\left(b_{e c 1} \leq b_{e a 1}\right) \cdot\left(b_{e c 1} \leq b_{e b 1}\right)\end{aligned}$ 


$$
b_{e 2}:=\mid \begin{aligned}
& b_{e a 2} \text { if }\left(b_{e a 2} \leq b_{e b 2}\right) \cdot\left(b_{e a 2} \leq b_{e c 2}\right) \\
& b_{e b 2} \text { if }\left(b_{e b 2} \leq b_{e a 2}\right) \cdot\left(b_{e b 2} \leq b_{e c 2}\right) \\
& b_{e c 2} \text { if }\left(b_{e c 2} \leq b_{e a}\right) \cdot\left(b_{e c 2} \leq b_{e b 2}\right)
\end{aligned}
$$$$
b_{e}:=\left(\begin{array}{c}
b_{e} 0 \\
b_{\mathrm{e} 1} \\
b_{\mathrm{e} 2}
\end{array}\right)
$$

- Momento de Inércia Transformado

\section{Viga T interna}

$$
\text { Razão modular } \quad M_{R}:=\frac{E_{\text {L.t }}}{E_{\text {L.n }}} \quad M_{R}=1
$$

Largura efetiva transformada da aba $b_{t_{k}}:=M_{R} \cdot\left(b_{e_{k}}-B_{w_{k}}\right)$

Largura efetiva transformada da mesa $b_{e t}{ }_{k}:=b_{t}+B_{w_{k}}$

Localização da linha neutra

$\mathrm{y}_{\mathrm{n}}:=\frac{\mathrm{D}}{2} \quad \mathrm{~A}_{\mathrm{n}_{\mathrm{k}}}:=\mathrm{D}_{\mathrm{k}} \cdot \mathrm{B}_{\mathrm{w}_{\mathrm{k}}}$

ybal $:=\frac{\mathrm{t}}{2}+(\mathrm{D}-\mathrm{t}) \quad \mathrm{A}_{\mathrm{bal}_{\mathrm{k}}}:=\frac{\mathrm{b}_{\mathrm{t}}}{2} \cdot \mathrm{t}$

$\mathrm{y}_{\mathrm{k}}:=\frac{\mathrm{A}_{\mathrm{n}_{\mathrm{k}}} \cdot \mathrm{y}_{\mathrm{n}_{\mathrm{k}}}+2 \cdot \mathrm{A}_{\mathrm{bal}_{\mathrm{k}}} \cdot \mathrm{ybal}_{\mathrm{k}}}{\mathrm{A}_{\mathrm{n}_{\mathrm{k}}}+2 \cdot \mathrm{Abal}_{\mathrm{k}}}$

Momento de inércia da viga $\mathrm{T}$ interna

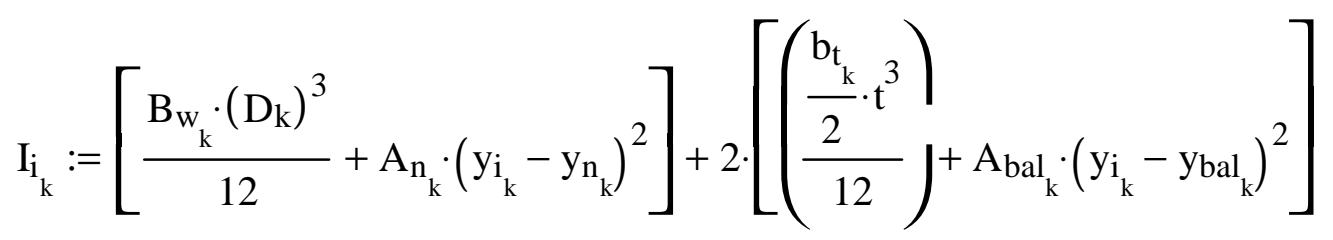


- Momento de Inércia Transformado

\section{Viga T Externa}

Largura efetiva transformada da aba $b_{\text {tex }}:=\left(\frac{b_{t}}{2}\right)$

Localização da linha neutra

$$
\operatorname{ybalx}_{\mathrm{k}}:=\frac{\mathrm{t}}{2}+\mathrm{D}_{\mathrm{k}}-\mathrm{t} \quad \mathrm{A}_{\mathrm{balx}_{\mathrm{k}}}:=\mathrm{t} \cdot \mathrm{b}_{\mathrm{tex}_{\mathrm{k}}}
$$

$\mathrm{yex}_{\mathrm{k}}:=\frac{\mathrm{A}_{\mathrm{k}} \cdot \mathrm{y}_{\mathrm{k}}+\mathrm{A}_{\mathrm{balx}_{\mathrm{k}}} \cdot \mathrm{ybalx}_{\mathrm{k}}}{\mathrm{A}_{\mathrm{n}_{\mathrm{k}}}+\mathrm{A}_{\mathrm{balx}_{\mathrm{k}}}}$

Momento de Inércia da viga T externa

$\left.\mathrm{I}_{\mathrm{ex}_{\mathrm{k}}}:=\left[\frac{\mathrm{B}_{\mathrm{w}_{\mathrm{k}}} \cdot\left(\mathrm{D}_{\mathrm{k}}\right)^{3}}{12}+\mathrm{A}_{\mathrm{n}_{\mathrm{k}}} \cdot\left(\mathrm{y}_{\mathrm{ex}_{\mathrm{k}}}-\mathrm{y}_{\mathrm{n}_{\mathrm{k}}}\right)^{2}\right]+\left[\left(\frac{\mathrm{b}_{\mathrm{tex}} \cdot \mathrm{t}^{3}}{12}\right)+\mathrm{A}_{\mathrm{balx}_{\mathrm{k}}} \cdot\left(\mathrm{y}_{\mathrm{ex}_{\mathrm{k}}}-\mathrm{y}_{\mathrm{balx}}\right)_{\mathrm{k}}\right)^{2}\right]$

7) Cálculo do fator de distribuição da carga de roda $\left(W_{f}\right)$

$$
\begin{aligned}
& \mathrm{D}_{\mathrm{T}}:=\mathrm{E}_{\mathrm{T}} \cdot \frac{\mathrm{t}^{3}}{12} \quad \mathrm{D}_{\mathrm{T}}=185.0561 \quad \mathrm{kN} . \mathrm{cm} \quad \mathrm{E}_{\mathrm{L} \cdot \mathrm{n}_{\mathrm{k}}}:=\mathrm{E}_{\mathrm{L} . \mathrm{n}} \quad \mathrm{B}_{\mathrm{e}_{\mathrm{k}}}:=\mathrm{E}_{\mathrm{L} \cdot \mathrm{n}_{\mathrm{k}} \cdot \mathrm{I}_{\mathrm{ex}_{\mathrm{k}}}} \\
& \lambda_{\mathrm{k}}:=\frac{\left(\mathrm{b}-\mathrm{B}_{\mathrm{w}_{\mathrm{k}}}\right)}{\mathrm{L}_{\mathrm{p}}} \quad \mathrm{C}_{\mathrm{k}}:=\frac{\left(\mathrm{b}-\mathrm{B}_{\mathrm{w}_{\mathrm{k}}}\right)}{\pi} \cdot \frac{\mathrm{D}_{\mathrm{T}}}{\mathrm{B}_{\mathrm{e}_{\mathrm{k}}}} \cdot \frac{\left[8 \cdot\left(\lambda_{\mathrm{k}}\right)^{2}+1\right]}{\left(\lambda_{\mathrm{k}}\right)^{4}} \\
& \mathrm{~W}_{\mathrm{f}}:=\frac{1+\mathrm{C}_{\mathrm{k}}}{\mathrm{n} \cdot \mathrm{C}_{\mathrm{k}}+\frac{2}{\pi} \cdot(\mathrm{n}-1)} \quad \mathrm{W}_{\mathrm{f}_{\mathrm{k}}}:=\mid \begin{array}{l}
\left(\mathrm{W}_{\mathrm{f}_{\mathrm{k}}} \cdot 1.6\right) \quad \text { if } \mathrm{N}_{\mathrm{L}}=1 \\
\mathrm{~W}_{\mathrm{f}_{\mathrm{k}}} \text { if } \mathrm{N}_{\mathrm{L}}=2
\end{array}
\end{aligned}
$$


8) Determinação do momento fletor de cálculo total $\left(\mathrm{Md}_{\mathrm{T}}\right)$

a- Cálculo do momento fletor máximo devido à carga móvel

$$
\begin{aligned}
& \mathrm{R}:=\frac{3 \cdot(2 \cdot \mathrm{P})}{2}+\mathrm{p} \cdot 60 \cdot\left(\frac{\mathrm{L}_{\mathrm{p}}-120}{2}\right) \quad \mathrm{R}=7.2 \quad \mathrm{kN} \\
& \phi:=1+\left(\frac{\alpha}{40+\frac{\mathrm{L}_{\mathrm{p}}}{100}}\right) \quad \phi=1.2857 \\
& \mathrm{M}_{\text {máx.v }}:=\mid \begin{array}{l}
{\left[\mathrm{R} \cdot\left(\frac{\left.\mathrm{L}_{\mathrm{p}}\right)}{2},-\left[\left(\mathrm{p} \cdot 60 \cdot \frac{\left.\mathrm{L}_{\mathrm{p}}-120\right)}{2}\right) \cdot\left(\frac{\mathrm{L}_{\mathrm{p}}-120}{4}+60\right)+2 \cdot \mathrm{P} \cdot 30\right]\right] \text { if } \mathrm{N}_{\mathrm{L}}=1\right.} \\
{\left[\mathrm{R} \cdot\left(\frac{\left.\mathrm{L}_{\mathrm{p}}\right)}{2},-\left[\left(\mathrm{p} \cdot 60 \cdot \frac{\left.\mathrm{L}_{\mathrm{p}}-120\right)}{2}\right) \cdot\left(\frac{\mathrm{L}_{\mathrm{p}}-120}{4}+60\right)+2 \cdot \mathrm{P} \cdot 30\right]\right] \text { if } \mathrm{N}_{\mathrm{L}}=2\right.}
\end{array}
\end{aligned}
$$

$\mathrm{M}_{\text {máx.v }}=504 \quad \mathrm{kN} . \mathrm{cm}$

$\mathrm{P}_{\mathrm{e}}:=\frac{4 \cdot \mathrm{M}_{\text {máx.v }}}{\mathrm{L}_{\mathrm{p}}} \quad \mathrm{P}_{\mathrm{e}}=10.08 \mathrm{kN}$

$\mathrm{P}_{\mathrm{k}}:=\mathrm{N}_{\mathrm{L}} \cdot \mathrm{W}_{\mathrm{k}} \cdot \mathrm{P}_{\mathrm{e}}$

$\mathrm{M}_{\text {máx.cm }}:=\frac{\mathrm{P}_{\mathrm{k}} \cdot \mathrm{L}_{\mathrm{p}}}{4}$ 
b- Calculo do momento tletor maximo devido a carga permanente

- Cálculo da carga permanente total suportada por uma nervura interna

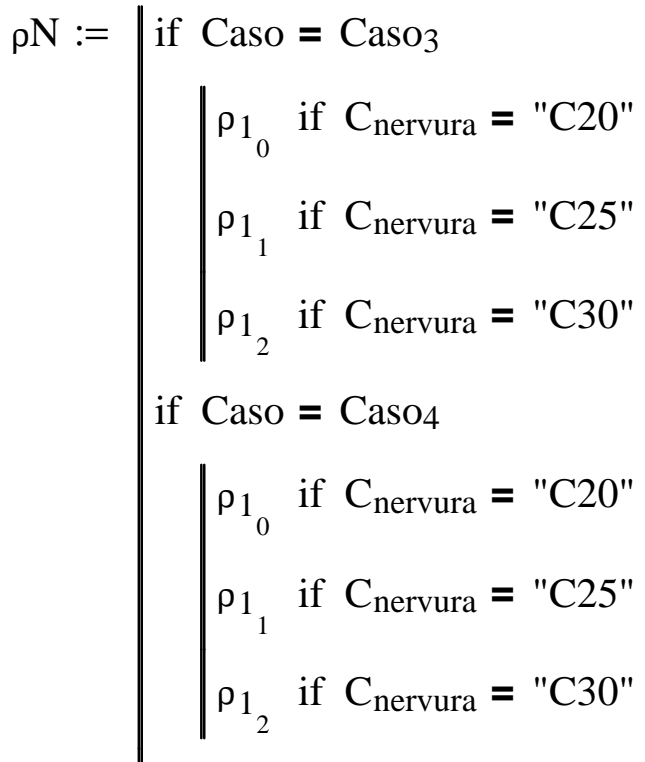

$$
\begin{aligned}
& \text { otherwise } \\
& \left\{\begin{array}{l}
\rho_{2} \text { if } C_{\text {nervura }}=" \mathrm{C} 20 " \\
\rho_{2} \text { if } C_{\text {nervura }}=" \mathrm{C} 30 " \\
\rho_{2} \text { if } C_{\text {nervura }}=\text { "C } 40 " \\
\rho_{2} \text { if } C_{\text {nervura }}=\text { "C } 60 "
\end{array}\right.
\end{aligned}
$$

$\rho \mathrm{N}=6 \times 10^{-4} \mathrm{~kg} / \mathrm{cm}^{3}$

b.1-Peso-próprio das barras de protensão, linearmente distribuído ao longo do vão

$$
\mathrm{P}_{\mathrm{bp}}:=\frac{\mathrm{P}_{\mathrm{b}}}{\mathrm{s} \cdot \mathrm{n}}
$$

b.2-Peso-próprio da nervura, linearmente distribuído ao longo do vão

$$
\mathrm{P}_{\mathrm{n}_{\mathrm{k}}}:=\left(9.81 \cdot \rho \mathrm{N} \cdot \mathrm{A}_{\mathrm{n}_{\mathrm{k}}}\right) \cdot 10^{-3}
$$


D.J-reso-proprio do tabuıeıro entre auas nervuras, ınearmente aıstrıbuido ao ıongo do vão

$$
\begin{aligned}
& \rho \mathrm{T}:=\quad \text { if } \mathrm{Caso}=\mathrm{Caso}_{2} \\
& \mid \begin{array}{l}
\rho_{2} \text { if } C_{\text {tabuleiro }}=" \mathrm{C} 20 " \\
\rho_{2} \text { if } C_{\text {tabuleiro }}=" \mathrm{C} 30 " \\
\rho_{2} \text { if } C_{\text {tabuleiro }}=\text { "C40" } \\
\rho_{2_{3}} \text { if } C_{\text {tabuleiro }}=\text { "C60" }
\end{array} \\
& \text { if } \mathrm{Caso}=\mathrm{Caso} 4 \\
& \rho_{2} \text { if } \mathrm{C}_{\text {tabuleiro }}=\text { "C20" } \\
& \rho_{2} \text { if } \mathrm{C}_{\text {tabuleiro }}=\text { "C30" } \\
& \rho_{2} \text { if } C_{\text {tabuleiro }}=\text { "C40" } \\
& \rho_{2} \text { if } C_{\text {tabuleiro }}=\text { "C60" } \\
& \mid \begin{array}{l}
\rho_{1_{0}} \text { if } \mathrm{C}_{\text {tabuleiro }}=" \mathrm{C} 20 " \\
\rho_{1_{1}} \text { if } \mathrm{C}_{\text {tabuleiro }}=" \mathrm{C} 25 " \\
\rho_{1_{2}} \text { if } \mathrm{C}_{\text {tabuleiro }}=" \mathrm{C} 30 "
\end{array}
\end{aligned}
$$

$\rho \mathrm{T}=6 \times 10^{-4} \mathrm{~kg} / \mathrm{cm}^{3}$

$$
\mathrm{A}_{\mathrm{k}}:=\left(\mathrm{S}_{\mathrm{k}}-\mathrm{B}_{\mathrm{w}_{\mathrm{k}}}\right) \cdot \mathrm{t} \quad \mathrm{P}_{\mathrm{k}}:=\left(9.81 \cdot \rho \mathrm{T} \cdot \mathrm{A}_{\mathrm{t}}\right) \cdot 10^{-3}
$$

b.4- Peso-próprio do revestimento asfáltico sobre uma seção do tabuleiro, linearmente distribuído ao longo do vão

$$
\mathrm{A}_{\mathrm{asf}_{\mathrm{k}}}:=\mathrm{S}_{\mathrm{k}} \cdot \mathrm{c}_{\mathrm{asf}} \quad \mathrm{P}_{\mathrm{asf}}:=\gamma_{\mathrm{kaf}} \cdot \mathrm{A}_{\mathrm{asf}}{ }_{\mathrm{k}}
$$

Portanto, a carga permanente total suportada por uma nervura interna é: $\mathrm{P}_{\mathrm{nt}_{\mathrm{k}}}:=\mathrm{P}_{\mathrm{bp}_{\mathrm{k}}}+\mathrm{P}_{\mathrm{n}_{\mathrm{k}}}+\mathrm{P}_{\mathrm{t}_{\mathrm{k}}}+\mathrm{P}_{\mathrm{asf}}$

Portanto: $\quad \mathrm{M}_{\text {máx.cp }}:=\frac{\mathrm{P}_{\mathrm{nt}} \cdot \mathrm{L}_{\mathrm{p}}{ }^{2}}{8}$ 
c- Cálculo do momento fletor de cálculo total

$\gamma_{\mathrm{g}_{\mathrm{k}}}:=1.4$ coeficiente de ponderação para estados limites últimos (ações permanentes de grande variabilidade)

$\gamma_{\mathrm{q}}:=1.4$ coeficiente de ponderação para estados limites últimos (ações variáveis)

Combinações em estados limites últimos

* Combinações últimas normais

$$
\mathrm{Md}_{\mathrm{k}}:=\gamma_{\mathrm{g}_{\mathrm{k}}} \cdot \mathrm{M}_{\text {máx.cp }}+\gamma_{\mathrm{q}} \cdot \mathrm{M}_{\text {máx.cm }}+0.75 \cdot \gamma_{\mathrm{q}} \cdot\left[(\phi-1) \cdot \mathrm{M}_{\text {máx.cm }}\right]
$$

9) Cálculo do cortante de cálculo total $\left(\mathrm{Vd}_{\mathrm{T}}\right)$

a- Esforço cortante devido à carga permanente, $\mathrm{V}_{\mathrm{cp}}$, no ponto $\mathrm{x}$

$$
\mathrm{x}_{\mathrm{cp}_{\mathrm{k}}}:=2 \cdot \mathrm{D}_{\mathrm{k}} \quad \mathrm{cm}
$$

$\mathrm{V}_{\mathrm{cp}_{\mathrm{k}}}:=\mathrm{P}_{\mathrm{nt}} \cdot\left(\frac{\mathrm{L}_{\mathrm{p}}}{2}-\mathrm{x}_{\mathrm{cp}_{\mathrm{k}}}\right)$

b- Esforço cortante devido à carga móvel, $\mathrm{V}_{\mathrm{cm}}$

Esforço cortante na distância $\mathrm{x}$ devido às cargas de rodas concentradas, sem distribuição de carga, $\mathrm{V}_{\text {crc }}$

$$
\begin{aligned}
& \mathrm{V}_{\mathrm{crc} 1}:=\frac{\mathrm{P} \cdot\left[\left(\mathrm{L}_{\mathrm{p}}-\mathrm{x}_{\mathrm{cp}}\right)+\left[\mathrm{L}_{\mathrm{p}}-\left(30+\mathrm{x}_{\mathrm{cp}}\right)\right]+\left[\mathrm{L}_{\mathrm{p}}-\left(60+\mathrm{x}_{\mathrm{cp}}\right)\right]\right]}{\mathrm{L}_{\mathrm{p}}} \\
& \mathrm{V}_{\mathrm{crc} 2 \mathrm{k}}:=\frac{\mathrm{p} \cdot 60 \cdot\left[\mathrm{L}_{\mathrm{p}}-\left(\mathrm{x}_{\mathrm{cp}_{\mathrm{k}}}+90\right)\right] \cdot\left[\frac{\mathrm{L}_{\mathrm{p}}-\left(\mathrm{x}_{\mathrm{cp}_{\mathrm{k}}}+90\right)}{2}\right]}{\mathrm{L}_{\mathrm{p}}} \\
& \mathrm{V}_{\mathrm{crc}}:=\mathrm{V}_{\mathrm{crc} 1}+\mathrm{V}_{\mathrm{crc} 2}
\end{aligned}
$$


Esforço cortante na distância $\mathrm{x}$ devido às cargas de rodas distribuídas, $\mathrm{V}_{\mathrm{crd}}$

$\mathrm{V}_{\mathrm{crd}}:=\mathrm{N}_{\mathrm{L}} \cdot \mathrm{W}_{\mathrm{k}} \cdot \mathrm{V}_{\mathrm{crc}_{\mathrm{k}}}$

Portanto:

$\mathrm{V}_{\mathrm{cm}_{\mathrm{k}}}:=\frac{1}{2} \cdot\left(0.6 \cdot \mathrm{V}_{\mathrm{crc}_{\mathrm{k}}}+\mathrm{V}_{\mathrm{crd}_{\mathrm{k}}}\right)$

c- Cálculo do cortante de cálculo total

Combinações em estados limites últimos

* Combinações últimas normais

$$
\mathrm{Vd}_{\mathrm{k}}:=\gamma_{\mathrm{g}_{\mathrm{k}}} \cdot \mathrm{V}_{\mathrm{cp}_{\mathrm{k}}}+\gamma_{\mathrm{q}} \cdot \mathrm{V}_{\mathrm{cm}_{\mathrm{k}}}+0.75 \cdot \gamma_{\mathrm{q}} \cdot\left[(\phi-1) \cdot \mathrm{V}_{\mathrm{cm}_{\mathrm{k}}}\right]
$$

10) Verificações

a- Verificação da seção transversal T

a.1- Verificação das tensões normais

a.1.1- Tensão de tração máxima na nervura

$$
\mathrm{c}_{\mathrm{k}}:=\mathrm{yi}_{\mathrm{k}}
$$

$\sigma_{\mathrm{t}_{\mathrm{k}}}:=\frac{\mathrm{Md}_{\mathrm{T}} \cdot \mathrm{c}_{\mathrm{k}}}{\mathrm{I}_{\mathrm{i}_{\mathrm{k}}}}$ 
Resistência à tração paralela às fibras $\left(f_{t 0 . k}\right), R_{t f}$

$$
\begin{aligned}
& \mathrm{f}_{\mathrm{c}}:=\mathrm{f}_{\mathrm{d}_{3,0}} \\
& \mathrm{f}_{\mathrm{t} 0 . \mathrm{d}}:=\mid \begin{array}{ll}
\text { if } \text { Caso }=\text { Caso } 3 \\
\mathrm{f}_{\mathrm{C}_{0}} \text { if } \mathrm{C}_{\text {nervura }}=" \mathrm{C} 20 " \\
\mathrm{f}_{\mathrm{C}_{1}} \text { if } \mathrm{C}_{\text {nervura }}=" \mathrm{C} 25 " \\
\mathrm{f}_{\mathrm{C}_{2}} \text { if } \mathrm{C}_{\text {nervura }}=\text { "C } 30 "
\end{array} \\
& \text { if } \mathrm{Caso}=\mathrm{Caso}_{4} \\
& \left\{\begin{array}{l}
\mathrm{f}_{\mathrm{c}_{0}} \text { if } \mathrm{C}_{\text {nervura }}=\text { "C20" } \\
\mathrm{f}_{\mathrm{c}_{1}} \text { if } \mathrm{C}_{\text {nervura }}=" \mathrm{C} 25 " \\
\mathrm{f}_{\mathrm{c}_{2}} \text { if } \mathrm{C}_{\text {nervura }}=" \mathrm{C} 30 "
\end{array}\right. \\
& \text { otherwise } \\
& \left\{\begin{array}{l}
\mathrm{f}_{\mathrm{c}_{0}} \text { if } \mathrm{C}_{\text {nervura }}=" \mathrm{C} 20 " \\
\mathrm{f}_{\mathrm{c}_{1}} \text { if } \mathrm{C}_{\text {nervura }}=" \mathrm{C} 30 " \\
\mathrm{f}_{\mathrm{c}_{2}} \text { if } \mathrm{C}_{\text {nervura }}=\text { "C } 40 " \\
\mathrm{f}_{\mathrm{c}_{3}} \text { if } \mathrm{C}_{\text {nervura }}=\text { "C60" }
\end{array}\right.
\end{aligned}
$$

$\mathrm{f}_{\mathrm{t} 0 . \mathrm{d}}:=\operatorname{round}\left(\mathrm{f}_{\mathrm{t} 0 . \mathrm{d}}, 2\right) \quad \mathrm{f}_{\mathrm{t} 0 . \mathrm{d}}=1.21 \mathrm{kN} / \mathrm{cm}^{2}$

$$
\sigma_{\mathrm{t}}:=\operatorname{round}\left(\sigma_{\mathrm{t}_{\mathrm{k}}}, 2\right)
$$

$$
\mathrm{R}_{\mathrm{tf}}:=\mid \begin{array}{lll}
\text { "O.K." } & \text { if } \sigma_{\mathrm{t}_{\mathrm{k}}} \leq \mathrm{f}_{\mathrm{t} 0 . \mathrm{d}} \\
\text { "Não" } & \text { if } \sigma_{\mathrm{t}_{\mathrm{k}}}>\mathrm{f}_{\mathrm{t} 0 . \mathrm{d}} & \mathrm{R}_{\mathrm{tf} \%_{\mathrm{k}}}:=\frac{\sigma_{\mathrm{t}}}{\mathrm{f}_{\mathrm{t} 0 . \mathrm{d}}}
\end{array}
$$

$\mathrm{D}_{\mathrm{k}}:=\sqrt{\left(\mathrm{D}^{2}\right)_{\mathrm{k}} \cdot \mathrm{R}_{\mathrm{tf} \%}}$ 
a.1.2 - Tensão de compressão máxima no tabuleiro

$\mathrm{c}_{\mathrm{k}}:=\mathrm{D}_{\mathrm{k}}-\mathrm{y}_{\mathrm{k}} \quad \sigma_{\mathrm{c}_{\mathrm{k}}}:=\mathrm{M}_{\mathrm{R}} \cdot \frac{\mathrm{Md}_{\mathrm{T}} \cdot \mathrm{c}_{\mathrm{k}}}{\mathrm{I}_{\mathrm{k}}}$

Resistência à compressão paralela às fibras $\left(\mathrm{f}_{\mathrm{c} 0 . \mathrm{k}}\right), \mathrm{R}_{\mathrm{cparalela}}$

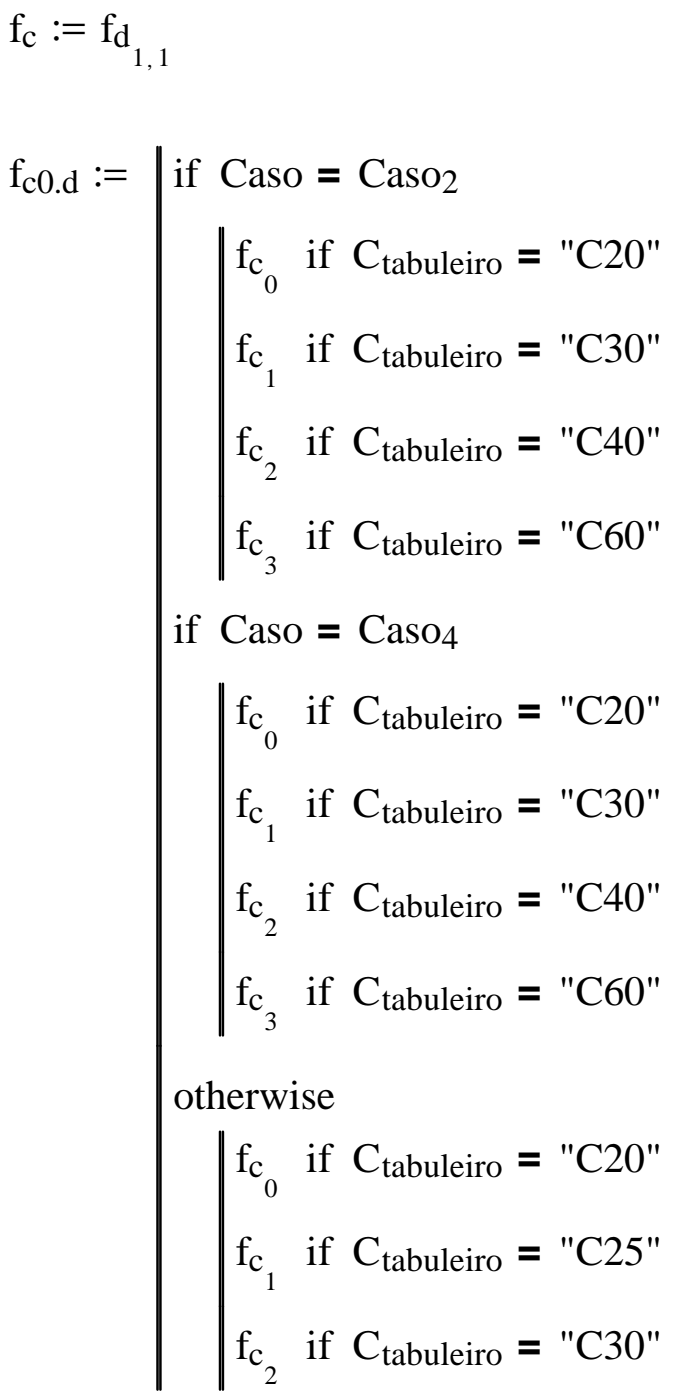

$\mathrm{f}_{\mathrm{c} 0 . \mathrm{d}}=1.2 \quad \mathrm{kN} / \mathrm{cm}^{2}$

$\mathrm{R}_{\text {cparalela }}:=\mid \begin{array}{ll}\text { "O.K." } & \text { if } \sigma_{\mathrm{c}_{\mathrm{k}}} \leq \mathrm{f}_{\mathrm{c} 0 . \mathrm{d}} \\ \text { "Não" } & \text { if } \sigma_{\mathrm{c}_{\mathrm{k}}}>\mathrm{f}_{\mathrm{c} 0 . \mathrm{d}}\end{array}$

$\mathrm{R}_{\text {cparalela }_{\mathrm{k}}}:=\frac{\sigma_{\mathrm{c}}}{\mathrm{f}_{\mathrm{c} 0 . \mathrm{d}}}$ 
a.2- Verifïcação das tensões de cisalhamento

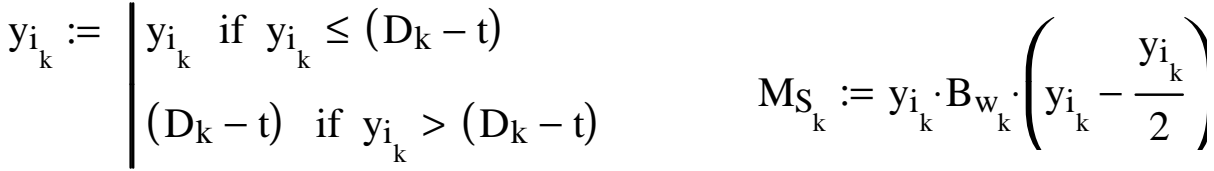

$$
\begin{aligned}
& \tau_{\mathrm{k}}:=\frac{\mathrm{Vd}_{\mathrm{T}} \cdot \mathrm{MS}_{\mathrm{k}}}{\mathrm{B}_{\mathrm{w}_{\mathrm{k}}} \cdot \mathrm{I}_{\mathrm{k}}}
\end{aligned}
$$

Resistência ao cisalhamento paralelo às fibras $\left(\mathrm{f}_{\mathrm{v} 0 . \mathrm{k}}\right), \mathrm{R}_{\text {cisparalelo }}$

$$
\begin{aligned}
& \mathrm{f}_{\mathrm{c}}:=\mathrm{f}_{2,0} \\
& \mathrm{f}_{\mathrm{v} 0 . \mathrm{d}}:=\mid \begin{array}{l}
\text { if } \text { Caso }=\mathrm{Caso}_{3} \\
\mid \begin{array}{ll}
\mathrm{f}_{\mathrm{c}_{0}} & \text { if } \mathrm{C}_{\text {nervura }}=" \mathrm{C} 20 " \\
\mathrm{f}_{\mathrm{c}_{1}} & \text { if } \mathrm{C}_{\text {nervura }}=\text { "C25" } \\
\mathrm{f}_{\mathrm{c}_{2}} & \text { if } \mathrm{C}_{\text {nervura }}=\text { "C } 30 "
\end{array}
\end{array} \\
& \text { if } \mathrm{Caso}=\mathrm{Caso} 4 \\
& \mathrm{f}_{\mathrm{c}_{0}} \text { if } \mathrm{C}_{\text {nervura }}=\text { "C20" } \\
& \mathrm{f}_{\mathrm{c}_{1}} \text { if } \mathrm{C}_{\text {nervura }}=\text { "C25" } \\
& \mathrm{f}_{\mathrm{c}_{2}} \text { if } \mathrm{C}_{\text {nervura }}=\text { "C } 30 " \\
& \text { otherwise } \\
& \mid \begin{array}{l}
\mathrm{f}_{\mathrm{C}_{0}} \text { if } \mathrm{C}_{\text {nervura }}=" \mathrm{C} 20 " \\
\mathrm{f}_{\mathrm{C}_{1}} \text { if } \mathrm{C}_{\text {nervura }}=" \mathrm{C} 30 " \\
\mathrm{f}_{\mathrm{c}_{2}} \text { if } \mathrm{C}_{\text {nervura }}=\text { "C } 40 " \\
\mathrm{f}_{\mathrm{C}_{3}} \text { if } \mathrm{C}_{\text {nervura }}=\text { "C60" }
\end{array}
\end{aligned}
$$

$\mathrm{f}_{\mathrm{v} 0 . \mathrm{d}}=0.1867 \mathrm{kN} / \mathrm{cm}^{2}$

$$
\mathrm{R}_{\text {cisparalelo }}:=\mid \begin{array}{ll}
\text { "O.K." } & \text { if } \tau_{\mathrm{k}} \leq \mathrm{f}_{\mathrm{v} 0 . \mathrm{d}} \\
\text { "Não" } & \text { if } \tau_{\mathrm{k}}>\mathrm{f}_{\mathrm{v} 0 . \mathrm{d}}
\end{array} \quad \mathrm{R}_{\text {cisparalelo\% }}:=\frac{\tau_{\mathrm{k}}}{\mathrm{f}_{\mathrm{v} 0 . \mathrm{d}}}
$$


a.3- Veriticação dos deslocamentos

- Cálculo do deslocamento devido à carga móvel

$\mathrm{z}:=\frac{\mathrm{L}_{\mathrm{p}}-120}{2} \quad \mathrm{z}=40 \quad \mathrm{~cm} \quad \mathrm{x}_{\delta}:=\mathrm{z}+30 \quad \mathrm{x}_{\delta}=70 \quad \mathrm{~cm} \quad \mathrm{P}_{\delta_{\mathrm{k}}}:=2 \cdot \mathrm{P} \cdot \mathrm{W}_{\mathrm{f}} \cdot \mathrm{N}_{\mathrm{L}}$

$\delta_{\mathrm{cm} 1_{\mathrm{k}}}:=\frac{\mathrm{P}_{\delta_{\mathrm{k}}} \cdot \mathrm{L}_{\mathrm{p}}{ }^{3}}{48 \cdot \mathrm{E}_{\mathrm{L} \cdot \mathrm{n}_{\mathrm{k}} \cdot \mathrm{I}_{\mathrm{k}}}}+\frac{\mathrm{P}_{\delta_{\mathrm{k}}} \cdot\left(\mathrm{x}_{\delta}\right)}{24 \cdot \mathrm{E}_{\mathrm{L} \cdot \mathrm{n}_{\mathrm{k}} \cdot \mathrm{I}_{\mathrm{k}}}} \cdot\left[3 \cdot \mathrm{L}_{\mathrm{p}}{ }^{2}-4 \cdot\left(\mathrm{x}_{\delta}\right)^{2}\right]$

$\delta_{\mathrm{cm} 2}:=2 \cdot\left[\frac{\mathrm{p} \cdot 60 \cdot(\mathrm{z})^{2}}{24 \cdot \mathrm{L}_{\mathrm{p}} \cdot \mathrm{E}_{\mathrm{L} \cdot \mathrm{n}_{\mathrm{k}} \cdot \mathrm{I}_{\mathrm{k}}}} \cdot\left[-\mathrm{z}^{2} \cdot \mathrm{L}_{\mathrm{p}}+2 \cdot \mathrm{L}_{\mathrm{p}}{ }^{3}+\mathrm{z}^{2} \cdot \frac{\mathrm{L}_{\mathrm{p}}}{2}-\frac{3}{2} \cdot \mathrm{L}_{\mathrm{p}}{ }^{3}+2 \cdot\left(\frac{\mathrm{L}_{\mathrm{p}}}{2}\right)^{3}\right]\right]$

$\delta_{\mathrm{cm}_{\mathrm{k}}}:=\delta_{\mathrm{cm} 1_{\mathrm{k}}}+\delta_{\mathrm{cm} 2}$

- Cálculo do deslocamento devido à carga permanente

$\delta_{\mathrm{cp}_{\mathrm{k}}}:=\frac{5 \cdot \mathrm{P}_{\mathrm{nt}} \cdot \mathrm{L}_{\mathrm{p}}{ }^{4}}{384 \cdot \mathrm{E}_{\mathrm{L} \cdot \mathrm{n}_{\mathrm{k}}} \cdot \mathrm{I}_{\mathrm{k}}}$

- Cálculo do deslocamento total

Combinações em estados limites de utilização

* Combinações de longa duração

$\delta_{\mathrm{t}_{\mathrm{k}}}:=\delta_{\mathrm{cp}_{\mathrm{k}}}+\psi_{2} \cdot \delta_{\mathrm{cm}_{\mathrm{k}}}$

Para elementos bi-apoiados $\quad \delta_{\lim }:=\frac{\mathrm{L}_{\mathrm{p}}}{200}$ 


$$
\text { Verificaçãost }_{\mathrm{k}}:=\mid \begin{array}{ll}
\text { "U.K." } & \text { if } \delta_{\mathrm{t}_{\mathrm{k}}} \leq \delta_{\lim } \\
\text { "Não" } & \text { if } \delta_{\mathrm{t}_{\mathrm{k}}}>\delta_{\lim }
\end{array} \quad \text { Verificação\% } \delta_{\mathrm{k}}:=\frac{\delta_{\mathrm{t}_{\mathrm{k}}}}{\delta_{\lim }}
$$

b- Verificação do puncionamento no tabuleiro

$\mathrm{V}_{\mathrm{k}}:=\frac{\mathrm{P}}{\mathrm{S}_{\mathrm{k}}} \cdot\left(\mathrm{S}_{\mathrm{k}}-\frac{\mathrm{a}+\mathrm{B}_{\mathrm{w}_{\mathrm{k}}}}{2}\right)$

Esforço cortante resistente, $\mathrm{V}_{\text {res }} \quad \mathrm{V}_{\text {res }}:=\sigma_{\mathrm{N}^{*}} \cdot \mathrm{b}_{1} \cdot \mathrm{t} \cdot \mu_{\mathrm{S}}$

$$
\mathrm{V}_{\text {local }}:=\mid \begin{array}{ll}
\text { "O.K." } & \text { if } \mathrm{V}_{\mathrm{k}} \leq \mathrm{V}_{\text {res }} \\
\text { "Não" } & \text { if } \mathrm{V}_{\mathrm{k}}>\mathrm{V}_{\text {res }}
\end{array} \quad \mathrm{V}_{\text {local }_{\mathrm{k}}}:=\frac{\mathrm{V}_{\mathrm{k}}}{\mathrm{V}_{\text {res }}}
$$

11) Cálculo do volume de madeira

a -Volume de madeira laminada colada das nervuras, $V_{\text {nervura }}$

$\mathrm{V}_{\text {nervura }_{\mathrm{k}}}:=\frac{\mathrm{n}}{10^{6}} \cdot\left(\mathrm{B}_{\mathrm{w}_{\mathrm{k}}} \cdot \mathrm{D}_{\mathrm{k}} \cdot \mathrm{L}_{\mathrm{p}}\right)$

b -Volume de madeira serrada do tabuleiro, $\mathrm{V}_{\text {tabuleiro }}$

$\mathrm{V}_{\text {tabuleiro }_{\mathrm{k}}}:=\left[\mathrm{b}-\left(\mathrm{n} \cdot \mathrm{B}_{\mathrm{w}}\right)\right] \cdot \mathrm{t} \cdot \frac{\mathrm{L}_{\mathrm{p}}}{10^{6}}$ 
$\mathrm{C}_{\text {tabuleiro }}=$ "C30"

$$
\mathrm{C}_{\text {nervura }}=\text { "C30" }
$$

$$
\delta_{\text {sup }}=0.5 \quad \mathrm{~cm}
$$

4) $\mathrm{L}_{\mathrm{p}}=200 \mathrm{~cm} \quad \mathrm{~b}=110 \mathrm{~cm} \quad \mathrm{t}=5 \mathrm{~cm} \quad \mathrm{n}=6$

$$
\mathrm{S}=\left(\begin{array}{c}
21.4 \\
21.2 \\
21
\end{array}\right) \mathrm{cm}
$$

5) $\mathrm{E}_{\mathrm{L} . \mathrm{t}}=812 \mathrm{kN} / \mathrm{cm}^{2}$

$$
\delta_{\text {máx }}=\left(\begin{array}{l}
0.0127 \\
0.0124 \\
0.0122
\end{array}\right) \mathrm{cm}
$$

Verificação do deslocamento local máximo $\quad \delta_{\text {localmáx }}=\left(\begin{array}{c}\text { "O.K" } \\ \text { "O.K" } \\ \text { "O.K" }\end{array}\right)$

$\sigma_{\text {máx }}=\left(\begin{array}{c}0.1291 \\ 0.129 \\ 0.1288\end{array}\right) \mathrm{kN} / \mathrm{cm}^{2}$

Verificação da Resistência à compressão perpendicular à fibra $\quad \mathrm{R}_{\text {cperpendicular }}=\left(\begin{array}{c}\text { "O.K" } \\ \text { "O.K" } \\ \text { "O.K" }\end{array}\right)$

6)

$$
\mathrm{B}=\left(\begin{array}{c}
9.2 \\
8.6 \\
8
\end{array}\right) \mathrm{cm}
$$$$
\mathrm{B}_{\mathrm{E}}=\left(\begin{array}{l}
7.6535 \\
6.9743 \\
6.2951
\end{array}\right) \mathrm{cm}
$$$$
\mathrm{rel}=\left(\begin{array}{c}
0.8319 \\
0.811 \\
0.7869
\end{array}\right)
$$

$$
\mathrm{b}_{\mathrm{e}}=\left(\begin{array}{l}
18.3069 \\
17.9485 \\
17.5901
\end{array}\right) \mathrm{cm}
$$

$$
\mathrm{b}_{\mathrm{t}}=\left(\begin{array}{l}
15.3069 \\
13.9485 \\
12.5901
\end{array}\right) \mathrm{cm}
$$

$$
\mathrm{D}=\left(\begin{array}{l}
22 \\
20 \\
18
\end{array}\right) \mathrm{cm}
$$




$$
\begin{array}{rlrl}
\mathrm{b}_{\text {eti }} & =\left(\begin{array}{c}
18.307 \\
17.949 \\
17.59
\end{array}\right) \mathrm{cm} & \mathrm{I}_{\mathrm{i}}=\left(\begin{array}{c}
5381.92 \\
4907.84 \\
4126.16
\end{array}\right) \mathrm{cm}^{4} \\
\mathrm{~b}_{\text {tex }}=\left(\begin{array}{c}
7.65 \\
6.97 \\
6.3
\end{array}\right)^{\mathrm{cm}} & \mathrm{I}_{\mathrm{ex}}=\left(\begin{array}{c}
4491.82 \\
4105.37 \\
3480.83
\end{array}\right)^{\mathrm{cm}^{4}}
\end{array}
$$

7)

$$
\mathrm{W}_{\mathrm{f}}=\left(\begin{array}{l}
0.475 \\
0.473 \\
0.468
\end{array}\right)
$$

8)

$$
\mathrm{M}_{\text {máx.cm }}=\left(\begin{array}{c}
240 \\
238 \\
236
\end{array}\right) \quad \mathrm{kN} . \mathrm{cm} \quad \mathrm{M}_{\text {máx.cp }}=\left(\begin{array}{c}
7.3 \\
7.51 \\
7.61
\end{array}\right) \quad \mathrm{kN} . \mathrm{cm} \quad \mathrm{Md}_{\mathrm{T}}=\left(\begin{array}{l}
418 \\
416 \\
411
\end{array}\right) \quad \mathrm{kN} . \mathrm{cm}
$$

9)

$$
\mathrm{V}_{\mathrm{cp}}=\left(\begin{array}{c}
0.08 \\
0.09 \\
0.1
\end{array}\right) \mathrm{kN} \quad \mathrm{V}_{\mathrm{cm}}=\left(\begin{array}{c}
2.21 \\
2.29 \\
2.37
\end{array}\right) \mathrm{kN} \quad \mathrm{Vd}_{\mathrm{T}}=\left(\begin{array}{l}
3.8682 \\
4.0174 \\
4.1573
\end{array}\right) \mathrm{kN}
$$

10)

Verificação da resistência à tração paralela às fibras, $\mathrm{R}_{\mathrm{tf}}$

$$
\begin{aligned}
& \sigma_{\mathrm{t}}=\left(\begin{array}{c}
1.21 \\
1.14 \\
1.16
\end{array}\right) \mathrm{kN} / \mathrm{cm}^{2} \quad \mathrm{R}_{\mathrm{tf} \%}=\left(\begin{array}{c}
1 \\
0.9421 \\
0.9587
\end{array}\right) \quad \mathrm{R}_{\mathrm{tf}}=\left(\begin{array}{c}
\text { "O.K." } \\
\text { "O.K." } \\
\text { "O.K." }
\end{array}\right) \\
& \mathrm{S}=\left(\begin{array}{c}
21.4 \\
21.2 \\
21
\end{array}\right) \quad \mathrm{D} 0=\left(\begin{array}{c}
22 \\
19.4129 \\
17.6242
\end{array}\right) \quad \mathrm{DD}_{\mathrm{k}}:=\operatorname{ceil}\left(\mathrm{D} 0_{\mathrm{k}}\right)
\end{aligned}
$$




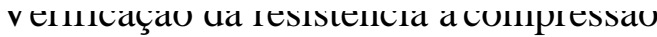
paralela às fibras, $\mathrm{R}_{\mathrm{cparalela}}$

$$
\begin{aligned}
& \sigma_{\mathrm{c}}=\left(\begin{array}{l}
0.4993 \\
0.5509 \\
0.6305
\end{array}\right) \mathrm{kN} / \mathrm{cm}^{2} \\
& \mathrm{R}_{\text {cparalela\% }}=\left(\begin{array}{l}
0.4161 \\
0.4591 \\
0.5255
\end{array}\right) \\
& \mathrm{R}_{\text {cparalela }}=\left(\begin{array}{c}
\text { "O.K." } \\
\text { "O.K." } \\
\text { "O.K." }
\end{array}\right)
\end{aligned}
$$

Verificação da resistência ao cisalhamento paralelo às fibras, $\mathrm{R}_{\text {cisparalelo }}$

$$
\tau=\left(\begin{array}{l}
0.0871 \\
0.0745 \\
0.0687
\end{array}\right) \mathrm{kN} / \mathrm{cm}^{2}
$$$$
\mathrm{R}_{\text {cisparalelo\% }}=\left(\begin{array}{l}
0.4664 \\
0.3992 \\
0.3679
\end{array}\right)
$$$$
R_{\text {cisparalelo }}=\left(\begin{array}{c}
\text { "O.K." } \\
\text { "O.K." } \\
\text { "O.K." }
\end{array}\right)
$$

Verificação dos deslocamentos

$$
\delta_{\mathrm{t}}=\left(\begin{array}{l}
0.0523 \\
0.0573 \\
0.0677
\end{array}\right) \mathrm{cm}
$$

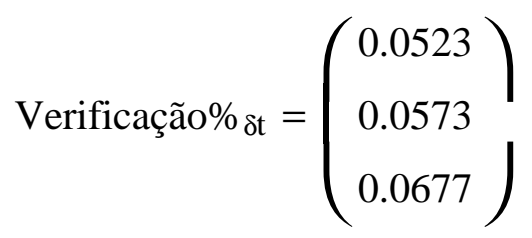$$
\text { Verificação } \delta t_{t}=\left(\begin{array}{c}
\text { "O.K." } \\
\text { "O.K." } \\
\text { "O.K." }
\end{array}\right)
$$

Verificação do puncionamento no tabuleiro

$$
\mathrm{V}=\left(\begin{array}{l}
1.486 \\
1.434 \\
1.381
\end{array}\right) \mathrm{kN}
$$

$$
\mathrm{V}_{\text {local} \%}=\left(\begin{array}{l}
0.4043 \\
0.3902 \\
0.3758
\end{array}\right)
$$

$$
\mathrm{V}_{\text {local }}=\left(\begin{array}{c}
\text { "O.K." } \\
\text { "O.K." } \\
\text { "O.K." }
\end{array}\right)
$$

$\mathrm{V}_{\text {res }}=3.675 \quad \mathrm{kN}$

11)

$$
\mathrm{V}_{\text {nervura }}=\left(\begin{array}{c}
0.0792 \\
0.096 \\
0.108
\end{array}\right) \mathrm{m}^{3} \quad \mathrm{~V}_{\text {tabuleiro }}=\left(\begin{array}{c}
0.092 \\
0.086 \\
0.08
\end{array}\right) \quad \mathrm{m}^{3} \quad \mathrm{~V}_{\text {nervura }}+\mathrm{V}_{\text {tabuleiro }}=\left(\begin{array}{c}
0.1712 \\
0.182 \\
0.188
\end{array}\right) \mathrm{n}^{3}
$$

